3.tint

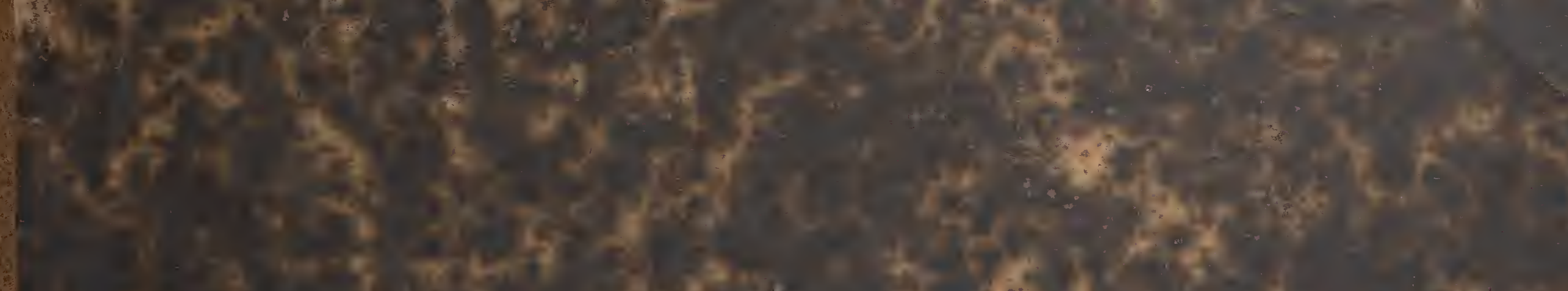

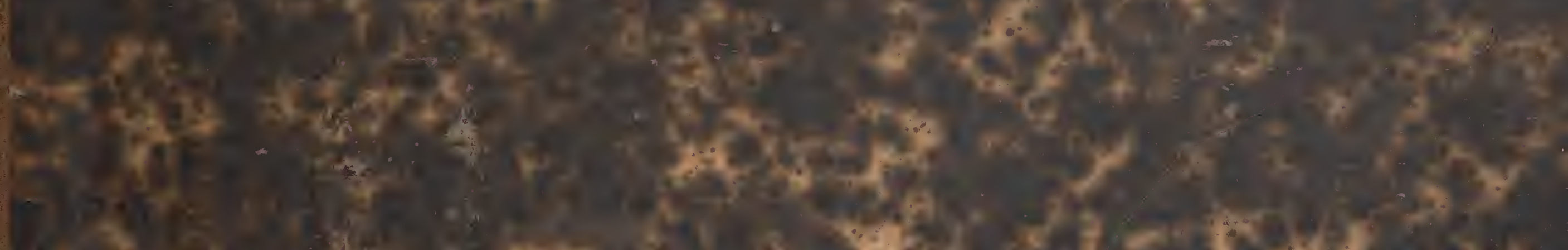

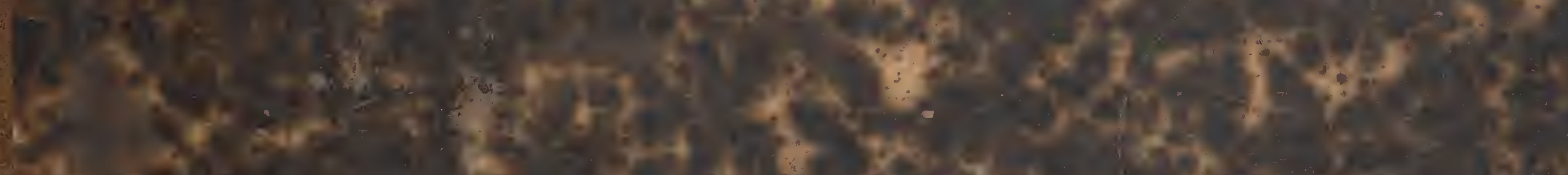
2.

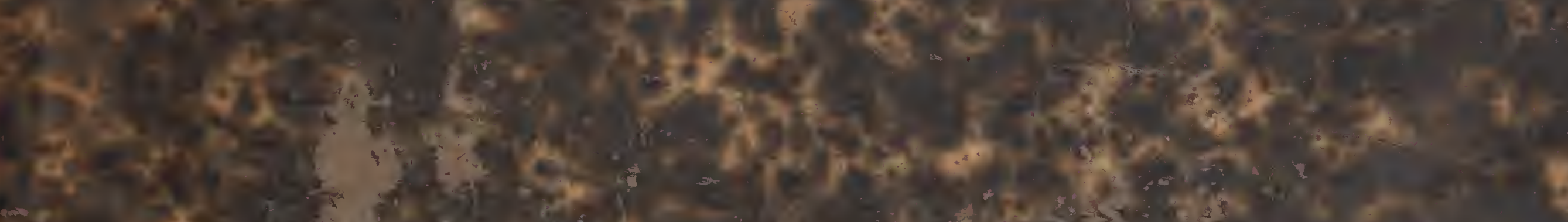

(2)

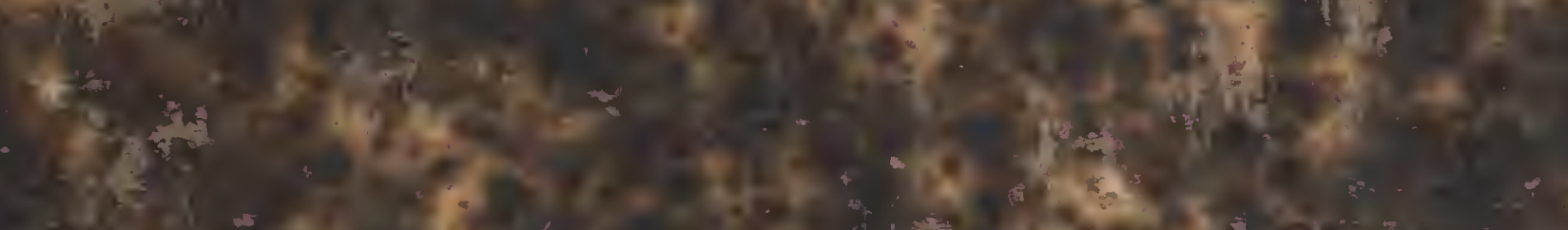

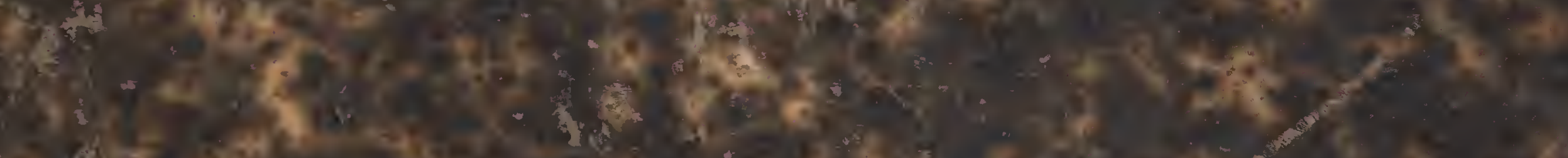

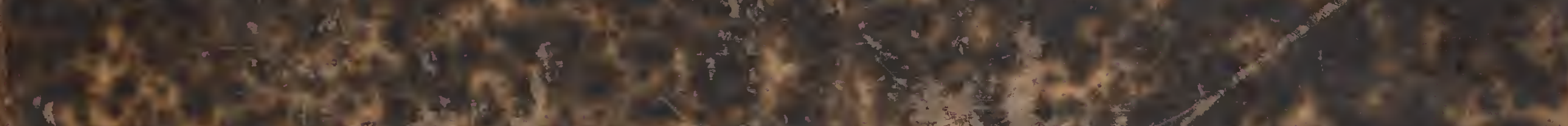

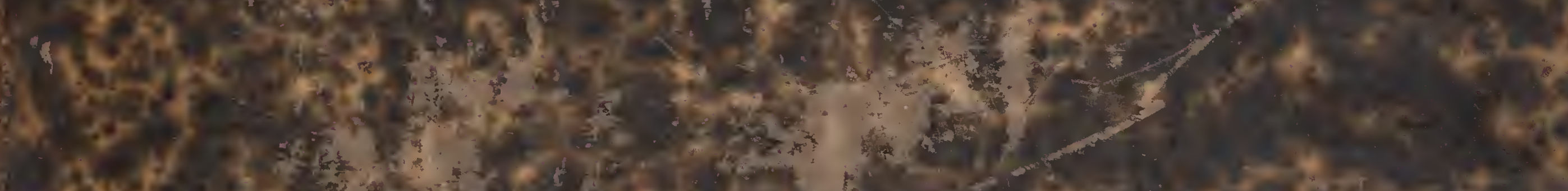

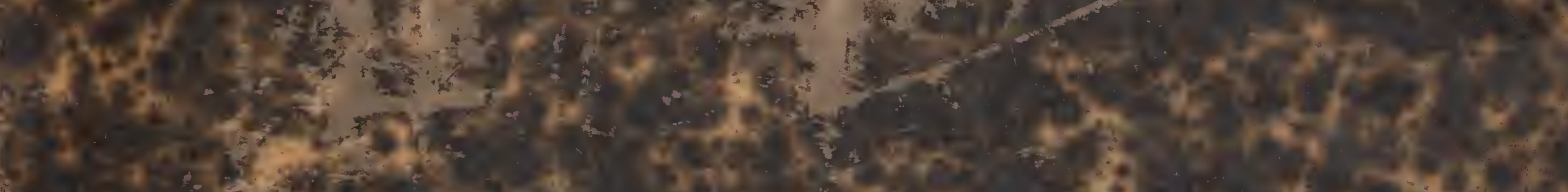

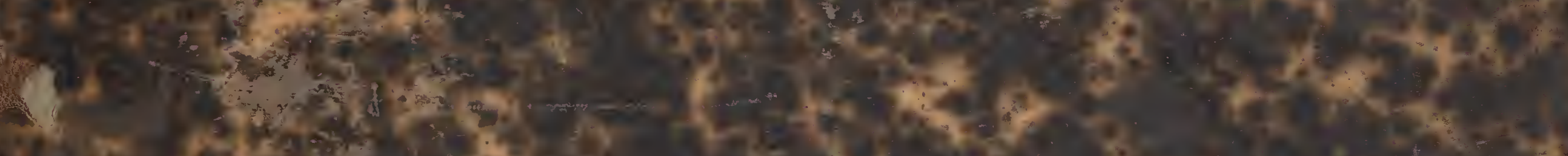

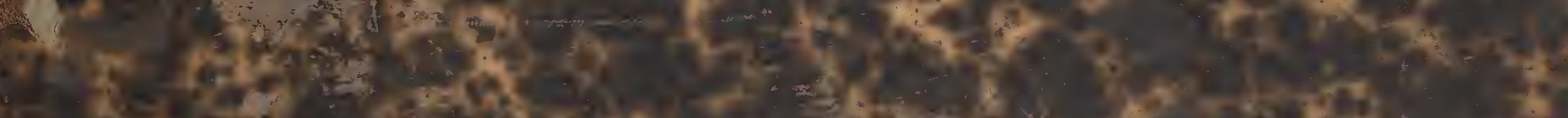

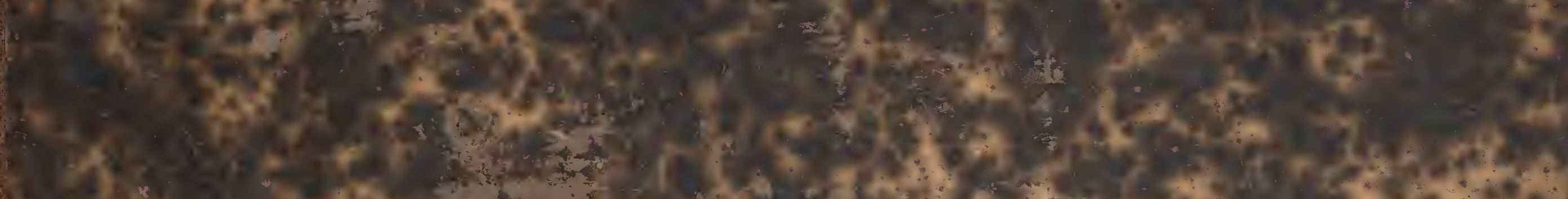

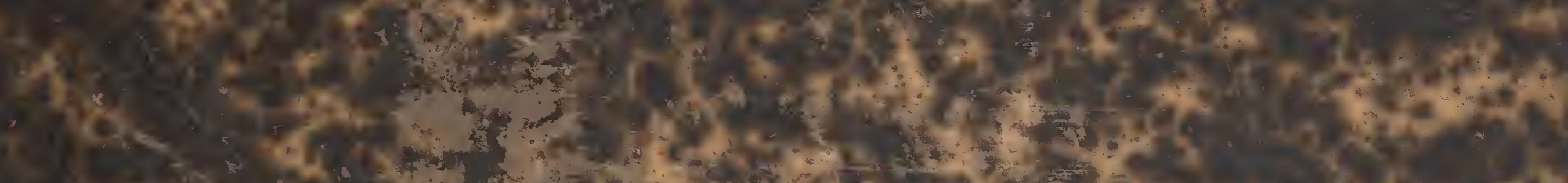

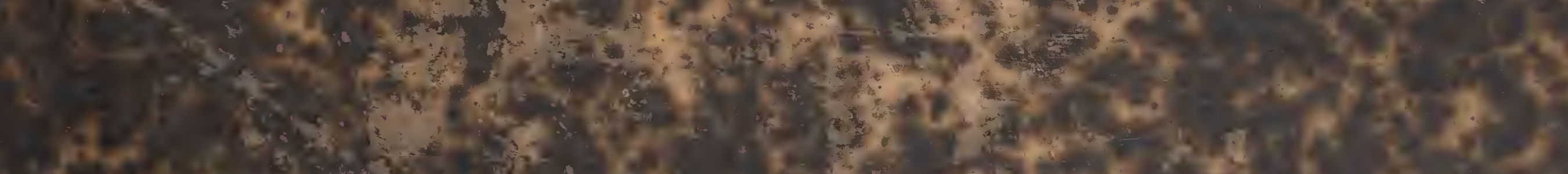

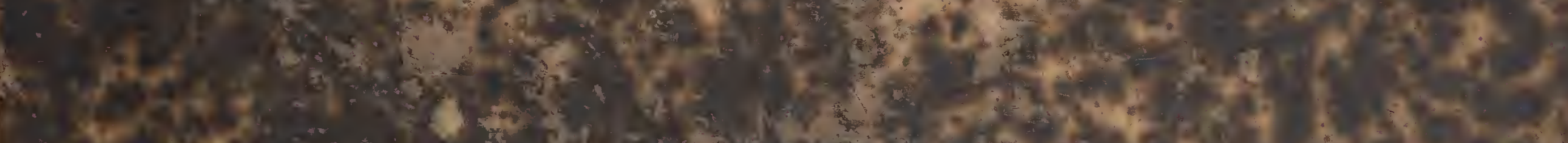

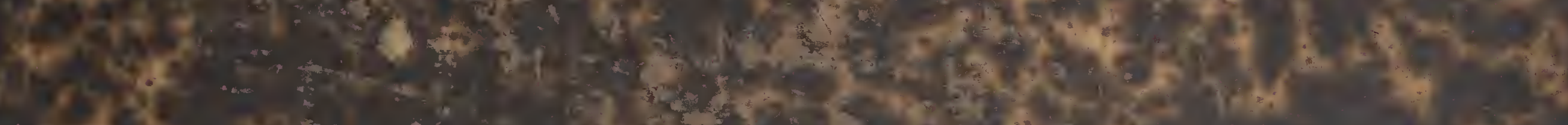

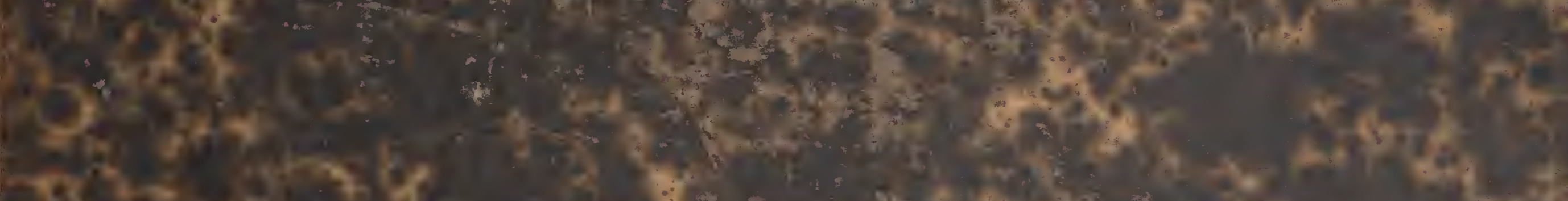

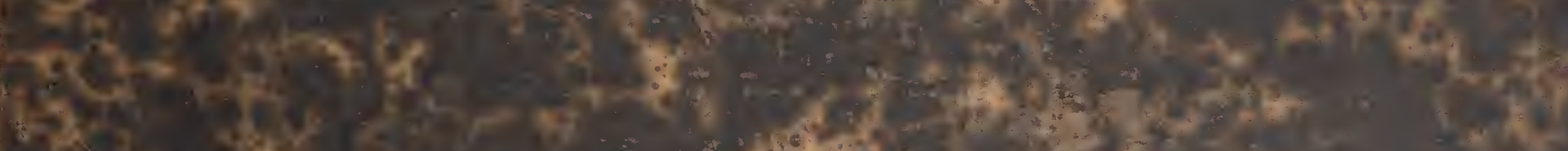

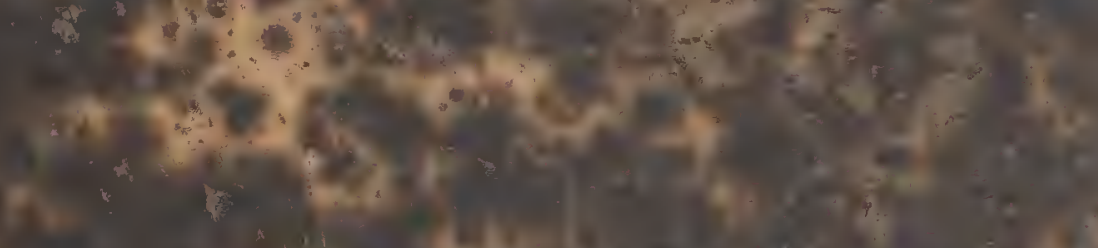
and 5 :

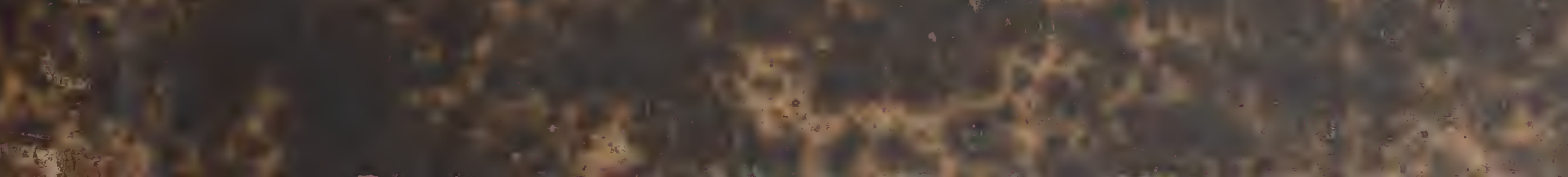




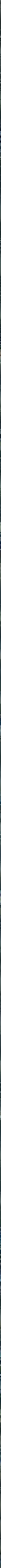




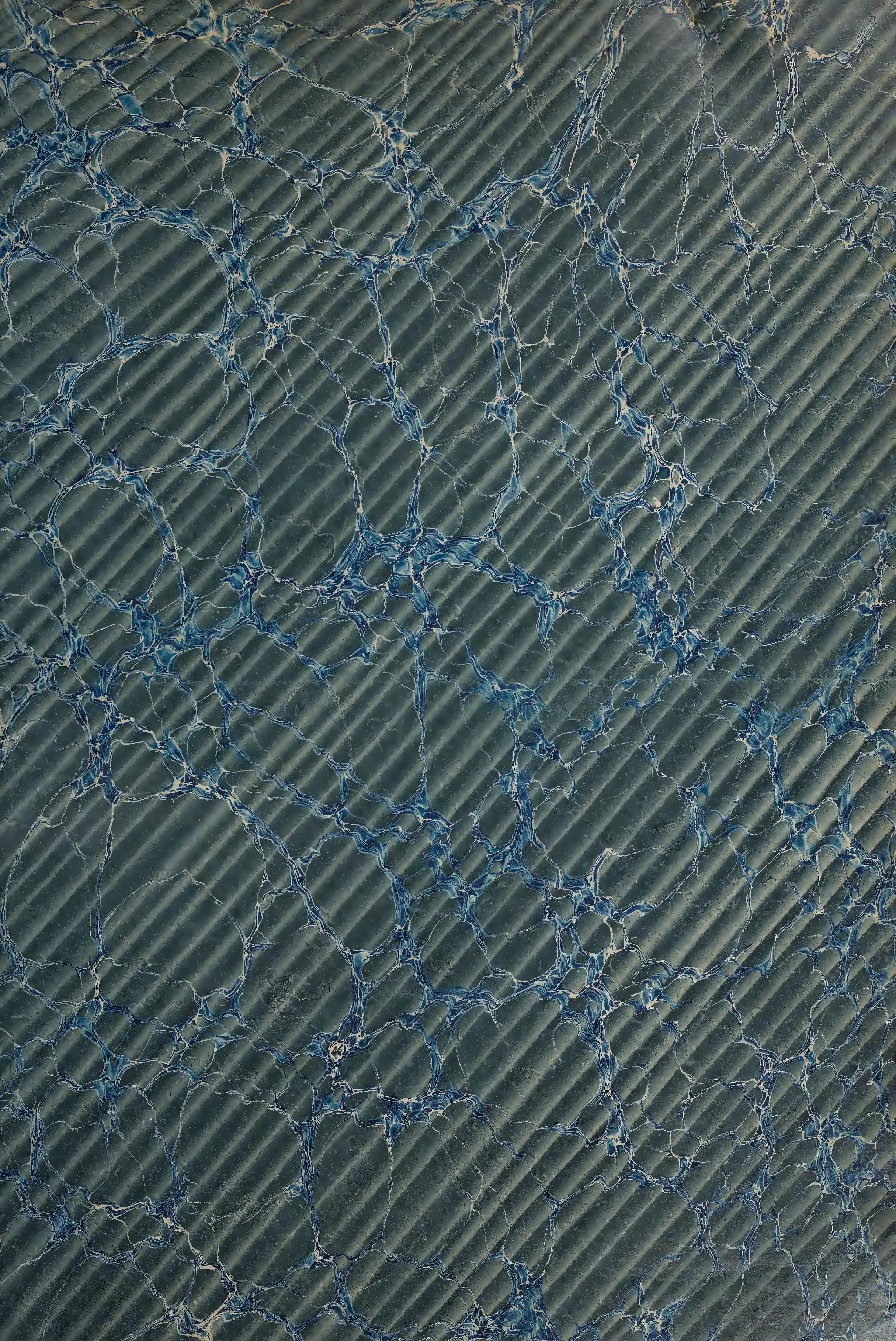




LES PIGEONS. 
A l'exception de cinq individus, que leurs grandes dimensions ont obligé de réduire, tous sont présentés de grandeur naturelle.

Les cinq individus réduits sont la Colombi-Galline Goura, planche 1, mis au tiers.
La Colombe Géant, pl. r.......
La Colombe Ramron, pl. 5......
Colombe Grivelée, pl. $6 \ldots \ldots$ à moitié.

La Colombe Largup, pl. $9 \ldots \ldots$.

Quoique le discours sur lordre des Pigeons finisse à la page 13 , et que les descriptions commencent à la page 23 , il n'y a point de lacune; c'est une faute d'impression.

Nota. Il faut avoir soin de placer la planche toujours en regard de l'explication. 


\section{LES PIGEONS,}

PAR MADAME KNIP,

\section{NÉE PAULINE DE COURCELLES,}

\section{LE TEXTE PAR C. J. THEMMINCK,}

DIRECTEUR DE L'ACADÉMIE DES SCIENCES ET DES ARTS DE HARLEM, ETC., ET DES MUSÉES ROYAUX DE HOLLANDE.

TOME PREMIER.

\section{DEUXIËME ÉDITION.}

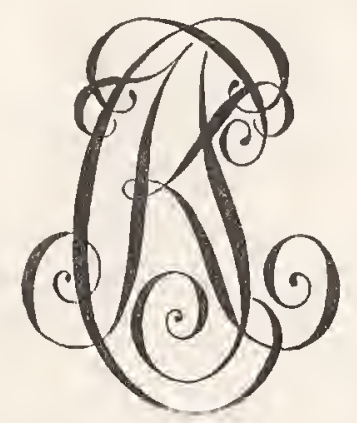

\section{A PARIS,}

$\operatorname{CHEZ}\left\{\begin{array}{l}M^{\mathrm{ME}} \text { KNIP, AUTEUR DES DESSINS, ET ÉDITEUR, RUE DU BAC, № } 77 . \\ \text { BELLIZARD, DUFOUR ET C }{ }^{\mathrm{IR}}, \text { LIBRAIRES, RUE DE VERNEUIL, }\end{array}\right.$

TYPOGRAPHIE DE FIRMIN DIDOT FRËRES, RUE JACOB, 56. 

Iemminck

Fo. Pravist-

Les $T_{i}$

Pigenow

C.

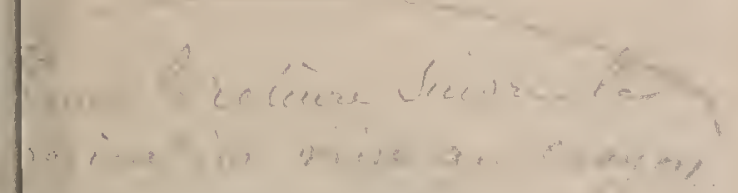

two nylats 



\section{TABLE.}

DISCOURS SUR LORDRE DES PIGEONS.

\section{LES COLOMBARS.}

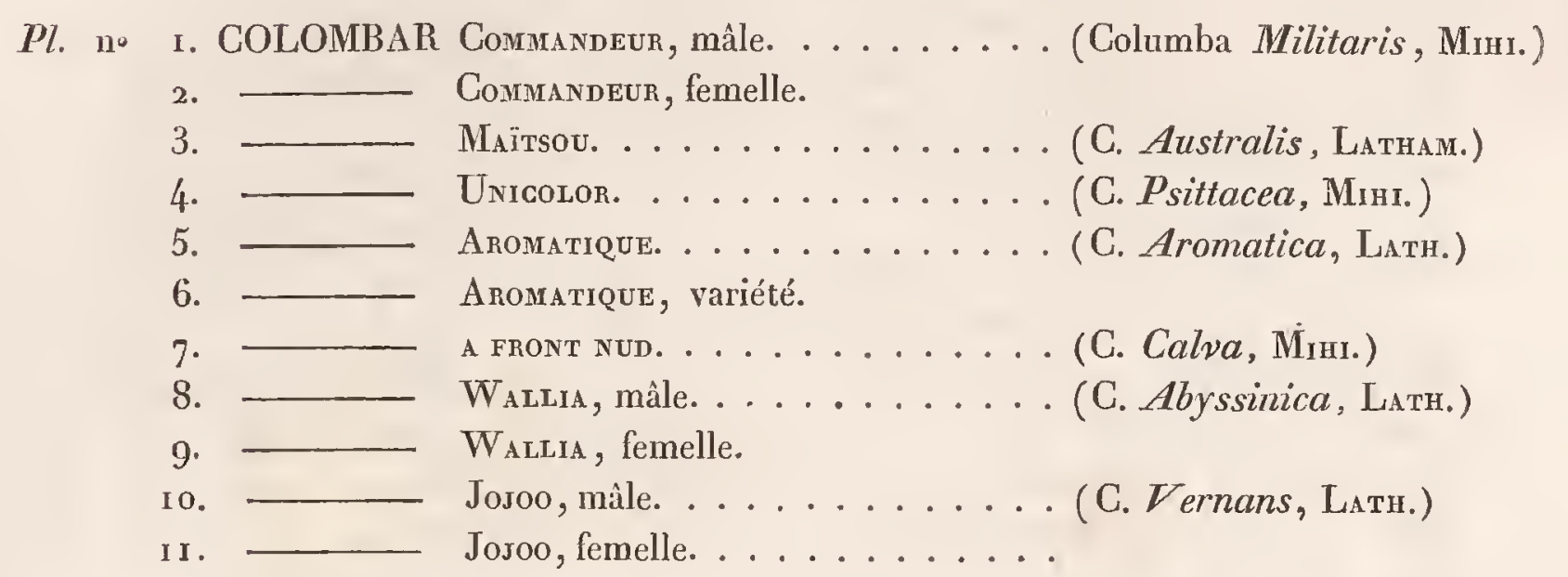

\section{LES COLOMBES.}

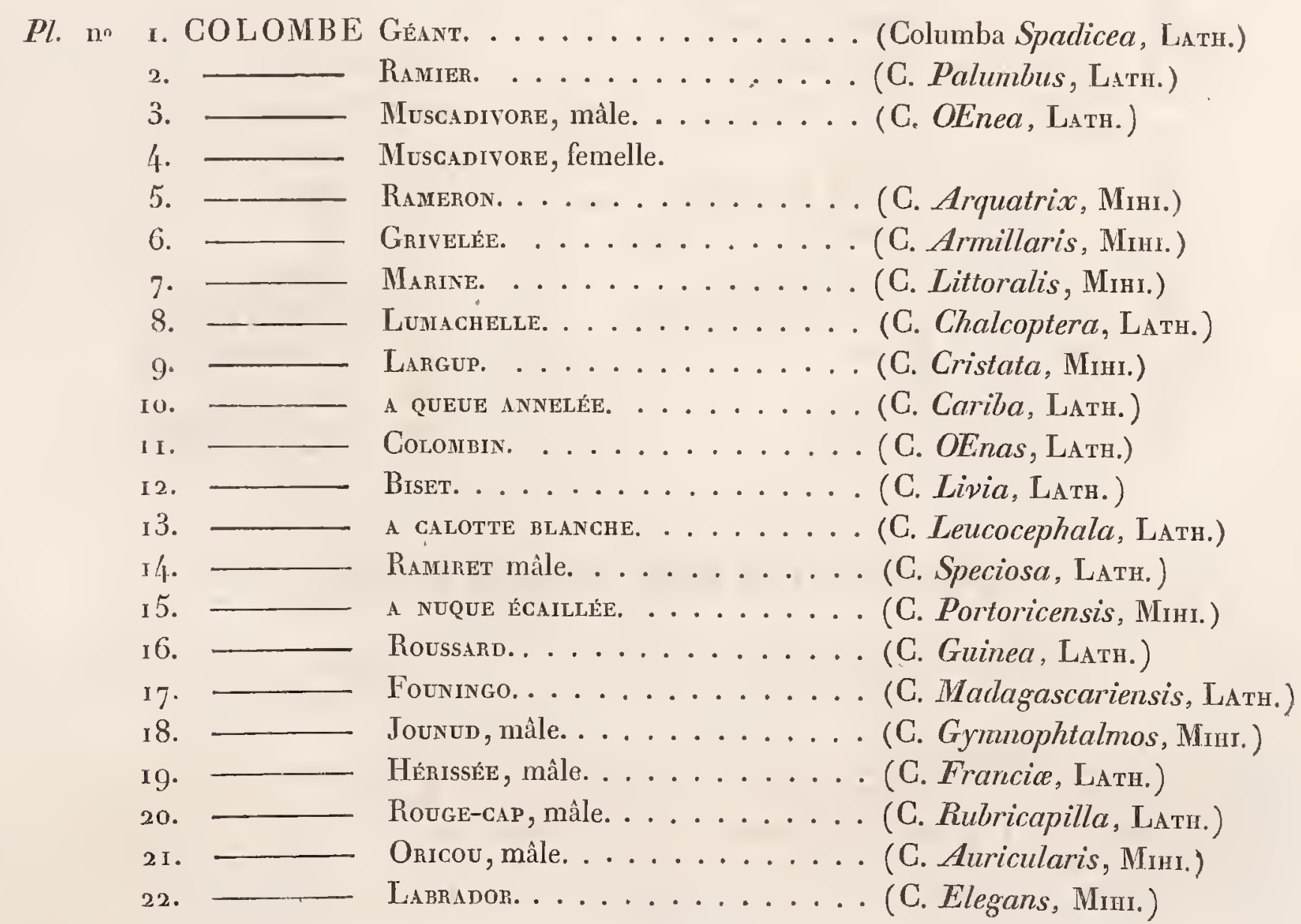




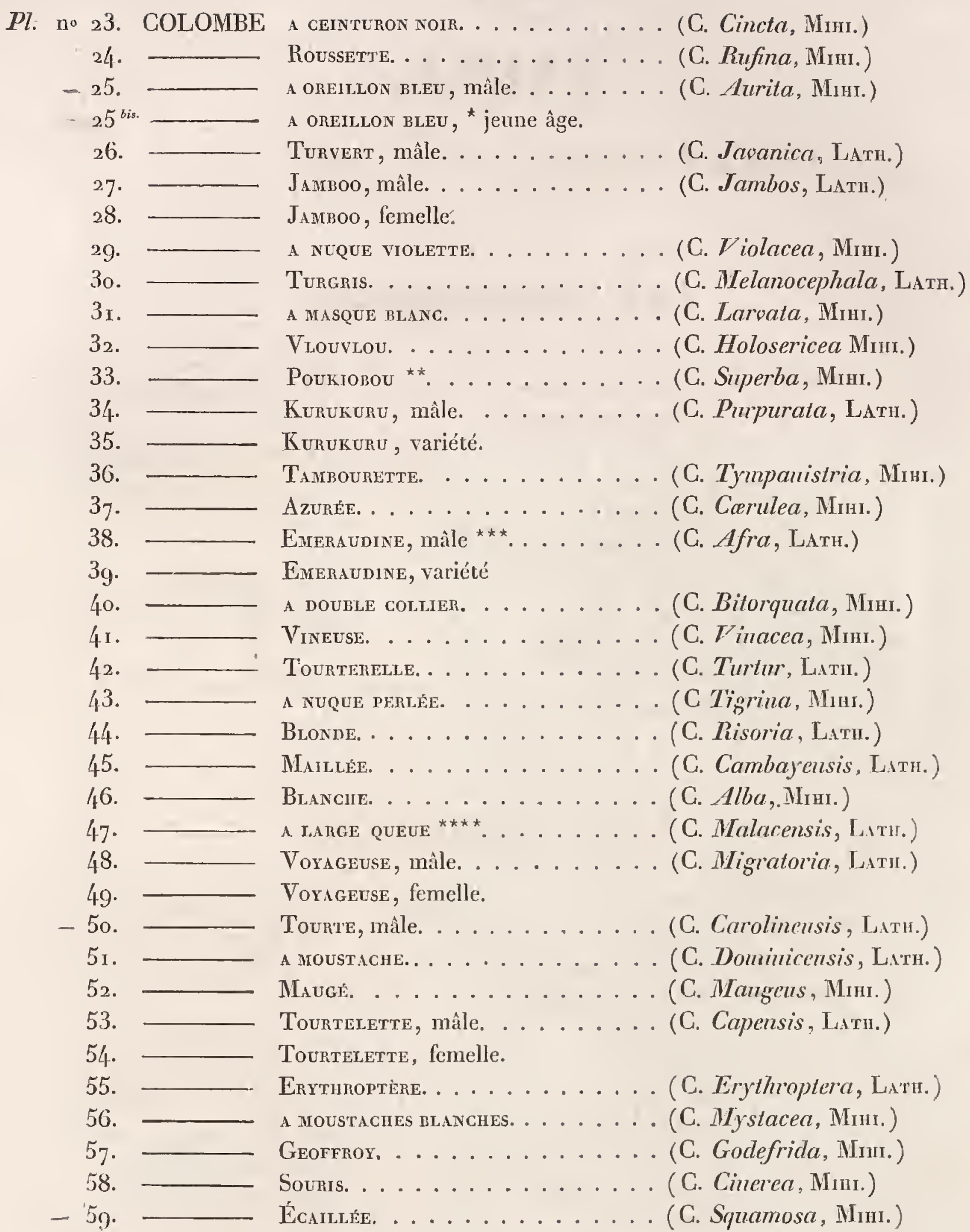

\section{LES COLOMBI-GALLINES.}

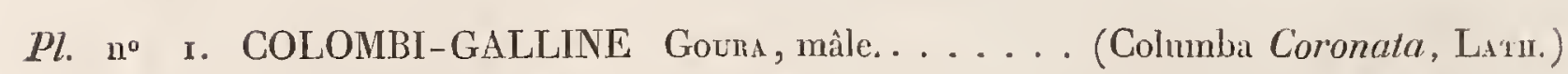
2. - a camall. . . . . . . . (C. Nicobarica, Lath.)

* La planche $\mathrm{n}^{\circ} 25$, de l'Oreillon jeune âge , doit se placer immédiatement aprìs celle de l'Oreillon mále, portant aussi le $\mathrm{n}^{\circ} 25$. ** La description de la calombe Poukiobou porte par erreur le n XXXI au licu du no XXXIII qui est celui de la planche. *** Dans quelques exemplaires, la planche $\mathrm{n}^{\circ} 58$, colombe Émeraudine porte le mot mále; c'est au contraire l'Émeraudine variété; et la planche $n^{\circ} 39$, Fmerandine variélé , devrait porter le mot mále.

**** C'est par erreur que la description de la colombe Large Queue porte le $n^{\prime \prime}$ LXVII au lieu du n $n^{\circ}$ XLVII. 
TAB L E.

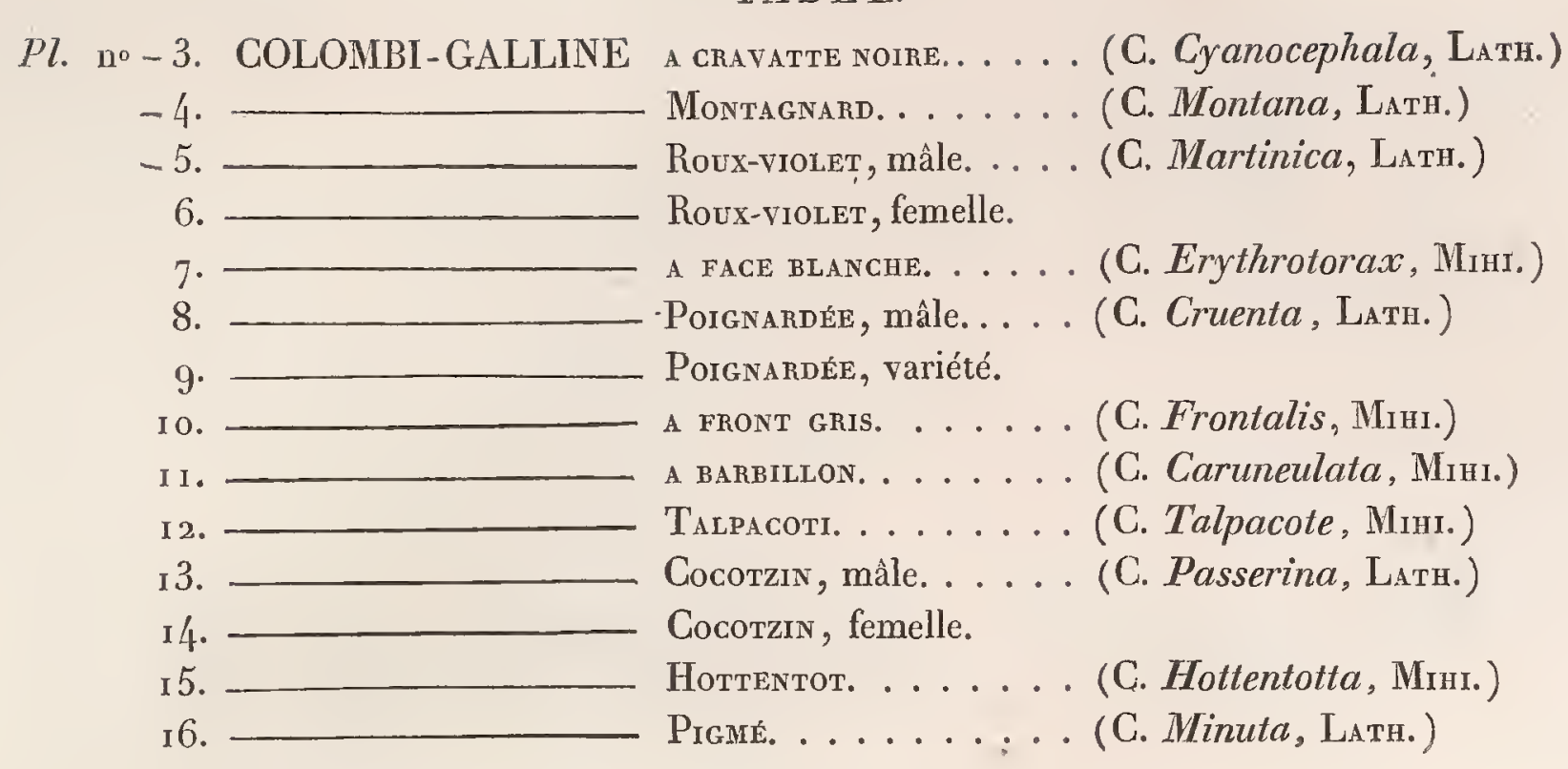





\section{DISCOURS}

SUR

\section{L'ORDRE DES PIGEONS.}

Nous suivrons pour l'ordre de classification des Pigeons la méthode de Latham, comme elle a été publiée dans son Index ornithologique, en établissant cependant certaines modifications nécessaires, et en rectifiant les erreurs que nous avons cru découvrir dans le traité de ce naturaliste. Pour la synonymie, nous nous sommes restreints aux auteurs les plus fidèles dans leurs descriptions, à ceux qui, faisant bien connoître les oiseaux, ne se contentent pas de les indiquer vaguement. Nous citerons à cette fin Latham, Linnæus, édition de Gmelin ; Buffon, Brisson, Edwards et Sonnerat.

L'ouvrage que nous offrons au public aura cet avantage qu'il renferme tous les individus connus qui se trouvent dans l'ordre des Pigeons. J'ai visité les principaux cabinets d'Histoire Naturelle de l'Europe, et j'y ai soigneusement recueilli tout ce qui pouvoit servir au complément de cet ouvrage.

Buffon nous apprend qu'il y a peu d'oiseaux aussi propres à fournir de longues courses que les Pigeons. Il ajoute que la 
plupart des races sauvages se trouvent dans presque tous les climats.

Les divers voyages autour du monde nous confirment dans cette assertion. Les Pigeons sauvages se trouvent dans presque toutes les contrées, même les plus brûlantes, où ils sont toujours les mêmes, sans varier de couleur; ils habitent dans ces lieux avec les autres espèces de Pigeons dont Buffon fait autant de rejetons du Bizet ou Pigeon Fuyard, sans que cependant ces rejetons supposés s'allient jamais arec leur souche primordiale; ce qu'il ne manqueroit pas de faire, si effectivement ils en tiroient leur origine.

Le Pigeon brun de la nouvelle Espagne dont parle Buffon, et que Fernandès nomme le Hoilotl $(a)$ celui indiqué par le même auteur sous le nom de Hoilotl (b) ainsi que le Kacahoilot (c), sont trop vaguement désignés; les descriptions que nous en avons sont si imparfaites, qu'il nous est impossible de distinguer les différences spécifiques. Il faudra se résoudre à rayer ces Pigeons de la liste nominale, jusqu'à ce que des indications plus exactes nous les fassent mieux connoître.

Buffon dit plus loin : "Le Pigeon indiqué par M. Brisson "sous le nom de Pigcon violet de la Martinique $(d)$, et qui est "représenté pl. n i 62 sous ce nom de Pigeon de la Martinique, " ne nous paroît être qu’une très légère variété de notre Pigeon " commun; celui de ce même auteur, appelé simplement Pigeon

(a) Columba Mexicana. Laht. Ind. orn. v. 2, p. 6u r, sp. 28.

(b) Columba Nævia. Lath. Ind. orn. v. 2, p. 6o I, sp. 29. Columba IInilotl. ibid. sp. 3n.

(c) Columba Cærulea. ibid. sp. 3 r.

(d) Columba Martinica. Lath. Ind. orn. v. 2, p. 595, sp. 7 . 
" de la Martinique, et qui est représenté dans les pl. enl. n I 4 I, "sous la dénomination de Pigeon roux de Cayenne, ne forment " nil'un ni l'autre des espèces différentes de celle de notre Pigeon; " on les appelle improprement Perdrix à la Martinique, où il " n'y a point de vraies Perdrix; mais ce sont des Pigeons qui ne " ressemblent à la Perdrix que par la couleur du plumage, et "qui ne diffèrent pas assez de nos Pigeons pour qu'on doive "leur donner un autre nom.»

Certes, il ne seroit guère venu dans l'idée des naturels de la Martinique de donner à cette espèce, ainsi qu'à plusieurs autres, le nom de Perdrix, si, par leurs observations, bien souvent mieux fondées que tous nos systèmes, ils n'avoient aperçu quelque analogie entre le genre de vie de ces Colombes et les allures des Perdrix. Ce n'est donc pas la couleur du plumage qui a donné lieu à cette dénomination de Perdrix, mais bien mieux la conformité de moeurs entre ces Gallinaces et quelques espèces de Colombes dont nous aurons occasion de parler plus au long en décrivant les individus qui appartiennent à cette petite famille.

Buffon rapporte le Ramier donné par Edwards, pl. $7^{6}(a)$, à notre Bizet, sans prendre notice des caractères de dissemblance qu'il dit exister entre ces oiseaux. Ce Ramier, qu'Edwards nomme Pigeon brun des Indes, est plus fort de taille que notre Bizet; il a le corps plus long et plus fort; toute la région des yeux et des oreilles est dénuée de plumes, et il relève souvent sa queue.

La Colombe voyageuse (b), quoique ayant la queue cunéiforme

(a) Columba Leucoptera. Lath. Ind. orn. v. 2, p. 295, sp. 6.

(b) Columba Migratoria. Lath. Ind. orn. v. 2, p. 6 6 2, sp. 70. 
et la taille allongée, n’a pas même fait d'exception : à en croire Buffon, elle ne diffère de nos Pigeons fuyards et devenus sauvages que par les couleurs et par les plumes de la queue, qui sont plus longues.

Il en est encore de même du Pigeon décrit par Brisson sous le nom de Pigeon vert des Philippines, et que $(a)$ Latham nomme Pigeon Perroquet ( $b$ ); il est d'un tiers plus petit que le Bizet, tout son plumage est d'un beau vert jaunâtre, relevé sur la poitrine par un large plastron d'un lilas tendre.

Cet oiseau, selon Buffon, ne diffìre de nos Pigeons fuyards que par la force des couleurs, qu'il attribue à l'influence des climats chauds, comme si le climat de Ceylan, d'où cette Colombe est originaire, possédoit le pouvoir magique de diminuer la taille et de changer totalement la couleur du plumage d'un oiseau qui, dans nos contrées tempérées, est d'un bleu couleur de plomb, en un vert jaunâtre éclatant et en lilas tendre.

Comment se peut-il que Buffon ait attribué un si grand pouvoir à l'influence des climats chauds?

Le Pigeon vert d'Amboine (c) des pl. enl. 165 n'a pas attiré plus particulièrement l'attention de ce naturaliste, quoique ce Pigeon, ainsi que plusieurs autres qui lui ressemblent, porte des caractères bien distincts qui le séparent de tous ses congénères; caractères que nous ferons observer plus loin en établissant la division des petites familles ou sections qui se trouvent dans la nombreuse tribu des Pigeons.

(a) Columba Vernans. Lath. Ind. orn. y. 2, p. 599, sp. 22.
(b) Parrot Pigeon. Lath. Synops. v. 4, p. $n^{\circ}$ 20.
(c) Columba Aromatica. Lath. Ind. orn. v. 2, p. 599, sp. 23. 
SUR L'ORDRE DES PIGEONS.

Le Pigeon de l'île de Saint-Thomas dont parle Marcgrave (a) est encore une espèce particulière (b) qui appartient à la petite famille des Colombars.

Je trouve dans Somnini une note de M. Virey (c), qui s'apercevant aussi de la grande confusion qui règne assez généralement dans les indications si peu vraies des divers auteurs, et présumant qu'il n'y a guère de caractères spécifiques pour les oiseaux autres que les couleurs, propose de rassembler dans la même phalange toutes les espèces du même genre qui ont une couleur fort dominante; ainsi les Pigeons, continue M. Virey, seroient distingués à peu près comme les Papillons; ces groupes faciliteroient l'étude de ces animaux et soulageroient la mémoire.

Ne seroit-il pas plus aisé de distinguer ces Pigeons verts par des caractères plus évidents que celui de la couleur du plumage? Les Pigeons dont M. Virey fait l'énumération diffèrent assez entre eux pour qu'on puisse facilement les reconnoître.

Le Pigeon indiqué par Hans Sloane $(d)$, qui est notre ColombiGralline à balafres blanches $(e)$, a encore été considéré comme une simple variété du Bizet. Cette Colombe diffère cependant du Bizet par son plumage d'un brun-pourpre. Elle est remarquable par deux traits blancs qui partent de la base du bec; sa longueur

(a) Marcgrave, Hist. nat. Brasil, p. 213.

(b) Columba Sancti Thomx. Lath. Ind. orn. v. 2, p. Goo, sp. 24.

(c) Buffon, édit. de Sonnini, v. 7, p. 214, note.

(d) Sloane Jamaica, p. 302, pl. 26r , fig. I.

(e) Columba Montana. Lath. Ind.orn. v. 2, p. 594 , sp. 4. - M. Sonnini se trompe dans la synonymie de l'espèce dont il est question. Le Pigeon dont parle Buffon à cet article n'est pas le Columba Jamaicensis de Latham, sp. 5, mais c'est le Columba Montana, sp. 4. 
totale est de neuf pouces, tandis que le Bizet en a quatorze depuis le bout du bec à l'extrémité de la queue.

Buffon fait aussi dériver de notre Pigeon sauvage le Pigeon que je décrirai sous le nom de Colombe à calotte blanche $(a)$, malgré les différences qui existent entre ces oiseaux.

Plusieurs Ramiers exotiques ont été considérés comme les descendants du Ramier sauvage d'Europe, sans prendre garde que cette espèce se rencontre aussi dans les climats brûlants, et. qu'elle y porte les mêmes distributions et nuances de couleurs comme dans les régions tempérées et froides; Buffon, qui ne pouvoit ignorer ce fait, attribue à l'influence du climat des différences qui ne laissent aucun doute sur l'identité des espèces.

Le Pigeon Ramier des Moluques, pl. enl. n 164 , auquel j’ai donné le nom de Colombe Muscadivore (b), est le premier que Buffon confond avec l'espèce indigène. "Quelque éloigné, dit " cet auteur, que soit le climat des Moluques de celui d'Europe, " il ressemble si fort à notre Ramier par la grandeur et la figure, "que nous ne pouvons le regarder que comme une variété " produite par l'influence du climat $(c)$."

La Colombe Muscadivore ressemble, il est vrai, pour la taille et les formes au Ramier d'Europe; mais la couleur verte dorée qui recouvre tout le bas, les ailes et la queue, l'éloigne beaucoup de ce dernier; ajoutez à cette différence une autre bien plus importante qui réside dans la conformation des pieds; le Ramier

(a) Columba Lencocephala. Lath. Ind. orn. v. 2, p. 594, sp. 5.

(b) Columba Enea Lath. Ind. orn. v. 2, p. 594, sp. 5.

(c) Buffon, édit. de Sonnini, v. 7, p, 241. 
SUR L'ORDRE DES PIGEONS.

Muscadivore les a plus forts, le tarse et les doigts sont plus nerveux, et ces derniers sont plus longs.

Le Pigeon à taches triangulaires d'Edwards, pl. 75 , qui est ma Colombe Roussard (a), ne peut pas être confondu avec le Ramier d'Europe, il en diffère par des caractères trop marquants; nous les déterminerons lorsque nous en serons à la description particulière de cette espèce.

Le Pigeon à queue annelée de la Jamaïque (b), indiqué par Hans Sloane, est encore rapporté par Buffon au Ramier d'Europe, quoiqu'il en diffère par la totalité des couleurs, par la taille qui est de deux ponces et demi moins forte, par les yeux d'un rouge plus vif, et par deux tubercules à la base du bec; tous ces caractères font de cette Colombe une espèce bien distincte.

Le Ramier de la Nouvelle Zélande (c) dont parle Latham n'est. pas, comme M. Virey le croit, une varjété du Ramier Caraïbe, c'est une espèce.

Dans la classification de ses Tourterelles, Buffon dit : "Celle " du Canada (d) ressemble si fort à la Tourterelle d'Europe, qu'il " ne faut la regarder que comme une variété produite par l"in" fluence du climat.) Un peu plus loin et en parlant de la Tourte $(e)$, qu'il dit être une espèce distincte, cet auteur est dans la supposition que la Tourterelle du Canada pourroit bien être la femelle de la Tourte ou Tourterelle de la Caroline.

\footnotetext{
(a) Columba Guinea. Lath. Ind. orn. v. 2, p. 602, sp. 35.

(b) Columba Caribæa. Lath. Ind. orn. v. 2, p. 6o3, sp. 36.

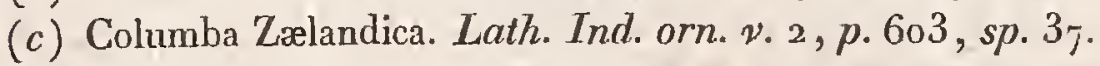

(d) Columba Canadensis. Lath. Ind. orn. v. 2, p. 6r 3, sp. 72.

(e) Columba Carofinensis. Lath. Ind. orn. v. 2, p. 6r3, sp. 7 I.
} 
Il y a ici une double erreur; d'abord cette prétendue Tourterelle du Canada n'est pas une variété de notre espèce produite par l'influence du climat, et secondement elle n'est pas la femelle de la Tourte ou Tourterelle de la Caroline; mais la Tourterelle du Canada est indubitablement la femelle de la Colombe Voyageuse (a); il faudra donc par la suite ajouter la symonymie de la Tourterelle du Canada à celle de la Colombe Voyageuse dont nous avons déjà parlé plus haut.

La Tourte, qui a la queue longue et cunéiforme, est une espèce bien distincte, non seulement de la Colombe Voyageuse, mais encore de. la Tourterelle d'Europe; Buffon se trompe quand il croit qu'il faut rapporter à la Tourte le Pigieon indiqué par Albin (b), et celui de Brisson (c), le même que Buffon nomme Tourterelle de la Jamaique, pl. enl. I 74; cet oiseau a la queue très courte et peu étagée; comparer enfin un Pigeon qui construit son nid à terre, et dont les habitudes tiennent beaucoup de celles des perdrix, à une espèce dont les mours sont entièrement opposées, c'est bien vouloir s'obstiner à rapprocher des espèces qui n'ont aucune analogie entre elles.

La Tourterelle du Sénégal des pl. enl. de Buffon, nº r6o $(d)$, que nous nommerons Colombe Émeraudine, n'est pas, comme cet auteur le présume, une variété de sa Tourterelle à Collier du Sénégal, pl. enl. r6 I (e) : la première de ces espèces n’a que huit

\footnotetext{
(a) Columba Migratoria. Lath. Ind. orn. v. 2, p. 61 $2, s p .70$

(b) Albin, tom. 2, p. 32, pl. 49.

(c) Turtur Jamaicensis. Bris. orn. v. I, p. ı65, pl. ı 3, f. I.

(d) Columba Afra. Lath. Ind. orn. v. 2, p. 6r I, sp. 64.

(e) Columba Vinacea. Lath. Ind. orn. v. 2, p.6 $6 \mathrm{I}$, sp. 63.
} 
SUR L'ORDRE DES PIGEONS.

pouces de longueur totale; elle a la queue courte, et deux taches de couleur d'émeraude ornent les ailes de cet oiseau; la dernière mesure dix pouces; elle est modelée sur les formes de la Tourterelle Vulgaire, et porte un collier noir sur la nuque. Nous devons encore faire observer que Buffon commet ici une seconde erreur en assimilant à la Tourterelle Vulgaire celle à Collier du Sénégal, dont nous venons de faire mention; cette dernière forme une espèce distincte, que nous considérons, d'après des naturalistes qui ont observé cet oiseau dans son pays natal, comme la souche de la Tourterelle à Collier $(a)$, dont l'espèce vit et se propage en domesticité dans presque toutes les contrées de l'Europe : nous désignons celle-ci dans notre monographie sous la dénomination de Colombe Blonde.

Après cet exposé succinct des principales erreurs que Buffon a commises en rapportant à nos espèces indigènes la plupart des espèces exotiques, nous allons faire connoître la méthode suivant laquelle nous nous proposons de classer les nombreuses espèces qui composent cette intéressante tribu.

Tous les Pigeons ont le bec droit, la mandibule supérieure plus ou moins renflée vers le bout, recouvrant l'inférieure qui forme un angle plus ou moins ouvert; à la base du bec une protubérance molle et charnue dans laquelle les narines se trouvent placées; les pieds robustes, munis de quatre doigts, les trois de devant presque divisés jusqu'à leur origine, celui de derrière s'articulant fort bas sur le tarse et à niveau des doigts de devant;

(a) Columba Risoria. Lath. Ind. orn. v, 2. p.6o7, sp. 5 т, 
la couleur dominante des pieds est le plus souvent rouge. La plupart des espèces vivent par couples, font un nid en commun, et pondent deux oeufs $(a)$; le mâle couve pendant quelques heures dans le milieu de la journée, tandis que la femelle pourvoit à ses besoins; ils se partagent le soin de nourrir leur progéniture, ce qu'ils font en dégorgeant dans l'osophage des petits des aliments qui auparavant ont été plus ou moins macérés dans leur. jabot.

A considérer la tribu des Pigeons, il paroît que cet ordre doit être divisé en trois familles ou sections. Cette subdivision est principalement fondée sur les mours et le genre de nourriture propre aux oiseaux qui composent ces familles; les quatre espèces de Pigeons qui habitent l'Europe semblent, il est vrai, présenter entre elles quelques légères différences dans les habitudes; mais les caractères qui tiennent aux formes extérieures et aux mœurs se trouvant les mêmes, on ne sauroit, dans une monographie, se permettre de classer ces espèces indigènes dans les subdivisions établies par les auteurs qui nous ont précédés, d'autant plus que les nombreuses espèces exotiques qui peuvent être comparées à celles d'Europe nous ont déterminés à rejeter cette ancienne classification.

Notre première division sera composée d'une petite famille de Pigeons qui se distinguent des autres espèces comprises dans les deux suivantes sections, par des caractères extérieurs très apparents et faciles à saisir; des différences se remarquent encore dans

(a) On trouve dans la troisième division des Pigeons que nous nommons Colombi-Gallines, une espèce qui pond un nombre d'œufs plus considérable. 
SUR L'ORDRE DES PIGEONS.

leur genre de vie : nous les désignons par la dénomination de Colombars.

Les Pigeons de cette division ont le bec épais, large à sa base, sensiblement renflé vers la pointe; la mandibule supérieure forme à son extrémité une forte courbure, et l'inférieure, en se renflant également, forme un angle ouvert ; cette partie dilatée est recouverte d'une substance cornée très épaisse formant une sorte de pince solide; le reste du bec est engagé dans une peau molle où sont placées les narines : le tarse est court; les doigts larges sont soudés à leur origine par une petite membrane; celui de derrière a une large membrane, dont il est comme liseré; les ailes sont longues et effilées; la première penne étant à peu près de la longueur de la seconde, qui est la plus longue, la queue est toujours composée de quatre pennes d'égale longueur entre elles. Si l'on en excepte cependant l'extérieure de chaque côté, qui est un peu plus courte que les autres. Les Colombars ont le naturel très farouche; ils nichent sur la sommité des arbres; le nid est composé de petites branches, la femelle y dépose deux oufs que le mâle couve durant une partie de la journée. Ces Pigeons habitent les grandes forêts et se montrent rarement en plaine; leur nourriture consiste uniquement en baies et autres fruits moux.

La seconde division comprendra, sous le nom de Colombe, le Ramier, le Bizet, ou Pigeon proprement dit, et la Tourterelle, ainsi que toutes les espèces exotiques dont la manière de vivre et les formes extérieures sont analogues à celles de ces espèces indigènes. Ces Pigeons, sans distinction de taille, appartiennent à la même famille, dans laquelle nous établissons deux sections; 
la première composée de Colombes dont la queue est carrée ou légèrement étagée; la seconde ceux qui ont la queue longue et très étagée en forme de cône : tous ont le bec droit et mince, les mandibules tendres et flexibles, la supérieure légèrement renflée vers le bout, et le tarse court à doigts entièrement divisés.

Ces Pigeons habitent les lieux boisés, ils nichent sur la sommité des grands arbres ou dans des troncs vermoulus; ils construisent leur nid le plus souvent de petites branches sèches qu'ils entrelacent grossièrement : tous se perchent habituellement de jour comme de nuit; dans cette action ils empoignent, avec les doigts, une branche, et s'y affermissent en la serrant fortement.

Notre troisième division comprendra, sous le nom de ColombiGallines, toutes ces espèces qui semblent former le passage des Pigeons aux vrais gallinacés; nous les nommons Colombi-Gallines, parceque joignant des caractères mixtes des uns et des autres, ils lient entre eux ces deux tribus. $\mathbf{A}$ chaque espèce il sera fait mention des caractères qui lui sont particuliers.

Les Pigeons Gallines qui composent cette division n'entreprennent point de longues courses comme les Pigeons proprement dits, ou Colombes; ils ont l'aile moins forte, leur taille est plus ramassée; ils portent la queue basse et pendante. Le bec de ces oiseaux, quoique formé sur le modèle de celui des Colombes, est cependant plus mince, plus flexible et moins renflé vers le bout que dans ces derniers; ils ont le tarse long, le plus souvent très lisse; les écailles sont petites, et les ongles sont menus; le doigt postérieur s'articule au niveau de ceux de devant, comme dans les oiseaux de l'ordre colombar; tandis que dans les oiseaux 
gallinacés, et particulièrement dans les Perdrix, ce doigt s'articule plus haut sur le tarse. Les ailes sont courtes et arrondies, la penne extérieure étant de beaucoup plus courte que la seconde, et celle-ci moins longue que la troisième. Ces Pigcons sont toujours à terre, où ils trottent comme les Perdrix : la plupart des espèces se réunissent en petites troupes composées comme celles des Perdrix; ils pratiquent leur nid à terre, le placent contre quelque buisson ou sur les branches rampantes. Les ColombiGallines ne se perchent point comme les autres espèces de Pigeons; ils se posent seulement sur les plus grosses branches des arbres, encore ne le font-ils que lorsqu'on les poursuit, ou. bien pour passer la nuit : ils choisissent souvent l'enfourchure d'une branche, et s'y tiennent blottis.

Nous terminons cette partie en observant que les Pigeons Colombars qui composent la première division habitent sur toute l'étendue de l'Afrique, dans les îles du vaste Archipel indien, à la Nouvelle-Hollande et dans les îles de l'Océan Pacifique : on ne trouve point des espèces analogues à ces Pigeons, ni en Europe, ni dans le Nouveau-Monde. Les Pigeons Colombes que nous réunissons dans la seconde division vivent dans les quatre parties du monde. Les Colombi-Gallines sont propres aux climats du Nouveau-Monde, de l'Afrique et de l'Asie : on ne les trouve point en Europe. 


\section{EXTRAIT du Rapport de l'Institut national, Classe des Sciences physiques et mathématiques.}

Le Secrétaire perpétuel pour les Sciences naturelles certifie que ce qui est ci-dessous est extrait du procès-verbal de la séance du lundi i 5 juin 1807 .

Nous avons été ehargés, M. La Cépède et moi (Cuvier), d'examincr douze figures coloriécs de Pigeons, que mademoiselle Patuine de Courceldes se propose de faire entrer dans un Ouvrage sur l'Histoire Naturelle de ce genrc d'Oiseaux, et qu'elle a soumis à l'approbation de la Classe.

Depuis long-temps les naturalistes ont cherché à suppléer à la paurcté du langagc par des peintures qui pussent faire saisir à l'oeil les formes variées des objets peu connus.

La première idée en appartient, dit-on, à Aristote; on voit encore dans quelques endroits de ses écrits des lettres qui servoient à expliquer des figures; celles-ei n’ont pas été copiées dans les manuscrits qui nous restent, et l'on doit peu les regretter si elles ressembloient à celles que l'on voit encore dans quelques manuscrits de Dioscoride.

Les naturalistes du seizième siècle employèrent des gravures en bois, et les figures de Rondelet, de Gessner et d'Aldrovande ne perdent pas tout leur mérite dans la grossièreté de cette méthodc de multiplieation.

Lcs gravures en taille-douce dcvinrent plus communes dans le dix-septième siècle, et permirent d'exprimer les plus petits détails des objets avec précision. Vers le commencement du dix-huitième siècle, les gravures enluminées devinrent nombreuses. La Hollande, et ensuite l'Allemagno exercèrent beancoup ee genre d'indnstrie, ct les ourrages publiés alor's dans ces deux pays sont encore à présent très utiles à la science.

Cet usage d'orner les livres d'Histoire Naturelle de planches eu eoulcurs est à présent général; et l'art de faire ces planches est devenu si parfait, qn'il est diffieile de eroire qu'il puisse jamais aller plus loin, quant à la vérité et la magnificencc.

C'est un art particulier qui doit différer en plusieurs points de la peinture ordiuaire. . . . . Mademoiselle de Courcelles a présenté, il y a quelque temps, ì la Classe, l'Histoire des 'Tangaras, des Manakins et des Todiers, dont le texte étoit rédigé par M. Desmarest; clle l'avoit orné de très belles planches, faites d'après ses dessins, et coloriées par' elle.

Les planehes de Pigeons qu'elle vieut de soumettre à votre examen nous parroissent dignes de la mème approbation.

Ce genre d'Oiseaux, par les envois des naturalistes voyageurs, commenec à devenir riche en espèces exotiques, dont un grand nombre sont remarquables par leur grandeur ou l'éclat de leu plumage, et dont nous parviendrons peut-êtrc à acclimater quelques uns.

Ce sont ces diverses espèces que mademoiselle de Courcelles se propose de peindre, et l'Histoire Naturelle ne peut en effet que gagner à voir fixer, par de belles gravures, tant de formes et de nuances diflérentes.

La Classe, qui a vu les figures que mademoiselle de Coureelles a mises sous nos yeux, a pu juger par elle-même de leur mérite sous le rapport de l'art.

Vos commissaires les ont comparées aux originaux déposés au Musćum d'Histoire Naturelle, et peuvent vous garantir qu'elles ne laissent rien à désircr sous le rapport de la ressemblanee et des caraetères distinetifs.

Ils n'hésitent donc point à vous proposer de leur accorder votre approbation.

Fait au Palais impérial des Beaux - Arts, le 15 juin 1807.

Signé LA CÉP ÈDE, CUVIER, Rapporteurs.

La Classe approuve le Rapport, et en adopte les conelusions.

Certifié conforme à l'original, le Secrétaire perpétuel, Cuvieli. 


\title{
LES COLOMBARS.
}

\section{CARACTERES ESSENTIELS}

Bec épais, racorni vers la pointe et sensiblement renflé, tarse court, doigts réunis à leur base.

\section{COLOMBAR COMMANDEUR, Mâte.}

\author{
PIANCHE $I^{n E}$
}

Columba Militaris, Mihi.

Columba S. Thomæ, Latr. Ind. orn. v. 2, p.600, sp. 24.

- Gret. Syst. I, p. 778.

S. Thomas Pigeon, Lath. Syn. थ. 4, p. 63 $\mathrm{x}, \mathrm{n}^{\circ} 22$

$\mathrm{J}_{\mathrm{E}}$ place à la tête de cette division la plus grande espèce connue. Sa longueur, depuis le bout du bec à l'extrémité de la quene, est de douze pouces et demi; le bec a onze lignes, celui-ci est très épais, large à sa base, la pointe en est renflée, et les bords des deux mandibules sont échancrées. Ce caractère paroît indiquer que l'oiseau fait sa principale nourriture de quelques fruits, dont les noyaux très durs occasionnent des fractures à celte partie. On ignore cependant à quel fruit ce Colombar donne la préférence, ses mours n'étant pas encore connues.

Latham fait très succinctement mention de ce Colombar sous lc nom de Pigeon de lîle de Saint-Thomas; Buffon en parle aussi en passant; mais ces descriptions vagues ne permettent guère de reconnoitre l'oiseau.

Le Commandeur mâle a toute la tête, jusque derrière l'orifice des oreilles, d'un gris-bleu clair; sur la poitrine est un large plastron jaune dont les extrémités se dirigent jusque sur le haut du dos, où une zone d'un grisbleu-cendré entoure cette couleur; le reste des parties supérieures est d'un vert-pomme sale; cette couleur prend une teinte de gris vers le croupion; les petites plumes du poignet de l'aile, qui forment une espèce d'épaulette, sont d'un beau brun-pourpré; les moyennes et les grandes 
pennes des ailes sont noires; les premières sont frangées de jaune-blanchàtre, et les dernières de jaune-olivacé; ceux-ci ont un petit bord jaune-blanchâtre; le ventre et tout le dedans des ailes sont d'un gris-bleuâtre; les cuisses sont d'un beau jaune de paille; les couvertures inférieures de la queue sont rousses, et chaque plume est terminée de blanc. Le dessus de la queue est moitié vert et moitié gris; cette dernière couleur règne sur l'extrémité de toutes les pennes latérales, mais les deux intermédiaires sont entièrement vertes; la queue en dessous est noire à son origine, ct d'un gris-blanchâtre vers son extrémité; le tarse est dénué de plumes, il est rouge de même que les doigts; es ongles et la couche racornie du bec sont gris.

Ce Colombar habite l'Inde, mais j'ignore quelle partie.

Un individu mâle, d'une conservation très pure, se trouve dans le beau cabinet de mon ami M. Raye de Breukelerwaert, et un autre est déposé au Muséum de Paris. C'est ce dernier individu qui a servi de modèle à mademoiselle Pauline de Courcelles. 


\title{
GOLOMBAR GOMMANDEUR, Femelle.
}

\author{
PL. II.
}

Columba Militaris, Femina.

Les femelles de presque toutes les espèces de Pigeons ne diffèrent, en général, guère de leur mâle; les deux sexes se ressemblent par les formes et la taille; il n'y a souvent qu'une légère différence pour les couleurs, dont les teintes sont moins prononcées dans les femelles.

La femelle du Commandeur diffère cependant assez de son mâle pour mériter d'ètre figurée.

La taille et les dimensions principales sont pareilles à celles du mâle; les couleurs de la tête, du dos et du croupion n'offrent point de différences; le plastron, qui dans le mâle est jaune, est d'un vert jaunâtre sale dans la femelle : elle a la nuque de couleur olive-foncée, et la zone sur le haut du dos est. d'un gris-clair; les épaulettes sur le fouet de l'aile sont d'un ton plus tendre que dans le mâle; les scapulaires sont d'un vert-grisâtre; le ventre, qui est gris chez le mâle, est verdâtre dans la femelle; les pennes latérales de la queue sont grises sur toute leur longueur, et les deux intermédiaires sont vertes; le dessous de la queue est pareil à celui du mâle, mais les plumes de l'abdomen sont terminées de jaune.

Il paroît que les jeunes de cette espèce sont plus ou moins de couleur grisàtre sur les parties supérieures, et de couleur olivacée sur les parties inférieures et sur la partie postérieure du cou; les pieds sont constamment d'un beau rouge.

Lindividu femelle qui a servi à cette description est au Muséum de Paris. 


\title{
COLOMBAR MAITSOU.
}

\author{
$P_{L}$, IIT.
}

\author{
Columba Australis. Lıtт. Ind. orn. v. 2, p.604, sp. 40 \\ - Gmex. Syst. I , p. 779 \\ Pigeon Ramier vert de MIadagascar. Buff. pl. enl. ir I. \\ Madagascar Pigeon. LАтн. Syn. v. 4, p.64., var. $A$.
}

I t paroìt qu'il se trouve, dans l'état sauvage, des Pigeons dont les tar'ses sont plus ou moins garnis de plumes, à peu près comme le sont les jambes des Tétras; ce caractère cependant ne sauroit constituer une différence générique ni même permettre une division en sous-genre. Tous ces Pigeons culottés, ou dont le tarse enticr est garni de plumes, ne s'éloignent du reste en aucune façon des autres espèces de leur famille.

Le Colombar auquel j’ai conservé une partie du nom qu’il porte à Madagascar, où les naturels l'appellent Founingo Maitsou, diffère à beaucoup d'égards du Founingo Ména-Rabou (a), auquel Buffon (b) l'a comparé. C'est à tort que cet auteur suppose qu'il n'existe entre ces oiseaux d'autre diflérence que celle du bleu au vert; ou que peut-être ils pourroient bien varier seulement de sexe ou d'âge.

Le Founingo Maitsou et le Founingo Ména-Rabou ne se ressemblent que par le seul caractère d'avoir tous les deux le tarse couvert de plumes jusqu'à l'origine des doigts; du reste ils diffèrent par la forme du bec, qui est en pince solide et racornie dans le premier, mince et flexible dans le dernier; les doigts du Founingo Maïtsou sont larges et réunis à leur origine, la plante des pieds est épatée comme dans les Calaos et les Martin-Pêcheurs; le Founingo Ména-Rabou a tous les caractères qui sont propres aux Colombes, et appartient à la classe de ceux qui ont autour des yeux un espace dénué de plumes.

Le Colombar Maïtsou, dont on ignore jusqu'ici la manière de vivre et le

(a) Columba Madagascariensis. Lath. Ind. orn. v. 2, p. 604, sp. 40.

(b) Buffon, édit. de Sonnini, w. 7, p. 245. Pigeon Ramier bleu de MLadagascar, pl. cnl. ז. 
genre de nourriture, paroît cependant frugivore comme toutes les autres espèces de cette famille; sa longueur depuis le bout du bec à l'extrémité de la queue est de douze pouces et demi; la tête, le cou, la poitrine et le ventre sont d'un vert-olivâtre clair; le dos, les couvertures du dessus des ailes, le croupion et les couvertures du dessous de la queue, sont d'un vertfoncé; vers le poignet de l'aile est une petite tache ou épaulette d'un brunpourpré; les grandes couvertures sont terminées de jaune, ce qui forme une bande transversale sur l'aile; les grandes pennes sont noires, et le rebord intérieur est légèrement liséré de jaune; le dessus de la queue est d'un gris foncé, depuis son origine jusqu'aux trois quarts de sa longueur; l'extrémité de toutes les pennes est d'un gris-clair; la queue en dessous est blanchâtre vers la pointe, et noire à son origine; les plumes qui recouvrent les cuisses et les tarses sont vertes, l'abdomen est de cette couleur avec des taches oblongues, d'un blanc pur; les couvertures inférieures de la queue sont rousses, avec les extrémités blanches. La base du bec est recouverte d'une membrane rougeâtre, la pointe du bec est d'un gris couleur de corne; les pieds sont rouges et les ongles gris.

Ce Colombar habite l'île de Madagascar. J'ai vu deux individus de cette espèce, un dans le cabinet de M. Raye, et un autre, qui est en très mauvais état, dans le Muséum de Paris. 


\title{
COLOMBAR UNICOLOR.
}

\author{
$P_{J .} I V$
}

Columba Psittacer. Mihi.

CE Colombar, quoique depuis long-tcmps connu, n'a cependant pas encore été décrit, soit qu'on l'ait considérć comme une variété accidcntelle des espèces précédentes, ou que par rapport à l'uniformité de ses couleurs il ait étć regardé comme un individu qui n'avoit pas encore attcintl'état d'adulte.

L'Unicolor a dix pouces et demi depuis la pointe du bec à l'cxtrémité de la queue, qui est arrondie et de moyenne longucur; la pointe racornic du bee, dont la courbure n'est pas très fortement prononcée en forme de croc, décrit plutôt une parabolc.

Ce Colombar a la tête, le cou, toutes les parties inférieures, ainsi que le dos et les couvertures alaires, d'un beau vert - clair; les grandes et les moyennes pennes des ailes sont noires, et ces dernières sont toutes frangées de jaune foncé; la queue est d'un gris-foncé à son origine, noire vers lc milien des pennes, et blanche sur le reste de sa longueur; les deux pennes intermédiaires sont entièrement vertes, et les deux autres, qui sont adhérentes de chaque còté à cclles-ci, ont de cette coulcur sur leurs barbes intérieures, ce qui fait que la queuc, quand clle n'cst pas étalće, paroît toute ver'te; lcs couvertures inféricures sont vertes avec les extrémités blanches; le bec est couleur de cornc, la pean nue qui en reconve la base est rougeàtre; les pieds sont d'un bleu-noirâturc, et les ongles sont bruns.

J'ai examiné plus de trente individus de cette espèce, qui me furcnt envoyés de Batavia; j'en ai vu plusieurs autres dans diverses collections; tous étoient à peu de chose près semblables, et je n'ai pu découvrir aucune différence qui caractérisât les sexes; les moins grands, et ceux qui, par la forme du bec, paroissoient être de jeunes oiseaux, avoient du gris cendré répandu sur tout le plumage; le bout du fouet de l'aile et quelques plumes des grandes couvertures étoient d'un gris-noirâtre, ce qui me fait présumer que les jeunes, a u sortir du nid, sont alors converts de plumes plus ou moins grises, et qu'ils ne prennent la livrée verte quaprès leur seconde mue.

Le Colombar Unicolor habite l'ile de Timor; il doit aussi se trouver à Java.

De mon Cabinet. 


\title{
COLOMBAR AROMATIQUE.
}

\author{
PL. $Y$.
}

Colomba Aromatica, La TH. Ind. orn. v. 2, p. $599, s p .23$.

- Gmel. Syst. v. 1, p. 778 .

Pigeon vert d'Amboine, Buffon, pl. enl. ז36.

Aromatic Pigeon, Latн. Syn. v. $4, p .63 \mathrm{r}, n^{\circ} 2 \mathrm{I}$.

Vor c I une espèce de Colombar, qui, suivant le sentiment de Buffon, se trouve avoir des liaisons intimes avec le Pigeon sauvage de nos climats: cet auteur suppose assez mal à propos que le Pigeon vert d'Amboine, de Brisson, qui est mon Aromatique, n'est qu'une variété de la Colombe Biset; il ne dit cependant pas à cet endroit si les dissemblances entre ces oiseaux (qui ne sont pas de peu de conséquence) sont le produit de l'influence du climat: cette supposition chérie de M. de Buffon n'a servi qu'à répandre l'obscurité et le doute sur les diverses espèces de Pigeons exotiques, tandis que son idée non moins ridicule de faire dériver tous les Pigeons proprement dits d'une mème souche primordiale, a fait confondre jusqu'aux espèces indigènes qui n'ont aucune analogie.

Je ne m’arrêterai pas ici à prouver l'identité d'espèces du Biset de nos climats et du Colombar Aromatique, les figures de grandeur naturelle suffiront pour prouver au moins expert en histoire naturelle, que ces oiseaux n'ont pas même les plus légers rapports.

L'Aromatique mesure en totalité neuf pouces et demi; il a le bec plus crochu que l'espèce précédente, et la courbure à la mandibule supérieure n'a lieu que vers la pointe, le reste de la partie cornée de cette mandibule est presque droite; le haut de la tête jusqu'à l'occiput est gris-cendré; cette couleur prend une teinte verdâtre sur la nuque; le cou, la poitrine, le ventre, les cuisses et l'abdomen, sont d'un vert-sale, les plumes de celte dernière partie sont plus ou moins terminées de blanc; les petites couvertures des ailes, les scapulaires, et le haut du dos, sont d'un brun-purpurin; les moyennes et grandes couvertures sont d'un vert-foncé, avec de larges bordures jaunes à l'extrémité de toutes les plumes; moyennes pennes frangées de jaune, grandes pennes entièrement noires; le croupion, les deux pennes intermédiaires de la queue, ainsi que les barbes intérieures des deux plumes adjacentes, sont d'un vert-olivâtre; les autres pennes caudales sont grises sur toute leur longueur; en dessous, la queue est noire ì son origine jusqu'aux 
trois quarts; l'extrémité de toutes les pennes est d'un gris-clair; l'iris des yeux est rouge, la partie cornée du bec est verdàtre, et la base est rougeàtre; cette couleur se trouve aussi sur les tarses et les doigts.

Le Colombar Aromatique habite l'île de Java, où les insulaires lui donnent le nom de Bouron-Jouane, dénomination par laquelle ils paroissent désigner en général toutes les diverses espèces de pigeons verts; le mot de Jouanc signifie vert en langue Savane, et le mot Bouron veut dire simplement oiseau. Cette espèce se nourrit principalement du fruit que produit le Fucus Religiosus; elle fréquente ordinairement les lisières des grands bois.

M. Laischenault a rapporté de Java un individu de celle espèce; je dois it ce voyageur des notes très intéressantes sur les diverses espèces de Pigeons et de Grallinacés qui habitent l'íle de Java. J'aurai occasion de parler encore de cet ami dans mon introduction générale.

\section{COLOMBAR AROMATIQUE, Variété.}

Columba Aromatica, Var.

Parm I plusieurs individus de l'espèce du Colombar Aromatique que nous avons eu occasion de comparer, il s'en est trouvé deux dont la distribution des couleurs principales varie en quelque sorte de celıi que nous avons représenté dans la planche précćdente; la premièrc de ces variétés a tout le dos d'un brun-pourpré et toutes les parties inférieures grises; celle que j’ai figurée ici a toute la tête, le cou, et la poitrine, d'un roux-cannelle, le haut $\mathrm{du}$ dos et les couvertures des ailes du même brun-pourpré que dans l'individu. précédent. Le ventre et le croupion sont d'un gris-bleu; les cuisses sont jaunes, ainsi que les bords de toutes les grandes couvertures des ailes; les plumes intermédiaires de la queue sont vertes et les latérales ont de celte couleur sur leurs barbes intérieures. La quene cn dessous est noire, et toutes les pennes sont terminées de blanc-sale.

Cet oiseau m'a ćté envoyé de Batavia avec plusieurs autres individus du Colombar Aromatique, représcnté $p l .5$. Ceux-ci nc varioient aucunement entre eux, ce qui me fait présumer qu’il doit y avoir peu de différence dans les couleurs entrc les sexes, et que l'individu que nous figurons ici n'en est qu'une variété accidentelle.

Cet oiseau est de mon cabinet. 


\section{A DDITION}

A L'ARTICLE DU COLOMBAR AROMATIQUE.

Pendant la publication de cet ouvrage il nous est arrivé d'autres Pigeons Colombars, que nous rapportons à l'espèce du Colombar Aromatique; nous les avons comparés tant avec les individus figurés dans nos planches 5 et 6 , qu'avec un dessin d'un Pigeon qui nous a été envoyé de Londres, sous le nom de Columba Curvirostra.

Cet oiseau, que nous présumions devoir former une espèce distincte dans cette famille, nous a paru, après une inspection plus exacte, ne former en effet qu'une simple variété du Colombar Aromatique, qui diffère bien sous quelques rapports des individus figurés dans nos planches 5 et 6 , mais que nous ne saurions cependant admettre comme espèce. Nous allons indiquer cette variété, ainsi que quelques autres dont les Ornithologistes ont fail autant d'espèces distinctes, que nous croyons devoir rapporter à l'Aromatique.

Le Pigeon Pompadour, que Latham (1) et Sonnini (2) ont décrit d'après le Pompadour-Pigeon figuré par Brown, doit être considéré comme une variété de l'Aromatique, il n'en diffère absolument que par la couleur jaune de paille qui revêt les petites plumes qui entourent immédiatement le bec, êt qui se trouvent entre celui-ci et les yeux : car on ne doit prendre aucune notice de ce que Brown dit à l'égard de la longueur de la queue de son PompadourPigeon, cet auteur avoue lui même que cette gravure, ainsi que la plupart de celles qui composent son ouvrage, ont été faites d'après les dessins qui lui ont été communiqués par M. Loten; au reste ces gravures sont très défectueuses; si on s'en rapportoit á celle qui représente le Pigeon dont nous parlons, on présumeroit que les ailes n'atteignent pas le croupion; il en est

(1) Lath. gen. synop., v. 4, p. 624. - Sp. 12.

(2) Sonnini, édit. de Buff., v. 7, p. $22 \mathrm{x}$. 
encore de même dans la gravure qui représente son Yellorw-faced Pigeon, qué Brown donne comme la femelle du Pompadour-Pigeon. Cette dernière a en effet la queue courte, et semblable à notre Aromatique, dont nous supposons qu'elle pourroit bien être la femelle, cependant nous ne saurions l'affirmer' n'ayant jamais vu en nature un individu tel que Brown le décrit, tandis que nous avons examiné un grand nombre de ceux à dos et couvertures des ailes couleur brun purpurin : il nous paroît donc préférable de faire simplement mention du Yellor-faced Pigeon de Brown, comme d'une variété du Colombar Aromatique.

Unc autre variété dont nous venons déjả de faire mention est le Hookbilled Pigeon de Latham (1), et le Pigeon à bec recourbé de Somnini (2), celui-ci ne diffère de notre Aromatique que par une bande noire qui traverse les pennes latérales de la queue vers leur extrémité; à cette legère différence on doit encore ajouter celle dans la couleur du bec, très difficile au reste à déterminer quand on doit faire les descriptions d’après des oiseaux empaillés, la couleur des becs et des pieds changeant dans ces oiseaux lorsquils sont secs.

Le renflement sensible du bec dans les Pigeons Colombars est. formé par la substance cornée qui termine les deux mandibules, elle consiste dans une épaisse couche ou enveloppe qui engage l'extrémité du bec; cette couche cornée est si peu adhérente au noyau ou à la partie osseuse du bee, que lorsque ces oiseaux sont secs, le plus légger effort suffit pour cmporter celte espèce de fourreau.

L'on nous léra à juste titre la remarque que le Pigeon décrit par Latham n'a que sept pouces et demi, ct que notre Colombar Aromatique en a neuf et demi; il nous paroît que l'auteur anglais se donne bien plus de licence en citant un individu de cette même espèce qui fait partie du cabinet de Sir J. Banks, et qui mesure environ dix pouces.

Il nous paroît aussi que la variété du Pigeon à bec recourbé, dont Lathan ct Somnini font mention, doit être assimilée au Pigeon à face jaune de Brown, et que ces diverses descriptions ont rapport à la femelle du Colombar Aromatique que nous ne connnoissons pas encore d'une manière précise.

Il est encore nécessaire d'observer que le Purple-shouldered Pigeon de

(1) Gen. Sym.v.4, p. 632, t. 50.

(2) Edit. de Buff., v. $7, p .227$. 
AU COLOMBAR AROMATIQUE.

Latham (1), donné par eet auteur eomme très analogue au PompadourPigeon de Brown ( qui est une variété de notre Aromatique), n'a aucun rapport avec cet oiseau; le Purple-shouldered Pigeon est de l'espèce de notre Colombar Comnandeur, et la description de l'anteur anglais doit être rapportée à cette dernière espèce.

La différence de taille que nous remarquons dans les divers individus de la même espèce est singulière; il paroît qu'on doit attribuer cette différence à la nature de la peau, et nous sommes persuadés qu'elle dépend uniquement du plus ou moins de soins que prennent ceux qui préparent les dépouilles de ces Pigeons Colonbars. La peau de ces oiseaux est extraordinairement minee et si eassante que, étant sèche, elle ne peut être maniée sans se déchirer en plusieurs pièces; elle se refuse absolument à toute extension, et il est impossible de rendre la forme naturelle à l'oiseau, lorsque la peau n'a pas été soigneusement rembourrée avee du coton ou de la filasse immédiatement. après que les chair's en ont été retirées; un individu ainsi préparé se distingue an premier coup-d'œil par la distance naturelle qu'ont entre elles toutes les plumes dn eorps, tandis qu'un individu qui n’aura pas subi préalablement une semblable préparation, aura la peau retirée, et on remarque que tontes les plumes sont compactes les mes sur les autres; il en est généralement ainsi de toutes les depouilles qui n'ont pas été rembourrées, mais la peau plus épaisse des autres espèces d'oiseaux souffre plus on moins qu'on l'étende après ayoir été ramollie; ce qui est impraticable pour la pean des Colombars : nous croyons devoir attribuer à cette seule cause la différence individuelle dans la taille que nous avons observée, dans les différentes espèces de Pigeons qui composent cette famille.

Il en est de même pour ee qui regarde la préparation des dépouilles des oiseaux de Paradis : quelles erreurs le rétréeissement de la peau ( sans parler des autres mutilations que les sauvages font subir' à ees oiseaux ) n'a-t-il pas fait eommettre aux naturalistes (2)? Ils ont établi d'après ces dépouilles racornies des earaetères génériques, que ces savants auroient été les premiers à rejeter, s̈̈ls avoient vu un seul individu de ces oiseaux dans son état parfait; il n’est pas déplaeé de donner iei les différenees dans les dimensions

(1) Columba Phœnicoptera. Lat. Ind. Orn., w. 2, p. $597, s p .15$; - et Gen. syn. supp., v. I, p. 20 r.

(2) Nous exceptons de ceux-ci M. le Vaillant, qui a donné les meilleures notions sur ces oiseaux, et qui les a décrits d'me manière à ne laisser rien à désirer. Voyez son Introduction à l'Histoire nalurelle des oiscaux de Paradis. 
des dépouilles d'oiseaux de Paradis grande émeraude, telles qu'on les envoie d'ordinaire en Europe, comparées avec celles prises sur un individu de cette espèce faisant partie de mon cabinet, qui a été préparé et rembourré de la manière usitée pour les oiseaux venant des colonies françaises; cet individu unique, quant à sa pureté et à ses formes naturelles, mesure seize pouces, depuis la pointe du bec jusqu'à l'extrémité de la queue, et le volume de son corps est pareil à celui de notre Corbine; tandis que sur les peaux racornies qu'on reçoit ordinairement des Moluques, la mesure mitoyenne, prise sur une grande quantité d'individus, est de douze ou de treize pouces depuis le bout du bec à l'extrémité de la queue. 


\section{COLOMBAR A FRONT NU.}

LA nouvelle espèce de Colombar que nous représentons dans la planche 7 se distingue par une nudité considérable qui engage le front. Cet espace dénué de plumes est formé par le prolongement de la peau qui enveloppe la base du bec; elle ressemble beaucoup à la plaque blanchâtre que le Foulque mâle porte sur le front; dans l'oiseau vivant elle doit être d'une vive couleur orangée, cette teinte étant encore très apparente dans la peau séchée : le bec de ce pigeon Colombar est solide, et la pointe de la mandibule supérieure est fortement courbée.

La longueur totale du Colombar à front nu est de onze pouces; son bec a dix lignes, l'extrémité des deux mandibules qui est recouverte de la couche cornée est d'un gris argentin; la tête, le cou, la poitrine et toutes les parties inférieures de l'oiseau sont d'un beau vert-clair; cette couleur change sur le haut du dos en gris-cendré, mais sur le reste des parties supérieures les teintes se nuancent en vert foncé; le poignet de l'aile est d'un violet foncé; l'aile batarde, les pennes secondaires et les rémiges sont noires, ces dernières n'ont point de liseré à leurs barbes extérieures, mais les pennes secondaires ainsi que quelques unes des moyennes couvertures de celles-ci ont un petit bord d'un blanc-jaunâtre; les pennes caudales intermédiaires sont vertes, les latérales sont d'un gris-clair depuis leur origine jusqu'aux trois quarts de leur longueur, ensuite elles ont du gris-foncé, et sont encore terminées de gris-clair; en dessous toutes les pennes sont noires, et terminées de gris-clair : les couvertures inférieures de la queue sont d'un rouxcanelle, et terminées de blanc; le tarse, depuis l'articulation du genou 
jusque vers la moitié de sa longueur, est couvert de plumes jaunes; le reste, ainsi que les doigts, sont orangés.

Cette espèce, dont nous ne connoissons que le seul individu déposé dans mon cabinet, habite l'Afrique; il faisoit partie d'une collection recueillie sur les côtes de Loango et d'Angole. 


\title{
COLOMBAR-WAALIA Mâle et Femelle.
}

\author{
PL. VIII et $I X$.
}

Columba Abyssinica. Litr. Ind. Orn. supp. q. 2, p. 60.

Le Colombar. Le Vaill. Ois. d'Afi.v. 6, pl. 276 et 277.

Waalia Pigeon. - Latri. gen. Syn. suppl. v. 2, p. 269.

Ce Pigeon, que M. Le Vaillant a rencontré dans l'Afrique méridionale, et qu'il décrit dans son ornithologie sous le nom de Colombar ou de Colombar à épaulettes violettes, est une espèce que cet auteur semble donner commé nouvelle, puisqu'il ne fait aucune mention dans son texte des auteurs qui ont indiqué cet oiseau avant lui; cependant Brųce décrit et figure ce Pigeon sous le nom de Waalia pigeon, et Latham en fait mention, d'après ce voyageur, dans son Index et dans son général Synop.

Nous conservons à cette espèce le nom que Bruce lui a donné, d'autant plus que la dénomination de Colombar à épaulettes violettes ne lui conviendroit sous aucun rapport, vu que la plupart des pigeons Colombars ont du violet sur le poignet de l'aile.

Bruce nous apprend que ces Pigeons habitent les parties basses de l'Abyssinie ou perchent sur les plus hauts arbres; ils y restent sans bouger durant la plus forte chaleur du jour; aux approches de la saison pluvieuse ils quittent cette contrée, et émigrent vers les parties méridionales de l'Afrique. M. Bruce observe que ces oiseaux volent en grandes troupes, et à une prodigieuse hauteur; leur chair est un mets exquis, cependant les Abyssiniens n'en mangent pas, et ont horreur de cette nourriture.

Le texte du naturaliste français nous apprend que ce Colombar construit son nid dans des trous d'arbres, qu'il fréquente habituellement les bois, et vit isolément par paires, mâle et femelle, enfin que la femelle pond quatre ouf's d'un blanc-fauve ou isabelle. 
En combinant les descriptions des voyageurs cités, nous pouvons conclure que le Colombar-Waalia fait sa ponte, durant la saison pluvieuse, dans la partie méridionale de l'Afrique, où il vit alors isolément pour vaquer à l'éducation de sa progéniture; qu'il se transporte vers le nord lorsque les jeunes Colombars sont en état de fournir à cette course, et que dans ces parages l'espèce continue à vivre en grandes bandes.

Nous ne pouvons passer outre sans réfuter une erreur de M. Le Vaillant : cet auteur dit « que le Ramier des Moluques, décrit par Brisson, tome $\mathbf{I}^{\mathrm{er}}$, " page 148 , et indiqué ensuite par Buffon comme une simple variété de " notre Ramier d'Europe, est encore une espèce qui appartient à la mème " famille des Colombars, ce que nous avons vérifié sur plusieurs individus " que nous avons vus (1). )

Si M. Le Vaillant ne terminoit point cette remarque par une assertion si positive, nous la passerions sous silence; il est cependant certain que le Ramier des Moluques de Brisson n'est pas un Colombar, comme le prétend M. Le Vaillant, mais que c'est un Pigeon qui appartient à notre première famille; nous avons décrit cet oiscau sous le nom de Colombe-Muscadivore, espèce à laquelle la description de Brisson, que M. Le Vaillant cite, se rapporte parfaitement.

Le Colombar-Waalia mesure en totalité onze pouces et demi; le bec a dix lignes, il est très épais, les deux mandïbules se renflent sensiblement du bout, et forment ensemble une pince solide, qui est plus large que dans toutes les autres espèces de cette famille. Le mâle a la tête et le cou, jusqu'à la poitrine, d'un gris légèrement nuancé de vert-olive; les scapulaires, le dos, le croupion ainsi que les couvertures du dessus de la queue, sont d'un vert-jaunâtre; toutes les petites couvertures du poignet de l'aile sont d'un violet tendre; les grandes couvertures, les pennes secondaires et les rémiges sont noires, bordées de jaune; le ventre est d'un beau jaunejonquille; l'abdomen est blanc; les couvertures inférieures de la qucue sont d'un roux-marron, terminées de roux clair; les pennes de la queue, qui sont au nombre de quatorze, sont toutes d'un gris-bleuâtre en-dessus, et noires terminées de gris-clair en-dessous.

Le tarse est emplumé jusque vers la moitié de sa longueur; le reste, qui est dénué de plumes, est rouge, ainsi que les doigts; les yeux sont orangés.

La femelle est un peu plus petite que le mâle, dont elle se distingue

(1) Voyez Le Vaillant, Ornith. d'Af., v. 6, p.65, article des Colombars. 
DES COLOMBARS.

encore en ce que le ventre n'est pas jaune; cette partie, ailssi que toutes les autres parties du corps, sont chez elle d'un vert-olivâtre uniforme; du reste, elle a en général les teintes moins vives que dans le mâle. Dans le premier âge, le mâle ressemble beaucoup à la femelle adulte, et cette dernière, dans le même état, n’a pas encore de violet aux épaulettes : cette circonstance relative à la livrée du jeune Colombar-Waalia nous porte à soupconner que notre Colombar-Maitsou pourroit bien être le jeune mâle de cette espèce; M. Le Vaillant est aussi de cet avis.

Nous avons vu que le Colombar-Waalia habite dans toute l'étendue de l'A frique; il est probable qu'il se trouve encore à Madagascar; il se nourrit uniquement de fruits comme toutes les autres espèces de cette famille.

M. Raye de Breukelerwaert possède dans son cabinet les, individus que nous avons figurés dans nos planches. 


\title{
COLOMBAR JOJOO, Mâle et Femelle.
}

\author{
$p_{L .} X$ et $X I$.
}

Columba Vernans. Lath. Ind. Om. v. 2, p. 599, sp. 22

- Guez. Syst. I, p. 789 .

Pigeon Vert des Philippines. Buff. pl. enl. I38.

Parrot Pigeon. Latr. gen., Syn. v 4, p. 629 el 630.

LE Colombar de cet article, à qui nous avons conservé le nom de Jojoo, que les Javans lui donnent, diffère des espèces précédemment décrites par son bec bien plus mince et moins renflé vers le bout que ne l'ont d'ordinaire les Pigeons de cette famille; il s’approche davantage par-là des Pigeons de notre première famille ou Colombes. Latham a fait un double emploi de l'espèce en la décrivant sous le nom de Parrot pigeon, où cet auteur parle, d'après Sonnerat, du mâle et de la femelle; et un peu plus haut il fait encore mention du Jojoo sous le nom de Purple pigeon, en donnant sa description d'après la mauvaise figure que Brown a publiée : Sonnini décrit aussi cette espèce sous le nom de Pigeon Vert à tête grise d'Antigue; il est cependant nécessaire d'observer que cet auteur parle, à l'article cité, de plusieurs espèces de Pigeons à tète grise, quïl réunit en une seule espèce; c'est en quoi ce naturaliste se trompc. Brisson décrit encore notre Colombar sous le nom de Pigeon Vert des Philippines. Nous renvoyons nos lecteurs, pour la synonymie de cette espèce, à notre index, qui termine ce volume.

Le Colombar Jojoo mesure en totalité dix ponces; son bec est court, mince et peu renflé du bout; la substance cornée qui recouvre l'extrémité des deux mandibules est blanche, mais la partie molle de la base du bec est rougeâtre. Le mâle a la tête, la gorge et toute la partie postérieure du cou d'un gris-bleuâtre; surla poitrine se dessinent deux larges ceintures; la supérieure est d'un beau lilas-clair, et l'inférieure d'un jaune-orangé; il y a 
DES COLOMBARS.

des individus sur lesquels le lilas-clair se prolonge sur les côtés du cou, et même jusque sur la nuque; le dos, les scapulaires et toutes les couvertures des ailes, tant grandes que petites, sont d'un vert-olive foncé, tontes ces couvertures sont terminées par un large espace d'un jaune-clair, ce qui forme une bande transversale sur chaque aile; les rémiges et les pennes secondaires sont noires, ces dernières sont finement liserées de jaunâtre; le ventre est gris-cendré, mais vers les cuisses cette couleur se nuance en teintes jaunâtres, et prend un ton d'un beau jaune jonquille sur l'abdomen; les couvertures inférieures de la queue sont rousses; les pennes caudales, au nombre de quatorze, sont gris-foncé à leur origine, ensuite elles ont une large bande noire, et sont terminées de gris plus clair; les deux pennes intermédiaires sont grises sur tonte leur longueur; les pieds sont d'un rouge de laque ; liris a deux cercles : l'extérieur est rouge, et celui qui entoure immédiatement la prunelle est bleu.

La femelle n’a point de lilas ni de jaune-orangé sur la poitrine comme le mâle. Cette partie, ainsi que tout le dessous de l'oiseau, est d'un vertjaunâtre-clair; la tête et la partie postérieure du cou est d'un gris-bleu; et toutes les autres parties supérieures sont comme dans le mâle.

Cette espèce habite aux îles de Luçon et d'Antigue; on les trouve aussi, à certaines époques, dans celle de Java. Sonnerat ne nous dit rien de leur manière de vivre et du genre de nourriture qu’ils préfèrent; il est à présumer quils se nourrissent de fruits.

Le mâle et la femelle de cette espèce font partie de mon cabinet. 


\section{LES COLOMBI-GALLINES.}

\section{GARACTERES ESSENTIELS.}

Bec long et menu; mandibule șupérieure peu ou point renflée; tarse long et grêle; doigts cntièrement divisés; ailes courtes, généralement arrondies.

\section{COLOMBI-G A LLINE, GOURA, Male.}

$$
\text { PLANCHE } I^{\text {II. }} \text {. }
$$

Columba coronata, LAтн. Ind. orn. v. 2, p, 5ั96.

- Giel. Syst. I, p. 774.

Phasianus cliristatus indicus. Brisson, orn. $\% .1, p .279$.

Le Pigeou couronné de Banda. Buffon, édit. de Sonnini, v. 7 , p. 255. - Buff., pl. enl. 118.

Le Goura de la nouvelle Gninée. Sonnerat, Voy.p. r69, 1. го作.

Great crowned Pigeon, LATr. Syn, v. 4, p. 620. - Edw. 1. 338.

LA petite famille d'entre les Pigeons que nous avons nommés ColombiGallines semble en effet se rapprocher beaucoup de l'ordre Gallinace : les habitudes de ces Pigeons-Grallines, leur genre de vie et un grand nombre de leurs caractères extérieurs, ont plusieurs traits de ressemblance avec ceux des diverses familles qui composent la grande tribu des vrais Gallinacés; il semble mème qu'ils ont été destinés à former le passage de ces oiseaux aux Pigeons; c'est ainsi que dans la nature tous les êtres se trouvent imperceptiblement liés par des espèces internédiaires qui, dans ce vaste ensemble des merveilleuses productions de cette mère prévoyante, paroissent consolider l'assemblage de l'harmonie la plus admirable avec l'ordre le plus parfait.

La famille des Colombi-Gallines renferme plusieurs espèces, qui se ressemblent bien moins entre elles par des caractères propres à tous les individus qui la composent, que par les rapports intimes qu'elles ont de commun avec les différentes petites tribus des Gallinacés, ce qui rend difficile la classification des espèces qui appartiennent à cette division. Pour ne 
pas s'y tromper, et pour décider sans balancer sur l'identité de leurs caractères, il seroit nécessaire qu'on connùt les mœurs de ces Pigeons; mais pour peu qu'on se soit fait un usage d'étudier la nature des oiseaux, et qu'on ait acquis l'habitude de se représenter l'ensemble des divers genres, et le plus ou le moins d'affinité qu'on y rencontre, on ne sauroit guère se tromper dans la classification des Colombi-Gallines, même cn ne prenant pour guide que leur conformité extérieure.

L'oiseau que nous décrivons dans cet article diffère, par beaucoup de caractères, des autres individus de la même section, il paroît mème isolć dans cette division; sa huppe d'une forme toute particulière et sa longue queue l'éloignent entièrement des autres Colombi-Gallines, qui ont toutes la queue très courte comme les perdrix. Le Groura ressemble tellement aux Hoccos, que, pour le transformer, il ne faudroit que lui substituer le bec d'un de ces oiseaux; sa queue alongée et arrondie, ses ailes courtes, son corps ramassé, ainsi que sa huppe, lui donnent entièrement la figure d'un Hocco, dont il a aussi les mouvements et les allures : ce n'est donc que par' ces mêmes rapports que Brisson a cru devoir placer le Groura parmi les Faisans, genre que cet auteur confondoil mal à propos avec celui des Hoccos.

On se tromperoil étrangement en présumant, d'après des rapports aussi intimes avec les Grallinacés, que le Groura tient plus par ses caractères et ses mours aux oiseaux de cet ordre qu'i ceux de l'ordre des Pigeons; il a le bec formé comme celui des Pigeons, dont il a le roucoulement; comme eux il ne pond que deux œufs, et éléve ses petits, en leur dégorgeant la nourriture d'avance macérée dans le jabot; il construit mème son nid sur la sommité des arbres; habitude par laquelle il s'éloigne non seulcment des vrais Gallinacés, mais aussi de la famille des Colombi-Grallines, dout toutes les autres espèces connues pratiquent leur nid à terre.

Le Groura, d'après l'énumération de la plupart de ses caractères connus, est de tous les Colombi-Grallines celui qui par sa forme extérieure ressemble le plus aux Gallinacés; tandis que, par' ses mour's, il a bien plus de rapport avec les Pigeons que toutes les autrcs espèces qui composent cette section.

Cet oiseau, quoiqu'ayant élé souvent apporté vivant en Hollande par les vaisseaux de la Compagnie des Indes, s'accoutume difficilement à la température humide de notre climat; il exige beaucoup de soins, et ne sauroit endurer le froid. L'Impératrice en a deux vivants, à la Malmaison, qui paroissent assez bien acclimatés. Je doute qu'on puisse jamais réussir à le rendre utile à nos basse-cours, où on est cependant parvenu à faire propager 
DES COLOMBI-GALLINES.

les diverses espèces de Hoccos, de Pénélopes et de Faisans, ainsi que plusicurs Colombes exotiques.

Sonnerat, qui a vu ces oiseaux à la Nouvelle-Guinée, ne nous donne aucur détail particulier sur leur manière de vivre; il se contente de dire qu’ils n'habitent point l'ìle de Banda, mais qu'ils ne se trouvent et ne se multiplient qu’à la Nouvelle-Guinée. Cette assertion est fausse, puisque ces oiseaux se trouvent non seulement is la Nouvelle-Guinée, mais aussi dans un grand nombre d'iles de l'Archipel des Moluques. Labillardière en a trouvé dans celle de Waygiou; le capitaine Forrest à Tomogui, où les naturels du pays les nomment Mututu; ils habitent aussi les îles des Papous, où on leur donne le nom de Manipi. Banda est la seule île où les Hollandais vont prendre ces oiseaux pour en peupler les ménageries de Java, où ils sont très communs. Les colons de cette île nomment le Goura Kroonvogel, ce qui signifie oiseau couronné.

Dans l'ćtat de domesticité, on peut nourrir cet oiseau de mais, dont il est très friand; il mange aussi de petites Cèves de marais et de petits pois secs; il fait entendre fréquemment un bruit sourd, produit par la colonne d'air qui s'échappe de sa poitrine, espèce de beuglement ventriloque qui paroît lui être commun avec le dindon, lequel fait un bruit à peu près semblable. Je n'ai jamais été à même d'examiner la trachée artère du Goura, laquelle doit influer beaucoup sur la manière dont ce son est produit, et j'ai tout lieu de croire que cet organe a beaucoup d'affinité avec celui des Hoccos et des Pénélopes, dont nous ferons connoître les différences qui, dans ces animaux, caractérisent les diverses formes de l'organe de la voix.

La longueur totale du Colombi-Hocco, prise depuis le bout du bec à l'extrémité de la queue, est de deux pieds trois pouces; le bec a deux pouces, le tarse trois pouces neufs lignes; les aîles ne dépassent pas l'origine de la quene qui est arrondie. La huppe, ou l'espèce de crête qui orne la tête de cet animal, est composée d'une infinité de baguettes très minces, munies de barbes soyeuses et désunies. Cette crête, que l'oiseau porte constamment relevée, est un ornement qui donne beaucoup de grace à tous ses mouvements.

Le bleu couleur de plomb domine sur la majeure partie du plumage; la tête, la huppe, le cou, ainsi que toutes les parties inférieures, sont aussi de cette teinte; les petites et les moyennes couvertures des ailes, ainsi que les plumes du haut du dos sont toutes terminées d'un beau brun-marron; les grandes couvertures sont de la même couleur à l'origine et ì l'extrémité, 
mais le centre de ces parties est d'un blanc pur; ce qui produit une large bande transversale sur les ailes, lorsque celles-ci se trouvent dans l'état de repos. Les pennes desailes et de la queue sont d'un bleu de plomb foncé; ces. dernières sont terminées de bleu cendré; le bec est noir et l'iris rouge; les tarses sont couvertes d'écailles arrondies, qui ne se touchent pas; la peau, qui isole chacune de ces écailles, est blanchâtre; les doigts, soudés à leur origine par une membrane, ont les écailles disposées de la mème manière que chez les autres espèces de Pigeons.

Le format de cet Ouvrage ne permettant pas de figurer cet oiseau de grandeur naturelle, $M^{\text {He }}$ Pauline de Courgelles (maintenant femme KNip), l'a représenté au tiers de sa grandeur. 


\title{
COLOMBI-GALLINE A CAMAIL, Mâle.
}

\author{
Pt. II.
}

Columba Nicobarica, Latr. Ind. orn. v. 2, p. Go5 , sp. 44 .

- Guel. Syst. x, sp. 783 - Briss. ข. 1, p. г53.

Pigeon des îles Nicobar. Buffon, éd. de Sominini, ข. 7, p. 250. - Buff. pl. enl. 491. Nicobar Pigeon. LATH. Syn. v. 4, p. 642.-Edw. 1. 339. - Albin. v. 3, t.47-48.

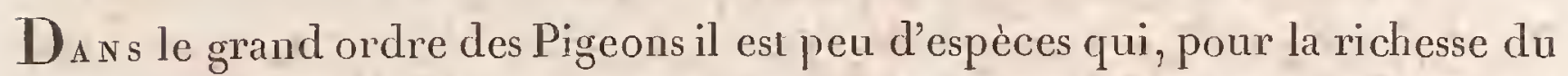
plumage, puissent rivaliser avec celui dont nous faisons le sujet de cette description; les couleurs brillantes répandues sur ce Colombi-Gralline, jointes à la forne élégante des longues plumes effilées qui retombent sur les côtés du cou, lui prètent des ornements qui récréent agréablement la vue : il charmeroit bien davantage nos yeux, si la nature avoil ajouté à ces brillantes parures, l'élégance d'une taille svelte et les mouvements légers; mais, d'ailleurs, pourvu de tous les apanages du luxe, il est loin d'avoir en partage les formes gracieuses des Colombes : son corps est ramassé, son vol est lourd, et ses mœurs ont plus de rapports avec ceux que nous remarquons dans les oiseaux gallinacés; il se tient de préférence à terre, court avec une grande célérité, et construit son nid comme les perdrix. Les longues plumes effilées qui prennent leur origine sur la partie postérieure du cou semblent rapprocher cet oiseau de la famille des Coqs.

Les auteurs qui ont décrit et figuré cet oiseau lui donnemt le nom de Pigeon de Nicobar ou Nicombar: nous avons changé cette dénomination défectueuse, vu que plus de dix espèces de Pigeons habitent dans celte île, et les îles adjacentes où le Colombi-Galline à camail se trouve de mênie qu’à celle de Nicobar. En général les noms de pays quelconques sont sujets à induire en crreur; les ornithologistes doivent éviter, autant que possible, de les donner aux oiseaux, parce qu'il est assez rare que la même espèce ne se trouve pas répandue dans plusieurs contrées, qui sont quelquefois très éloignées les unes des autres.

Dans le Buffon de Sonnini, M. Virey relève une erreur du voyageur Makinstosh (a) pár une autre erreur non moins ridicule. Le voyageur cité

(1) Makinstosh, Voyage en Europe, en Asie et en Afrique, t. r, lett. 42, p. 390 . 
imagine assez mal à propos que le Colombi-Gralline à camail est un rejeton du Pigeon sauvage et du Perroquet, sur quoi M. Vircy ajoute que cette supposition est fausse, et qu'elle prouve seulement que cet oiseau a beaucoup d'analogic avec les Perroquets; j'ignore comment M. Virey réussiroit à prouver ce rapport.

Albin donne deux mauvaises figures de son Pigeon de Nicobar, l'une comme le mâle et l'autre comme la fcmelle de l'espèce, tandis qu'en eflet l'autcur u'a représenté que deux femelles; je ne cite, au reste, ces planches défectuenses que par rapport à cette crreur. Buffon et Edwards donnent aussi des figures imparfaites de la femelle de cette espèce; mais aucun auteur n'a encore représenté un individu mâle : celui-ci se distingue de la fcmclle par une petite membrane ou espèce de crête charnue, qui s'élève sur la base de la mandibule du bec, à environ la hautcur de deux lignes; la femelle, dont lẹ couleur's sont moins vives que celles du màle, n'a pas cette espèce de crêtc arrondie.

Le Colombi-Galline à camail est à peu près de la taille du Ramier; sa longueur totale est de quatorze pouces et demi; son bec, peu renflé vers le bout, a un pouce neuf lignes; la queue est très courte el peu élagéc; les ailes pliées atteignent à son cxtrémité; les longues plumes du cou qui forment le camail ont l'extrémité de leurs barbes désunics et soyeuses comme dans les Coqs. La couleur du plumage cst, en général, d'un beau vert-foncé changeant en bleu-purpurin cl en cuivre de rosette; les grandes pennes des ailes sont d'un noir-blcuâtre, à légers reflcts de vert-doré; la queuc cst d'un blanc pur, le bec noir et l'iris de couleur noisettc; l'ceil est entouré d'une espace nue d'un brun-terne; le tarse couvcrt d'ćcailles exagones est d'un bleu-noiràtre ainsi que les doigts; les ongles sont jaunes.

J'ai vu vivants plusicurs oiseaux de cette espècc. M. Amershof en avoil, ily a quelques années, rassemblé scize individus dans sa belle ménagerie. Ces Pigeons ne se perchent que pour passer la nuit, encore doit-on aroir soin do placer les juchoirs qui leur sont destinés à un pied, ou tout au plusà deux pieds de terre; ils font entendre un roucoulement sourd, qui n'est pas à beaucoup près aussi agréable quc celui de nos Colombes-Ramiers; ce sont, du reste, des animaux stupides, fort tranquilles, dont le naturel peu farouche est susceptible d'être cultivé en domesticité. Ils deviendroient un orneinent brillant dans nos volières, si on pouvoil parvenir à les faire propager dans nos contrées; mais jusqu'ici nous n'avons point d'exemple que ces beaux oiseaux aient produit hors de leur pays natal; j’ai néanmoins lieu de croire quarec les 
DES COLOMBI-GALLINES.

soins nécessaires rien ne seroit plus facile : la volière de mon père a fourni des exemples plus extraordinaires d'oiseaux qui y ont propagé; diverses espèces de Loxies des Indes, plusieurs Fringilles de la Zone Torride, et quelques Pigeons exotiques y ont produit une quantité de petits; les Paddas de la Chine, le Cardinal rouge et noir du Cap de Bonne-Espérance, y pulluloient comme dans leur pays natal.

Le Colombi-Galline à camail habite l'ìle de Sumatra, celle de Nicobar', située au nord de cette dèrnière, ainsi que plusieurs îles du vaste Archipel des Moluques.

L'individu qui a servi de modèle appartient au Muséum de Paris.

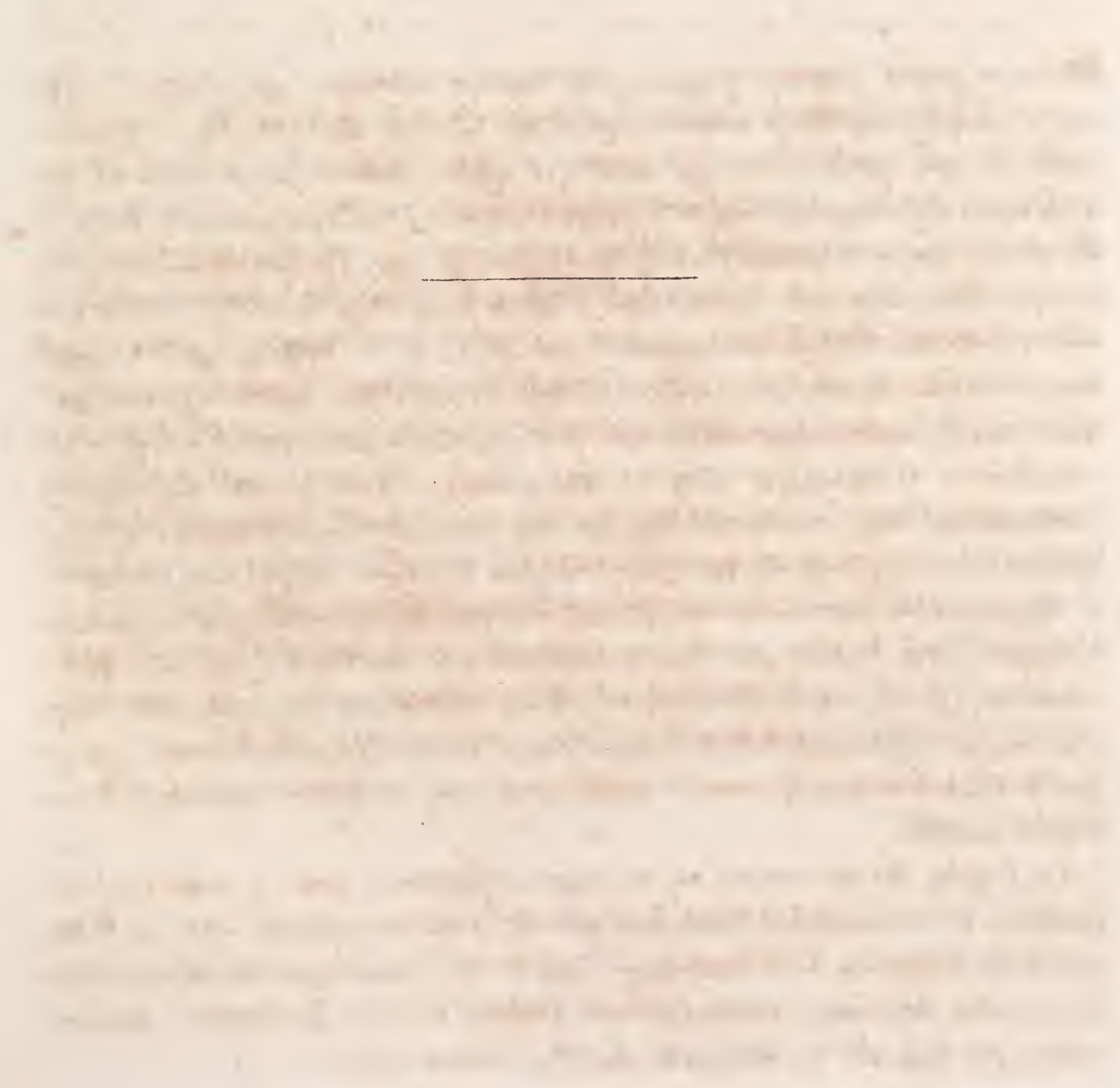




\section{COLOMBI-GALLINE A CRAVATE NOIRE.}

$$
\text { PL. III. }
$$

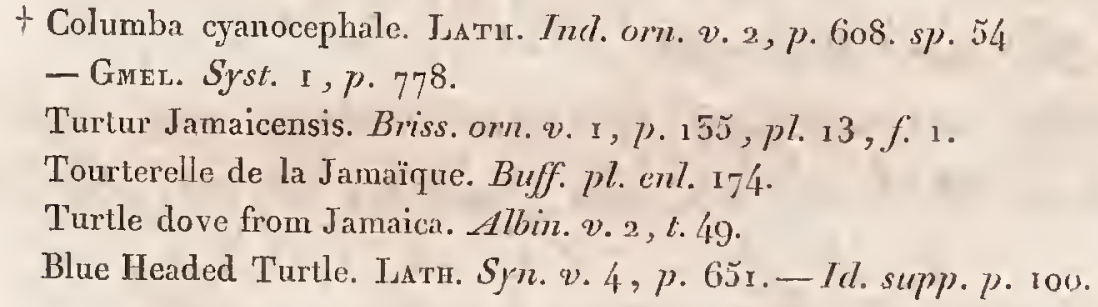

Dans le grand nombre d'espèces de Pigeons exotiques que Buffon a très mal à propos considérés comme autant de rejetons de notre Biset sauvage, celui de cet article n'est pas même excepté; Buffon ne se contente pas seulement de comparer notre Colombi-Galline à cravate noire au Biset, il dit encore que sa Tourterelle de la Jamaique, pl. 174 , qui est l'oisean désigné, pourroit bien être une variété dans l'espèce de la Tourte; autre erreur non moins ridicule. Comment supposer, en effet, qu'un Pigeon qui a le corps trapu, les ailes courtes et la queue seulement arrondie, puisse être comparé à une espèce entièrement différente? La Tourte a la taille svelte; la queue est cunéiforme et fortement étagée; non content d'avoir si mal adroitement confondu les deux espèces de Pigeons que nous venons d'indiquer, le mème auteur nous apprend un peu plus loin que le Pigeon décrit par Edwards, pl. I4, pourroit bien ètre la femelle de la Tourterelle de la Jamaïque, quoique la figure assez exacte que donne Edwards de son Pigeon rert des Indes orientales, pl. 14, auroit dú désabuser M. de Buflon sur une supposition aussi peu fondée, l'oiseau qu'Edwards représente étant la Colombe Turvert, espèce que Buffon décrit aussi, sous le même nom, sans se douter seulement de ce double emploi.

Le Pigeon de cet article vit et trotte toujours à terre comme les rrais perdrix; il construit son nid à peu près de la même manière que ces Gallinacés; les habitants de la Jamaique, sans doute trompés par ces affinités dans les mours, donnent à notre Colombi-Galline le nom de Perdrix, dénomination par laquelle ils désignent plusieurs autres espèces. 
Le Colombi-Galline à cravate noire a la base du bec supérieur entièrement couverte de plumes; les narines sont placées dans un étroit espace charnu. Celte espèce n'a pas de renflement sensible vers le bout de la mandibule supérieure; l'inférieure ne forme point, comme dans les autres familles, un angle plus ou moins ouvert : cette mandibule est, au contraire, droite comme dans quelques espèces de Cailles à trois doigts $(a)$; j’ai même trouvé parmi ces dernières un individu qui a le bec tellement ressemblant à celui de notre Colombi-Galline, qu'on pourroit l'adopter indifféremment de l'un de ces oiseaux à l'autre, sans que ce changement parùt.

La taille du Colombi-Galline à cravate noire égale celle d'une Perdrix grise; la longueur totale de l'oiseau est de dix pouces quatre lignes; le bec a onze lignes; la quene est de moyenne longueur et tant soit peu arrondie; le tarse a un pouce quatre lignes; le haut de la tête et la gorge sont bleus; sur le devant du cou est une espèce de cravate noire qui se prolonge jusque sur la poitrine, ou elle est entourée d'un cercle blanc, formé par les plumes extérieures de cette cravate, qui toutes sont terminées de la couleur indiquée; une bande d'un blanc pur prend son origine au dessous de la mandibule inférieure clu bec, passe sous les yeux et aboutit derrière la tête, où une espace noire de la forme d'un fer à cheval ceint l'occiput; toutes les parties supérieures sont d'un bistre vineux, mais la poitrine est plus vivement colorée de cette teinte; la base du bec est rougeâtre, les yeux sont d'un brun-roux; les Tarses ont des écailles rougeâtres très petites et de forme exagone; on aperçoit la peau nue dans les intervalles qu'elles laissent entre elles; les ongles sont gris.

Cette espèce habite à la Jamaïque; elle se trouve encore à Cuba, dans presque toutes les autres îles méridionales, et dans lés autres contrées les plus chaudes del'Amérique; on a rapporté depuis peu plusieurs individus vivants de cette espèce; leurs dépouilles, au reste, ne sont pas rares dans les collections (b).

(a) Nous formerons un genre de ces prétendues Cailles, sous le nom de Turnix; ees oiseaux, dont un grand nombre d'espèees sont déjà eonnues, diffërent trop par leurs mœurs des véritables Perdrix, pour ne pas les distinguer génériquement.

(b) A la Malmaison on voit encore quatre de ces individus vivants, qui viennent du voyage du eapitaine Baudin; un de ees oiseaux nous a servi de modèle. 


\title{
GOLOMBI-GA LLINE MONTAGNARD.
}

\author{
PL. IV.
}

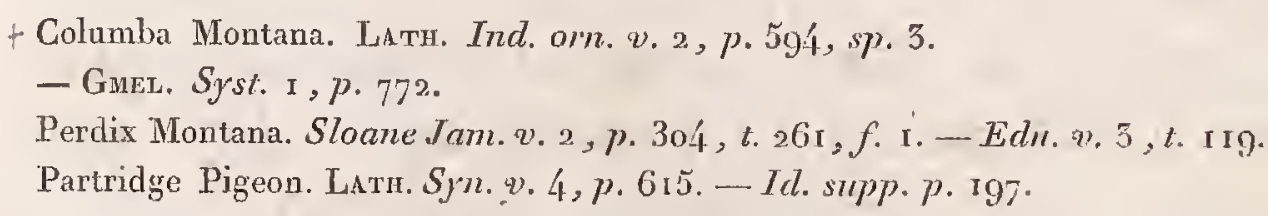

Sr les formes extérieures du. Colombi-Galline Montagnard ont beaucoup de ressemblance avec celles de nos Perdrix vulgaires, et si elles ont donnć lieu à la dénomination impropre de Perdrix de montagne, par laquelle HansSloane désigne cet oiseau, il cst en même temps certain que la manière de vivre du Montagnard n'a pas peu contribué à lui faire soupçonner des rapports plus intimes avec ces gallinacés; il est cependant nécessaire de faire observer que, quoique un grand nombre de Colombi-Gallines se rapprochent beaucoup de la famille des Perdrix, et qu’ils marquent évidemment le passage des Pigeons aux diverses familles des gallinacés (de même que ces derrières se trouvent avoir des espèces qui forment la nuance, et lient entre eux leurs différentes tribus), il est néanmoins hors de tout doute que les ColombiGallines tiennent aux Pigeons par des caractères trop marquants pour se permettre de les en séparer par des caractères génériques propres à toutcs les espèces. Nous avons déjà dit que ces oiseaux diffèrent entre eux par de très légères nuances, et que nous ne les avons réunis dans une même section, que par rapport à leur plus ou moins d’affinités avec les gallinacés.

Le Montagnard est un oiseau silencieux et farouche; il est inquiet en captivité. Sa manière d'être dans cet état indique un naturel craintif et peu sociable. Accoutumé à vivre sur lcs montagnes et dans les lieux isolés, il est dans une agitation continuelle; le nnoindre bruit ou la présence de l'homme l'effarouche; toujours blotti dans quelque coin reculé, il ne sort guère de sa cachette que pour satisfaire à ses besoins. Pour passer la nuit, cet oiseau choisit de préférence une élévation quelconque, où il aime à se poser, au défaut d'un endroit convenable à cette fin; il se perche aussi sur des bâtons peu élevés de terre. Son vol est lourd; il doit même en état de liberté se trouver 
DES COLOMBI-GALLINES.

peu propre à fournir à une longue course, les ailes de ce Pigeon étant courtes et arrondies comme celles des Perdrix.

Hans Sloane, qui paroît avoir observé cette espèce à la Jamaïque, nous dit qu'elle vit sur les montagnes élevées et dans les bois, où elle construit son nid sur les branches basses ou recourbées vers la terre; le nid est fait avec de petits morceaux de bois entrelacés de coton; il est si étroit qu'au bout de quelques jours, à l'époque où les Pigeonneaux commencen t à se convrir de plumes, ils sont obligés de se laisser tomber ì terre, où les parents continuent à les nourrir.

Latham, qui décrit la femelle de cette espèce, place mal à propos dans sa synonymie l'oiseau indiqué par Brisson, sous le nom de Pigeon roux de Cayenne : ce dernier, d'une espèce différente, est notre Colombi-Gralline roux-violet mâle, qui va faire le sujet de l'article suivant. Edwards donne une figure passable de notre Montagnard mâle, sous le nom de Perdrix de montagne.

Ce Colombi-Galline est de la taille d'une Tourterelle; sa longueur, depuis le bout du bec à l'extrćmité de la queue, est de neuf pouces et demi; le bec qui est alongé, mince et peu renflé vers la pointe, a environ un pouce; le tarse a treize lignes; celui-ci, de même que les doigts, sont grêles; la queue est courte, légèrement étagée; les ailes, d'une forme arrondie, dépassent d'un pouce seulement son origine : le mâle se distingue par deux balafres blanches qui prennent naissance à l'angle du bec; la première passe au dessous des yeux, et la seconde sur la partie supérieure du hau du cou; elles sont séparées par une bande de couleur brune; la tête et la partie postérieure du cou sont d'un vert-doré à légers reflets pourprés; la poitrine est d'un vinacé tendre; cette couleur prend une teinte de blanc-jaunâtre sur le ventre et sur les autres parties inférieures; les petites couvertures alaires, le dos et les couvertures supérieures de la queue, sont d'un beau violet à reflets pourprés; le dessus des ailes et l'origine de toutes les grandes pennes sont d'un brunroux, le bout de ces dernières est noirâtre; la queue cst rousse; la base du bec, le tour des yeux et les pieds sont d'un beau rouge; l'iris est brun-clair. Un individu de cette espèce, que j’ai eu vivant, m’a servi à cette description : on trouve ces Pigeons dans l'Amérique septentrionale (a).

(a) N'ayant point trouvé cet oiseau dans les collections de Paris, j’ai fait mon dessin d'après celni que m'envoya M. Temminck. (Note du Dessinateur.) 


\title{
COLOMBI-GALLINE ROUX-VIOLET, Mâle et Femelle
}

\author{
P.. $V$ et $V I$.
}

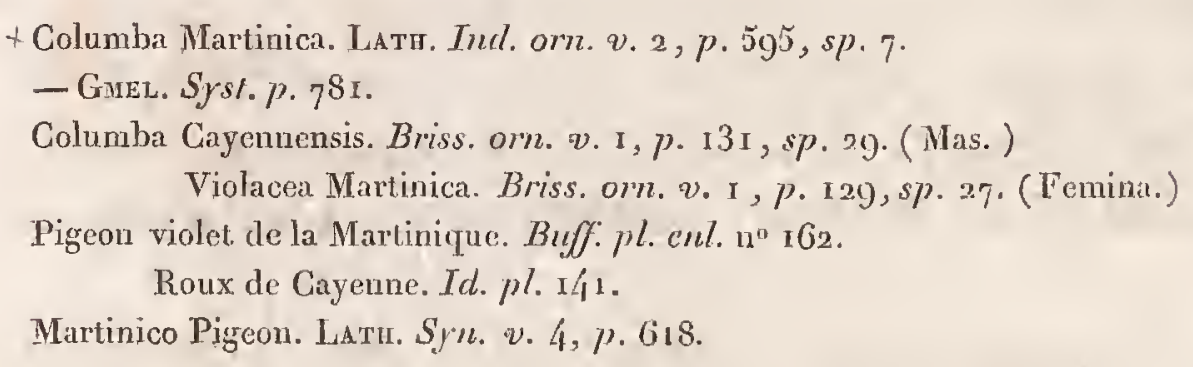

Buffor, guidé par le désir de diminuer les espèces nominales des divers auteurs, entrainé par son idée favorite d'atribuer un si grand pouvoir is l'influence des climats chauds sur le plumage des oiseaux, et séduit par lit supposition mal fondée que notre Pigeon sauvage auroit bien pu produire un grand nombre d'espèces qui habitent dans les diver's parages des Indes, en Afrique et en Amérique; Buffon, dis-je, ne manque pas de soupcomner l'affinité d'espèce entre notre Colombi-Galline roux-violet et le Biset sauvage. Cet auteur dit : "Qu'il y a toute apparence que l'oiseau désigné tire son "origine de nos Pigeons fuyards. "Gette comparaison fautive est une des plus ridicules que Buffon se soit permise au sujet de la majeure partie des Pigeons exotiques qu'il cite; il n'est mème guère ì présumer que ce naturaliste ait jamais vu le Colombi-Gralline dont nous donnons la figure du mâle et de la femelle; les planches enluminées de Buffon, $n^{\circ}$ i 62 et I 4. I, représentent deux mâles de cette espèce; elles sont àu reste calquées d'après les figures que Brisson donne de son Pigeon roux de Cayenne, et de celui appelé par cet auteur Pigeon violet de la Martinique, dont le premier est le mâle, et l'autre la femelle de notre Colombi-Gralline roux-violet. Latham donne mal à propos comme une variété de cette espèce le Pigeon que Brisson nomme simplement Pigeon de la Martinique, page 105. Ce dernier diffère de notre Colombi-Galline de cet article, par tous les caractères de disparatie établis entre cette famille et celle des Colombes. L'espèce indiquée par 
Brisson appartient à la dernière de ces divisions, nous la décrirons sous le nom de Colombe à oreillon bleu.

Ces Pigeons sont toujours à terre, où ils courent comme les Perdrix; ils vivent par petites troupes et se réunissent plusieurs couvées ensemble; le père et la mère ne quittent guère leur progéniture qu'au renouvellement des feux de l'amour : ce sont des oiseaux trapus, à tarse long, à queue et à ailes courtes; ils ne fréquentent les arbres que pour passer la nuit, encore se posent-ils le plus souvent sur les plus épaisses et les plus basses branches; ils pratiquent leur nid à terre, pondent deux oeufs, et nourrissent leurs petits comme les autres espèces de Pigeons; j'inclinerois beaucoup à soupçonner que les jeunes Colombi-Grallines courent plus promptement que ceux des autres familles de Pigeons; la nature, qui ne fait rien sans une cause fondamentale, n'auroit-elle placé à terre le nid de la plupart de ces oiseaux que pour faire diversion? Ne lui supposons point des vues si peu analogues à la grandeur de ses intentions : le nid des Colombi-Grallines ne parô̂t construit sur la terre que pour faciliter aux Pigeonneaux (peut-être plus précoces que ceux des espèces de Pigeons-Colombes et Colombars) la faculté de répondre à cet instinct : les jeunes Pigeons sont long-temps à se couvrir des plumes nécessaires au vol; si donc, avec l'instinct de chercher plus tôt que lés autres à se rendre à terre, le nid se trouvoit placé sur la sommité d'un arbre, le jeune animal périroit infailliblement; mais à niveau de la terre il abandonne l'endroit qui l'a vu naître sans les moindres dangers, et satisfait ainsi aux vues bienfaisantes du Créateur.

La longueur totale du Colombi-Gralline roux-violet est de huit pouces dix lignes: le bec a huit lignes et demie, le tarse un pouce; ses ailes, lorsqu'elles sont pliées, s'étendent un peu au-delà de la moitié de la longueur de la queue qui est courte et arrondie; le mâle a le dessus de la tête, le derrière du cou, le manteau, les couvertures des ailes, ainsi que le croupion, d'un rouxcannelle, qui, suivant les incidents de la lumière, prend un ton du plus riche violet-pourpré; les couvertures supérieures de la queue sont de cette couleur; la gorge et les joues sont d'un roux-clair blanchissant; cette teinte devient de plus en plus violacée en descendant vers la poitrine, et reprend son premier coloris sur le ventre et les couvertures du dessous de la queue; sur les joues se dessine une tache roux-cannelle de forme quadrangulaire de chaque côté; vers le bas de la poitrine se remarque aussi une tache d'un rouxviolâtre foncé, qui semble marquer l'insertion du poignet des ailes, lorsque celles-ci sont dans l'état du repos; les grandes pennes alaires sont d'un brun- 
pourpré. La femelle diffère du mâle par ses couleurs, qui, quoiqu'également distribuées, ont cependant une teinte plus brunâtre et bien moins lustrée de violet que chez ce dernier; le mâle, ainsi que la femelle, ont le bec et les pieds d'un jaune-rougeâtre : on ignore la couleur de l'iris des yeux.

Maugé a trouvé cette jolie espèce de Pigeons à Porto-Ricco. Ce naturaliste a rapporté plusieurs individus dans un état de pureté qui prouve évidemment tous les soins qu’il mettoit dans ses travaux utiles; sa mort prématurée est une perte sensible pour l'Histoire Naturelle. Les deux individus qui ont servi de modèle appartiennent à M. Dufresne, Naturaliste, attaché au Jardin des Plantes à Paris; le Muséum de ce Jardin possède aussi un Colombi-Galline roux-violet et sa femelle. Deux semblables individus font partie de mon cabinet. 


\section{COLOMBI-GALLINE A FACE BLANCHE.}

$$
\text { P.. VII. }
$$

Columba Erythrotorax. Miti.

LA longueur totale de ce Pigeon est d'environ dix pouces et demi; son bec, qui est mince et peu renflé vers la pointe, a neuf lignes; sa queue est foiblement étagée, et ses ailes sont arrondies, la penne extérieure étant la plus courte de toutes.

La face de ce Colombi-Galline est d'un blanc-grisâtre; le haut de la tête, le cou et la poitrine sont d'une belle couleur vineuse, qui prend une nuance plus foncée sur cette dernière partie; une espèce de collerette d'un violet à reflets dorés ceint la nuque du mâle; le ventre, les cuisses, l'abdomen et les couvertures du dessous de la queue ont un ton de rouille foncé; le dos, les ailes, les couvertures supćrieures de la queue, ainsi que les deux plumes intermédiaires de celle-ci, sont couleur de suic; les grandes pennes des ailes sont noirâtres, bordées de gris; les plumes latérales de la queue sont, en dessus, noires depuis leur origine jusqu'aux trois quarts de leur longueur, le reste est gris; en dessous, toutes les pennes de la queue sont noires, et leur pointe est blanche; les pieds sont rouges, de mème que les papilles charnues qui entourent les yeux; le bec est noir, et les ongles sont bruns. Nous ignorons le nom du pays de ce Pigeon.

M. Raye de Breukelerwaert, qui possède dans son cabinet le seul individu que nous ayons vu, dit qu'il lui a été adressé de Surinam. 


\title{
COLOMBI-GALLINE POIGNARDÉ.
}

\author{
PL. VIII et IX.
}

Columba Cruentata. Latr. Ind. Orn. v. 2, p. 6ri. - Gane. Syst. x , p. 785.

La Tourterelle grise ensanglantée. Sonnerat, $p .25, t .2$ I. - Somnini, $v .7, p .302$.

Red breasted Turtle. - LAT1r. Syn. ข. 4, p. 657 .

Sonnerat a décrit le premier cette charmante espèce, dont le caractère marquant est d'avoir, au milieu de la poitrine, une tache de sang, comme si elle avoit été blessée d'un coup de poignard. Je me suis souvent diverti de lillusion que cette apparence de plaie a produite sur les personues qui ont observé ces oiseaux dans les volières de mon père; la jouant dans une vaste enceinte avec plusieurs centaines d'oiseaux exotiques, il étoit facile de croire que ces Pigeons pouvoient s'être blessés; il est fréquemment arrivé que les curieux venoient me faire part d'une catastrophe dont ils n'admiroient que davantage l'effet après avoir été détrompés de l'illusion qui y donnoit lieu.

Sonnini décrit aussi notre Colombi-Galline poignardé sous le nom de Tourterelle ensanglantée; cet auteur cite encore, à la page 289 , à l'article d'une variété du Turvert, un passage du voyageur Gemelli Carreri (1), qui n'a aucun rapport avec cette prétendue variété du Turvert, mais bien avec l'espèce de cet article.

La longueur totale de ce Colombi-Gralline est de dix pouces et demi; son bec est long et mince, et sa queue, qu'il porte pendante comme les Perdrix grises et rouges, est légèrement étagée. Le mâle et la femelle se

(1) 11 y a aux Philippines une sorte de Tourterelle qui a les plumes grrises sur le dos et blanches sur l'estomac, au milieu duquel on voit une tache ronge comme une plaie frâ̂che dont le sang sortiroit. Gmelli Carreri, $t .5$, p. 266. Il est certain qque ce voyageur a désigné par ce passage notre Colombi-Galline poignardé. 
ressemblent,.. à quelques légères teintes près, qui chez cette dernière sont moins pures.

Le front et le haut de la tête est d'un gris-cendré; l'occiput et la partie postérieure du cou est d'un violet foncé à reflets verts; le dos, les scapulaires, les petites couvertures des ailes, ainsi que les parties latérales de la poitrine sont d'un gris d'ardoise; toutes les plumes de ces parties sont terminées par une bande d'un vert brillant et métallique; la gorge, les côtés du cou et le milieu de la poitrine est d’un blanc pur; sur cette dernière partie se dessine cette tache qui représente une plaie fraîche; les plumes du ventre, desflancs, de l'abdomen, ainsi que les couvertures du dessous de la queue sont couleur de chair; les moyénnes couvertures alaires sont d'un roux pourpré depuis leur origine jusqu'aux trois quarts de leur longueur, leur extrémité est d'un cendré-clair, ce qui forme cinq bandes transversales sur chaque aile; les rémiges sont d'un gris-brun cendré finement liseré de roussàtre; les deux pennes intermédiaires de la queue sont, gris-brun; toutes les latérales sont grises à leur origine, traversées d'une bande noire vers le milieu, et terminées de gris-cendré; le bec, les yeux, ainsi que les pieds sont rouges.

Une variété accidentelle de cette espèce, dont nous donnons la ligure dans notre planche 9 , a été présentée par les auteurs comme une espèce distincte : elle paroit entièrement blanche, mais en l'examinant attentivement on découvre les traces de toutes les distributions des différentes couleurs propres à l'espèce, foiblement tracées sur son plumage : la beauté de cette charmante variété se trouve encore relevée par la tache ensanglantée sur la poitrine, qui, dans l’individu que nous avons observé, conservoit tout son éclat.

Cette espèce habite aux îles Philippines. Sonnerat l'a trouvée à Manille.

Plusieurs individus du Colombi-Galline poignardé font partie de mon cabinet. Celui qui se trouve déposé dans les galeries du Muséum de Paris est entièrement dégragé par les fumigations. 
COLOMBI-GALLINE A FRONT GRIS.

$$
\text { P. X. }
$$

Columba Frontalis. Mihi.

UnE autre espèce de Colombi-Galline, que nous présumons former une espèce nouvelle, semble propre au climat du nouveau continent. Sa longueur totale est de neuf pouces et demie. Le front cst d'un beau gris, se nuançant dans quelques individus en teintes plus ou moins bleues; ledos, les ailes et les couvertures supérieures de la queue sont de couleur olive foncée à légers reflets pourprés; les grandes pennes des ailes sont d'un gris noirâtre en dehors, rousses en dedans depuis leur origine jusqu'aux trois quarts de leur longueur; la dernière rémige est la plus courte de toutcs, ses barbes intérieures sont tronquées, ce qui fait que l'cxtrémité de cette penne se termine en pointe; la queue est d'un brun-olivâtre, mais les trois pennes latérales de chaque côté sont terminées de blanc; la gorge est d'un roux clair; la poitrine et le ventre sont de couleur vineuse; l'abdomen et les couvertures inférieures de la queue sont blancs; le bec est noir et les pieds sont rouges.

Le mảle se distingue par un espace de couleur vineuse à légers reflets pourprés qui se dessine sur la partie supérieure du dos; les femelles n'ont pas de ces teintes brillantes, cn général les couleurs de celles-ci sont plus ternes, et l'espace blanc qui ceint le front n'est pas aussi considérable.

Cette espèce se trouve à la Guiane française. Deux individus, l'un mâle, l'autre femelle, sont déposés dans les galeries du Muséum de Paris. Je possède deux individus semblables dans mon cabinet. 


\section{COLOMBI-GALLINE A BARBILLON.}

Columba Carunculata, Mihi.

Le Colombi-Galline. Le Vaill. Ois. d'Afr. v. 6, pl. 278.

Le Vaillant nous fait connoitre, dans son Ornithologie d'Afrique, une nouvelle espèce de Colombi-Galline, qui doit attirer particulièrement l'attention du naturaliste, en ce que les mours de cet oisea n nous offrent des dissemblances remarquables avec la manière de vivre de la plus grande partie des Pigeons connus. Nous avons déjà fait remarquer ailleurs que la division de la famille des Pigeons-Gallines n'est point basée sur des caractères propres à toutes les espèces qui la composent, mais que c'est une division dans laquelle nous réunissons tous les Pigeons, qui, par leur forme extérieure aussi-bien que par leurs moeurs, ont quelque analogie avec les divers genres de Gallinacés: car si on s'en tenoit à la règle stricte de n'admettre parmi les Colombi-Gallines que telle espèce qui auroit pour caractères une queue courte et étagée comme les Perdrix, les ailes arrondies, ayant la penne extérieure très courte, et la troisième la plus longue de toutes, et le tarse long et lisse, on ne pourroit admettre dans cette division plusieurs Pigeons qui, par l'analogic quiils ont avec certaines espèces de Gallinacés, doivent nécessairement y trouver leur place. Nous avons encore des raisons bien décisives pour en agir de la sorte, si des formes extérieures de ces oiseaux nous passons aux mours, aux habitudes et à la manière de se nourrir.

L'oiseau qui fait le sujet de cet article est, de tous les Pigeons connus de nos jours, celui qui, par son port ainsi que par ses mours, a le plus d'analogie avec les oiseaux gallinacés. Le voyag urr cité, qui a observé ses 
habitudes, l'ayant décrit de manière à ne laisser rien à désirer, nous transcrirons en entier la partie descriptive de son texte, qui a rapport à la manière de vivre de cet oiseau.

"Notre Colombi-Galline (dit Le Vaillant) tient des Pigeons proprement " dits, ou des Colombes, par la forme de son bec, qui est absolument le " même que chez ces derniers, et par la nature de ses plumes; mais il en " diffère par le barbillon nu et rouge qui pend sous son bec, par ses “ tarses plus longs que chez les Pigeons, par la forme arrondie de son corps, “ par le port de sa queue courte qu’il tient pendante comme les perdrix “ portent la leur, et enfin par ses ailes arrondies; caractères qui, tous, en “ le rapprochant des Gallinacés, placent naturellement cette intéressante “ espèce entre les Colombes et les Gallines, comme pour marquer et " former le passage entre ces deux genres.

“Cet oiseau niche à terre, dans un petit enfoncement recouvert de " buchettes et de quelques brins d'herbes sèches, sur lesquelles la femelle " pond de six à huit oufs d'un blanc-roux, que le mâle et la femelle " couvent alternativement. Les petits, qui naissent couverts d'un duvet gris“ roussattre, courent au sortir de la coque; et dès cet instant ils ne “ quittent plus le père et la mère, qui les mènent par-tout en les rap" pelant sans cesse et les couvrant de leur's ailes pour les réchauffer ou " les préserver de l'ardeur du soleil. Leur première nourriture est des “ nymphes de fourmis, les insectes morts, et les vers que le père et. la mère " montrent aux petits, et qu’ils mangent seuls; bientôt ils sont en état de les " trouver eux-mèmes; devenus plus forts, ils se nourrissent de toutes sortes " de graines, de baies et d"insectes : et quoiqu'ils aient acquis tout leur " développement, ils ne se séparent par couple qu'au temps des amours, “ manière d'ètre qui, à quelques légères nuances près, est la mème pour " tous les oiseaux qui appartiennent au grand ordre des Gallinacés (1). 》

Nous avons donné à cette nouvelle espèce le nom de Colombi-Gralline à Barbillon, parceque ce caractère marquant dans cet oiseau sert très bien à le distinguer des autres espèces qui composent cette famille. Il a une plaque de peau nue qui engage son front et le tour de son bec; un mamelon charnu se dirige sur sa gorge en s'étendant ver's ses oreilles. Sa taille est à peu près celle de la Colombe Tourterelle, quoique moins élancée que cette dernière; sa longueur totale est de dix pouces. 
DES COLOMBI-GALLINES.

La tête, les joues, le cou et la poitrine sont couverts de plumes d'un gris ardoisé; les scapulaires et les couvertures supérieures des ailes sont d'un gris argentin, terminées par un liseré blanc; le ventre, les couvertures supérieures et inférieures de la queue, le croupion et toutes les couvertures du dessous des ailes, ainsi que les flancs et le bord extérieur de la dernière penne de chaque côté de la queue sont d'un blanc pur; la queue, qui est légèrement étagée, est d'un brun roux en dessus et noirâtre en dessous; le bec est rouge à sa base, et noir à sa pointe; les pieds sont d'un rouge vineux; enfin les yeux ont un double cercle, l'un jaune et l'autre rouge.

La femelle n'a pas de barbillon, elle est plus petite que le mâle, et ses couleurs seroient semblables aux siennes, si elles n'étoient plus ternes; les couvertures de ses ailes ne sont point liserées de blanc.

Le Vaillant a trouvé cette nouvelle espèce dans l'intérieur des terres, au pied des monts Herisies du pays des Namaquois. Liindividu qu'il a rapporté, et qui fait partie de son cabinet, nous a servi de modèle. 


\title{
COLOMBI-GALLINE TALPACOTI.
}

\author{
$p_{L .} X I I$.
}

+ Columba Talpacoti. Mithi.

LE Colombi-Galline de cet article, l'une des petites espèces de cette famille, mesuré de la pointc du bec à l'extrémité de la queue, a environ six pouces et demi; son bec est très mince, non renflé vers la pointe, ayant l'extrémité de la mandibule supérieure un peu courbée. Nous avons remarqué que ce Pigeon se distingue de toutes les autres espèces de cette famille par le tarse, dont lc côtć extérieur est garni dans toute sa longueur par une étroite bande composéc de petites plumes duvetées ct très courtes.

Le haut de la tête est d'un gris-bleu, se nuançant sur le front en grisblanc; la gorge et les côtés du cou se lavent en gris nuancé de vineux; tout le dos, les couvertures des ailes, tant grandes que petites, celles de la queue, ainsi que le devant du cou, la poitrine et toutes les partics inférieures sont d'un roux foncé nuancé de légères teintes vineuses; sur quelques unes des moyennes et des grandes couvertures des ailes se remarquent de petites taches d'un beau noir; ces taches sont placées sur les barbes extérieures de ces couvertures, mais leurs barbes intérieures sont d'un roux uniforme; les rémiges et les pennes secondaires sont d'un brun noirâtre; en dessous l'ailc est grise, et les couvertures inférieures ainsi que les plumes qui recouvrent les flancs sont noires; les pennes intermédiaires de la queue sont d'un brun roussàtre; les latérales, qui vont toutes en diminuant de longueur, sont noires; l'extérieure de chaque côté a sa pointe rousse; le bec est d'un brun rougeâtre; et les pieds sont d'un rouge orangé.

Le Talpacoti habite l'Amérique méridionale; il est à présumer que ses mours ont des rapports avec celles que nous savons être propres á quelques espèces de Colombi-Gallines qui habitent l'Afrique; mais ne voulant rien 
DES COLOMBI-GA L LINES.

donner au hasard; nous nous bornons à décrire cette espèce, ainsi que plusieurs autres, d'après les dépouilles que nous avons soigneusement examinées. C'est d'après les seuls caractères extérieurs propres à celte espèce que nous lui avons assigné une place parmi les Pigeons gallines, laissant aux naturalistes qui auront occasion d'étudier ses mours le soin d'enrichir la science de leurs découvertes.

Le Colombi-Galline Talpacoti fait partie de mon cabinet; nous avons vu cet oiseau dans diverses collections : l'individu qui a servi de modèle fait partie du Muséum de Paris. 


\title{
COLOMBI-GALLINE COCOTZIN Màle et Femelle.
}

\author{
$P_{L .} X I I I$ et $X I V$.
}

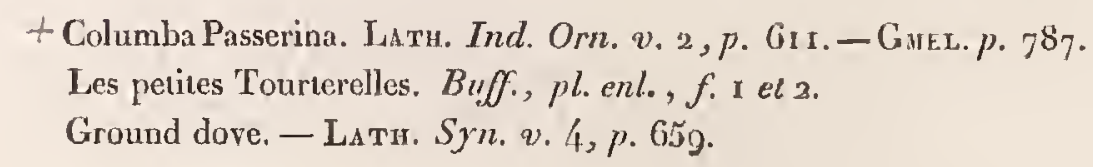

CEtre petite espèce de Colombi-Galline semble tenir beaucoup des mœurs des Perdrix; elle en a les habitudes et le vol. M. Vieillot, qui a observé ces oiseaux à Saint-Domingue, m’a dil qu'aucune espèce ne se rapproche antant de la Perdrix; c'est au point que lor'squ'on les voit à terre, la première idée qui vient est celle de les croire de véritables Perdrix; elles cherchent leur nourriture à terre, se levant précipitamment plusieurs fois, exécutent des vols courts, et se rabattent brusquement comme le font les Perdrix; la chair de ces oiseaux est un mets très recherché et des plus délicats : on les prend le plus souvent dans des espèces de trappes faites de joncs.

Les Cocotzins fréquentent les lieux pierreux situés près des buissons; on les trouve non seulement sur le continent de l'Amérique méridionale, mais aussi dans toutes les îles Caraibes; Maugé les a rapportés de Porto-Rico, où ils sont très multipliés. Les colons français désignent le Cocotzin par le nom d'Ortolan; les Anglais le nomment Pigeon de terre, et les Hollandais Pigeon des pierres: la voix de ces oiseaux est semblable à celle de notre Tourterelle, mais elle est plaintive et peu sonore.

Le Cocotzin n'est guc̀re plus gros de corps qu"une alonette huppée; sa longueur, depuis le bout du bec jusqu'à l'extrémité de la queue, est d'un peu plus de six pouces; son bec a sept lignes; les ailes, lorsqu'clles sont pliées, ne s'étendent qu'au quart de la longueur de la quene; les parties supéricures de la tête et du cou sont d'un beau cendré; chez le mâle, cettc partie est d'une teinte plus bleue; le dos, le croupion et les couvertures du 
dessus de la queue sont d'un brun cendré foncé; le front, la gorge, la partic inférieure du cou et la poitrine sont de couleur vineuse, avec quelques taches brunes qui occupent le milieu de chaque plume, et les font paroître écaillées; les côtés et le ventre sont d'un vineux très clair; les couvertures du dessous des ailes et les barbes intérieures des rémiges sont couleur de rouille; les couvertures supérieures des ailes sont mêlées de cendré foncé et de vineux; il y a un nombre assez considérable de petites taches d'un bleu d'émail sur les moyennes et sur les grandes couvertures; les deux pennes du milieu de la queue sont d'un brun-cendré très foncé, et les latérales sont presque noires; l'iris est orangé; le bec est d'un rouge pâle à son origine, et noirâtre vers le bout; les pieds sont rouges et les ongles noirs.

La femelle diffère du mâle en ce que toutes les couleurs sont plus foibles, que la poitrine a plus de blanc, que les écailles de la poitrine sont moins bien prononcées, et que les petites taches des ailes n'ont pas des reflets aussi brillants que chez le mâle.

Des individus du Cocotzin se trouvent dans plusieurs collections; le mâle et la femelle font partie de mon cabinet. Ceux qui ont servis de modèle à madame Knip appartiennent au Muséum. 
COLOMBI-GALLINE HOTTENTOT.

Columba Hottentotta. Mihi.

Le Colonabi-Caille. Le Vaill. Ois. d'Afr. v. 6, pl. enl.

LE vaste continent de l'Afrique, si riche en productions ornitologiques, voit aussi naître sur son sol des petites espèces de Colombi-Gallines dont les formes et les mours ont beaucoup de ressemblances avee celles qui habitent le Nouveau-Monde; M. Le Vaillant, qui le premier a fait connoître notre Colombi-Galline Hottentot sous le nom de Colombi-Caille, nous apprend que ces Pigeons se réunissent en très grandes troupes, composées de plusieurs familles, et quïls habitent les lieux arides et pierreux de la partie méridionale de l'Afrique; M. Le Vaillant croit cependant que l'espèce ne niche pas dans les cantons stériles et brưlés où il l'a trouvée; il présume qu'elle ne fait qu'y passer un certain temps de l'année, et cette supposition semble d'autant plus fondée, que toutes les recherches de ce naturaliste pour découvrir le nid de ces oiseaux ont été infructueuses.

Le Colombi-Galline Hottentot, que nous représentons est absolument modelé sur les mêmes formes que les petites espèces de Colombi-Gallines du Nouveau-Monde. Comme elles il a le vol court, il sé rabat fréquemment, cherche sa nourriture à terre, où il se tient de préférence pendant le jour; ce n'est que vers la nuit quïl se retire dans les buissons, où on le trouve perché sur les branches basses.

Le mâle a l'occiput, le derrière du cou, le manteau, les couvertures des ailes, le croupion et les couvertures du dessus de la queue d'un beau roux-cannelle; chaque plume de ces parties est terminée de brun; le front et la gorge sont blancs; le devant et les côtés du cou ont, sur un fond 
DES GOLOMBI-GALLINES.

gris-vineux clair, des écailles noires qui sont liserées de blanc dans leur partie supérieure; le milieu du sternum, le ventre, les cuisses, ainsi que les couvertures inférieures de la queue, sont d'un roux clair; les pennes des ailes sont, en dehors, du même roux que le dos, et noirâtres sur les barbes intérieures; la queue, qui est courte et arrondie, est, en dessus, d'un roux-cannelle, et en dessous, gris-noirâtre; le bec est brun-jaunâtre; les pieds sont rouges ainsi que les yeux.

La femelle diffère du mâle en ce qu'elle est plus petite, et que ses coûleurs sont moins brillantes que celles de ce dernier.

M. Le Vaillant a trouvé cette espèce sur les montagnes du pays des GrandsNamaquois. 


\title{
COLOMBI-GALLINE PIGMÉ.
}

\author{
p.. XVI.
}

\author{
+ Columba Minuta. Latr. Ind. Orn. v. 2, p. 612. \\ Petite Tourterelle brune. Briss. Orn. v. 1, p. r $16, p l .8$, flg. 2. \\ Le Pigeon Nain. d'Azara. Voy. Amér. mérid., v. 4, p. $137, n^{0} 3{ }_{2} 5$. \\ Passerin-Turtle. Latr. Syn. v 4, p. 660
}

L'EsPÈce de cet article a presque toujours été confondue avec le Gocotzin; sa petite taille et sa ressemblance apparente avec ce Pigeon ont pu en quelque sorte légitimer cette erreur. Convaincus comme nous le sommes que ces oiseaux forment effectivement deux espèces très distinctes, nous les décrivons séparément, en nous conformant aux vues de l'excellent observateur Brisson, qui en avoit aussi jugé ainsi.

Le Colombi-Galline Pigmé est décrit dans l'ouvrage de M. de Azara, lequel renferme les descriptions des oiseaux que ce voyageur a trouvés au Paraguay ct sur les bords de la rivière de la Plata; ce livre, dont la traduction française vient de paroître, est sur-tout recommandable pour la vérité des descriptions et l'exactitude des observations : nous y avons reconnu au premier coup-d'oil quelques unes des espèccs dont nous avons parlé dans cette monographie; trois espèces de Pigeons décrits dans l'ouvrage de M. de Azara ne nous étoient point connues : c'est pour compléter, autant que possible, notre monographie, que nous faisons mention de ces oiseaux à la suite des Colombes; les naturalistes trouveront au surplus tous les détails dans l'index qui terminc ce volume.

Le Colombi-Galline Pigmé est en effet la plus petite espèce que nous connoissons dans cette famille; sa longueur totale n'excède pas cinq pouces et demi; la tête, le derrière du cou, le dos, le croupion et les couvertures du dessus de la queue sont d'un brun-cendré très brillant; les couvertures supérieures des ailes sont de ce même brun, mêlé d'une teinte roussâtre; 
sur ces couvertures sont sept petites taches d'un bleu d'émail; les plus grandes plumes de recouvrement sont terminées de blanc; le front et la gorge sont d'un blanc roussàtre; la partie inférieure du cou et la poitrine sont d'un vineux clair; les côtes, le ventre, l'abdomen et les couvertures inférieures de la queue sont d'un blanc mêlé de roussâtre; les couvertures inférieures de l'aile sont d'un beau roux; les deux plumes du milieu de la queue sont brunes; toutes les latérales sont cendrées, et terminées de noir; la penne extérieure de chaque côté est terminée de blanc; les pieds sont rouges, et le bec est brun : la femelle diffère du mâle seulement par des teintes plus foibles.

Ce Pigeon habite à la Guiane française, il se trouve aussi au Paraguay, ses voyages s'étendent jusque dans les îles Caraibes; Maugé en a rapporté de Porto-Rico, d'autres ont été envoyés de Saint-Domingue.

Un individu de cette espèce fait partie du Muséum de Paris; et j'en conserve un absolument semblable dans ma collection. M. de Azara fait mention d'une petite espèce de Colombi-Gralline, sous le nom de Picui; cet oiseau me paroit différer du Colombi-Galline Pigmé, non seulement par la taille, mais aussi par les couleurs du plumage; je m'en rapporte trop à la scrupuleuse exactitude du voyageur espagnol, pour me conformer aux vues du traducteur de la partie ornithologique de son ouvrage, qui présume que son Pigeon Nain et son Picui ne sont que des variétés d'âge ou de sexe. Quoi quill en soit, voici la description que M. de Azara donne du Picui, qui est sans contredit du nombre des Pigeons-Grallines:

" La longueur totale du Picui est de sept pouces trois lignes; les parties " inférieures sont d'un blanchâtre un peu mêlé de brun sur le devant du cou « et les côtes du corps, avec une légère teinte vineuse à la poitrine; un noir " velouté colore les couvertures du dedans de l'aile; le front et les côtés de " la tête sont blanchâtres; le dessus de la tête, du cou et du corps, aussi " bien que les couvertures supérieures des ailes, sont d'un brun pur, mais “ il y a sur les mêmes couvertures une rangée de petites taches d'un bleu “ d'émail, du noir sur quelques-unes, et un trait blanc sur d'autres; les “ pennes sont d'un brun noiràtre; l'extérieure de chaque côté de la queue " est blanche; les deuxième, troisième et quatrième ont du blanc vers leur " extrémité, et le reste brun comme les autres pennes; le tarse est d'un " rouge violet et obscur; le bec d'un bleu foncé; un espace nu et bleuâtre “ entoure l'oeil, et s'étend jusqu'à l'angle de la bouche. »

M. de Azara observe que le Picui diffère également de l'espèce que nous 
désignons sous le nom de Talpacoti, en ce qu'il est plus gros, en ce que ses ailes sont moins longues, qu'il préfère les lieux moins sombres, et qu'il s'éloigne davantage des forêts. On le rencontre ordinairement par paires, quelquefois en famille, et même en bandes de vingt-cinq individus; son nid, aplati et composé de petites branches, sans matières molles à l'intérieur, est placé sur les buissons et les arbres de moyenne hauteur; la ponte est de deux oufs blancs.

Le Picui est très commun au Paraguay et dans les contrées arrosées par la rivière de la Plata. 


\section{LES GOLOMBES.}

\section{CARAGTERES ESSENTIELS.}

Bec mince; pointe plus ou moins renflée; narines recouvertes d'une peau molle; tarse court, lisse ou emplumé; ailes longues; queue carrée, étagée, ou en forme de cône.

PREMIERE SECTION.

Queue carrée ou légèrement étagée.

\section{COLOMBE GÉANT.}

$P_{L A N C H E} I^{n E}$.

Columba spadicea, Litr. Ind. orn. supp. v. 2, pl. LX, sp.7.

Chesnut-shouldered Pigeon, LA Tr. Syn. supp. Ir, add. p. 575

$\mathrm{L}_{\mathrm{E}}$ vaste Archipel de l'Asie australe, si riche en productions diverses, vient de fixer, depuis un petit nombre d'années, l'attention particulière de quelques gouvernements intéressés aux progrès des sciences; les voyages entrepris à diverses époques autour du monde ont fait découvrir une infinité d'iles qui recèlent, pour toutes les parties de l'histoire naturelle, un nombre considérable d'objets nouveaux : ces pays, encore peu exploités, nous ont fait connoître plusieurs nouvelles espèces de Pigeons, dont la plupart se trouvent décorés de couleurs brillantes. Il en est parmi eux qui ont certaines parties de leur plumage d'une forme particulière.

L'espèce qui fait le sujet de cet article, déjà remarquable par sa grande taille, se distingue encore des autres Colombes de cette division par sa queue un peu fourchue, les plumes latérales étant de deux lignes plus longues que les intermédiaires; toutes ces plumes sont larges d'un pouce six lignes, rudes au toucher, comme le sont celles des Calaos et des Anhingas.

Latham donne une description imparfaite de cette magnifique Colombe; 
il se contente de nous apprendre très succinctement les couleurs de l'oiseau, sans prendre notice de la conformation des pennes caudales; à juger même d'après le peu que ce naturaliste en dit, on seroit en droit de présumer qu'il ne cite cet oiseau que sur de simples ouï-dires.

La Colombe géant, mesurée depuis le hout du bec à l'extrémité de la queue, a environ dix-neuf pouces; cette dernière en a sept et demi : les pennes qui la composent sont au nombre de douze; leur partie supérieure est d'un brun bistre, à reflets de vert et de pourpre foncé; l'extrémité est de couleur d'ocre; en dessous, la queue est d'un gris blanchàtre, changeant légèrement en vert métallique; vers son extrémité est une large bande d'un brun bistre. Les ailes, qui aboutissent vers la moitié de la longueur de la queue, ont les grandes pennes de couleur gris-de-lin foncé, à reflets de vert éclatant sur les barbes extérieures; les moyennes pennes et les grandes couvertnres sont gris-de-lin clair' cette couleur prend des teintes verdâtres à certaines réflexions de la Iumière; les moyennes couvertures sont vertes dorées; les pelites couvertures, les scapulaires et le hant du dos mordorés, à reftets métalliques; l'occiput et les parties postérieures du cou sont d'un vert rembruni; la tète, les parties antérieures du cou, ainsi que la poitrine, sont d'un beau vert foncé, à reflets éclatants; le ventre et toutes les parties inférieures sont d'un blanc pur; le bec et les pieds sont rouges.

Cette belle Colombe habite les îles des Amis; il est probable qu'elle se trouve aussi dans d'autres parties du vaste Archipel austral.

Je n'ai vu qu'un individu de cette espèce; il fait partie de mon cabinet.

Le format que nous avons choisi pour cel ouvrage ne nous ayant pas permis de le figurer de grandeur naturelle, nous l'avons réduit à moitié. 


\title{
COLOMBE RAMIER, Màle.
}

\author{
PL. II.
}

Columba Palumbus, Latr. Ind. om. 2, p.6от. - Guet. Syst. 1, p. $77^{6}$. - Frisch.t. 138

- Briss. Orm. v. 1, p. 8g. sp. 6.

Le Pigeon ramier. Buffon, 2, p. 531 , t.24. - Pl. enl. 3 х6.

Ring Pigeon, Lath. Syn. v. 4, p. 635, sp. 29. Id. supp.p. 198.

Ringeltaube. Meyer Deuls. Orn. p. 48, pl. enl.

Les quatre parties du monde nourrissent une foule d'oiseaux qui appartiennent au genre pigeon; tous les pays chauds en sont abondamment peuplés : l'Europe est de toutes les contrées du globe celle où ce genre est le moins abondant: quatre espèces principales y vivent dans l'état sauvage; on peut considérer ceux-ci comme espèces vraiment distinctes les uncs des autres, vu qu'il ne s'est pas encore trouvé entre eux d'exemple d'une production féconde, fruit du mélange naturel.

Buffon n'admet en Europe que trois espèces de Pigeons, et deux autres qu'il regarde comme intermédiaires; il se fonde sur ce que les Grecs ne donnoient jamais des noms différents à leur's oiseaux, qu'autant qu'ils se trouvoient persuadés qu’il y avoit effectivement diversité d'espèces : à partir de ces principes, M. de Buffon se seroit donc vu dans la nécessité d'établir cinq espèces de Pigeons propres aux climats de l'Europe, puisque les Grecs désignent ce nombre par des dénominations différentes.

En effet, Buffon s'est abusé en considérant l'OFnas des Grecs, ainsi que leur Phaps, comme espèces intermédiaires; ces deux espèces nominales ne forment effectivement qu'une espèce réelle; les descriptions de ces Pigeons paroissent se rapporter au même oiseau. Nous présumons au reste, avec quelque fondement, que les Grees ont bien connu notre Colombin, qu'ils ont sans doute désigné par leur Phaps. Ces Pigeons Colombins, peu abondants en individus, n'ont pas été soigneusement observés par Buffon; il a donné plus de crédit aux opinions du vulgaire, qu’il ne s'est appliqué à chercher la vérité dans la nature.

On est encore assez généralement d'opinion, en France, que le Biset et le 
Colombin sont de la même espèce : lorsqu'il sera question de ces oiseaux, nous tâcherons de les mieux faire connoître, et nous prouverons leur dissemblance spécifique.

Le Ramier est la plus grande espèce d'entre nos Pigeons indigènes, il n'habite pas l'Europe dans toutes les saisons de l'année, la plupart de ces oiseaux émigrent dans le mois de novembre, et reviennent s'établir dans nos contrées vers le commencement de mars; on ne les voit qu'en avril dans les climats septentrionaux. Buffon a vu plusieurs nids de Ramiers dans le commencement d'avril, les Ramereaux étoient déjà forts à cette époque. - Ce Pigeon fait deux pontes par an, la première est en avril; les Ramereaux premnent alors leur essor dans le mois de mai : la seconde ponte se fait en juillet, et les Ramereaux volent en aoùt. Dans ces deux périodes de l'année on voit régulièrement de jeunes Ramiers.

Le Ramier place son nid sur la cine des plus hauts arbres, et le construit en entrelaçant assez grossièrement une certaine quantité de branches sèches; c’est là que la femelle dépose ses oufs, au nombre de deux, quelquefois elle en pond trois, mais ce cas est extraordinaire; le mâle et la femelle couvent alternativement; l'incubation est de seize ou de dix-huit jours.

Ce Pigeon aime à se percher sur les branches élevées de quelque arbre mort, habitude quili a en partage comme presque tous les oiseaux dont le naturel est farouche, et qui s'enfuient à la première indice du danger; perché sur la sommité d'un arbre mort, l'oiseau aperçoit au loin son ennemi : aussi est-il très difficile d’approcher du Ramier à portée du fusil. On ne parvient guère à le tirer dans les bois, mème en employant toutes les ruses. Cet. oiseau, très méfrant, prend son essor au plus léger bruit.

Les Ramiers ont pour ennemis la Martre des arbres, qui leur ravit leurs oufs et leurs petits; le Milan et le Faucon pèlerin les guettent du haut des airs; ils paroissent ne pas craindre beacoup la Buse, puisque, outre un fait. rapporté à cette occasion par $\mathbf{M}$. Mayer, j’ai été dans le cas de faire aussi une observation à cet égard. Dans une campagne voisine de la Haye, on prend toutes les années, avec de petits filets, un nombre considérable de Ramiers; les Buses sont toujours en très grande abondance dans ce lieu, que cependant les Ramiers ne quittent pas. Ils ne paroissent point craindre ces rapaces.

Je ne suis pas du sentiment de M. de Buffon, qui présume que les plus grandes races de nos Pigeons de volière sont issues des Ramiers; si la chose étoit ainsi, on verroit certainement parmi ces Pigeons domestiques 
des individus dont le plumage porte quclque indice d'une telle origine: au reste, le Ramier ne propage pas avec le Biset, même en captivité, et cela seul détruit la supposition de M. de Buffon. Il est assez connu de nos jours que le Biset doit être considéré comme le type de nos Pigeons de colombier, et que les variétés accidentelles de ces derniers proviennent, pour la plupart, des races de nos Pigeons de volière. Nous nous étendrons plus au long sur ces pigeons soumis aux caprices des hommes, el. nous ferons connoître toutes les races constantes de ces oiseaux à l'article du Biset sauvage.

Le Ramier se trouve dans plusieurs contrées de l'Asie et de l'Afrique; mais on auroit beaucoup de difficultés à reconnoître l'espèce dans toutes les indications que les divers voyages autour du monde nous donnent de cet oiseau. Ces indications sont trop succinctes, non seulement pour y retrouver le Ramier de nos climats, mais même toute autre espèce cxotique. On parle dans ces relations de Ramiers d'un gris plus ou moins obscur, sans autres définitions de conleurs, ou bien d'attributs caractéristiques.

Dampier (1) a vu des Ramiers à la baie de Tous les Saints; il est incertain cependant si effectivement ces pigeons étoient de l'espèce qui habite en Europe, ou bien si ces Ramiers, dont le plumage est d'un gris plus ou moins obscur, étoient des espèces propres aux climats de l'Amérique; nous connoissons dans cette partie du monde plusieurs Colombes, dont les teintes principales du plumage sont d'un gris plus ou moins sombre; et ceux-ci sont néanmoins des espèces différentes de nos Ramiers d'Europe.

La Colombe ramier, mesurée depuis le bout du bec à l'extrémité de la queue, a environ dix-sept pouces et demi; son envergure est de deux pieds cinq pouces; la queue dépasse les ailes de deux pouces lorsque celles-ci sont dans l'état du repos.

Le Ramier se distingue par une tache blanche qui se dessine des deux côtés du cou; toutes les autres parties du cou sont d'un cendré bleuâtre, avec des reflets de vert et de pourpre; les parties inférieures du plumage sont d'un gris clair; le manteau et les petites couvertures des ailes sont d'un cendrébleuâtre; le dos et le croupion ont une teinte de gris bleuâtre; les grandes pennes alaires sont noires, avec un petit liseré blanc; le blanc pur règne sur les barbes intérieures des couvertures les plus voisines du bord de l'aile; la queue est d'un cendré bleuâtre, passant au noir vers l'extrémité des pennes; le genou est recouvert de plumes; la partie nue du tarse et les doigts sont d'un beau

(I) Dampier, v. 4, p. 66 . 


\section{HISTOIRE}

rouge; le bec est d'un blanc rougeâtre à sa base, recouverte d'une carnosité molle, qui paroît saupoudrée de blanc; l'iris est d'un jaune clair.

La femelle ressemble au mâle pour les couleurs, mais sa taille est plus petite; les jeunes ont une teinte de gris-cendré très foncé; le collier blanc n'est point visible dans la première année, ce n'est qu'à leur première mue qu'ils prennent ce caractère. L'individu qui a servi de modèle appartient à M. Dufresne du Jardin des Plantes. 
COLOMBE MUSCA DIV ORE, Male et Femelle

\author{
PL. III et $I V$
}

Columba anea. LA тн. Ind. orn. v. 2, p. 6о2. sp. 33

- GMEL. Syst. I, p. 780 .

Palumbus Moluccensis. Briss. orn. v. ז, p. 148, sp. 41.

Pigeon ramier des Moluques. Bufff. v. 2, p. 58, pl. enl. 164 .

- Sonnini, édit. de Buff: q. 7, p. 240.

Pigeon cuivré mangeur de muscade. Sonnerat, Voy.p. x68, t. 102.

Nutmeg. Pigeon. Latr. Syn. v. 4, p. 636, sp. 3o. -Id. p. 637, var. $A$.

$P_{A R M I}$ le nombre considérable d'erreurs que Buffon a commises à l'égard de l'origine de la plupart des Pigeons exotiques, quïl suppose mal à propos être des variétés provenues d'espèces qui fréquentent habituellement les régions de l'Europe, aucune, sans contredit, n'est plus mal fondée que celle oủ ce naturaliste met en doute les différences spécifiques qui caractérisent la Colonbe dont nous faisons le sujet de cet article.

«Quelque éloigné, dit Buffon, que soit le climat des Moluques de celui de " l'Europe, ce pigeon ressemble si fort à notre Ramier par la grandeur et la " figure, que nous ne pouvons le regarder que comme une variéte produite “ par l'influence du climat. »

Pour faire des rapprochements semblables, il faut sans doute avoir l'esprit préoccupé d'un système qu'on tâche d'étayer indistinctement par toutes sortes de suppositions; on peut difficilement se persuader, en lisant d'un bout à l'autre la partie des Pigeons dans l'ouvrage de Buffon, que ce célèbre naturaliste en soit l'auteur.

Sil est prouvé que les climats chauds opèrent, par leur seule influence, des variations ou plutôt des changements si peu conformes aux gradations régulières que nous remarquons toujours dans la nature, les travaux du naturaliste doivent, dans ce cas, se borner uniquement à la connoissance des espèces qui habitent une contrée que celui-ci aura soigneusement exploitée; il sera dans la nécessité d'écarter toute étude tendant à embrasser l'ensemble des productions que lui offrent les divers climats; des recherches 
ultérieures le porteroient dans des doutes que ni lui, ni un nombre considérable de ses successeurs ne seroient dans le cas de pouvoir résoudre.

Nous avons donné à cette Colombe le nom de Muscadivore, parceque dans certains temps de l'année, sur-tout aux époques où les muscades sont en maturité, elle en fait sa principale nourriture: ce Pigeon donne la préférence au macis dont'les noix des grandes muscades se trouvent entourées; pour les petites noix, il ne se contente pas d'en enlever la pulpe, mais les avale avec l'enveloppe; le macis servant uniquement de nourriture, se trouve trituré dans les viscères digestifs sans que la noix éprouve la moindre altération en passant dans ces organes: le Muscadivore, en parcourant les îles voisines, sème ces noix en les rendant avec ses excréments.

Voies sublimes et admirables de la nature! jusque même dans les actions les plus insignifiantes en apparence qu'effectuent tes créatures, tu te proposes un but d'utilité que les hommes, ingrats pour tes bontés prévoyantes, sont loin d'imiter pour leurs semblables: tandis quils abusent des riches dons de la nature, celle-ci pourvoit à maintenir la balance égale, en plaçant, pour réparer leurs dilapidations, une fugitive Colombe qui, parcourant un espace considérable de mers, vient porter, comme par un charme, l'abondance dans des lieux où l'homme se seroit gardé de faire produire la terre.

Il paroît que les Muscadivores émigrent à certaines époques de l'année; ce temps est sans doute celui où les jeunes Colombes se trouvent en état de suivre la troupe; apparemment ces émigrations se font quand le museadier ne peut plus leur fournir la nourriture qui leur convient.

On voit arriver ces oiseaux en bandes innombrables, et peupler les forêts de l'île de Java; mais vers le temps des pontes ils l'abandonnent. - Une note que mon ami M. Laischenault a eu la complaisance deme communiquer, porte que les Colombes muscadivores se nourrissent, à Java, du fruit du ficus religiosus, appelé, en langue javane, pohon vrique; c'est une petite figue de la grandeur d'une cerise que produit le figuier bagnan.

Il est étonnant que Sonnerat, qui a vu cet oiseau à la Nouvelle-Guinée, en parle dans des termes si peu propres à faire reconnoître l'espèce; ce voyageur' dit que le Muscadivore est du double plus fort de taille que notre Ramier d'Europe. Il me paroît que Sonnerat ne s'est pas trop bien rappelé que la Colombe ramier a déjà dix-sept pouces et demi de longueur totale.

Le capitaine Forster, dans les relations de son voyage autour du monde, dit, à la page 332 de l'édition anglaise, qu'à l'île de Tanna se trouve une espèce 


\section{DES COLOMBES.}

de Pigeon qui se nourrit de muscades: il y a toute apparence que cette espèce désignée par le capitaine Forster est la mème que celle dont nous donnons l'histoire.

Les divers individus de l'espèce de Muscadivore diffèrent assez sensiblement entre eux pour la taille; il en est de ceux-ci comme des autres espèces de Pigeons, et c'est aussi le cas pour les diverses espèces de Perdrix; ces oiseaux varient presque toujours de taille à raison de l'abondance ou de la disette en grains ou en fruits qui leur servent de nourriture; un terrain aride produit en général des oiseaux moins forts et plus petits, tandis qu'exposé sous le même degré, un canton fertile et abondant en toutes sortes de nourritures contribue à donner aux individus d'une mème espèce une taille plus élancée, et décore leur plumage de teintes plus vives et plus fraîches.

Cette espèce a le bec supérieur foiblement arqué vers la pointe; il est plus fort, d'une substance plus cornée que ne l'est d'ordinaire le bec des Pigeons. Les tarses sont robustes, très courts, el en partie emplumés: les doigts nerveux ont des rebords charnus qui forment une plante de pied épatée, comme dans les Pigeons Colombars; les pieds de cette Colombe ressemblent absolument à ceux des Calaos; la carnosité de la partie supérieure du bec estrecouverte par de petites plumes.

Le mâle adulte a toute la tête, le cou, ainsi que les parties inférieures du plumage, d'un beau gris-bleuâtre; le manteau, le dos, les grandes et les petites couvertures des ailes sont d'un beau vert foncé, à reflets métalliques; les grandes pennes alaires, ainsi que les pennes secondaires, sont d'un bleu verdoyant; la queue, composée de douze plumes, est d'un beau bleu de roi, changeant en vert doré, en dessous ces plumes sont noirâtres; les couvertures inférieures de la queue sont d'un roux ferrugineux; les pieds sont rouges, le bec et les ongles noirs, et l'iris est d'un rouge orangé.

La femelle, toujours moins forte de taille que son mâle, a en général tout le plumage d'une couleur plus terne que ce dernier; le cou et le ventre sont d'une teinte vineuse : sur la nuque est une grande espace roussâtre foncé.

Les jeunes Muscadivores sont d'un roux plus ou moins foncé par-tout où le mâle adulte a du gris; dans cet état, les ailes et le dos sont d'un brun bistre à reflets de vert; les grandes pennes des ailes et celles de la queue sont d'un noir grisonnant.

Le Muscadivore habite les Moluques et la Nouvelle-Gruinée; on m’a assuré qu'il se trouvait aussi dans quelques îles de l'Océan Pacifique. Un mâle de cette 
10 HISTOIRE

espèce, ainsi qu'un jeune individu à l'époque de son passage du jeune âge à l'âge fait, m’a été envoyé de Batavia; j’ai vu un mâle à Londres, dans le Leverian Muséum; la femelle déposée aux galeries du Muséum de Paris a servi de modèle; le mâle fait partie de mon cabinet. 
COLOMBE RAMRON, Màle.

$P_{L .} V$.

Colomba Arquatrix. Mihi.

Le Ramron. Le Vallant, Hist. halur. des Ois. d'Afrique.

Le Vaillant a découvert, dans ses voyages en Afrique, vers le tropiquedu Capricorne, unc nouvelle espèce de Colombes qui habite en grandes troupes les immenses forêts de la partie méridionale de ce continent; c'est dans le charmant pays d'Anteniquoi que Le Vaillant vit, pour la première fois, cette belle espèce, et eut occasion d'étudier ses mours, qui, se rapprochent à beaucoup d'égards de ceux de nos Colombes ramiers, ils diffèrent néanmoins par des caractères trop tranchés pour se permettre de confondre ces deux espèces, lors même que la distribution des couleurs répandues sur cette Colombe ne suffiroit pas pour déterminer sa dissemblance spécifique.

La dénomination de Ramron indique déjà en partie une habitude bien singulière de cct oiseau; il paroit en effet s'amuser d'une façon toute particulière de se jouer dans l'air. Jamais són vol n'est régulier et soutenu comme dans la plupart des Pigeons: en partant de dessus un arbre, le Ramron commence par décrire une parabole; il continue, tant que dure sa course, is former par intervalles des arcs-boutants, et c'est en faisant ce manège que l'air retentit au loin du son mélodieux de sa voix.

Le Ramron a un ennemi terrible dans l'Aigle blanchard, dont nous devons aussi la découverte au voyageur cité (I); c'est dans les ébats amoureux du Ramron, lorsque cette Colombe voltige, en décrivant des cercles au-dessus de l'arbre où sa femelle est perchée, que le Blanchard part de l'endroit oú il étoit cn embuscade; si le Ramron n’a pas le temps de se précipiter dans l'épaisseur du bois avant que son adroit adversaire ne se soit placé entre la sommité des arbres et lui, il tombe infailliblement dans les serres de cet Aigle, qui, joignant la rusc à la vélocité de sa course, ne manque pas de s'emparer de sa proie.

Le Ramron, mesuré depuis le bout du bec à l'extrémité de la queue, a

(1) Le Vaillant, Histoire naturelle des Oiseaux d'Afrique, vol. I, à l'article du Blanelard. 
à peu près quinze pouees; le bec a treize lignes, et le tarse en a douze. Les teintes dominantes qui décorent cet oiseau sont le bleu couleur de plomb plus ou moins foncé, et le rouge vineux; cette dernière couleur se trouve r'épandue sur le front, sur le haut du dos et sur toutes les parties inférieures; elle est d'une teinte plus claire sur le cou et sur la poitrine; les plumes de cette partie ont du noir sur leur centre, et paroissent maillées. Le haut de la tête, de même que l'occiput, est d'un gris-bleuâtre; sur les petites et sur les moyennes couvertures des ailes, se dessinent plusicurs taches blanches de forme arrondic; d'autres de la même couleur, mais de forme triangulaire, sont semées sur le ventre: une partie du tarse est couverte de plumes, le reste est nu, d'un jaune clair; les doigts et les ongles sont de cette couleur : le bec est jaune foncé, mais la peau molle qui recouvre les narines est orangée; les yeux sont d'un brun orangé.

Le Ramron est connu, dans la colonie du Cap de Bonne-Espérance, sous le nom de (Olyf-Duif), ce qui signifie Pigeon d'Olivier; cet oiseau fait sa nourriture principale d'une espèce de fruit semblable à l'olive.

On sera sans doute étonné de me voir décrire les moeurs de quelques Pigeons africains avant mon ami Le Vaillant, qui publie l'Histoire des oiseaux découverts par lui dans cette partie du monde: il m'est bien agréable de faire connoître ici l'aménité de caractère de ce naturaliste, qui n'a d'autres torts envers la foule de ceux qui tâchent à lui nuire dans leurs écrits, que de posséder des talents bien supérieur's à ceux-ci en étude de la nature: tandis que ces calomniateurs, sans doute jaloux de ne pouvoir joindre ce talent à leur âpre étude de cabinet, condamnent sans réserve cette partic, ¿̇ la vérité un peu négligée dans les ouvrages de M. Le Vaillant; son ornithologie d'Afrique sera nonobstant, en dépit de tous les détracteurs, une source où les soi-disant naturalistes, qui ne connoissent la nature que par les livres, seront obligés de venir compiler la partie de cette science qui leur est le plus souvent étrangère.

J'ai dit, dans l'introduction de cet ouvrage, que mon ami Le Vaillant m'avoit: fait part de toutes ses notes sur les Pigeons et les Gallinaces africains, que je lui devois des observations intéressantes sur ces oiseaux, qui, n’ayant encoreété décrits par aucun auteur, se seroient trouvés simplement figurés dans cette monographie, d'après des individus de ces espèces déposés dans mon cabinet, sans autres indications de mours ou d'habitudes.

Le public, en joignant sa reconnoissance à la mienne, ne rendra qu'un hommage bien mérité à un désintéressement si rare.

Le Ramron mâle fait partie de mon cabinet. 


\section{COLOMBE GRIVELÉE}

Columba Armillaris. Miki

Les parages de l'Asie australe nourrissent une nouvelle espèce de Colombe, dont nous ne trouvons pas même d"indications dans les divers voyages. Nous avons rapporté de Londres deux individus de ce Pigeon, que nous désignons par le nom de Colombe grivelée, le ventre étant marqué de taches irrégulièrement semées. Aucune particularité sur la manière de vivre de cet oiseau ne nous étant connue, nous sommes obligés de nous en tenir à la description succincte des couleurs qui caractérisent cette belle espèce.

La Colombe grivelée, quoique plus petite de taille que le Ramier d'Europe, est modelée sur les formes de cet oiseau. Sa longueur, depuis le bout du bec a l'extrémité de la queue, est de quinze pouces et demie; le bec a quatorze lignes; la peau molle qui en recouvre la base est de couleur rosée, et paroît saupoudrée de blanc. Un bleu couleur d'ardoise règne sur le plumage supérieur et sur le devant du cou; la mème teinte se trouve encore sur une espèce de ceinturon qui se dessine des deux côtés de la poitrine, mais dont les extrémités ne se joignent point; le front et la gorge sont d'un gris blanchâtre; une espèce de hausse-col prend son origine de chaque côté au-dessous de l'orifice des oreilles, et descend sur la poitrine. Il est d'un blanc pur, et paroît imiter un ornement encore de mode il y a peu de temps; toutes les élegantes avoient coutume de se parer de certains colliers qu'on désignoit par le nom d'esclavages; ceux-ci ressemblent, par la manière dont ils descendent sur la gorge, au collier qui se dessine sur la poitrine de notre Colombe. Toutes les parties inférieures de cet oiseau sont blanches; sur le milieu du ventre il y a des taches oblongues. Les plumes de flancs de l'abdomen et les couvertures inférieures de la queue ont du noir en forme de fer de lance à leur centre; elles sont toutes frangées de blanc pur; les grandes pennes des ailes sont d'un brun terne, toutes ont le bord des barbes extérieures liserées d'un 
brun roux; les quatre pennes latérales de chaque côté de la queue sont terminées de blanc.

Nóus avons figuré cet oiseau d'après un individu d'une conservation très pure qui se trouve dans ma collection. Cet oiseau, ainsi que le précédent, ont été réduits à moitié, le format ne nous permettant pas de les représentcr de grandeur naturelle. 


\section{COLOMBE MARINE.}

$$
\text { PL. VII. }
$$

Golumba Littoralis. Mihi.

Columba Abba. Lath. Ind. orn. ข. 2, p. 602, sp. 34.

- Grel. Syst. I, p. 780 .

Pigeon blanc Mangenr de muscade. Sonneral. Vor. p. x $69, t .103$.

Pigeon Ramier blanc Muscadirorc. Sonnini, édit. de Buff. v. 7, p. $25 \%$.

White nutmeg Pigeon. Lath. Syn. v. 4, p. 638, sp. $5 \mathrm{r}$.

C'est à juste titre que Sonnini ne réunit pas le Ramier blanc muscadivore avec le Pigeon cuivré mangeur de muscades, comme l'ont fait assez mal a propos plusieurs ornithologistes; le muscadier servant, en certains temps de l'année, de nourriture à ces deux espèces, il ne s'ensuit pas qu'elles doivent être considérées comme ayant des rapprochements intimes; il est cependant évident que la préférence que ces oiseaux donnent au fruit du muscadier peut ètre considérée comme l'unique motif sur lequel on se soit permis des analogies touchant ces deux espèces, qui ne se ressemblent du reste en aucune manière.

Nous avons cru nécessaire de substituer un nom plus caractéristique à la place de la phrase par laquelle ce Pigeon est désigné dans Sonnini; la dénomination de Colombe marine nous paroît plus convenable à cette fin; elle donne à connọitre une habitude particulière propre à cette espèce, et lui convient mieux que celle de Pigeon Ramier blanc Muscadivore, dénomination par laquelle nous avons déjà désigné une Colombe qui semble faire sa principale nourriture de la pulpe dont les noix muscades sont entourées.

Mon ami M. Laischenault, qui a souvent été à mème d'observer cette Colombe à l'île de Java, où elle habite en certains temps de l'année, m'a communiqué, sur sa manière de vivre, une note très intéressante.

Les Javans désignent cette Colombe par le nom de Bouron dora-lourw, ce qui signifie oisenu Pigeon de mer: en effet, ces oiseaux habitent de préférence les rochers qui bordent la mer dans la partie où est l'île de Java. C'est dans les trous et les crevasses naturelles des rochers qu'ils nichent et élèvent leurs petits. Ces oiseaux viennent par grandes troupes se poser sur l'espèce de 
palmier appelé par les Javans poukio-kebau; ils sont très friands du fruit que produit cet arbrc; après lc temps des pontcs, ct lorsque les jeunes Colombes marines sont cn état de suivre leurs parents, tous quittent l'île de Java, et émigrent vers d'autres parages. En combinant cc fait rapporté par M. Laischenault, avcc ce que Sonnerat dit de son Pigcon blanc mangeur de muscades, il est à présumer que la Colombe marine vient habiter la NouvelleGuinée à certaines époques régulières de l'année; d'après Sonncrat, qui a très bien désigné l'cspèce, il paroît donc qu'clle y vit des mêmes aliments qui servent de nourriture au Muscadivorc, et qu'elle dissémine les muscades avec ses excréments, sans que ces noix souffrent la moindre altération en passant par les organes de la digestion.

Nous avons donné un exposé de cette manière, qui contribue a propager en abondance le muscadier, à l'article de la Colombe Muscadivore. Il est éncore d'autres cspèces de Pigeons qui ont cette habitude toute particulière de contribuer à multiplier en abondance certains arbres fruiticr's; le capitaine Forrest parle d'un Pigeon de Ceylan qui plante le Cinnamon (1). Les Voyages de Parkinson (2) nous appremnent qu'il y a des Pigeons qui servent à propager, par un instinct à peu près semblable, le loranthus stelis de Linnæus, que les insulaires d'Othaeite désignent par le nom de tootaoopa.

La Colombe marine, mesurée depuis le bout du bec à l'extrémité de la queue, porte treize pouces; tout le plumage de cct oiseau est d'un blanc très pur, si on en exceptc cependant les grandes pennes alaires, qui sont entièrement noires, les moyennes pennes de ces dernières blanches à leur origine, mais noires sur les trois quarts de leur longueur, enfin les extrémités des plumes caudales qui sont de cettc dernière couleur; sur celles-ci le noir se dessine en forme de demi-lunc. Les pieds et le bec sont d'un gris livide; cette teinte colore aussi la peau nue, formant un cerclc ćtroit autour des yeux; ceux-ci sont d'un jaune clair.

La Colombe marine ne fréquente pas exclusivement les parages de la Nouvelle-Guinée; clle se trouve encore répandue dans toutes les îles situécs entre ce pays et l'île dc Java, puisqu'on a rapporté de ces oiseaux des Móluques, et qu'il est probable quïls nichent aussi dans les îles voisines de celle de Java.

(1) Voyez Forrest, Voyage, p. 345.

(2) Voyez Parkinson, Voyage South-Seas, p. 58. 
COLOMBE LUMACHELLE, Mâle.

P. VIII.

Columba chalcoptera. Laтн, Ind. orn. v. 2, p. 604, sp. 5 g.

Bronze-winged Pigeon. Plill. Bot. Bay. 1. p. 16z. - Wните's. Journal, t. p. I 46 .

- Latri. Syn. supp. 2, p. 266.

La Tourterelle aux ailes dorées. Sonnini, édlit. de Buff. v. 7, p. 3og.

$\mathrm{U}_{\mathrm{NE}}$ des plus belles espèces de Pigeons qu’on connoisse, est sans contredit la Colombe Lumachelle, qui fait le sujet de cet article. Des points brillants d'un éclat radieux sont semés sur les ailes de cet oiseau, dont le plumage'. généralement de couleur uniforme sur tout le reste du corps, contribue encore à relever la richesse éblouissante de ces taches, qui paroissent comme autant de rubis, de saphirs et d'opales.

Le capitainc Phillip, dans son voyage à la Nouvelle-Galles, et le chirurgien général White, dans son voyage au port Jackson, font mention de cette Colombe: Labillardière, qui en tua aussi à la Nouvelle-Follande, l'avoit déjà trouvée au cap de Diemen: les naturalistes qui accompagnoient le capitainc Baudin en ont rapporté deux individus tués au canal d'Entrecasteaux. Liespècc paroit en général très abondante dans toutes les parties de l'Océan pacifique: on les trouve aux îles Norfolk, dans les diverses parties de la Nouvelle-Hollande; ils sont principalement très communs dans les environs de Sidney-Cove et de la baie Botanique.

Les Colombes Lumachelles se plaisent dans les lieux sablonneux et arides, elles aiment à sc tenir à terrc ou sur des branches basses; on ne les voit à la baic Botanique quc depuis le mois de septembre jusqu’à cclui de février. Ces oiseaux se montrent toujours par paires; ils pratiquent leurs nids dans les trous d'arbres peu élevés de terrc, et souvent sur la terre mème, et pondent deux œufs blancs; leur nourriture principale est un petit fruil ressemblant à la cerise; on trouve toujours les noyaux de ce fruit dans leurs gésiers. Il est facile de s'assurer du lieu de leur rctraite, le roucoulement très sonore de cette espèce imitant à une certaine distance le beuglement des vaches. Les insulaires de 
la Nouvelle-Hollande désignent le Lumachelle par le nom de Goad-Gang; les Anglais l'appellent Ground-Pigeon, ce qui signifie (Pigeon de terre.)

Nous allons décrire le mâle et la femelle, ainsi que le jeune âge de cette espèce, d'après trois individus que j'ai rapportés de Londres; nous n'avons figuré que le mâle dans nos planches coloriées, pour ne pas multiplier inutilement le nombre des gravures; la description mettra le naturaliste à même de reconnoître facilement les deux autres.

Le mảle adulte a quinze pouces et demi, depuis la pointe du bec à l'extrémité de la queue; le front est d'un blanc pur, et se nuance successivement par de légères teintes en rose clair; cette couleur devient plus violacée en approchant de l'occiput, et forme, en passant sur les yeux, une espèce de fer à cheval. Les orifices des oreilles sont recouvertes par de petites plumes blanches. La couleur dominante sur les parties supérieures est d'un cendrébrun; chaque plume est bordée de jaune terreux. Les grandes couvertures des ailes ont vers leur extrémité une tache d'mu éclat radieux. Les reflets chatoyants du rubis et de l'opale brillent à l'envi sur ces plumes, qui par leur réunion, lorsque l'aile est dans l'état du repos, forment deux bandes transversales sur cette partie; ces plumes sont terminées d'un beau blanc conleur de perle. Les petites et les moyennes couvertures ont encore de ces mèmes taches brillantes, plus ou moins irrégulièrement distribuées; elles sont terminées de gris-jaunâtre. Sur les pennes secondaires des ailes il y a de grands miroirs d'un vert-pourpré. La queue est composée de dix-huit pennes cendrées (1), avec une bande noire vers leur extrémité; les deux plumes du milieu sont de la couleur du corps: le dessons de la queue est aussi gris-cendré, mais toutes les pennes sont traversées par une barre brune. Les parties inférieures du corps sont grises, avec des teintes vineuses sur la poitrine. Le dedans des ailes est roux de rouille; le bec est noirâtre, mais sa base est rougeâtre; les piedss sont rouges.

La femelle n'a point de blanc sur le front; tonte la tête est d'un gris-cendré; cette couleur règne sur les autres parties de l'oiseau, mais les teintes sont en général plus claires que chez le mâle; les bords de toutes les plumes sont d'un blanc jaunâtre; les taches brillantes sur les ailes sont beaucoup plus petites et moins vives; leur chatoyant n'imite pas celui qui brille dans les rubis, mais les reflets sont plutôt d'un vert métallique. Les miroirs sur les plumes secondaires sont aussi moins grands et plus ternes.

(I) Latham et Sonnimi comptent seulement seize plumes à la quene du Lumachelle. Ces auteurs se trompent en ne lui donnant que ce nombre; tous les individus observés par nous aroient dix-huit pennes. 
DES GOLOMBES.

Les jeunes Lumachelles ont la livrée d'un cendré-noirâtre, et toutes les plumes sont bordées de couleur de terre d'ombre. Le front et la gorge sont blanchâtres, et les miroirs sont de couleur sombre, avec des legers reflets verdâtres.

Les individus qui ont servi à cette description sont dans ma collection; deux mâles dans le plus parfait état de conservation sont au Muséum de Paris; plusieurs se voyent à Londres. 


\title{
COLOMBE - L AR GUP.
}

\author{
P.. IX.
}

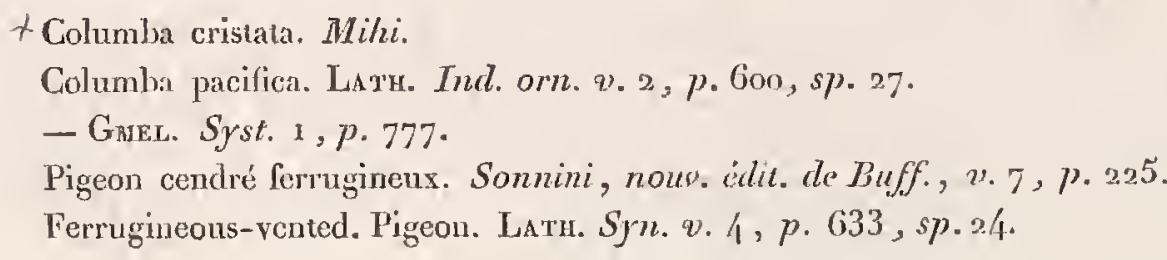

Vorc encore mn. Pigeon bicn remarquable, qui se distingue de tous ses congénères par un caractèrc d'autant plus particulier, qüil esı jusqu’à présent unique dans les oiseaux qui composent cette nombreuse tribu.

Dans presque tous les genres d'oiseaux on connoit des espèces qui, pour ornement extraordinaire, portent sur la tète des plumes plus ou moins longues, capables d'érection : le genre columbace ne nous avoit pas encore présenté ce caractère avant l'époque où nous écrivons.

Nous avons donné le nom de Colombe-Largup à ce Pigeon, par rapport à la largeur que présente l'ensemble des plumes occipitales; celles-ci s'alongent tout à coup sensiblement, et forment unc huppe touffue, qui ceint l'occiput; ce caractère très marquant dans la Colómbe représentée dans nos planches paroìt être échappé à Latham; le naturaliste anglais rend défectueusement les couleurs brillantes qui parent cet oiseau. On pourroit même présumer, avec assez de fondement, que Latham décrit notre Colomb-Largup, on d'après quelque mauvais dessin, ou bien simplement d'après des ouï-dires. Sonnini ayant traduit le texte du naturaliste anglais, n’a rien ajouté à la connoissance plus parfaite de l'espèce.

Le Largup a la taille de notre Biset, il mesure en totalité treize pouces deux lignes; le bec, qui a un pouce, est fortement courbé vers la pointe. Lá tête, le cou, la poitrine et. le ventre sont d'un gris nuancé en teintes de pourpre clair, à reflets métalliques sur le cou et sur la poitrine; au-dessous des yeux, ainsi que sur la gorge, est une grande tache d'un janne-terreux. Le. manteau, les scapulaires et les petites couvertures des ailes sont d'un violetpourpré à reflets: les grandes couvertures et les pennes secondaires sont. 
DES COLOMBES.

noirâtres, avec de légers reflets pourprés sur les premières. Le noir verdâtre règne sur le dos et sur toutes les pennes caudales. Les cuisses, l'abdomen, ainsi que les couvertures inférieures de la queue ont une belle couleur ferrugineuse, les grandes pennes alaires sont teintes d'un roux vif; les pieds sont rouges, le bec et les ongles sont bruns.

Cette magnifique espèce se trouve aux îles des Amis, dans la mer du Sud; Labillardière (1), qui ne donne aucun détail relativement aux couleurs de cette Colombe, dit qu'il tua dans ces parages un individu de cette espèce.

La Colombe-Largup est de ma collection. Nous en avons vu une chez M. Raye de Breukelerwaert, et une autre à Londres. Cette espèce est encore très rare dans les cabinets. Ses grandes dimensions ne nous permettant pas de la figurer de grandeur naturelle, nous l'avons réduite à moitié.

(I) Voyage à la recherche de La Peyrouse. V. 2, p. 105. 


\title{
COLOMBE A QUEUE ANNELÉE.
}

\author{
$P_{L .} X$ \\ + Columba Caribæa, Latri. Ind. orn. v. 2, p.6o3, sp. 36. \\ - Guex. Syst. ข. ז, p. $77^{3}$. \\ Le Pigeon à queuc annelée de la Jamaïque. Briss. oin. ข. I, p. г 38 , sp. 34. \\ fling-tail Pigeon, Lath. Sym. v. 4, p.639, sp. 33. - BRowNe Jam. p. 468. \\ - Sloane Jam. p. 3 oz.
}

Si Buffon s'est souvent mépris en prenant le Ramier vulgaire ou bien le Biset sauvage pour type de la plus grande partie des Pigeons qui habitentles climats étrangers, ce naturaliste n'a pas mal présumé en supposant l'identité spécifique de la Colombe à queue annelée, qui lui étoit connue par les descriptions de Browne et de Hans Sloane. D'après ces seules indications, Buffon ne balance pas à placer ce Pigeon comme une troisième variété du Ramier, et c'est en quoi il a un grand tort. Le Pigeon de cet article n'a pas les plus légères analogies avec notre Ramier, il ne faut pour cela que les comparer; au lieu qu'il a des ressemblances bien caractérisées avec une Colombe indigène dont nous allons nous occuper à l'article suivant, et que nous désignerons par le rom de Colombin.

Outre la taille, qui est la mème dans la Colombe à queue annelée et le Colombin, nous trouvons encore dans la barre qui traverse les plumes caudales de ces deux Pigeons un caractère de ressemblance bien constaté; ajoutez à ceci le peu de différence dans les couleurs, qui ne varient que par des teintes plus brillantes et plus fraîches répandues sur la livrée de la Colombe à queue annelée, moins pures dans le Colombin.

Nous considérons donc la Colombe à queue annelée comme une espèce analogue très voisine de celle du Colombin qui habite l'Europe; les différences peu sensibles entre ces oiseaux ne nous paroissent occasionnées que par l'influence du climat; nous conservons cependant à chacune de ces espèces, ou, pour mieux nous expliquer, à chacune de ces races, une dénomination différente, vu qu'il n'en est pas de cette Colombe comme de l'espèce du Biset, qui est la même en Afrique, en Europe et en Asie: dans ces diverses contrées elle n'a subi, par l'influence des climats, qu'une très légère différence dans les 
teintes plus ou moins vivement coloriées des plumes du cou; au lieu que les dissemblances observées entre le Colombin et lc Pigeon de cet article sont plus considérables; les Colombes à queue annelée paroissent au reste propres aux régions de l'Amérique septentrionale.

Longueur tolale, quinze pouces; bec, neuf lignes; la tête, la partie inférieure du cou et la poitrine sont de couleur pourprée; la partie supérieure du cou est d'un pourpre changeant en vert; ces couleurs ont à différentes lumières des reflets éclatants; le dos, le croupion et les couvertures du dessus de la queue sont d'un bleu-cendré; les ailes, les scapulaires, ainsi que toutes les grandes pennes sont d'un gris rembruni; le ventre a des teintes de gris foncé à légers reflets pourprés; les pennes de la queue sont, depuis leur origine jusque vers la moitié de leur longueur, d'un gris d'ardoise; une large bande de gris plus clair les traverse toutes; et clles sont terminées de grisnoirâtre; la base du bec est charnu, de couleur rougeâtre, la pointe est jaune. L'iris des yeux ct les pieds sont d'un rouge foncé.

La variété dont parle Latham, dans son supplément page 199, n'appartient pas à cette espèce; la queue de notre Colombe est carréc, tandis que l'oiseau donné par l'auteur anglais comme une variété, a la queue étagée et de forme cônique.

Maugé a trouvé la Colombe à queue annelée à Porto-Rico; elle y habite par grandes bandes de plusieurs centaines. Browne observa cette espèce à la Jamaïque, où elle fréquente ordinairement les lieux bas et les terrainsc ultivés. Sa nourriture principale consiste en toute sorte de grains; elle est aussi très friande de la baie du café. Ces Pigeons paroissent répandus dans toutes les Antilles et les Lucayes; nous ignorons s’ils fréquentent la terre-ferme des deux continents de l'Amériquc. Il est probable qu'ils n'entreprennent point de longs voyages, puisque Browne nous apprend que ces Colombes se trouvent à la Jamaïque durant toute l'année.

Nous avons vu plusieurs de ces individus dans divers cabinets à Londres; celui qui a été rapporté de, Porto-Rico, par Maugé est au Muséum de Paris; il a servi de modèle à madame Knip. 


\title{
COLOMBE COLOMBIN.
}

\author{
PL. XT.
}

\author{
Columba OEnas. LAтн. Ind. orn. v. 2, p. 589. sp. ז. \\ - Gmex. Syst. 1 , p. 769.-Friscr. t. 139. \\ Le Pigeon sauvage. Brisson. orn. v. I, p. $86, s p .5$. \\ Stock Pigeon, or Stock Dove. Latr. Syn.v. 4, p.604. - Id. supp. p. I97. \\ Holiztaube. Bechstein. orn. taschenb v. $x, p .23 \mathrm{x}, s p .2$.
}

IL existe dans nos climats deux espèces bien distinctes de Pigeons proprement. dits. La première, d'où proviennent nos Pigeons de colombier, habite et niche en état de liberté dans les rochers et les vieilles masures; au défaut d'un pareil gite, elles s'accommodent aussi des troux vermoulus de quelque vieux arbre; cette cspèce est connue sous le nom de Biset. Unc autre espèce presque toujours mal observée, et plus mal décrite encore par les naturalistes, vit aussi en état sauvage dans nos contrées; ses mours, bien différentes de celles que nous obervons dans le Biset, ne permettent en aucune manière de la confondre avec celui-ci; elle demeure toujours dans les bois, et pose son nid sur la cime des plus hauts arbres; son naturel est farouche comme l'est celui des Pigeons Ramiers, ct son genre de vie semble en général se rapprocher beaucoup de cette espèce. Dạns les forêts de la Bourgogne et de la Lorraine, où cet oiseau se rend toutes les années vers le temps des pontes, les habitants lui donnent le nom de petit Ranier, et le distinguent de l'autre espèce, qu'ils nomment simplement Ramier: dans les pays boisés de l'Allemagne on lui donne le nom de Pigeon bleu ou petit Pigeon bleu des bois. Nous avons lieu de croire que ces oiseaux viennent nicher dans les grandes allées de marronniers, au jardin des Tuileries: nous y avons vu, dans le tèmps des pontes, deux espèces de Pigeons, dont la voix et le roucoulement très différent attira notre attention; nous fümes convaincus que cette supposition étoit vraie, car en voyant partir ces oiseaux de dessus les arbres, nous distinguâmes effectivement deux sortes de Pigeons; les uns étoient de l'espèce du Ranier ordinaire, les autres nous parurent de l'espèce du Colombin; ils étoient d'une taille inférieure à celle du Ramier, et n'avoient pas le croupion blanc, caractère qui distingue 
le Biset. Le nom de Ramiret (petit Ramier) auroit convenu à cette Colombe, mais la dénomination de Ramiret ayant été donnée, quoique mal à propos, à une Colombe étrangère à l'Europe, nous n'avons pu en faire usage pour celle-ci. Le Colombin émigre aux approches de l'hiver.

De tous les auteur's qui ont décrit cette espèce, il n'y a que Brisson dont l'exposé fidèle rend parfaitement bien l'oiseau. Ce națuraliste a décrit le Colombin avec cette vérité et cette exactitude qu'on trouve répandues dans tout son livre; on peut même, en consultant l'ouvrage de Brisson, se passer de gravures, tant ses descriptions sont calquées d'après la nature. Les oiseaux enluminés de Frisch nous présentent la seule bonne gravure qui a été donnée du Colombin; en général, la plupart des planches de cet ouvrage, quoique grossièrentent exécutées, sont cependant vraies; sur-tout celles qui ont été faites d'après la nature.

Un naturaliste qui veut éviter toute méprise et double emploi doit se borner à citer de pareils auteurs dans sa synonymie. Je soutiendrai toujours qu'on fait plus de tort à l'étude de la nature en citant des descriptions tronquées et des indications vagues, qu'en les vouant à un oubli éternel : on en voit une preuve dans la citation de la planche d'Albin (1), qui, à en croire les synonymies, doit représenter notre Colombin. Comment ces grands génies, en compilant dans les étroites limites de leur bibliothèque, n'ont-ils pas vu que cette planche d'Albin ne ressemble en aucune manière à notre Colombe, et que l'auteur, sous un nom différent, a figuré un Ramier qui n'avoit pas encore atteint l'état d'adulte?

Le Colombin est un peu plus fort de taille que le Biset; sa longueur, depuis le bout du bec jusqu'à celui de la queue, est de quatorze pouces; son vol est de deux pieds deux pouces; le bec a onze lignes; les ailes pliées atteignent, à un pouce près, l'extrémité des pennes caudales; la tềte est d'un cendré bleuâtre, la partie supérieure et les côtés du cou sont d'un beau vert, changeant en violet et en couleur de cuivre de rosette, selon qu’ils se trouvent exposés aux rayons de la lumière; la partie supérieure du dos et les couvertures des ailes sont d'un cendré obscur; la partie inférieure du dos, le croupion et les couvertures du dessus de la queue, d'un cendré clair; la partie inférieure du cou, depuis la tête jusque vers le milieu de sa longueur, est cendrée; le reste du cou, ainsi que la poitrine, est de couleur de lie de vin; le ventre, les flancs, l'abdomen et les couvertures du dessous de la queue sont

(1) Allin, v. $2, \mathrm{pl} .46$. 
d'un cendré claịr; les premières grandes pennes de l'aile sont noires, et ont leur bord extérieur blanc, toutes les suivantes, ainsi que les moyennes, sont cendrées à leur origine, et noires vers leur bout; sur chaque aile sont deux taches noires (1), l'une sur les deux moyennes pennes les plus proches du corps, et l'autre sur les trois grandes couvertures de l'aile qui tombent sur celles-là : ces taches ne sont que sur les barbes extérieures et vers le bout de chacune de ces plumes. Toutes les plumes de la queue sont cendrées depuis leur origine jusque vers les deux tiers de leur longueur; le reste est noir, excepté la moitié des barbes extérieures de la penne latérale qui est blanche. En dessous de la quene il y a une barre d'un gris clair qui traverse toutes les pennes à un pouce de leur extrémité. Le bec est d'un rouge pâle; les pieds sont rouges et les ongles noirs.

L'individu qui a servi de modèle fait partie de la belle collection de M. Dufresne, attaché au Muséum de Paris. Le Colombin est très difficile à se procurer.

(I) Noús ignorons ce qui a pu porter Latham à dire que l'OEnas a sur chaque aile deux harres transversales de couleur noire: on supposeroit par-là que l'auteur anglais a décrit un Biset, si, du reste, le texte de Latham ne se rapportoil au Colombin. 


\title{
COLOMBE BISET SAUVAGE.
}

\author{
P. $X I I$.
}

Columba livia, Lath. Ind. omn. v.2, p. 5ijo, sp. 2.

- Guer. Syst. I, p. 769

Le Biset. Buffon, v.2, p. 498-Pl. enl. 5 10. - Somini, édit. de Buff., v. 7, p. ז54.

- Briss. Orn. ข. 1, p. $82 . s p .3$.

Biset Pigeon, Lath. Syn. v. 4, p. Go5.

Nous réunissons sous cet article, et regardons comme autant de descendants du Biset sauvage, tous les Pigeons de colombier, les diverses races de Pigeons de volière, qui, par la forme du bec et des parties principales, ressemblent à cet oiseau, le Pigeon domestique des naturalistes, la prétendue espèce de Pigeon romain, ainsi que ses variétés, et le Pigeon de roche, ou Rocherai. Ces oiseaux produisent ensemble des individus féconds qui se reproduisent à leur tour, et forment, par l'entremise dẹ l'homme, ces races particulières que nous remarquons dans les Pigeons de volière; ceux-ci se maintiennent par les soins qu'on prend de les assortir. Ce sont particulièrement ces Pigeons dont les différentes nuances sont presque innumérables. Les hommes, en les perfectionnant pour leur jouissance, ont multiplié ces races, plus par luxe que par nécessité; ils ont altéré leurs formes, et lẹr sentiment de liberté s'est trouvé totalement détruit.

Le produit en grand nombre est la source des variétés dans les espèces. Nos colombiers, peuplés par une quantité de Pigeons accoutumés et familiarisés avec ces bâtisses, ont successivement offert des variétés accidentelles, parmi lesquelles on aura choisi les plus belles, et les plus particulièrement bigarrées; celles-ci, isolées de la troupe, élevées avec des soins assidus, et. assorties suivant le caprice, ont successivement engendré toutes ces races particulières dont l'homme est le créateur, et qui,'sans lui, n'auroient jamais existé.

Nos Pigeons de colombier, captifs volontaires, abandonnent cependant quelquefois les établissements commodes que nous leur offrons, et désertent nos colombiers; ils paroissent se rendre à leur ancien état de nature, et 
choisissent des trous de vieilles tours ou des creux d'arbres pour nicher et élever leur progéniture: ceux-ci, soit par instinct ou par besoin, reviennent souvent s'installer de nouveau dans les bâtisses que leurs parents avoient fuies. Au reste, ces pigeons déserteurs, qu'on nomme aussi quelquefois Rocherais, ne diffèrent en aucune manière du Biset de colombier, ni même du véritable Biset sauvage que nous représentons dans la planche qui accompagne cet article.

Buffon donne un exposé très clair et en même temps utile pour ce qui concerne la manière d'établir les colombiers et d'y propager les Pigeons. Voici en substance le texte de cet auteur :

“ Les Pigeons de colombier ne sont qu'i-demi domestiques, et retiennent “ encore de leur premier instinct l'habitude de voler en troupe; ils produisent " souvent trois fois l'année, pondent, à deux jours de distance, presque " toujours deux cufs, rarement trois, et n'élèvent jamais que deux petits, « dont ordinairement l'un se trouve mâle, et l'autre femelle; il y en a même « plusieurs, et ce sont les plus jeunes, qui ne pondent qu'une fois. Le pro“ duit du printemps est toujours plus nombreux, c’est-à-dire, la quantité de « pigeonneaux dans le même colombier est plus abondante qu'cn automne, “ du moins dans ces climats. Les meilleurs colombiers, oú les Pigeons se « plaisent et multiplient le plus, ne sont pas ceux qui sont trop voisins de “ nos habitations; placez-les à quatre ou cinq cents pas de la ferme, sur la « partie la plus élevée de votre terrain, et ne craignez pas que cet éloignement « nuise à leur multiplication; ils aiment les lieux paisibles, la belle vuc, « l'exposition au levant, la situation élevée où ils puissent jouir des premiers « rayons du soleil. J'ai souvent vu les Pigeons de plusieurs colombiers situés " dans le bas d'un vallon en sortir avant le lever du soleil, pour gagner un “ colombier situé au-dessus de la colline, et s’y rendre en si grand nombre, « que le toit étoit entièrement couvert de ces Pigeons étrangers, auxquels les « domiciliés étoient obligés de faire place, et quelquefois même forcés de la “ céder. C'est sur-tout au printemps et en automne qu'ils semblent rechercher “ les premières influences du soleil, la pureté de l’air ét les lieux élevés. Le “ peuplement de ces colombiers isolés, élevés et situés haut, est plus facile, “ et le produit bien plus nombreux que dans les autres colombiers » (1).

Le Biset sauvage est, comme nous l'avons dit, le type de nos Pigeons de colombier; il ne diffère de ceux-ci que par sa couleur tant soit peu plus bise;

(I) Bnffon, ì l'article du Biset. 
les plumes du bas du cou ont des teintes moins vives, et les reflets ne sont pas si éclatants que dans les Pigeons de colombier. Ces oiseaux sont voyageurs; ils émigrent toutes les années de nos climats, et vont chercher sous un ciel plus doux la chaleur, qui leur paroît agréable et nécessaire. L'Europe, l'Asie et.l'Afrique nourrissent des Bisets dans l'état sauvage; ils sont en petite quantité dans les climats exposés au froid, mais les pays chauds en sont abondamment peuplés : on trouve beaucoup de Bisets en Perse et en Égypte. Maugé observa ces oiseaux à Ténériffe, où ils habitent par grandes bandes, et nichent dans les énormes rochers qui bordent la mer dans ces parages. Près du village des Grouanches, fameux par ses momies, Maugé tua plusieurs Bisets sauvages; mais ces oiseaux tombant toujours entre les rochers et dans les précipices, ce naturaliste ne put se procurer qu'un petit nombre d'individus. Par cette habitude qu'a le Biset de nicher dans les trous des rochers, et de préférer ces demeures à celles qu'il pourroit construire sur les arbres, il est facile de voir que nos Pigeons de colombier doivent leur origine à cette espèce: des oiseaux qui, dans l'état de liberté, vont de préférence placer leurs nids dans les rochers, ẻtoient bien plus propres à s'accoutumer à nos colombiers, que des espèces de Pigeons accoutumés à vivre dans les forêts. Une preuve sert à nous confirmer dans cette opinion : les Pigeons fuyards ou déserteurs de nos colombiers retournent à leur état primitif, donnent toujours la préférence aux vieilles tours et aux masures pour y nicher; ce n'est qu'à leur défaut qu'ils construisent dans les trous des arbres, mais jamais sur les arbres, comme le font les Ramiers et les Colombins.

Le Biset sauvage, mesuré depuis le bout du bec à l'extrémité de la queue, porte treize pouces; son envergure est de vingt-six pouces; les ailes, lorsqu'elles sont pliées, touchent presque le bout de la queue; le bec a dix lignes; la tête, la partie supérieure du dos, les couvertures des ailes, la poitrine et le ventre sont d'un cendré tirant sur le bleu les couvertures des ailes sont d'une teinte plus foncée; la partie inférieure du dos est blanche, le cou est d'un beau vert à reflets; les grandes pennes des ailes sont noirâtres; les secondaires et les grandes couvertures sont d'un cendré tirant sur le bleu; elles sont terminées de noir, ce qui forme sur chaque aile deux bandes transversales; la queue est du même bleu que le corps; toutes les pennes sont terminées de noir, et la plus extérieure de chaque côté a ses barbes extérieures blanches; le bec est d'un rouge pâle; les pieds sont rouges et les ongles noirs. 
Un individu, rapportẹ de Ténériffe par Maugé, est au Muséum de Paris. Les Bisets de colombier sont d'ordinaire un peu plus forts de taille; le cou et la poitrine sont plus brillants; souvent le ventre a même des teintes vineuses à reflets cuivrés : ces légères varietés dépendent de l'abondance de nourriture.

Pour décrire les variétés infinies qui se trouvent dans les Pigeons de volière, un volume ne suffiroit pas, comme un volume de planches ne pourroit les contenir toutes. Nous nous bornerons donc uniquement à faire connoître et à décrire succinctement les principales races de cette grande famille, qui servent à propager tous les individus remarquables par leur taille ou leur couleur. 


\section{PIGEON DOMESTIQUE.}

Columba domestica. Lath. Ind. orn. v. 2, p. 589, sp. 2.

Le Pigeon commun. Buff., v. 2, p. 5о1._pl. enl. 466.

White-runped Pigcon. Latr. Syn. v. 4, p. 605.

Les Pigeons domestiques sont les premiers descendants du Biset sauvage: leurs couleurs varient beaucoup; les uns sont blancs, d'autres noirâtres, d'autres roux; le plus grand nombre sont d'un gris bleu; leur cou est souvent d'un vert doré à reflets; quelques individus sont très bigarrés; mais généralement tous, de quelque couleur qu'ils soient, ont la partie inférieure du dos blanche, le bec brun; la membrane, à sa base, est rougeâtre et comme saupoudrée de blanc; les pieds sont rouges.

\section{PIGEON ROMAIN.}

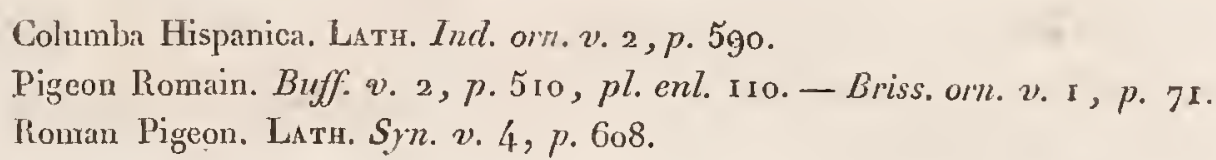

L $\Lambda_{\Lambda}$ race des Pigeons Romains est de forte taille; ils ont souvent jusqu'à quinze pouces, mesure prise depuis le bout du bec jusqu'à l'extrémité de la queue; leur vol est de vingt-sept pouces, et les ailes pliées touchent vers le bout des pennes caudales. Le Pigeon Romain varie aussi pour les couleurs et pour les formes des plumes. Le bec est plus ou moins rouge dans les uns, noirâtre dans les autres; on en trouve de patus à plumes très longues aux doigts, qui semblent gêner l'oiseau dans ses mouvements; d'autres sont huppés, et ne diffèrent que par les plumes de l'occiput, qui sont contournées et redressées. 


\section{PIGEON GROSSE-GORGE.}

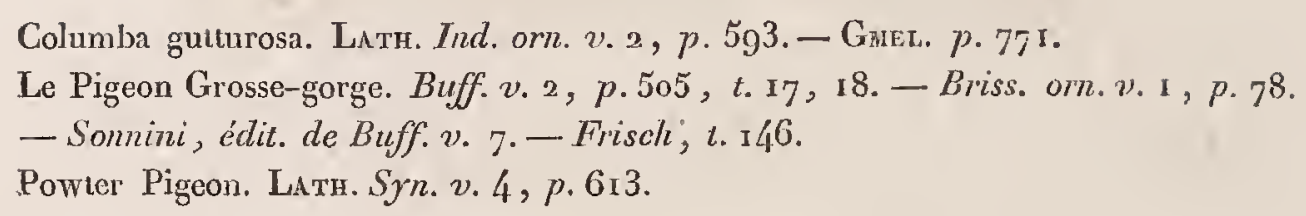

LE Pigeon Grosse-gorge est d'ordinaire de forte taille. Cet oiseau a la faculté toute particulière d'enfler prodigicusement son jabot; c'est en aspirant l'air, et en l'y retenant, qu'il parvient à se gonfler de telle sorte, que le jabot paroît plus grand que tout le reste du corps; il lui arrive même de perdre l'équilibre en faisant ce manège: lorsqu'il prend son essor, il gonfle toujours son jabot. On trouve des Pigeons Grosse-gorge de toutes les livrées. Les plus beaux et les plus recherchés sont ceux qui se trouvent particulièrement bigarrés : au reste, ceci dépend souvent du caprice de l'amateur. Il y a cependant des variétés qui paroissent plus difficiles à obtenir : pour se les procurer, il faut une étude particulière. On m'a assuré que des gens possèdent à un si haut degré ce talent de produire et de créer pour ainsi dire des bigarrures extraordinaires dans le plumage des Pigeons, qu'il n'est guère de variété de plumage qu'ils n'obtiennent à volonté ; mais ils sont souvent obligés, pour atteindre à leur but, de croiser une infinité de variétés, afin d'arriver à celle qu'ils désirent.

\section{PIGEON TURG OU BAGADAIS.}

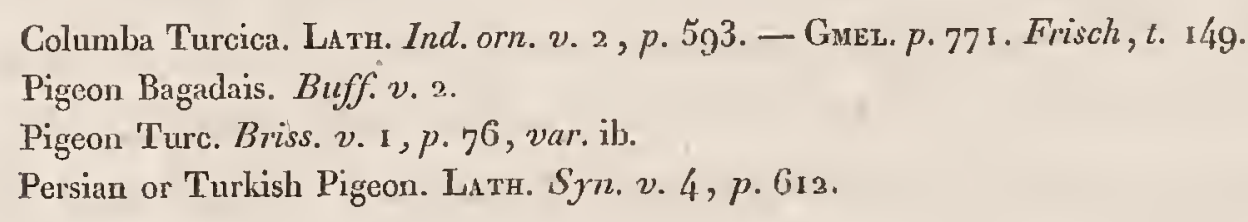

Les Pigeons qui peuvent être rapportés à cette race sont d'une assez forte taille; ils sont généralement peu féconds, et soignent, pour la plupart, très mal leurs petits : les amateurs en font peu de cas, quoique ces oiseaux soient particuliers. 
Les plus beaux individus sont cenx dont les tubercules de la base du bec et du tour des yeux ont un volume extraordinaire. Nous avons vu des mâles de cette race avoir ces caroncules si grandes, et former une masse si prodigieuse, que la pointe du bec étoit à peine visible, et que les yeux se trouvoient surchargés de ces chairs, au point de laisser à peine la faculté de la vue.

Cette race est le plus souvent de couleur sombre; on ne voit que très rarement des individus bigarrés; les tout blancs sont plus abondants. Tous ces Pigeons ont des mamelons plus ou moins volumineux autour des yeux et sur la base du bec.

\section{PIGEON NONAIN.}

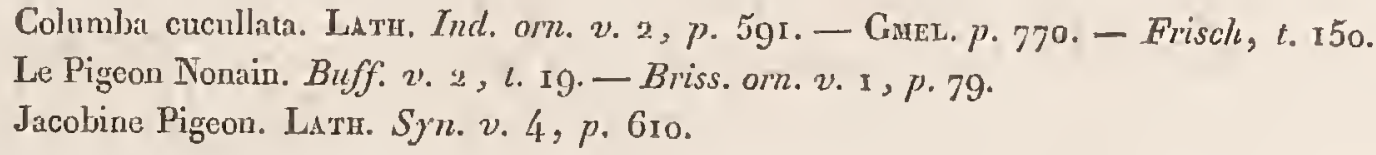

Les Pigeons de la race des Nonains ont le bec toujours plus court que les autres; les plumes de l'occiput et celles de la partie supérieure du cou paroissent placées à rebours et contournées en haut; elles forment une espèce de capuchon semblable à celui des moines. Les Pigeons Nonains sont de toutes couleurs; les plus beaux individus sont ceux qui sont noirs, mais dont les grandes pennes des ailes et la tête sont blanches: on les appelle Nonains-Maurins.

Les Pigeons Coquilles Hollandais doivent être rangés avec cette race, dont ils paroissent être originaires.

\section{PIGEON A CRAVATE.}

Columba Turbila. Lath. Ind. v. 2, p. 592. - Gued. p. 771. - Frisch, t. I 47. Pigeon à Cravate. Buff. v. 2, p. 513, t. 23. - Briss. orn. v. 1, p. 75.

Turbit Pigeon. Lath. Syn. v. 4, p. 611 .

LE Pigeon Cravate est l'un des plus petits Pigeons; il n'est guère plus gros qu'une tourterelle. Buffon dit qu'en les appariant ensemble, ils produisent des mulets ou métis. On distingue le Pigeon Cravate du Pigeon Nonain, en 
ce que le Pigeon Cravate n’a point de demi-capuchon sur la tête et sur le cou, et qu'il n'a précisément qu'un bouquet de plumes qui semblent se rebrousser sur la poitrine et sur la gorge; ce sont de très jolis Pigeons bien faits, qui ont l'air très propre; mais on ne les élève guère; ils ne s'apparient pas volontiers avec les autres Pigeons.

Cette race nous paroît avoir des caractères constants qui ne nous permettent guère de les soupçonner originaires du Biset sauvage; le bec excessivement court, gros et dur, éloignent beaucoup ces Pigeons des autres races; les difficultés que les amateurs éprouvent à les faire propager avec les diverses races provenues du Biset, jointes à leur petite taille, détruisent en quelque sorte toute supposition à l'égard de leur identité spécifique. Nous ne saurions cependant nous permettre des conjectures sur l'origine de ces Pigeons à Cravate; leur esclavage, qui remonte à des temps trop reculés, sera une entrave à toute perquisition.

Les Pigeons Gravates sont de toutes couleurs; les plus beaux et les plus estimés sont ceux qui ont le plumage blanc, avec des mantcaux noirs ou roux; on en voit aussi de tout noirs et de tout roux : ceux qui ont la cravate d'une couleur tranchée sont fort estimés des amateurs.

\section{PIGEON PAON.}

Columba Laticauda. LAтн. Ind. orn. v. 2, p. 5ig. - GmeL. p. 770. - Frisch, t. 15 ז. Le Pigreon Paon. Buff. v. 2, p.5r⿺, t. 22.-Briss. orn. v. 1, p. 80.

Broad and narrow-tailed Shaker Pigeon. Latri. Syn. v. 4, p. 611 .

Le Pigeon Paon est ainsi nommé parcequ'il a la faculté de redresser et d'étaler sa queue à peu près de la même manière que le Paon relève et épanouit ses plumes dorsales. On pourroit aussi appeler cette race Pigeons Dindons, leurs plumes caudales étant aussi placées sur un nerf érecteur capable de s'allonger et de se rétrécir à volonté : lorsque ces Pigeons redressent leur queue, ils la poussent en avant; comme ils retirent en même temps la tête en arrière, elle touche la queue; et quand l'oiseau veut regarder derrière lui, il passe la tête entre l'intervalle des deux plans qui la composent. Ils tremblent d'ordinaire pendant tout le temps de celte opération, et leur corps paroît alors agité par la contraction violente dẹs muscles. 
C'est d'ordinaire lorsqu'ils sont en amour qu'ils étalent ainsi leur queue; mais ils se parent aussi dans d'autres temps.

Ces Pigeons ne sont pas recherchés des amateurs; ils ne quittent guère les alentours de leur volière; apparemment que la crainte de se voir emportés par le vent, qui, en donnant avec force dans leur large queue, les démonteroit infailliblement, est cause qu'ils ne se risquent pas très loin de leur domicile et n'entreprennent point de longues courses. Au reste, ces Pigeons, qui par eux-mêmes ne peuvent faire de longs voyages, ont été transportés fort loin par les hommes; peut-être même ne sont-ils pas originaires de nos climats, car plusieurs doutes s'opposent à leur identité spécifique avec le Biset sauvage. Des caractères marquants, tel que le nombre de plumes à.la queue, ne nous permettent pas de considérer le Biset sauvage comme le type des Pigeons Paons.

Les Pigeons Paons sont pourvus d'un nombre considérable de pennes caudales : la plupart des espèces de Pigeons indigènes et exotiques n'ont généralement que douze plumes à la quene; la majeure partie des Pigeons Paons ont trente plumes, et cela variant du plus au moins, les plus recherchés des amateurs ont trente-deux et trente-quatre pennes à la queue; ils sont cependant assez rares.

Les Pigeons Trembleurs, et ceux qui relèvent seulement en partie leur queue, sont originaires de cette race.

\section{PIGEON CULBUTANT.}

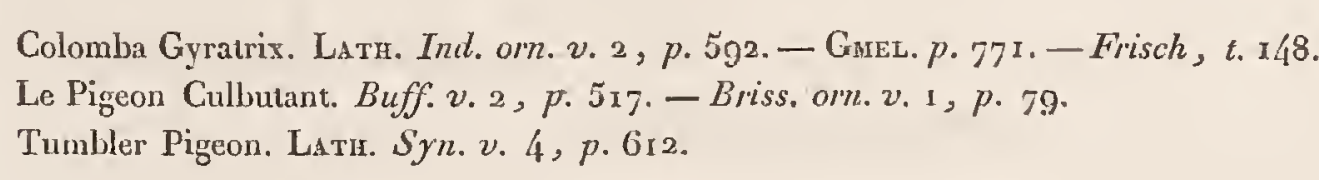

LE Pigeon Culbutant est une des plus petites espèces. Il semble, dit Buffon, que tous ses mouvements supposent des vertiges qui peuvent être attribués à la captivité; il vole très vite, et s'élève le plus haut de tous; ses mouvements sont très précipités et fort irréguliers; il imite en quelque façon les gestes et les sauts des danseurs de corde et des voltigeurs; il se tourne sur lui-même comme une balle qu'on jette en l'air. On se sert de ces Pigeons pour attirer les autres; et les contorsions qu'ils font en l'air les rendent assez 
curieux; on en élève un grand nombre: ils propagent très bien et abondamment.

Les Pigeons Culbutants, de même que les Pigeons Tournants, qui ne forment qu'unc subdivision dans cette race, ont les ailes très longues; quelquefois elles dépassent la queue. Ces Pigeons tirent leur origine du. Biset; mais on doil considérer la race comme viciéc el dégradée par la main de l'homme.

Plusieurs autres races mitoyennes, un plus grand nombre encore de variétés accidentelles, se trouvent dans cette tourbe immense des Pigeons de volière. Les décrire, les connoittre toutes, seroit un ouvrage aussi ennuyeux pour l'auteur qu'il seroit de peu d'utilité pour l'étude de la nature; ce n'est aussi qu'arec quclque dégoùt que nous nous cn occupons : on ne peut guère s'occuper de ces races dégradées que d'après de simples suppositions, que l'on hasarde pour la plupart. Les soins de l'homme, qui, cn s'étendant sur la culture et l'éducation des oiseaux, ont totalement dénaturé leur penchant à la liberté, sont les causes premières que ceux-ci ne nous offrent plus que l'image d'un esclavage très ancien, dont nous remarquons toutes les traces dans l'altération de leur's qualités intéricures. Accoutumés à vivre par les soins que nous lcur accordons, ils ne quittent jamais les alentours de leur volière, où ils se laisseroient plutôt mourir d'inanition que dc chercher eux-mêmes leur subsistance. Habitués à recevoir leur nourriture, on à la trouver toujours préparée dans le même licu, ils ne savcnt vivie que pour manger.

On peut donc, dit Buflon, regarder cette dernière classe, dans l'ordre des Pigeons, comme absolument domestique, captive sans retour, entièrement dépendante de l'homme. On ne peut douter qu'il ne soit l'auteur de toutes ces races, d'autant plus perfectionnées pour nous, qu'elles sont plus d.égénérćes, plus viciées pour la naturc. 


\title{
COLOMBE A CALOTTE BLANCHE, Màle.
}

\author{
PL. XIII. \\ + Columba Leucocephala. Latr. Ind. om. q'. 2, p. 5ý4. \\ - GMeL. Syst. I, p. $77^{2}$. \\ Le Pigeon de roche de la Janaïque. Briss, orn. v, 1, p. r37.-Bniffon, v. 2, p. 539 . \\ - Sonnimi, édit. de Buff. $2 \because 7, p, 2 \mathrm{x} 6$. \\ Pigeon à la couroune blanche. Seligm. samm. selt. Fogel, ข. I, t. 50. \\ Bald-pated Pigeon. Sloane Jam. p. 3o3, 261 , t. 2. \\ - Browne Jant. p. 468 \\ Whitc-cromned Pigcon. Cat. Car. v. I, t. 65.-LAтн. Syz. ». 4, p. 616 , sp. 5
}

Bufron considère encore la Colombe de cet article comme ne faisant ayec le Biset sauvage qu'une mème espèce; les formes générales et les couleurs principales de ces deux Colombes sont effectivement, à peu de chose près, semblables; l'habitude qu'elles ont en commun de choisir les crevasses et les trous des rochers pour y nicher paroît légitimer cette supposition de Buffon, sur-tout quand on considère que cet auteur n'établissoit des rapprochements que sur les descriptions des divers naturalistes et sur les observations de quelques voyageurs.

Il en eût été bien différemment, si le célèbre naturaliste cité eût vécu de nos jours, dans ces temps où les découvertes nouvelles fournissent à l'étude de la nature des renseignements plus exacts sur les diverses espèces déjà décrites, et placent sous les yeux de l'observateur les individus qu'on ne connoissoit du temps de Buffon que par les descriptions imparfaites des voyageurs, souvent peu versés dans l'étnde de la nature: en réfutant donc les idées de ce grand génie, on doit toujours considérer qu'à l'époque où il débrouilloit le cahos répandu sur l'histoire naturelle cette science ne se trouvoit encore qu'à son berceau.

Nous avons vu que l'espèce de Pigeon à laquelle nous donnons le nom de Colombe à calotte blanche habite et niche dans les trous des rochers. Sa nourriture principale sont les baies du bois doux. Ces oiseaux sont, à certains temps de l'année, un gibier très recherché et de bon goût, principalement quand ils se nourrissent eu abondance de ces baies douces. Il y a 
cependant des époques où la saveur de leur chair est amère: probablement se nourrissent-ils alors d'un autre fruit qui contribue á leur donner ce gontt.

Les Colombes à calotte blanche se trouvent à la Jamaïque, à SaintDomingue, aux îles de Bahama et à celle de Porto-Rico. Maugé a rapporté plusieurs individus de l'espèce tués et préparés par lui dans cette dernière île, où ils sont répandus en grande abondance.

La longueur de cet oiseau, depuis le bout du bec à l'extrémité de la queue, est de treize pouces; le bec a un pouce; les ailes, lorsqu'elles sont pliées, s’étendent jusqu'aux déux tiers de la longueur de la queue.

Dans les individus adultes, toute la partie supérieurc de la tête est couverte de belles plumes blanches, qui forment une espèce de calotte; l'occiput est ceint d'une couleur pourprée changeant en violet; la partie postéricure du cou est revêtue de plumes couchées de manière à imiter des ćcailles; elles sont toutes d'un beau vert à reflets métalliques, et leur bord extérieur est terminé de noir : par leurs formes, ces plumes ressemblent à celles qui décorent le dos du Paon. Tout le reste du corps est d'un bleu de quelques teintes plus'claires que la couleur d'ardoise; les grandes et les moyennes pennes des ailes, ainsi que celles de la queue, ont une teinte plus rembrunie. Los yeux sont entourés d'une peau blanchâtre, ct leur iris est jaune, le bec rouge à sa base, et blanc vers le bout. Lés pieds sont rouges et les ongles gris.

Des individus de cette espèce sont dans mon cabinet, dans celui de M. Raye de Breukelerwaert, à Amsterdam, au Muséum de Paris. Nous en avons vu encore dans plusieurs autres cabinets. Celui de M. Dufresne a servi de modèle. 


\title{
COLOMBE RAMIRET, Maile.
}

\author{
PL. XIV. \\ + Columba speciosa. Latr. Ind. orn. v. 2, p. 6o5, sp. 40 \\ - Guel. Syst. I, p. 783. \\ Le Ramiret, ou Pigeou Ramiret de Cayenne. Buff. v. 2, p. 54r. pl. enl. 213. \\ Scallop-Nccked Pigeon. Latr. Syn. v. 4, p.643, sp. 3g.
}

A larticle de la Colombe Colonibin, nous avons dit que le nom de Ramiret: (petit Ramier) auroit été une dénomination plus convenable et plus analogue à cette espèce, propre à nos climats; mais nous avons fait observer en mềme temps que ce nom de Ramiret ayant déjà été donné par Buffon au Pigeon liguré dans notre planche XIV, il s'opposoit des difficultés pour transférer cette dénomination à l'espèce du Colombin. La crainte qu'un pareil changement ne puisse donner occasion à quelque erreur nous a déterminés à suivre, pour la synonymie, les auteurs qui nous ont précédés.

Buffon et Latham sont les seuls auteurs qui désignent cette espèce, encore la décrivent-ils très succinctement. Le premier de ces naturalistes en a donné une figure passablement exacte dans les planches enluminées.

Le Ramiret mâle mesure en totalité treize póuces deux lignes, la femelle n'en a que douze et demi; les ailes dépassent de très peu l'origine de la queue; celle-ci est courte, presque carrée, et conposée de douze pennes.

Une espèce de capuchon, d'un brun violacé, engage toute la tête jusque derrière les orifices des oreilles; le cou et la poitrine sont couverts de plumes qui, par leur distribution, font ressembler ces parties à un tissu maillé; toutes ces plumes ont, vers leur centre, des espèces de croissants plus ou moins blancs. Cette couleur est entourée d'un large bord, brillant, sur les plumes des parties supérieures, d'un beau pourpre changeant en violet, coloré, sur celles des parties inférieures, de vert foncé à reflets violacés. Le manteau, le dos et les petites couvertures des ailes sont revêtus de plumes d'un beau roux pourpré; les grandes pennes des ailes, ainsi que les pennes secondaires sont d'un cendré brun. La queue est d'un noir brunissant. Le ventre, l'abdomen et les couvertures inférieures de la queue sont blanchâtres, mais les 
flancs ont des teintes violacées; toutes leș plumes de ces dernières parties sont frangées de violet. Les pieds sont rouges, les ongles bruns, ct le bec, rougeâtre à sa base, prend une teinte de jaune blanchâtre vers le bout des deux mandibules.

La femelle, dont les couleurs sont en général plus ternes, n'a pas le dos et les ailes d'un brun violacé comme chez le mâle; ces parties sont d'un gris terreux; les pennes alaires et caudales sont d'un noir brun grisonnant; les plumes du cou et de la poitrine ne brillent pas de ces reflets éclatants qui sont les apanages du mâle. Toutes les parties inférieures de la femelle sont d'un blanc sale, nuancé d'une légère teinte violacée.

Les Ramirets habitent à la Guiane française; on les a rapportés de Cayenne, où l'espèce paroìt abondante. Nous ignorons absol ument la manièrede vivre et le genre de nourriture du Ramiret.

Le mâle et là femelle sont dans ma collection. Le Ramiret qui a servi de modèle appartient à M. Dufresne, du jardin des Plantes. 


\title{
COLOMBE A NUQUE ÉCAILLÉE.
}

\author{
$P_{L .} X V$
}

+ Columba Portoricensis. Mihi

Nous ne trouvons dans aucun ouvrage d'histoire naturelle, ni dans les relations de voyages, des détails relativement à la Colombe de cet article. Nous la considérons, pour cette raison, comme une espèce qu'on peut appeler nouvelle.

Maugé est le premier qui a rapporté de Porto-Rico des individus de la Colombe à nuque écaillée. Il est probable que ce zélé naturaliste n’a pas manqué d'étudier les mours ct la manière de vivre de cet oiseau; mais comme il ne nous reste, des nombreux travaux de ce voyageur, aucun écrit, ni même des notes (au moins qui nous soient connues), nous nous trouvons dans la nécessité de gạder le silence sur la partie descriptive la plus intéressante à donner touchant les espèces nouvelles que nous faisons connoître.

Cette Colombe est une de ces espèces dont le tour des yeux a une nudité plus ou moins considérable. Nous formons de ces Colombes à joues dénuées de plumes une petite section, où nous désirons placer en série naturelle toutes les espèces qui ont ce caractère : cette section sera terminée par la Colombe Oricou. Nous n'avons cependant pas jugé le caractère de nudité aux jones assez important pour former de ces Pigeons une subdivision dans la famille des Colombes.

La Colombe à nuque écaillée mesure, depuis le bout du bec à l'extrémité de la queue, quatorze pouces et demi; le bec a treize lignes; les tarses sont robustes, et lcs doigts, garnis de rebords charnus, forment une plante de pied épatée. La queue, composée de douze pennes, est longue et carrée; l'extrémité des ailes aboutit ver's le milieu de la longucur des pennes caudales;

Un bean gris-bleu foncé est répandu sur toutes les plumes du dos, sur les petites et les moyennes couvertures alaires, et sur les parties inférieures. Un pourpre vineux colore le devant du cou et la poitrinc; des teintes de cette 


\section{HISTOIRE}

dernière couleur sont répandues sur la tête. La nuque est richement décorée par des plumes couchées les unes sur les autres, et disposées de manière à imiter des écailles : ces plumes, suivant les incidents de la lumière, jettent des reflets de violet, de pourpre et de vert; elles sont toutes terminées de couleur mordoré mat: la réunion d'une quantité de ces plumes forme, audessous de l'occiput, un espace longitudinal mordoré qui imite le velours. Les scapulaires sont d'un gris terreux; les grandes pennes des ailes et celles de la queue sont de couleur d'ardoise; les pieds sont rouges, les ongles jaunes, la base du bec rougeâtre, l'iris d'un beau rouge, et l'espace nu où l'œil se trouve placé est semé de petites papilles d'un rouge incarnat.

Nous n'avons vu d'autres individus de la Colombe à nuque écaillée que ceux rapportés par Maugé : ils sont au Muséum de Paris, chez M. Dufresne, et dans ma collection. Celui de M. Dufresne a servi de modèle. 


\title{
COLOMBE ROUSSARD, Maile.
}

\author{
$P_{L .} X V I$.
}

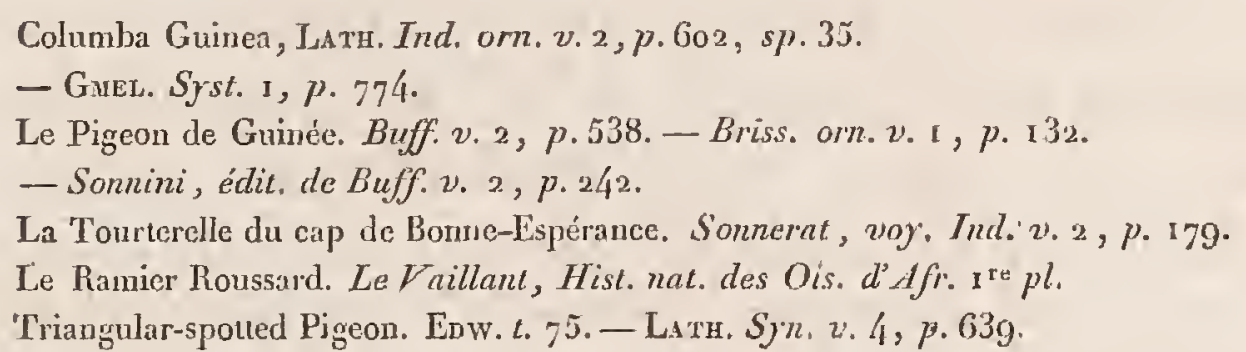

D'a près Le Vaillant, qui a observé cette Colombe dans la partie de l'Afrique qu'il a visitée, nous donnons à l'espèce le nom de Roussard, qui nous paroitt plus convenable que celui de Pigeon de Guinée. Il en est encore de même de la dénomination de Pigeon à taches triangulaires, par laquelle Edwards le désigne. Ce dernier joint à la description de son Pigeon une gravure très recommandable pour son exactitude.

Buffon ne manque pas de trouver aussi à cette espèce des traits de ressemblance avec les Pigeons de nos climats; mais cette fois-ci il établit des comparaisons avec le Ramier. Le Biset, quoique bien plus assorti à notre Roussard, pour ce qui regarde la taille et les formes totales, n'est pas considéré par ce naturaliste comme le type de ce Pigeon.

Comme cette monographie est destinée à répandre une connoissance plus parfaite sur les espèces connues, nous désirons aussi, en relevant les erreurs commises par les naturalistes qui nous ont précédés, donner des preuves non équivoques de celles-ci. En comparant donc nos figures du Ramier vulgaire et du Roussard, et en confrontant notre texte avec celui de Buffon, il ne sera pas difficile de se convaincre que l'espèce désignée sous la dénomination de Roussard n'est pas une de ces variétés produites par l'influence des climats. Au reste, voici le sentiment de Buffon.

“ Le Pigeon de Guinée, dit cet auteur, étant à demi patu, et à peu près " de la grandeur du Ramier d'Europe, nous le rapporterons à cette espèce 
" conme simple variété, quoiqựil en diffère par les couleur's, étant mar" qué de taches triangulaires sur les ailes, et qu^il ait tout le dessous “ du corps gris, les yeux entourés d'une peau rouge et nue, l'iris d'un beau “ jaune, le bec ṇoirâtre; mais toutes ces différences de couleur dans le " plumage, le bec et les yeux, peuvent être regardées comme des variétés “ produites par le climat. »

Si les différences de couleur dans le plumage, le bec et les yeux, n'ont pas paru d'une conséquence majeure, et que, pour former du Roussard une espèce distincte de celle du Ramier, il soit besoin d'autres preuves de dissemblance, on pourroit encore ajouter que le Roussard est plus petit de beaucoup; qu'il a les ailes plus longues en proportion de sa taille; qu'il a une nudité considérable à l'entour des yeux; que toutes les plumes de la poitrine et du cou sont autrement conformées; enfin qu’il n'est pas même modelé sur les formes de notre Ramier indigène.

M. Le Vaillant, qui a observé le Roussard dans son pays natal, pourra nous donner des renseignements exacts sur les manières de vivre de cette espèce. Nous sommes au reste persuadés que ee naturaliste est de notre avis relativement aux dissemblances que nous trouvons entre l'espèee du Ramier et celle du Roussard. M. Le Vaillant ne nous ayant communiqué qu'une note peu eirconstanciée relativement à l'espèce de cet article, nous renvoyons nos lecteurs, pour ce qui peut coneerner plus amplement les mœurs du Roussard, à la partie descriptive des Pigeons africains, qui doit paroître incessamment dans l'Histoire naturelle des Oiseaux d'Afrique.

Le Roussard habite dans toute l'étendue de la partie méridionale de l'Afrique, depuis le eap de Bonne-Espérance jusqu’à la rivière de la Goa: on le trouve aussi sur les côtes de Gruinée et sur celles d'Angole. Mon ami Le Vaillant m'a dit que cette espèee niche indifféremment, et suivant l'oeeasion, ou sur la sommité des arbres, ou bien dans quelques trous de rochers, oủ la femelle pond deux oeufs blancs. Le Roussard va souvent en plaine, et fréquente par bandes innombrables les champs cultivés. Il fait sa principale nourriture de grains. Dans la colonie du Cap, on désigne l'espèce par le nom de Boseh-Duyf (Pigeon des bois).

La longueur totale du Roussard, prise de la pointe du bec à l'extrémité de la queue, est de douze pouces et demi. Le bee a un pouce; il est conformé comme celui de nos Pigeons vulgaires; les yeux se trouvent plaeés dans un espace dénuć de plumes; la peau lisse qui revêt cet espace est d'un rouge vif; l'extrémité des ailes, lorsqu'elles sont fermées, aboutissent 
environ aux deux tiers de la longueur de la queue : celle-ci est composée de douze pennes.

Toute la tête, la gorge, le ventre, l'abdomen, le croupion et les couvertures du dessus et du dessous de la queue sont d'un gris-bleu clair. Le haut du dos, les scapulaires et toutes les couvertures des ailes sont. d'un rouxcanelle pourpré. Une tache blanche, de forme triangulaire, termine le centre de chacune de ces plumes de recouvrement: les grandes et les moyennes pennes alaires sont d'un brun cendré; le bord antérieur des barbes se trouve liseré d'une couleur plus claire; les pennes caudales sont grises depuis leur origine, et terminées de noir.

Toutes les plumes du cou et celles de la poitrine sont échancrées vers le bout en forme de fer de lance; cette échancrure paroít être occasionnée par l'interruption de la baguette et le manque de barbes centrales adhérentes à celle-ci, tandis que les barbes latérales s'allongent considérablement, et sont terminées de chaque côté en pointe; toutes ces pointes bifourchues sont rousses à leur origine, et nuancées, sur leurs pointes latérales, de vert métallique, ce qui leur donne des reflets dorés, suivant les incidents de la lumière. Nous figurons séparément une de ces plumes sur la planche qui représente le Roussard mâle.

La femelle ne diffère du mâle que par des couleurs moins vives; les taches triangulaires sur les ailes sont beaucoup plus petites, et moins blanches que dans le mâle. La partie nue qui entoure l'œil paroît aussi moins grande chez la femelle.

Le bec est noirâtre, et la membrane qui recouvre les narines cendrée; les pieds sont d'un rouge pâle, les ongles bruns, et l'iris est d'une belle couleur orangée.

Je possède un de ces individus; celui du Muséum de Paris a servi de modèle. 


\title{
COLOMBE FOUNINGO:
}

\author{
PL. XVII.
}

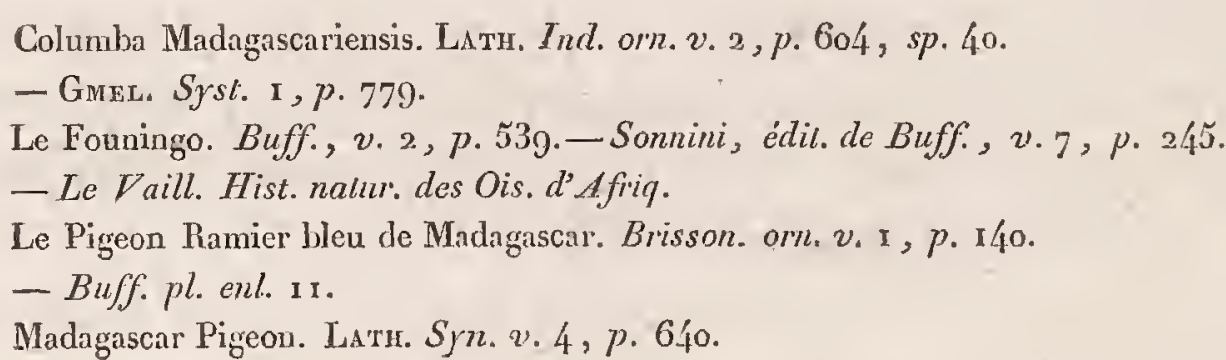

Le Founingo est encore de la classe des Colombes qui ont un caractère marquant par la nudité plus ou moins considérable dans laquelle les yeux se trouvent placẻs. Ce caractère semble être échappé à Buffon, lorsque cet anteur a pu établir des ressemblances entre le Founingo Menérabou de cet article et le Fonningo Maitsou, figuré dans notre planche troisième de la division des Colombars.

Buffon, en parlant de ces Pigeons, dit qu'il n'y a entre eux d'autres différences que celle de la couleur verte à la couleur bleue, et que pentêtre ils ne diffèrent effectivement que de sexe ou d'âge. Il seroit inutile de réfuter cette supposition à un naturaliste moins célèbre que Buffon; mais c'est par rapport à la juste renommée dont jouit ce savant que nous ne devons passer sous silence aucune de ses erreurs.

La Colombe Founingo diffère du Colombar Maitsou par la taille, par les formes totales, par les couleurs, la construction du bec et des pieds, et par l'espace dénué de plumes sur les joues. Le Founingo est d'un beau bleu violacé sur tout le plumage; le Colombar Maitsou a diverses teintes de vert sur sa livrée. Le premier a le bec très long, mince et flexible, les pieds et les doigts conformés comme dans tous nos Pigeons vulgaires. Le Maitsou a le bec épais, très renflé du bout, et corné, la base des deux mandibules engagée dans une peau nue, les pieds courts, et la plante de céux-ci épatée; il n'a point de nudité apparente à l'entour des yeux; tandis que le Founingo a un grand espace dénué de plumes, au centre duquel les yeux se trouvent placés. En comparant nos planches enluminées, qui représentent 
ces oiseaux de grandeur. naturelle, on ne manquera pas de s'apercevoir de toutes les différences que nous vénons de présenter.

Le Founingo ne se trouve pas exclusivement à Mádagascar, où il paroît cependant nicher; mais il est probable qu'après le temps des pontes il émigre de cette île, et vient peupler et embellir par sa présence les romantiques forêts de l'Afrique méridionale. Le Vaillant nous a dit avoir trouvé le Founingo dans cette partie du monde.

Le Founingo a dix pouces six lignes, mesure prise depuis le bout du bec à l'extrémité de la queue; celle-ci est longue de trois pouces trois lignes; son bec à onze lignes; ses ailes, lorsqu'elles sont pliées, s'étendent presque jusqu'au bout de la queue.

Cette belle espèce a la majeure partie du plumage d'un bleu foncé, nuancé de violet, et brillant. Les plumes du cou et de la poitrine sont longues et étroites; ce bleu est plus terne sur ces parties, et semble couvert d'une poussière grisâtre; les pennes de la queue et leurs couvertures inférieures sont d'un pourpre violacé très éclatant. Les yeux sont placés au centre d'une peau nue, colorée du plus bel incarnat. Les pieds, qui sont couverts de plumes presque jusqu'à l'origine des doigts, sont rouges; le bec est aussi de cette couleur, mais la pointe est noirâtre; les ongles sont noirs.

Le Founingo a été rapporté de Madagascar. 
COLOMBE JOUNUD, Mailc.

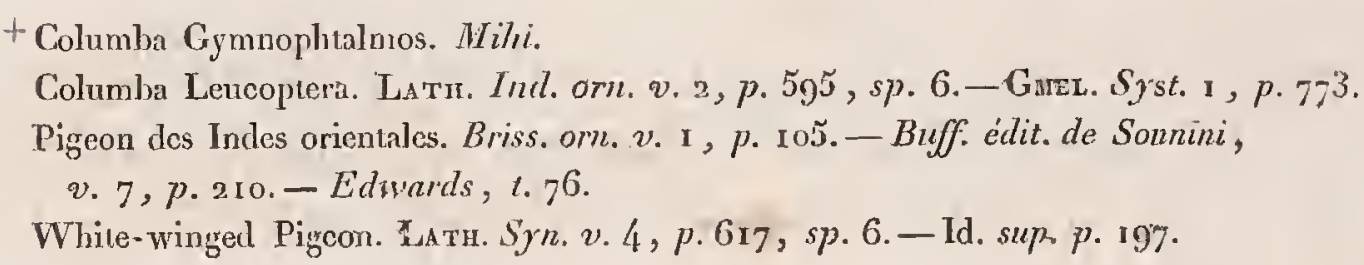

Sr l'on s'en rapportoit à ce qui a été dit de cette Colombe par les auteurs que nous venons de désigner dans notre synonymie, on auroit de la difficulté à reconnoitre l'espèce. Brisson, Edwards et Latham lui donnent la taille d'une Tourterelle; ils fixent sa longueur totale à huit ou neuf pouces, tandis qu'effectivement ellc approche bien plus de la taille du Colombin, étant du reste modelée sur les formes des Pigeons proprement dits. La planche d'Edwards qui représente notre Colombe Jounud est assez exacte: il paroit cependant que l'individu qu'il a figuré est une femelle, la nudité à l'entour des yeux se trouvant peu considérable.

La Colombe Jounud mesure, depuis le bout du bec à l'extrémité des pennes caudales, treize pouces; le bec a onze lignes; il est fortement renflé dụ bout; le tour des yeux, ainsi qu'un espace considérable des joues, est dénué de plumes; la peau nue de ces parties est semée de papilles charnues, dont la couleur est d'un beau bleu foncé, foiblement violacé; la queue est composée de douze pennes.

La tête, le haut du cou, la gorge et la poitrine sont d'une belle teinte vineuse; cette couleur est aussi répandue sur le ventre, et se nuance plus foiblement sur les cuisses; la nuque et les côtés du bas du cou se nuancent en bleu clair et en pourpre tendre. Deux zones ou demi-lunes se dessinent sur l'extrémité des plumes de ces parties; la zone supérieure est blanche, et l'inférieure ou celle qui termine chaque plume est bleuâtre, avec de légers reflets violacés. Au-dessous des orifices des oreilles se trouve unelongue tache noirâtre, placée transversalement, composée de plumes très courtes, de façon qu'elle ne paroît que lorsque l'animal étend un peu le cou. Le haut du dos, 
les scapulaires, les petites et les grandes couvertures des ailes sont d'un grisbrun terne; il y a du blanc sur le bord extérieur des ailes; les grandes et les moyennes pennes de celles-ci sont noires, et toutes sont bordées de gris à leurs barbes extérieures; le dos et le croupion sont d'un gris-bleu clair; la queue est grise en dessus, et blanchâtre en dessous; l'abdomen et les couvertures inférieures de la queue sont d'un blanc pur; le bec et l'iris sont rougeâtres, les pieds et les doigts d'un rouge rembruni.

La femelle est plus petite que son mâle; elle a les couleurs du plumage d'une teinte moins vive, et la nudité qui entoure les yeux n'est pas, à beaucoup près, si considérable ni si vivement colorée que dans le mâle.

Nous ignorons jusqu’à présent la manière de vivre et les mours du Jounud. Edwards nous apprend qu'il relève souvent et subitement la queue.

Le Jounud mâle qui.nous a servi de modèle se voyoit autrefois dans la collection du prince d'Orange; maintenant il appartient au Muséum de Paris. Une femelle fait partie du cabinet de M. Raye de Breukelerwaert, à Amsterdam. 


\title{
COLOMBE-HÉRISSÉE, Màle.
}

\author{
$p_{\text {L. }} X I X$.
}

Columba Francix. LAтr. Ind. orn. v. 2, p. 604, sp. 42 .

- Gmex. Syst. I, p. 779.

Le Pigeon-Hollandais. Sonnerat, voy. Ind. v. $2, p .175, t$. 10r.

Le Ramier-Hérissé. Le Vaill. Hist. nat. des Ois. d'Afr.v. 6, pl.

Hackled Pigeon. LAтH. Syn. v. 4, p. 64r, sp. 36 .

CE magnifique Pigeon se distingue de toutes les autrés espèces de la famille colombace par la forme singulière des plumes du cou. La nature lui a prodigué ses riches dons, en décorant de couleurs fraîches et brillantes. l'élégante livrée de cet oiseau. Des plumes étroites et lustrées ornent sa tête; il porte sur le cou une large touffe composée de longues plumes qui se dessinent élégamment sur le haut du dos, où elles paroissent former une espèce de manteau nuancé de tcintes d'un blanc argentin. Cette couleur opère un contraste admirable avec les diverses teintes de bleu foncé répandues sur les autres parties du corps: lorsque les doux feux de l'amour: viennent, au renouvellement de la saison, aiguillonner le désir des jouissances, ou bien lorsqu'un objet imprévu inspire la crainte à cette Colombe, elle s'embellit encore en redressant et en faisant revenir par-dessus sa tête toutes les longues plumes dont le cou est décoré.

Sonnerat est le premier voyageur qui a fait connoître l'espèce; il dit qu'elle se trouve à l'ille de France. On nous a assuré que la Colombe-Hérissée habite aussi à Madagascar; et ce qui paroît le prouver, c'est que Le Vaillant a rencontré de ces Pigeons par troupes nombreuses dans ses voyages en Afrique.

Toutes les plumés de la tête, du cou et de la poitrine, sont longues, étroites, et se terminent en pointe. Leur forme est extraordinaire; l'extrémité est dure, cartilagineuse et polie; elle paroît former un prolongement aplati de la baguette; sa substance ressemble aux appendices lustrés qui terminent quelques plumes alaires du Jaseur de Bohême, ainsi qu'à ces larges lames cartilagineuses dont est pourvue une espèce de coq sauvage 
des Indes. Nous aurons occasion, dans la suite de cet ouvrage, de faire connoître plus particulièrement cette intéressante espèce.

La Colombe-Hérissée mesure en totalité de douze à treize pouces. Sonnerat s'abuse en disant que sa taille est plus forte que celle du Ramier vulgaire. Latham, en copiant le voyageur cité, commet la même erreur : le bec de notre oiseau avoit un pouce depuis la pointe jusqu'aux angles des deux mandibules, qui se trouvent engagées dans une peau nue; cet espace dénué de plumes se prolonge sur les joues, et aboutit derrière l'orifice des oreilles: celles-ci sont seulement recouvertes de quelques poils; les ailes atteignent vers le milieu de la queue, dont toutes les pennes sont d'égale longueur; le tarse est couvert de plumes jusque vers l'origine des doigts. La tête, le cou et la poitrine sont d'un beau gris blanchâtre; le reste du corps, les ailes et le dessous de la queue sont d'un beau bleu-violet foncé; les grandes pennes alaires n'ont de cette couleur que sur leurs barbes extérieures, les barbes intérieures étant noirâtres. La queue, en dessus, est colorée d'un rouge cramoisi vif; les baguettes des pennes du centre sont d'un bleu foncé, mais celles des plumes latérales sont de la même couleur que leurs barbes; la partie nue des joues est couverte d'une peau lisse, colorée d'un rouge incarnat; les yeux, placés au centre de cette nudité, sont rouges, de même que la base du bec, dont la pointe est jaunâtre; les pieds et les ongles sont d'un noir bleuâtre.

Deux individus de cette espèce sont au Muséum de Paris; ce sont les mêmes envoyés par Sonnerat pour le cabinet du roi : l'état de dégradation oì se trouvent ces oiseaux prouve évidemment contre l'opération destructive des fumigations qu'on employoit autrefois pour garantir les oiseaux des insectes rongeurs; procédé au reste bien plus dangereux et plus nuisible aux collections d'histoire naturelle que les légions voraces des insectes destructeurs : les soins qu'on prend aujourd'hui à la conservation de ce riche dépôt font honneur à l'administration.

M. Le Vaillant nous a dit posséder un individu de la Colombe-Hérissée, tué par lui dans ses voyages en Afrique. 


\title{
COLOMBE ROUGE-CAP, Màle.
}

\author{
PL. $X X$.
}

\author{
Colımba Rubricapilla. LAтн. Ind.orn. ข. 2, p. $5_{99}, s p .19$. \\ - GMed. Syst. I, p. 784. \\ Le Pigeon Violet à tête rouge d'Antigue. Sonnerat, voy. Nouv. Guin., $p .112, t .67$ \\ - Sonnini, édit. de Buff. v. 7, p. 26r. \\ Red-Crowned Pigeon. Latr. Syn. v. 4, p.628, sp. 17.
}

$\mathbf{L}_{\mathrm{A}}$ faculté de relever et de hérisser en quelque sorte les plumes de la tête et du cou est aussi une habitude propre à l'espèce de Colombe que nous nommons Rouge-Cap, dénomination bien plus simple, que nous préférons à celle de Pigeon Violet à tếte rouge, par laquelle Sonnerat et Sonnini désignent cet: oiseau.

On peut ranger ce Pigeon dans la classe des oiseaux qui se trouvent ornés d'une manière extraordinaire par des plumes de parade capables d'érection: celles-ci, quoique ne se trouvant pas disposées sur un nerf érecteur; comme dans presque tous les oiseaux pavaneurs, ont néanmoins la faculté de se redresser, par l'attitude que ce Pigeon sait donner à son corps; l'oiseau, en baissant la tête et en la retirant en mème temps sur la poitrine, raccourcit considérablement le cou, ce qui oblige toutes les plumes à se relever; celles-ci, très longues et effilées, lui forment comme une large perruque. Le Rouge-Cap est encore remarquable par des carnosités placées sur la mandibule supérieure du bec; sa base est engagée dans une peau nue qui forme entre cette partie et l'oeil plusieurs tubercules; dans les plis de ces carnosités naissent de petites plumes très courtes.

Les plumes du cou ont aussi une forme particulière : la longueur totale de celles placées sur la nuque est de quinze lignes; leur baguette cependant n'a que six lignes; le prolongement de ces plumes est occasionné par les barbes latérales, qui dépassent les baguettes de plusieurs pouces, se terminent en pointe aiguë, et forment un angle ouvert; ces barbes sont entièrement désunies entre elles, et soyeuses : les plumes du devant du cou sont à peu près 
de même nature, mais la partie excédante des barbes latérales n'est pas si allongée. Nous figurons une de ces plumes sur notre planche.

Le Rouge-Cap, mesuré depuis la pointe du bec jusqu'à l'extrémité de la queue, a environ dix pouces. Cette dernière est courte, et les pennes foiblement étagées; les ailes pliées atteignent à leur extrémité ; des plumes d'un beau noir bleuâtre, à nuances violettes, revêtent le ventre, le dos, les ailes et la queue; sa coulcur paroit comme saupoudrée de grisâtre sur les barbes des pennes caudales et alaires : des plumes fines, à barbes déliées, disposées en calotte, et d'un rouge très éclatant, recouvrent le sommet de la tête; un beau gris nuancé de bleuàtre colore le cou, le haut du dos et la poitrine; cette couleur prend des teintes claires, et devient blanchâtre en approchant du corps. Lorsque l'oiseau ne relève point les plumes de ces parties, il semble revêtu d'un camail touffu. Les pieds, dont le tarse est à moitié recouvert de plumes, sont, ainsi que les doigts et les ongles, d'un gris cendré; la base du bec est noiritre, mais la pointe est jaunâtre; les carnosités sont colorées d'un beau rouge incarnat; un cercle gris-clair entoure l'iris; il est suivi d'un autre cercle d'un beau rouge.

Ces Pigeons habitent aux îles Panay. Sonnerat les a trouvés à Antigue. Plusicurs individus ont été rapportés vivants en Hollande, où ils ont vécu long-temps dans la ménagerie de M. Grver's, à Rotterdam.

Un des deux individus de l'espèce du Rouge-Cap, déposés dans les galeries du Muséum de Paris, nous a servi de modèle. Un mâle fait partie de mon cabinet. Il n'auroit pas été inutile de représenter ce Pigeon dans l'état de parure; mais, ne voulant pas augmenter le nombre déjà considérable des planches, nous avons cru devoir nous abstenir de donner celle-ci. 


\title{
COLOMBE ORICOU, Mâle.
}

\author{
P $t . X X I$.
}

Columba Auricularis. Milıi

$S_{1}$ la nature a décoré et embelli à nos yeux une multitude de ses productions, en leur accordant les apanages du luxe et les ornements recherchés d'une parure élégante et gracieuse, elle semble aussi avoir pris plaisir à affubler grotesquement quelques uns d'entre les êtres que sa main a formés. Nous ne saurions souvent nous rendre raison des fins qu'elle s'est proposées en donnant à quelques oiseaux des appendices plus ou moins extraordinaires; ce n'est qu'en étudiant les moeurs et les diverses habitudes de ces espèces que nous pouvons espérer de parvenir à la connoissance des voies sages et bonnes qui l'ont guidée dans l'œuvre de la création. En nous appliquant à connoitre la manière de vivre des animaux, nos lumières se développeront insensiblement sur l'état de leur organisation, ainsi que sur les causes qui y ont. souvent donné lieu : ce n'est qu'en nous attachant de préférence à observer la nature animée, et en établissant les rapports qu’ont entre eux les divers êtres, que nous viendrons à bout de simplifier el d'orner en même temps de plus de charmes cette science, malheureusement trop encombrée par les idées philosophiques de savants qui s’imaginent avoir découvert du centre de leur bibliothèque les règles immuables suivant lesquelles ils prétendent dicter des lois à la nature.

Il est peu d'oiseaux qui se trouvent aussi singulièrement décorés que l'est la Colombe de cet article. Des prolongements charnus sont adhérents à la peau nue qui recouvre le devant du cou; ils forment trois barbillons à-peu-près semblables à celui que porte le Dindon ; une carnosité arrondie, de la grosseur d'une cerise, semée de tubercules, s'élève sur la base de la mandibule supérieure du bec. Ces appendices, quoique extraordinaires, ne nuisent pas à la parure de cette Colombe; elles ajoutent mème à sa beauté, principalement 
lorsque ces carnosités sont décorées de leurs teintes vives et naturelles. Une troupe de ces Pigeons doit former un coup-d'œil ravissant.

L'Oricou est à-peu-près de la taille du Pigeon vulgaire, ou Biset; sa longueur, depuis le bout du bec à l'extrémité de la queue, est de onze pouces quatre lignes; le bec a onze lignes; les pennes caudales sont d'égale longueur, et les ailes pliées atteignent jusqu'aux deux tiers de la queue.

Les joues, jusque derrière l'orifice des oreilles, sont dénuées de plumes; la peau nue se dirige sur tout le devant du cou, où elle donne naissance à trois appendices ou barbillons flottants : le premier prend son origine à la base de la mandibule inférieure du bec, et forme plusieurs plis sur le devant du cou; les deux autres se dirigent sur chacune des parties latérales de cette peau; ces dernières prennent naissance au-dessous des yeux : les narines sont surmontées d'une épaisse carnosité d'un beau rouge.

Le plumage de cette Colombe est d'un blanc uniforme; la queue seulement est grise à son origine, et noire vers le bout; les barbes extérieures des pennes latérales de chaque côté sont blanches jusqu'aux trois quarts de leur longueur; les grandes et les moyennes pennes des ailes sont d'un gris-blanc à leur origine, et noires vers leur extrémité; la penne extérieure de chaque aile est entièrement de cette couleur; l'aile bâtarde est d'un gris noirâtre.

Nous renvoyons nos lecteurs, pour les formes de cet oiseau, à la planche très exacte qui représente la Colombe Oricou de grandeur naturelle.

Nous avons vu une variété entièrement blanche qui n'avoit du noir que sur la queue; d'autres avoient le plumage plus ou moins marqué de taches grises et noires : ces derniers nous ont paru être de jeunes oiseaux. Les pieds sont constamment d'un beau rouge, et le bec est noir.

Nous présumons que l'Oricou habite les îles de la mer Pacifique, c’est du moins par des vaisseaux venant de ces parages que quelques individus ont été rapportés en Angleterre. Le Pigeon qui a servi de modèle à notre planche coloriée est déposé dans le cabinet de M. Raye de Breukelerwaert, à Amsterdam. Cet amateur possède aussi la variété de cette espèce, dont les ailes sont entièrement blanches. 


\section{COLOMBE LABRADOR.}

PL. XXII.

Columba Elegans. Milhi.

CE magnifique Pigeon, qui, par les zones brillantes disposées sur les ailes, ressemble à la Colombe que nous avons décrite sons le nom de Lumachelle, en diffère cependant essentiellement, et paroît former une espèce distincte. C'est au dernier voyage de découvertes aux Terres Australes, entrepris par' ordre du Gouvernement français, qu'on doit la connoissance de celte belle espèce, dont deux individus ont été rapportés par les naturalistes qui furent de cette expédition.

La Colombe Labrador est d'un tiers moins grande que la Colombe Lumachelle; sa longueur totale est d'environ onze pouces; le bec a dix lignes, le tarse a un pouce; les ailes pliées aboutissent vers la moitié de la longueur de la queue, qui est foiblement arrondie.

Le front est roussâtre clair; l'occiput est comronné d'un espace ovale de couleur gris-blanc; une large bande eouleur chocolat prend son origine derrière les yeux, et entoure cette espèce de diadème; une autre bande plus étroite, d'un blanc pur, se dirige sur les côtés du cou; l'espace entre l'oeil et le bec est brun; la nuque, les scapulaires, ainsi qu'un large plastron qui se dessine sur le haut de la poitrine, sont de couleur brun chocolat; les côtés du cou, la poitrine, le ventre et l'abdomen sont d'un beau gris foncé; le dos, le croupion et les petites convertures des ailes sont d'un brun olivâtre; les moyennes couvertures forment sur l'aile, lorsque celle-ci est dâns l'état du repos, deux larges bandes transversales qui brillent de l'éclat radieux des pierres précieuses; la première, ou la bande supérieure, imite le chatoyant du rubis et de l'opale., tandis que l'inférieure resplendit de l'éclat du saphir et de l'émeraude. Ces plumes brillantes sont terminées d'un beau blanc-argentin: les grandes et les moyennes pennes des ailes sont rousses sur leurs barbes intérieures jusqu’aux trois quarts de leur longueur; leur pointe, ainsi que les barbes extérieures, sont brunes; le dedans des ailes est d'un roux ferrugineux. Les pennes de la queue ont leurs barbes intérieures, ainsi qu'une partie 
DES COLOMBES.

des barbes extérieures, grises; elles ont une bande noire vers les trois quarts de leur longueur, et sont terminées de brun, comme les bords des barbes extérieures et les deux pennes intermédiaires: les pieds sont rouges, et le bec est noir.

Deux individus de cette espèce ont été rapportés par l'expédition du capitaine Baudin : ils sont déposés dans les galeries du Muséum de Paris.

Nous avons reçu un dessin de ce Pigeon, fait à Londres d'après un individu déposé dans la collection de sir Joseph Banks.

La Colombe Labrador habite les rivages brumeux de la partie méridionale de la terre de Diemen. C'est dans les parages du canal d'Entrecasteaux que les naturalistes français trouvèrent cette rare et nouvelle espèce. 


\title{
COLOMBE A CEINTURON NOIR.
}

\author{
P. XXIII
}

Columba Cincta. Mihi.

$\mathrm{L}_{\mathrm{A}}$ Colombe à ceinturon noir, quoique de beancoup plus forte de taille que notre Colombe Tourterelle, paroît cependant modelée sur les formes de cette dernière. Nous ne sommes pas instruits jusqu’à présent de la manière de vivre de cette nouvelle espèce, encore très r'are dans les collections d'Histoire naturelle; nous n'en connoissons absolument que le seul individu qui a servi de modèle à la planche qui représente cette Colombe de grandeur naturelle.

La Colombe à ceinturon noir mesure en totalité treize pouces. Un camail d'un blanc pur couvre la tête et le cou; le blanc prend des teintes jaunâtres sur la poitrine, où cette couleur se dessine fortement sur unlarge ceinturon d'un noir velouté qui entoure la partie inférieure de la poitrine; les angles de ce ceinturon, qui marquent l'insertion du poignet de l'aile, remontent sur le dos, où ils se lient à une espèce de manteau d'un beau noir verdoyant: cette dernière conleur prend des teintes d'un vert foncé sur les grandes plumes des ailes, dont les six pennes extérieures ont le bout arrondi, tandis que les suivantes sont coupées verticalement. Le croupion est verdâtre; la quene, composée de quatorze pennes d'égale longueur, est, en dessus, d'un noir verdâtre, et toutes les pennes ont leur bout terminé de gris tirant au vert; en dessous, la queue est cendrée, et les extrémités des pennes sont blanchẹ. Le ventre, les cuisses et l'abdomen sont d'un beau jaune; les couvertures de la queue sont grises, frangées de jaune sur les bords des barbes; les tarses se trouvent en plumes jusqu'aux doigts, qui sont d'un jaune foncé; le bec est d'un blanc jaunâtre.

Cette Colombe habite l'Asie australe: nous ne saurions cependant dire avec certitude quelle partie. Le seul individu que nous avons vu de cette belle espèce fait partie de notre cabinet : il a été adressé de Batavia, sans indication de lieu où l'espèce se trouve répandue. 
DES GOLOMBES.

59

COLOMBE ROUSSETTE, Màle.

PI. XXIV.

${ }^{+}$Columba Rufina. Mihi.

$\mathrm{L}_{\mathrm{A}}$ longueur totale de cette nouvelle espèce est de onze pouces dix lignes. Elle paroît modelée sur les formes de notre Biset; et n'en diffẹ̀re sous ce rapport que par le seul caractère d'avoir' les ailes plus courtes en proportion de la longueur de la queue.

La Colombe Roussette a la partie inférieure du cou, le haut du dos, ainsi que les petites couvertures des ailes, d'un roux foncé, nuancé d'une légère teinte de violet; cette dernière couleur domine sur le ventre, et se nuance en gris-vineux vers les cuisses. L'abdomen et les couvertures inférieures de la queue sont gris; les grandes et les moyennes pennes des ailes, de même que celles' de la queue, sont d'un gris-cendré, les premières sont liserées sur les barbes extérieures de gris plus clair. Le dos, le croupion et les couvertures inférieures des ailes sont d'un gris bleuâtre; la gorge est blanche.

Les mâles de cette espèce se distinguent par un grand espace d'un vert foncé à reflets dorés, qui couronne l'occiput. Les femelles ont le plumage généralement d'une teinte moins vive; elles n'ont pas cet espace doré sur l'occiput, qui est d'un roux-violet. Le bec est de couleur livide; les pieds son trouges' et les ongles bruns.

Cette Colombe se trouve à la Guiane française. On en trouve aussi aux îles de Cuba, Saint-Domingue et la Jamaïque. Nous avons vu des individus de cette espèce dans plusieurs collections. Celui qui nous a servi de modèle appartient au Musée de Paris. 
COLOMBE A OREILLON BLEU, Màlc.

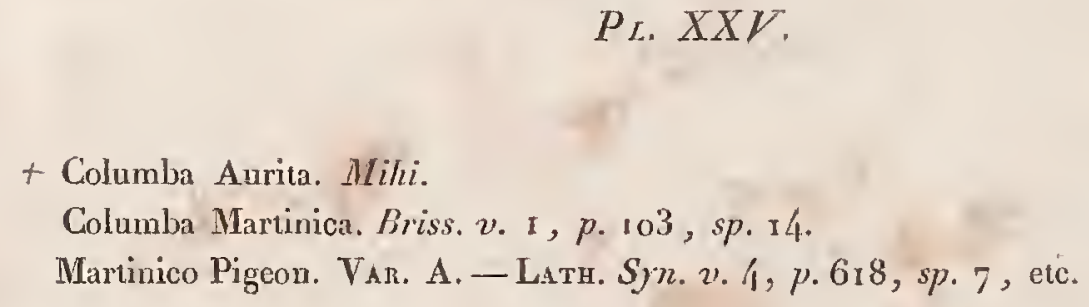

Nous avons fait observer, en décrivant le Colombi-Gallinc roux-violet, que Latham avoit eu tort de soupconner à ce Pigeon quelque conformité avec celui qui fait le sujet de cet article. Nous ne saurions trouver d'autre analogie pour les réunir que la seule dénomination de Perdrix, par laquelle on a également désigné le Colombi-Galline roux-violet (1) et notre Colombe à Oreillon bleu. Cette dénomination de Perdrix, qui peut seule être en rapport avec l'espèce de la famille des Pigeons-Gallines, n'en a pas le plus léger avec notre Orcillon bleu, ce dernier appartenant à la famille des Colombes ou Pigeons proprement dits; au reste, nous renvoyons les naturalistes tant à la planche annexée à cet article qu’à celle qui représente le Colombi-Galline roux-violet, persuadés qu’ils ne trouveront guère à ccs Pigeons les rapports donnés par les divers ornithologistes, et quills s’accorderont de préférence aux vues de Brisson, qui ne paroit pas soupçonner l'identité des espèces mentionnées. Ce savant naturaliste décrit notre Colombe à Oreillon bleu avec cette exactitude et cette vérité qui font un des premiers mérites de son ouvrage; nous allons donner en substance le texte de l'auteur français.

La longueur de cet oiseau, prise du bout du bec à l'extrémité de la queue, est de dix pouces; le bec a dix lignes et demie; ses ailes, lorsqu'ellessont pliées, s'étendent jusqu'aux deux tiers de la longueur de la queue; toutes les pennes de celle-ci sont d'égale longueur.

La tête, la gorge, le cou et la poitrine sont d'un marron tirant sur le

(1) Le Colombi-Galline roux-violet est décrit par Latham sons le nom de Martinico Pigeon; par Brisson, sous les dénominations de Pigeon violet de la Martinique, et de Pigeon roux de Cayenne. Buffion en donne deux figures, pl. I/1 et 162 . 
pourpre; mais les plumes qui entourent le bas du cou, c'est-à-dire la partie la plus voisine du corps, sont d'un violet doré très éclatant, et forment comme une espèce de collier : huit ou dix plumes d'un beau bleu violacé à reflets d'or, placées immédiatement au-dessous de l'orifice des oreilles, nous ont paru un caractère marquant; c'est d'après ce caractère que nous avons établi le nom donné à l'espèce (1). Le dos, le croupion, les couvertures des ailes et celles du dessus de la queue sont d'un brun tirant sur le roux, avec quelques taches noires sur les grandes couvertures des ailes les plus proches du corps; le ventre, les cuisses et les couvertures au-dessous de la queue sont d'un fauve clair et vineux; les grandes pennes des ailes sont noirâtres et ont leur bord extérieur blanchâtre; les moyennes sont aussi d'un brun noirâtre, et terminées d'un espace d'un gris-blanc. Les deux plumes du milieu de la queue sont de la mêne couleur que le dos; les latérales sont, depuis leur origine jusque vers les deux tiers de leur longueur, d'un brun tirant sur le roux du côté extérieur, et d'un cendré foncé du côté intérieur ; ensuite elles ont une bande transversale noire, et leur bout est gris-blanc. Le bec et les ongles sont noirs, et les pieds sont rouges.

La Colombe à oreillon bleu se trouve à la Martinique. Nous ne sommes pas instruits de sa manière de vivre, ni du genre de nourriture qui lui est propre.

Nous avons vu plusieurs Colombes à oreillon bleu. Celle qui a servi dé modèle à notre planche colorée fait partie du cabinet de M. Raye de Breukelerwaert, à Amsterdam.

(1) La description de Brisson, qui s'accorde en tout autre point avec la nôtre, ne parle pas de ces plumes brillantes qui forment une espèce d'oreillon; il nous paroìt probable que ce naturalistc a décrit une femelle de l'espèce, et que celui que nons figurons en est le mâle. 


\title{
COLOMBE-TURVERT, Màle.
}

\author{
PL. $X X V I$
}

Columba Javanica. Latr. Ind. orm. v.2, p. 610, sp.60. - Ganet. Syst. 1, p. 781.

Columba Coeruleocephala. Latr. Ind. orn. ข. $2, s p .6$ I.

Columba Cyanocephala. Gmex. Syst. I, p. $78 \mathrm{r}$.

Columba Albieapilla. LATH. Ind. orn. v. 2, p. 597, sp. I I.

Columba Indica. Ibidem, p. $598, s p$. 16.-Guex. $p$.

Le Turvert. Buff. Ois. v. 2, p. 556. - Sonnini, édit. de Buff., v. 7, p. 288.

Tourterelle de Java. Buff. pl. enl. I 77 .

Le Pigeon Ramier d'Amboine. Brisson, orn. $v .1, p .150, p l$. I5 , f: 1 .

Javan Turtle. LAтн. Syn. ข. 4, p. 654.

Blue-crowned Turllc. Ibidem, $p .655, s p .5_{2}$.

Greeu-winged Pigeon. La Th. Syn. v. 4, p. 625. - Id. supp.p. 198. - Edwards, t. 1作.

Nous réunissons ici sous la dénomination de Turvert non seulement le Pigeon décrit par Buffon, et figuré par lui dans la planche enluminée 177 , mais aussi le Pigeon ramier d'Amboine, de Brisson, ainsi que le Blue-crowned Turtle, le Grey-headed Pigeon, et le Green-ixinged Pigeon de Latham. Ces espèces nominales n'en forment qu'une réelle, toutes les indications mentionnées devant plutôt s'appliquer à des variétés accidentelles dans l'espèce de notre Turvert. Cependant nous ne saurions nous conformer avec les idées de quelques ornithologistes, qui réunissent encore deux autres Colombes (1) à celle de cet article. Ces espèces, quoique analogues à notre Turvert, diffèrent, sous plusieurs rapports, de ce dernier, et forment autant d'espèces distinctes dont nous aurons occasion de parler dans la suite.

Sonnini, dans la nouvelle édition de Buffon, volume 7 , page 219 , nous donne une description qui se rapporte à l'espèce du Turvert. L'auteur cité

(r) Sonnini réunit sous l'article du Turvert non seulenient la Tourterelle à gorge pourpre d'Amboine, dcs planehes cnluminées de Buflon, 142 , mais aussi le Black-capped Pigeon de Lathan1, Buffon, planche 214 . Nous décrirons cette dernière espèce sous le nom de Turgris ; quant à la Colombe à gorge pourpre, nons n'avons pu nous la procurer en nature. Il est cependant certain qu'elle forme une espèce différente du Turvert, ainsi que du Turgris. 
a eu tort d'ajouter cette description à l'article de son Pigeon vert à tête grise d'Antigue. Nous ferons connoître par la suite ce Pigeon vert à tête grise, qui est du nombre de ceux dont le bec est recouvert d'une substance cornée, formant une pince solide. Nous désignons cette famille par le nom de Pigeons Colombars.

Le Turvert est plus fort de taille que la Colombe Tourterelle de nos climats; sa longueur, prise du bout du bec à l'extrémité de la queue, est de dix pouces. Cette dernière est courte; les pennes sont foiblement étagées entre elles, et les ailes, dans l'état du repos, aboutissent vers les deux tiers de leur longueur.

Le devant de la tète est blanc, et cette couleur s'étend de chaque côté en une bande étroite qui passe par-dessus les yeux. Le haut de la tête, dans la plupart des individus, est d'un bleuatre foncé ; les côtés de la tête, le cou et la poitrine sont rougeâtres, et cette couleur est plus sombre à la partie supérieure du cou. Le dos et toutes les couvertures des ailes sont d'un vert foncé éclatant et doré, qui se change, suivant que l'animal est exposé à différents jours, en une très belle couleur de cuivre de rosette; quelqués unes des petites couvertures du poignet de l'aile sont ou terminées de blanc, ou entièrement blanches; ce qui forme autant de petites taches dessinées agréablement sur le fond vert doré du plumage. La partie inférieure du dos, le croupion et les couvertures du dessus de la queue sont cendrés; le ventre, les cuisses et les plumes de recouvrement du dessous de la queue sont bruns, avec une légère teinte de rouge. Les couvertures du dessous de l'aile sont rousses; les pennes alaires sont d'un brun foncé ; mais leurs barbes intérieures sont rousses; celles de la queue sont noires, excepté les deux plus extérieures de chaque côté, qui sont cendrées et terminées de noir. Le bec est rougeâtre, la membrane qui est au-dessus des narines bleuâtre, les pieds rouges, et les ongles d'un brun clair.

On trouve des Turverts qui n'ont point de blanc au front, dont toute la tête est de couleur noirâtre. Ces individus paroissent former des variétés accidentelles dans l'espèce: leur plumage est en général d'une teinte plus sombre, la poitrine et le cou sont plus rembrunis. Dans l'état de captivité, sur-tout lorsqu'on les nourrit de chenevis, ils se décorent de plumes noires semées au hasard sur toutes les parties : cette bigarrure est assez jolie.

La Colombe Turvert paroît répandue sur toutes les îles de l'Asie australe et du vaste Océan indien; elle est très abondante à Ceylan; on la trouve par troupes nombreuses à Java et à Sumatra; leurs essaims peuplent les vastes 
et antiques forêts de ces îles. Sonnerat les a rencontrés a l'ile Panaye et à celle d'Antigue (1).

Les Chinois connoissent l'espèce sous le nom de Yaupuan. Les Javans lui donnent le nom de Bouron Glimouhane. Dans le séjour que firent les naturalistes français à Timor, lors du dernier voyage de découvertes aux Terres australes, ils y trouvèrent aussi le joli Pigeon que nòus décrivons. Trois individus tués par ces naturalistes sont déposés dans les galeries du Muséum de Paris. Ces individus ne diffèrent de ceux qui nous ont été adressés, tant de Java que de Ceylan, que par leur plus forte taille. Il est probable que cette légère différence doit son origine à une plus grande abondance de nourriture que ces oiseaux trouvent sous le ciel fertile de l'île de Timor.

Nous avons reçu et conservé vivants plusieurs individus de l'espèce de Turvert. Ces Pigeons, très peu remuants, s'accoutumaient facilement à la captivité, pourvu qu'on ne les privât pas de la chaleur nécessaire. Tous les moyens mis en usage pour les faire produire dans nos climats furent infructueux. Leur nourriture habituelle consistoit en blé de Turquie écrasé. Dans les saisons les plus froides de l'année, on doit leur donner un peu de chenevis avec le blé de Turquie.

Les dépouilles de ces Colombes se trouvent dans plusieurs collections d'histoire naturelle.

(1) Le Pigcon vert à tête grise d'Antiguc. Sorneral, voy. Nouv. Guin, , p. 112, t. 66. 


\title{
COLOMBE JAMBOO, Màle et Femelle.
}

\author{
$P_{\text {f. }} X X V I I$ et $X X V I I I$.
}

Columba Jambos mas. LAти. Ind. orn. v. 2, p. 598 , sp. 18.

Colomba Jambu. Gned. Syst. r, p. 784 .

Le Piseon Jamboo. Sonnini, édit. de Buff. $2 \% .7, p .265$.

Jamboo Pigeon. Lath. Sjn. v. $4: p, 627$, sp. I6.

Nous conservons à cette espèce une partie du nom qu'elle porte à Sumatra. Mardsen (1), qui a donné la description détaillée de cette île, est le premier auteur qui en fait mention en ces termes:

“ Le Pooni-Jamboo est un bel oiseau; il est plus petit que le Pigeon or" dinaire; il a le dos, les ailes et la queue verts, la poitrine et le cou “ blancs, mais l'extrémité du cou a une teinte légère de rouge d'œillet; le “ devant de la tête est d'un rouge d'oeillet foncé semblable à la fleur du “Jamboo; le blanc de la poitrine s'étend par une bande étroite, resserrée “ d'un côté par le vert, et de l'autre par le rouge d'oillet jusqu'aux yeux, "qui sont jaunes; le bec est également jaune. »

La Colombe Jamboo, mesurée de la pointe du bec à l'extrémité de la queue, a environ neuf pouces et demi. Les ailes pliées atteignent vers le milieu de la longueur de la queue, qui est étagée; les tarses sont à moitié couverts de plumes.

Une teinte vive d'oeillet foncé est répandue sur les plumes de la tête et des joues (2). Sous la gorge est un espace longitudinal d'un noir mat; un plastron de forme ovoïde, coloré d'une teinte rosée, se dessine sur la poitrine. Toutes les parties supérieures de l'oiseau sont d'un beau vert foncé, et les parties inférieures blanchâtres; le dessous de la queue est noir, mais

(1) Mardsen, Hisı. Natur. de Sumatra, traduc. franç., v. 2.

(2) Cete conleur brillante ressemble à celle de la fleur de Jamboo, arbre dont le firuit a la forme d'une poire, et qu'on dit être un mets excellont. Il y en a de deux espèces. Eugenia malacensis, et Jambos. Lis. 
toutes les pennes sont terminées de blanc. Les couvertures inférieures sont d'un brunfoncé ; les pieds sont rouges et les ongles jaunes.

La Colombe Jamboo se trouve à Sumatra et à Java. Sa nourriture favorite est la baie du rum-pooni. En captivité, on pourra donner à ce Pigeon du riz bouilli, dont il s'acconmode à merveille.

Plusieurs individus nous ont été envoyés de Batavia. Ces oiseaux ne se trouvent cependant pas aux environs du chef-lieu de la colonie hollandaise; on ne les rencontre que dans l'intérieur des terres couvertes d'épaisses forêts.

Aucun auteur ne fait mention de la femelle de cette belle espèce; elle diffère cependant beaucoup du mâle par la distribution des couleurs. Nous présunons que, sous ce rapport, il sera intéressanț de joindre, planche 28 , la figure de la seule femelle que nous ayons eu occasion d'examiner.

Toutes les parties supérieures du corps, le cou et la poitrine, sont d'un vert uniforme, mais plus terne que chez le mâle. L'espèce de capuchon qui sur ce dernier est d'un rouge éclatant, est d'un brun-verdàtre chez la femelle; la gorge est brune, le ventre et le croupion sont d'un blanc-grisâtre, scmé sur les flancs de taches irrégulières plus ou moins vertes; la queue en-dessous est noirâtre, et toutes les pennes sont terminées de grisâtre.

Cette espèce est encore fort rare dans les collectious d'histoire naturelle. J'ai vu un mấle dans le beau cabinet de M. Raye de Breukelerwaert, à Amsterdam; M. Geevers, à Rotterdam, possède le mâle et la femelle. Cette dernière est figurée dans notre planche $n^{\circ} 28$. Je conserve encore deux mâles dans ma collection. 


\title{
COLOMBE A NUQUE VIOLETTE.
}

\author{
P.. XXIX.
}

Columba Violacca. Mili.

$E_{N}$ ne jetant qu'un coup-d'œeil superficiel sur la nouvelle espèce de Colombe représentée dans notre planche 29 , on la prendroit pour un individu de l'espèce décrite dans cet ouvrage sous le nom de ColombeGalline roux-violet: il est nécessaire de prévenir les naturalistes que, quoique ces Pigeons semblent avoir quelques rapports entre eux pour la conformité de taille et les distributions des couleurs, il n'existe effectivement aucune analogie entre ces oiseaux qui permette de les considérer comme appartenant à une même espèce.

En comparant notre Colombe-Galline roux-violet (famille $3^{\circ}$, pl. 5 et 6 ) à la Colombe à nuque violette, il est facile de s'apercevoir des différences qui caractérisent ces espèces: les formes extérieures du Colombi-Gralline indiquent, à ne pas s'y méprendre, tous ces caractères que nous avons jugé apparteniraux Pigeons qui composent cette famille, tandis que celui-ci a en partage les formes analogues propres à plusieurs espèces de Pigeons compris dans la famille des Colombes. Nous lui trouvons la taille s̉velte, la queue allongée et étagée, les ailes longues et le tarse court; caractères qui sont bien différents dans les Pigeons-Gallines: les différences dans les mœurs de ces oiseaux doivent offrir encore de nouvelles preuves pour établir la certitude de leur dissemblance spécifique; mais la manière de vivre du Pigeon de cet article ne nous étant pas connue, nous réservons ces comparaisons à une époque plus favorable, nous bornant ici à faire connoître les formes extérieures de cette nouvelle espèce.

La Colombe à nuque violette, mesurée du bout du bec à l'extrémité de la queue, a neuf pouces; les ailes pliées aboutissent vers le milien de la longueur de la queue, qui est étagée.

Ce Pigeon a les parties supérieures du corps, y compris les ailes et toutes 
les pennes de la queue, d'un beau roux-pourpre foncé; les grandes pennes alaires sont rousses; sur la nuque sont quelques plumes brillantes, qui forment une espèce de collier d'un beau violet à reflets dorés : le front, la gorge, le ventre, les côtes, l'abdomen et les couvertures du dessous de la queue sont d'un blanc pur; la poitrine est teinte d'une légère nuance de violet pourpré à reflets bronzés; les yeux sont entourés d'un espace nu de couleur rouge; le bec et les pieds sont rougeâtres.

Il est probable que ce Pigeon habite le Nouveau Monde; nous ne saurions cependant l'assurer positivement. Le seul individu de l'espèce que nous ayons trouvé occasion d'examiner, et qui a servi de modèle, est déposé dans les galeries du Muséum de Paris. 


\title{
COLOMBE TURGRIS.
}

\author{
$p_{\text {L. }} X X X$.
}

Columba Melanocephala. Latr. Ind.orn. v. 2, p.610, sp.5g. - GaeL. Syst. 1, p. $78 \mathrm{r}$.

- Forster, Zool. ind. $p .16$, avec une très bonne figure, $t .7$.

Turvert. Buff. v. I , p. 555.-Sonnini édlit. de Buff. v. 7, p. 29\%

'Tourterelle de Batavia. Buff. pl. enl. 214.

Black-Capped Pigeon. Татн. Syn. v. 4, p. 654

Lathas a eu raison de ne pas se conformer au sentiment de Buffon, qui réunit le Pigeon de cet article à l'espèce du Turvert, représenté dans notre planche 26. Il en diffère effectivement sous tous les rapports, ces oiseaux formant deux espèces très distinctes, comme il est facile de s'en assurer en lisant notre description du véritable Turvert, et en confrontant nos deux gravures. M. Forster, dans sa Zoologia Indica, nous donne une très bonne figure du Turgris. Celle de Buffon est passable; l'individu d'après lequel ce naturaliste a fait exécuter sa planche étoit totalement dégradé; ce dont il est facile de se convaincre en comparant cette planche avec la nôtre, d'après un individu de la plus grande pureté.

La Colombe Turgris porte huit pouces depuis le bout du bec à l'extrémité de la queue, qui est foiblement étagée; les ailes pliées aboutissent vers le milieu de sa longueur; les pieds ont le tarse à moitié couvert de plumes.

Le front et les côtés de la tête sont d'un gris-cendré clair ; une large raie ou bande noire prend naissance entre l'espace des yeux vers l'occiput, et se dirige sur le derrière du cou, où elle disparoit dans la couleur griscendré qui revêt encore cette partie; sous la gorge est une bande longitudinale d'un beau jaune-paille; la poitrine, le ventre et toutes les parties supérieures de l'oiseau sont d'un beau vert foncé et uniforme; les quatre ou cinq grandes pernes des ailes ont leurs barbes intérieures noirâtres; toute l'aile en dedans est grise; la quene en-dessous est d'un gris foncé, avec les extrémités de toutes les pennes blanchâtres: l'abdomen est d'un jaune 
brillant, et les couvertures inférieures de la queue, qui aboutissent presque à l'extrémité des pennes, sont d'un rouge-cramoisi foncé (1); les tarses sont à moitié couverts de plumes vertes: le bec est de couleur de corne; les pieds sont d'un rouge-jaunâtre, et l'iris est d'un brun-rougeâtre.

La Colombe Turgris se trouve à Java, où elle habite les grands bois. On voit ces oiseaux aux environs de Bagnania-Vangria, contrée située dans la partie est de cette île. M. Laischenault a rapporté un bel individu de ceite espèce que le Muséum possède maintenant : il n'est pas instruit dú nom que les Javans lui donnent.

On voit encore dans les galeries de cet établissement l'individu dégradé par les fumigations qui a servi de modèle à la planche de Buffon.

(1) Latham se trompe sans doute en avançant que les trois pennes latérales de la quetre sont rougges: cet auteur aura peut-être été induit en erreur par rapport à la longueur des couvertures de la queue, dont les plumes latérales sont assez propres à favoriser une pareille méprise. 


\title{
COLOMBE A MASQUE BLANC, Màle.
}

\author{
PL. $X X X I$.
}

Columba Larvata. Mihi.

Tourterelle à Masque blanc. Le Vaillant, Hist. nat. des Ois. d'Afr. v. 6, pl. $26 \mathrm{~g}$.

$\mathrm{O}_{\mathrm{N}}$ pourroit, d'après les habitudes qui tiennent aux mours de cette nouvelle espèce, trouver des motifs pour la classer dans notre division des ColombiGallines. Le Vaillant, qui découvrit cet oiseau dans la partie méridionale de l'Afrique qu'il a parcourue, nous apprend que ce Pigeon fréquente toujours les grandes forêts, où, se tenant le plus souvent à terre, il est difficile de le découvrir; son nid, peu élevé, est d'ordinaire pratiqué dans quelque buisson. En combinant ces habitudes avec l'extérieur de ce Pigeon, nous lui trouvons aussi quelques caractères analogues aux Colombi-Gallines; il nous a cependant paru qu'à sa taille svelie, au peu de-longueur du tarse, à l'étendue des ailes qui aboutissent vers le milieu des pennes caudales, et enfin à la forme allongée et étagée de la queue; il paroissoit aussi que le masque blanc participoit aux caractères distinctifs que nous avons établis pour la famille des Pigeons-Colombes. Il semble donc (et c'est aussi le sentiment de Le Vaillant) que l'espèce dont nous nous occupons est destinée, dans une histoire générale des Pigeons, à former le passage, et lier plus étroitement la famille des Colombes à celle des Pigeons-Perdrix ou ColombiGallines.

Ne pouvant mieux faire, pour ce qui concerne la partie descriptive de cette espèce, que de citer le naturaliste à qui la découverte en est due, nous transcrirons en entier son texte: "Cette Tourterelle d'Afrique (dit Le "Vaillant), que je n'ai trouvée nulle part ailleurs que dans le pays d'Auti" niquoi, est caractérisée par un masque blanc qui lui enveloppe le front, " les joues et la gorge, pendant que tout le cou, la poitrine, le manteau, " ainsi que le croupion, sont d'un brun-roux jouant au pourpre, au vert " ou au bleu d'acier poli, suivant les incidents de la lumière; le dessous du 
“ corps, ainsi que les couvertures du dessous de la queue, sont d'un roux “ uniforme; les pennes des ailes, sur fond noirâtre, sont bordées extérieu-

« rement de gris-bleuâtre, ainsi que celles de la queue; le bec est bleuâtre, " les pieds sont d'un rouge-vineux, et les yeux orangés.» La femelle ne diffère du mâle que par ses couleurs moins nettes que celles de ce dernier.

La Tourterelle à masque blanc ne se trouve que dans les grands bois : il est fort difficile de la tuer, parceque, se tenant toujours à terre, on l'aperçoit difficilement à travers le fourré; lorsqu'on la fait même partir, on l'entend souvent s'envoler avec grand bruit sans pouvoir la découvrir; car elle ne se perche guère que sur les branches basses des arbres ou dans les buissons, entre les ramifications desquels elle place son nid, qui est plat, et ne contient jamais que deux œufs; ces derniers sont d'un blanc-fauve.

Mon ami Le Vaillant a eu la bonté de me donner un mâle de cette espèce. 


\section{COLOMBE VLOUVLOU.}

$P_{L .} X X X I I$.

Columba Holosericea. Mihi.

Liespece de Pigeon qui fait le sujet de cet article ne nous paroit pas avoir été connue avant cette époque: nous ne trouvons dans les ouvrages les plus récents sur l'ornithologie aucune indication que nous puissions rapporter à ce rare oiseau; il semble même jusqu'ici ne pas avoir d'analogue parmi l'ordre nombreux des Pigeons. La coupe singulière de ses ailes et la nature de son plumage l'isolent au milieu dẹ oiseaux de sa classe : ses habitudes si elles nous étoient connues, offriroient peut-être des observations intéressantes; mais nous n'avons malheureusement point de détails à donner sur les mours de l'espèce dont nous nous occupons: cette partie, l'une des plus utiles pour l'étude de I'histoire naturelle, nous est souvent interdite par le peu de zèle de ceux qui rassemblent les divers objets d'histoire naturelle dans les pays lointains. Je n’ai jamais omis de la recommander à mes amis demeurant dans les divers cantons de l'Inde. Le succès de toutes mes tentatives pour me procurer des notions exactes sur les mours des oiseaux qu'on m'expédie n'a que foiblement couronné mon attente : je dois cependant à l'activité de quelques uns des observations nouvelles insérées dans cet ouvrage, ainsi que dans les deux volumes suivants, qui traitent des Grallinacées.

D'après les formes extérieures du Pigeon que nous nommons Vlouvlou, il paroît que l'espèce doit être rangée dans notre première subdivision ou famille des Colombes : sa longueur, prise du bout du bec à l'extrémité de la queue, est de dix pouces quatre lignes; la queue est carrée, composée de quatorze pennes; les couvertures, tant inférieures que supérieures, atteignent l'extrémité des grandes pennes; les ailes sont larges; leurs grandes pennes ou remiges sont singulièrement conformées; depuis leur origine jusqu'au trois quarts de leur longueur, elles sont courbées en forme de sabre; leur extrémité décrit une parabole en sens inverse, et fait revenir la pointe en dehors; le bout de toutes ces pennes est profondément échancré 
et divisé en deux parties; le prolongement des barbes intérieures se forme en pointe arrondie, tandis que les barbes extérieures sont terminées en pointe aiguë : nous figurons une de ces plumes dans notre planche. Le bec de ce Pigeon est peu long, et menu; les tarses sont couverts, jusqu'aux doigts, de plumes composées de barbes excessivement déliées et fines. Tout le plumage de l'oiseau est velouté, et principalement celui des ailes, qui imite le plus beau velours changeant.

Ce magnifique Pigeon a tout le plumage supérieur, les ailes, le cou, la poitrine et les flancs d'un vert tendre, changeant aux diverses inflexions de la lumière: de la mandibule inférieure du bec se prolonge, sur une partie du cou, une bande longitudinale d'un blanc pur; un ceinturon de cette couleur, suivi d'un autre plus large de couleur noire, se dessine sur la poitrine, et se confond avec la tcinte jaune-verdâtre du ventre. Sur les ailes sont deux larges bandes d'un gris argentin: elles sont formées par les grandes couvertures, dont les plumes sont vertes aux extrémités, et grises au milieu; les pennes secondaires ont leurs barbes extérieures vertes; les rémiges sont colorées, sur une partie des barbes extérieures, de gris-argentin nuancé de teintes verdâtres; les barbes intérieures et l'extrémité des pennes sont noires; la queue est du mêmé vert que le corps, mais vers l'extrémité de chaque penne est une zone d'un vert plus foncé; le dessous de la queue est gris, et les couvertures inférieures sont d'un beau jaune; les plumes qui recouvrent les tarses sont blanches; les pieds sont gris, et le bec noir.

La Colombe Vlouvlou habite les îles de l'Océan-Pacifique; on la trouve dans l'ìle de Sandwich.

Nous ne connoissons absolument de l'espèce que le seul individu qui a servi de modèle à la planche qui accompagne cet article : il fait partie de mon cabinet. 


\title{
COLOMBE POUKIOBOU.
}

\author{
$P_{L .} X X X I^{-}$
}

Columba Superba. Mihi.

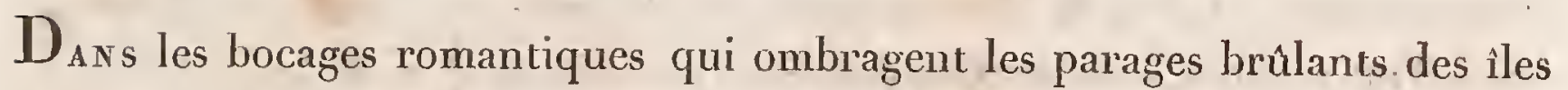
du vaste Océan-Pacifique, habite une nouvelle espèce de Pigeon qui, par ses formes extéricures, doit être rangé dans notre division des Colombes; une livrée embellie de couleurs fraîches et vives nous trace en ce magnifique oiseau la séduisante image des beautés de la nature, tandis que ses teintes agréablcment nuancées nous font admirer l'art magique avec lequel elles ont été distribuées.

Les caractères distinctifs de l'espèce dont nous nous occupons ici sont d'avoir la qucue allongée et arrondie, les pennes au nombre de seize, et les ailes aboutissant vers la moitié de la longueur de ces pennes; les tarses sont converts de plumes jusque vers la moitié de leur longueur, et la mesure totale de l'oiseau, prise du bout du bec à l'extrémité de la queue, est de neuf pouces et demi. Une calotte d'un violet éclatant couvre la tête; l'occiput et les joues sont d'un vert-pré tendre; la nuque est colorée de brun-rougeâtre; le manteau, le dos, les grandes et les moyennes couvertures des ailes sont d'un vert brillant nuancé de quelques teintes olivacées; sur les grandes et sur quelques unes des moyennes couvertures se dessine, vers leur extrémité, une tache ovoïle de couleur blent-11oirâtre; le poignet de l'aile porte une espèce d'épaulette d'un bleu légèrement violacé; les pennes secondaires des ailes sont noires sur leurs barbes intéricures, et d'un vert foncé en dehors; toutes ces pennes, ainsi que leurs couvertures, se trouvent bordées de jaunc: les rémiges sont noirâtres, bordées de jaune-blanchâtre; la queue, qui, comme nous venons dc le dire, est composée de seize pennes, est d'un vert-olivacé à son origine, d'un beau vert foncé au centre, et terminée de blanc nuancé de vert; les trois pennes latérales de chaque côté 
sont noires; les autres ont leurs barbes intérieures de cette couleur; le dessous de la queue est gris, et terminée de blanc. Diverses nuances de gris-cendré et de violet tendre sont répandues sur le devant du cou; l'origine de toutes les plumes de cette partie est colorée de violet, tandis que leur extrémité est grise. Un large croissant d'un bleu foncé ceint la poitrine; le ventre et l'abdomen sont blancs; les flancs sont verts, marqués de taches blanches; les couvertures inférieures de la queue, blanches depuis leur origine, ont sur leurs barbes intérieures des taches oblongues vertes; les yeux, placés dans un cercle dénué de plumes, sont rouges; le bec est couleur de corne, et les pieds sont rougeâtres.

Une étiquette au pied de cet oiseau portoit le nom de Poukiobo: nous soupconnons que c'est la dénomination par laquelle les insulaires d'O-Taiti (lieu d'où on nous a assuré que l'espèce est originaire) le désignent.

Nous n'avons eu occasion d'examiner de cette belle espèce de Colombe que le seul individu conservé dans mon cabinet. 


\section{OL OMBE :K UR U K UR U, Màle.}

$P_{L .} X X X I V$, et variété, $P_{L .} X X X V$.

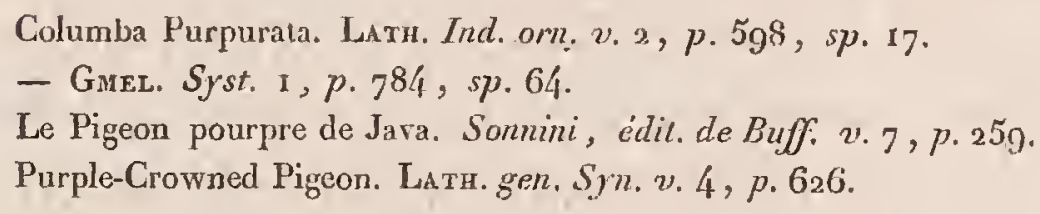

Les îles de l'Océan Pacifique nourrissent encore la belle espèce de Colombe que Latham a nommée Pigeon à couronne pourpre. L'ornithologiste anglais nous en donne une très bonne description dans le Synopsis of Birds. Il y fait aussi mention de quelques variétés de ce Pigeon; le plumage de cette espèce paroît assez susceptible d'éprouver des changements qui nous semblent propres aux diverses îlés que ces oiseaux habitent; variétés au reste qui sont peut-être dues aux différences de sexe ou d'âge.

Il ne sera pas inutile de prévenir les naturalistes qu'ils doivent se garder de confondre parmi ces variétés l'espèce que nous avons décrite dans l'article précédent; il seroit aussi possible qu'on vînt à la supposition que ces oiseaux, offerts par nous comme espèces distinctes, ne différoient que de sexe, en prenant (comme il nous est arrivé avant une inspection exacte) lè premier de ces Pigeons pour le mâle, et celui de cet article pour la femelle; les différences qui distinguent ces oiseaux sont cependant assez niarquantes, et nous allons les exposer afin d'éviter par la suite toute méprise.

Le Poukiobou mesure en totalité neuf pouces et demi, et le Kurukuru n'a guère plus de huit pouces et demi (1): le premier a la queue allongée et composée de seize pennes; le dernier l'a plus courte, et elle n'est pourvue que de quatorze pennes; tontes les plumes du con du Kurukuru, ainsi que

(I) Nous avons mesuré 'des individus de l'espèce du Kurukuru qui n’avoient que lmit pouces, d'autres en avoient environ neuf. Cette inégatlité dans la taille, que nous avons déja fail remarquer ailleur's, paroît tenir ì des causes purement locales. 
des variétés de ce Pigeon, sont échancrées du bout, tandis que celles du Poukiobou, étant sans échancrures, sont arrondies. Chez ce dernier, les rémiges extérieures sont les plus longues; mais dans l'espèce du Kurukuru, les grandes pennes alaires vont en diminuant de longueur jusqu'à l'extérieure, qui est la plus courte de toutes : celle-ci est terminée en pointe. Il nous reste maintenant à faire connoître les variétés qui se trouvent dans l'espèce du Kurukuru, ensuite nous en ferons connoître le jeune âge. Nous figurons dans la planche 34 le Kurukuru niâle tel qu'on le trouve habituellement; c'est dans cet état que nous avons eu occasion d'en examiner plus de vingt individus venant d'O-Taïti : nous en avons encore trouvé deux au Muséum de Paris, rapportés par les naturalistes qui accompagnèrent le capitaine Baudin dans le voyage de découvertes aux Terres Australes. Nous ne sommes cependant pas instruits dans quelle île ils ont été tués.

La première variété, qui nous paroît la plus constante, a tout le haut de la tête d'un beau rouge-rose. Cette coụleur est entourée, dans les individus adultes, par une bande jaune; l'occiput, le cou et la poitrine sont d'un gris-cendré, nuancé de légères teintes verdâtres, plus sombres cependant sur la partie postérieure du cou; toutes les parlies supérieures du corps sont d'un beau vert lustré, marqué de taches vertes, plus foncées sur les grandes couvertures des ailes les plus proches du corps; les couvertures moyennes sont frangées de jaune. Les rémiges sont noires intérieurement, et vertes sur les barbes extérieures.; la dernière penne de l'aile est noire, et ses barbes sont tronquées, ce qui fait qu'elle est terminée en pointe. Les barbes extérieures de toutes les pcnnes caudales sont vertes, mais les barbes intérieures sont noirâtres; l'extrémité de toutes les pennes est d'un blanc nuancé de vert; le ventre a plusieurs nuances de jaune et d'orangé; l'abdomen et les couvertures inférieures de la queue sont jaunes; les tarșes sont à moitié emplumés; le reste, ainsi que les doigts, sont couverts d'écailles noires; l'origine du bec est de cette couleur, mais la pointe est blanchấtre; les yeux sont d'un jaune pâle.

Une variété que Latham dit être propre aux îles de Tongotaboo et d'Ulieta, mais qui se touve aussi à Timor, est représentée dans notre planche 35 : elle diffère de la précédente, en ce que le front et le sinciput sont d'un violet pourpré très foncé, sans être entouré d'une bande jaune; le vert de toutes les parties supérieures est plus foncé et bleuâtre; - les couvertures ne sont pas frangées de jaune; le ventre, ainsi que l'abdomen est vert ; enfin les pieds sont d'un brun rougeâtre, et le bec entièrement noir. Les naturalistes 
français qui furent de l'expédition commandée par le capitaine Baudin ont trouvé cette dernière variété du Kurukuru dans l'île de Timor.

Nous avons encore eu occasion d'examiner une variété qui n’avoit pas la plus légère apparence de violet sur la tête: nous ignorons si on doit attribuer cette différence au sexe.

Le jeune âge de cette espèce a le front coloré de gris-lilas entouré par une bande d'un jaune olivacé; l'occiput, le cou et la poitrine ont des teintes de gris et de jaunâtre terne; les ailes, le dos et la queue sont d'un vert foncé, mais peu brillant; toutes les couvertures sont frangées de couleur d'ocre; l'extrémité des pennes caudales n'a qu'une bande très étroite d'un gris foncé; le ventre, l'abdomen et les couvertures inférieures de la queue ont diverses nuances de couleur olive et de gris verdâtre; le bec est gris, et les pieds sont bruns.

Dans l'individu que nous avons examiné, toutes les plumes étoient minces, déliées et soyeuses; elles paroissoient indiquer que l'oiseau se trouvoit encore revêtu de sa première livrée; celleş de la poitrine ne laissoient distinguer que foiblement l'échancrure triangulaire, ’qui, dans les individus adultes, est très apparente, et telle que nous en avons figuré une plume dans notre planche 55 .

Les insulaires des diverses parties de l'Océan Pacifique désignent la Colombe de cet article par les dẻnominations suivantes. Ceux de Tongo-Taboo lui donnent le nom de Kurukuru, que nous avons adopté; les natifs d'OTáiti connoisssent l'espèce sous le nom d'Oopa ou Oopara. Latham nous dit que ce Pigeon fait sa principale nourriture du fruit du bananier, et qu'il s'apprivoise facilement.

Il est assez probable que la belle Tourterelle verte dont Bougainville fait mention est de la même espèce que celle de cet article; mais on ne sauroit s'en rapporter à des indications si vagues. Sonnini, dans sa nouvelle édition de Buffon, parle aussi du Kurukuru ; mais cet auteur se trompe en confondant cette espèce avec celle que Brown décrit sous le nom de Purple-Pigeon: le dérnier de ces Pigeons n'appartient même pas à la famille des Colombes. Nous le ferons mieux connoître dans notre seconde famille, sous le nom de Colombar Jojoo.

Nous avons reçu plusieurs individus de l'espèce du Kurukuru, qui nous ont été adressés de Batavia. Ces oiseaux ne sont pas rares dans les collections en Angleterre. L’individu quii nous a servi de modèle appartient à M. Dufresne du Muséum. 


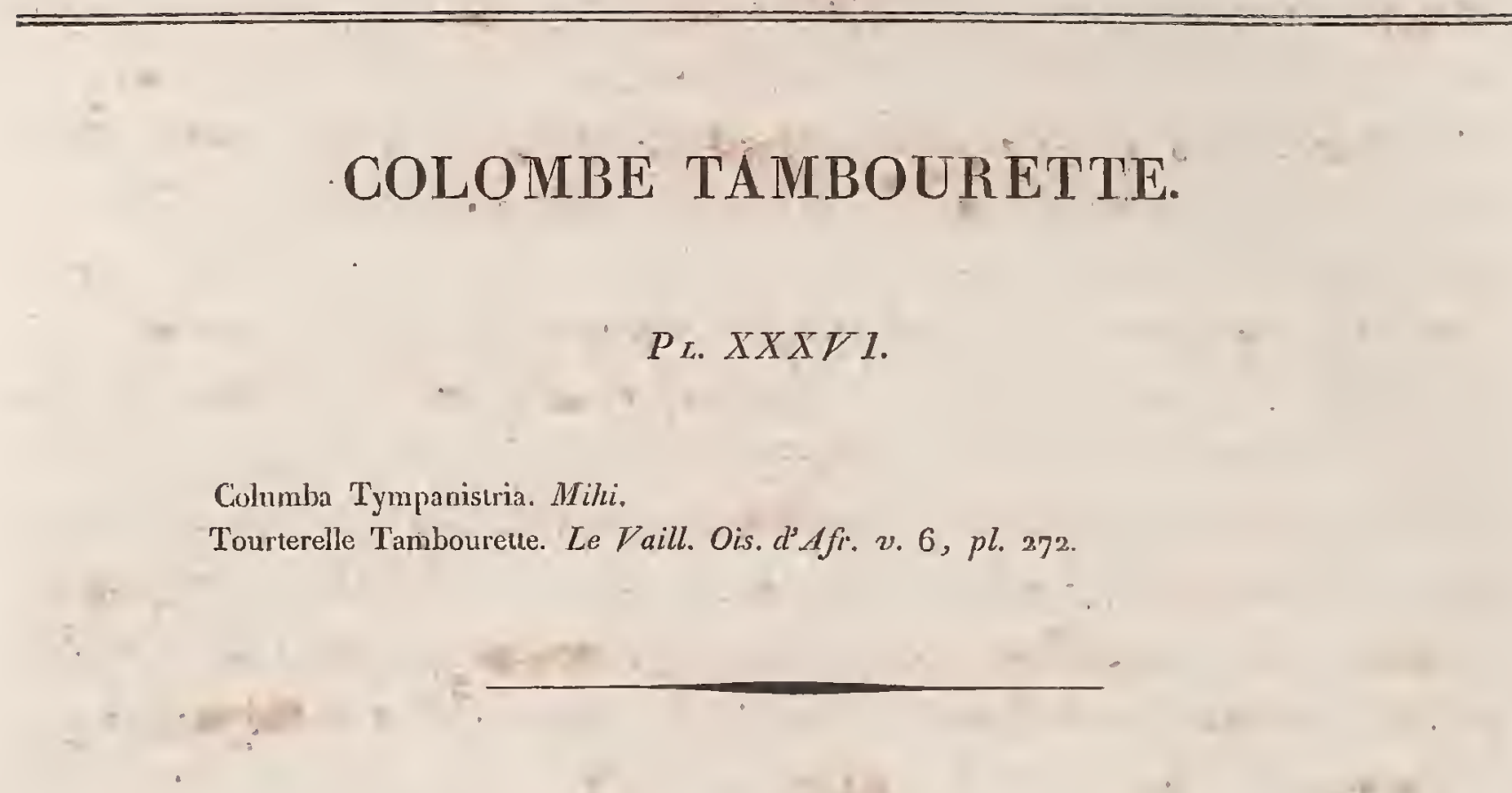

CEтte nouvelle espèce, dont aucun ornithologiste ancien n'a encore fait mention, a été trouvée en Afriqué par M. Le Vaillant. Cet ami a eu la bonté d'en déposer un individu dans ma collection, lors de son retour de ses voyages; et il vient récemment de me communiquer une note sur les mours de l'espèce.

Le roucoulement de ce Pigeon imite, à s'y méprendre, les sons d'un tambourin entendu d'une certaine distance, ce qui a déterminé le naturaliste cité à donner à l'espèce le nom de Tambourette. Elle habite les mêmes cantons que l'espèce de la Colombe Emeraudine, décrite et figurée par nous dans la planche 58 de cct ouvrage. La première, quoique modelée à peu près sur les formes de l'Emeraudine, et peu différente de celle-ci dans la distribution des couleurs, est cependant une espèce distincte: la Colombe Tambourette est plus forte de taille, son roucoulement est différent, ses mours varient encore avec ceux de l'Emeraudine. Cette dernière est douce et familière; elle place son nid sur les ramifications du gaulis ou dans les buissons. La Tambourette, au contraire, est vive dans ses mouvements, et sauvage; elle place son nid dans les grands bois, sur la sommité des arbres. M. Le Vaillant me dit que, sur plus de deux cents individus qu'il a tués de l'espèce de l'Emeraudine, il n'a pu se procurer que vingt-sept individus de la Colombe Tambourette. Nous renvoyons les lecteurs, pour les détails ultérieurs qui ont rapport à cette espèce, à l'Ornithologie africaine, où M. Le Vaillant se propose de la décrire.

La Colombe Tambourette mesure en totalité neuf pouces un quart. Le front, une espèce de sourcil qui passe sur les yeux, ainsi que toutes les 


\section{DES GOLOMBES.}

parties inférieures, sont d'un blanc pur; le haut de la tête, la partie postérieure du cou et le manteau sont d'un brun terreux; sur les couvertures des ailes les plus proches du corps se dessinent quelques grandes taches d'un bleu noirâtre, qui donne des reflets de vert foncé; les rémiges sont rousses sur l'intérieur des barbes, et brunẹ en dehors, la penne extérieure est la plus courte de toutes, et l'extrémité de sa barbe intérieure est tronquée; le croupion est d'un gris-brun, traversé de deux bandes plus foncées; la queue, composée de douze pennes, a les six pennes du centre d'un brunroux; la suivante de chaque côté a de cette couleur sur sa barbe extérieure, mais l'intérieure est grise à son origine, et terminée de noir; les deux latérales de chaque côté sont grisés à leur origine; il y a du noir vers leur extrémité, et la pointe est grise; les pieds sont jaunes; le bec et l'iris sont bruns.

La femelle a du blanc sale sur les parties où le mâle a du blanc pur : du reste, les deux sexes se ressemblent.

La Colombe Tambourette habite la partie méridionale de l'Afrique, vers le pays des Cafres. 


\title{
COLOMBE AZURÉE.
}

\author{
PL. $X X X V I I$.
}

Columba Crerulea. Mihi.

'Toutes les parties supérieures de cette jolie Colombe étant d'une brillante et vive couleur d'azur, nous en avons tiré son signalement spécifique. On nous a assuré que l'espèce habite au Bengale; ce dont nous ne saurions cependant garantir l'authenticité.

La longueur totale de la Colombe azurée est de neuf pouces; ses ailes atteignent à la moitié de la longueur de la queue, qui est arrondie.

Un bleú céleste ou couleur de turquoise orientale est répandu sur les parties supérieures; les joues et la gorge sont d'un blanc pur. On remarque sur le devant du cou et de la poitrine des teintes d'un brun fauve, nuancé d'un ton vineux; le ventre et l'abdomen sont blanchittres; les pieds et le cercle nu qui entoure les yeux sont rouges; la base du bec est rougeàtre, mais la pointe est d'un blanc jaunâtre.

Un individu de cette belle espèce faisoit partie du cabinet de M. Holthuysen, à Amsterdam. 


\title{
COLOMBE ÉMERAUDINE, Mâle et Variété.
}

\author{
P.. $X X X V I I I$ et $X X X I X$
}

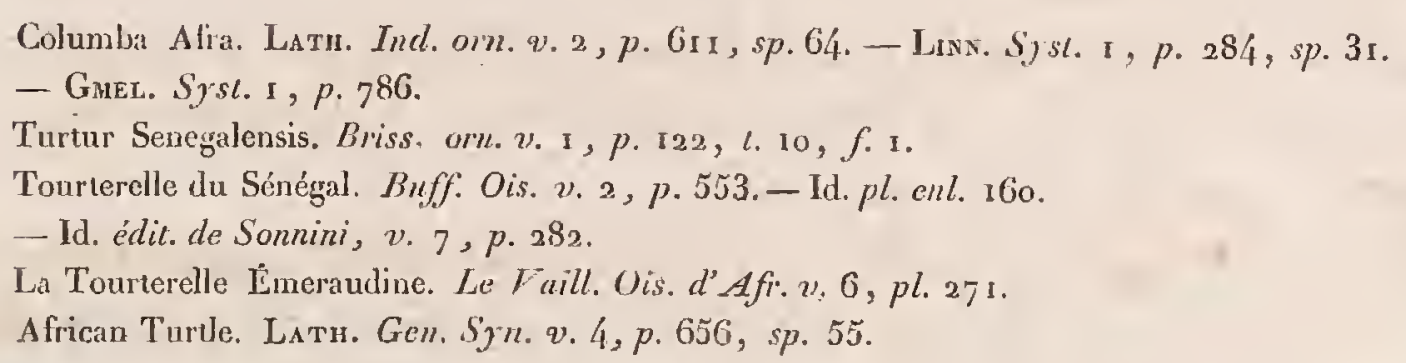

C'́st à tort que Buffon réunit sous lc même article de sa Tourterelle du Sénégal (assez cxactemcnt figurée dans les planches enluminées, $n^{\circ} .160$ ) deux autres espèces bien différentes, avec lesquclles la première n'a aucun rapport : ce naturaliste dit que sa Tourterelle à collier du Sénégal, pl. ${ }_{161}$, n'est qu'une variété de notre Émeraudine. Comme (continue le même auteur) la Tourterelle à collier d'Europe n'est qu'une variété de l'cspèce commune, voici, à ce quïl nous semble, deux erreurs. La première consiste dans la prétendue identité spécifique de notre Émeraudine avec la Tourterelle à collier du Sénégal, que nous ferons mieux connoìtre sous la dénomination de Colombe Blonde, pl. 4́. Cettc erreur va principalcment fixer notre attention à cet article, et nous relèverons la seconde, lorsquc nous parlerons de la Tourterelle vulgaire de nos climats.

Il est étonnant, si Buffon s'est effectivement assuré, par l'inspection des deux espèces de Pigeons désignés, que ce naturaliste éclairć ait pu se méprendre cn les confondant; mais il nous paroît plus vraisemblable quic sa description ait étć faite d'après les planches enluminées de son ouvrage. Quoi qu'il en soit, il est ccrtain que ces oiseaux n'ont entre eux aucun rapport. La Colombe Émeraudine est de plus d'un pouce et demi moins grande que la prétendue Tourterelle à collier du Sćnégal; il s'en faut qu'elle ait la queue aussi allongée en proportion du volume de son corps; ses ailes sont moins longues, son roucoulement est différent. Enfin il suffira de dire, pour relever toute incertitude sur ce que nous avançons, quc la 
Tourterclle à collier du Sénégal des planches enluminées 161 n'est qu'une Tourtcrelle à collier, et le véritable type de l'espèce qui, dans nos climats, se trouve réduite à la domesticité; espèce qui, comme nous le verrons plus loin à l'article de la Colombe Blonde, n'a que peu perdu de sa parfaite ressemblance avec la souche primordiale.

Il est encore une autre espèce que Buffon réunit à notre Émeraudine. Cet auteur présume que la Tourterelle à gorge tachetée du Sénégal, de Brisson, étant de la même grandeur et du même climat, n'est qu'une variété. Nous nous proposons de relever cette erreur à l'article de notre Colombe maillée, planche 45 de cet ouvrage.

Notre Colombe Émeraudine a été décrite par Brisson sous la dénomination de Toưrterelle du Sénégal. Latham, et en dernier lieu Le Vaillant, ont aussi donné une description exacte de cet oiseau : c'est à ce dernier que nous devons la connoissance plus parfaite de l'cspèce.

La Colombe Émeraudine est d'un tiers plus petite que la Colombe Tourterelle d'Europe: elle s'en distingue particulièrement par sa queue très courte et arrondic; sa longueur totale est de huit pouces; les pennes de sa queue n'ont que deux pouces neuf lignes; le dessus de la tête est d'un grisbleuâtre, qui blanchit un peu vers le front; la gorge est blanche; la partie inférieure du cou et la poitrine sont d'une couleur lie de vin claire, qui blanchit vers le bas-ventre, et les coavertures inférieures de la queue, le derrière du coú, le manteau et les couvertures alaires sont gris-brun; il y a sur quelques unes des couvertures les plus proches du corps, des taches d'un vert éclatant; les pennes secondaires de l'aile sont ronsses, qui est la couleur de toute sa partie intérieure; les rémiges sont d'un gris-brun sur leurs barbes extérieures; le croupion, d'un gris cendré, est traversé de deux bandes noirâtres; les couvertures supérieures dẹ la queue portent également deux båndes noires sur fond gris; les pennes caudales sont toutes noires en dessous, excepté la plus extérieure de chaque côté, qui èst blanche à son cóté extérieur, depuis son origine jusqu'aux deux tiers de sa longueur; en dessus, les deux du milieu sont brunes, et les latérales sont grisbrun à leur origine, et noirâtres vers leur' bout; lc bec est noir-brun; les yeux sont rougeâtres, et less pieds d'un rouge vineux.

La femelle est plus petite que le nâle, et lui ressemble en tout, à l'exception que les taches vertes des ailes sont chez elle plus petites que chez. ce dernier. Le mâle fait partie de ma collection, et la variété appartient it M. Dufresne, naturaliste. 
Une variété de cette espèce, que nous avons figurée planche 59 , diffère en ce que la totalité du plumage est d'une teinte plus claire. Un ton vineux y domine généralement par demi-teintes; les couvertures inférieures de la queue sont noires, et les grandes taches brillantes répandues sur les couvertures des ailes sont, dans cette variété, d'un beau violet à reflets pourprés; du reste, elle ressemble en tout à notre Émeraudine de la planche 38.

“ La Colombe Émeraudine, dit Le Vaillant, est très abondante vers les " rivières du Gamtos, du Louri et du Van-Staaden; on en voit aussi beau" coup sur les bords de la petite et de la grande rivière des Poissons, et " dans tout le pays des Cafres: elle niche dans les buissons et sur les rami" fications du Gaulis, et pond deux œufs blancs. Le roucoulement du mâle " s'exprime de la manière la plus touchante; c'est une suite de sons " langoureux cou-cou-cou-cou répétés à pèrte dhaleine, et en baissant " insensiblement la voix. Ces sons remplissent tellement l'air environnant, " que, malgré que l'oiseau les exprime souvent près de vous, car il est peu "farouche, on a peine à distinguer le lieu d'où ils partent. »

Cette espèce habite, comme on voit, la partie méridionale de l'Afrique, jusqu'aux pays des Cafres: on la retrouve encore au Sénégal. La variété décrite par nous, planche 39 , faisoit partie d'un envoi de ce pays : nous en avons reçu deux individus parfaitement semblables. L'Émeraudine figurée dans notre planche 58 fait partie du cabinet de M. Dufresne, au jardin des Plantes. 


\section{COLOMBE A DOUBLE COLLIER.}

$P_{L .} X L$.

Columba Bitorquata. Mihi.

Nous donnons ici la figure d'une espèce de Pigeon dont aucun auteur n’a fait mention; la longueur totale de l'oiseau est de onze pouces; le bec a dix lignes: celui-ci, quoique ayant ses deux mandibules semblables á celles de tous les autres Pigeons qui composent cette division, en diffère cependant en ce que la mandibule supéricure est courbée vers sa pointe, et forme un crochet très marquant; du reste, le bec est mince et peu renflé du bout.

La tête est d'un gris-cendré; le cou, la poitrine et le ventre sont de couleur vineuse. Ce Pigeon se distingue de tous ses congénères par deux colliers qui se dessinent sur la nuque; le premier, ou le collier supérieur, cst d'un blanc pur, et l'inférieur noir; le dos, les scapulaires et les moyennes couvertures des ailes sont d'un gris terreux; les petites couvertures sont d'un bleu couleur de plomb; les grandes et les moyennes pennes alaires sont grises; les trois plumes latérales de chaque côté de la queue sont noires intérieurement, depuis leur origine jusqu'au trois-quarts de leur longueur; le reste, ainsi que toute la barbe extérieure de ces pennes, est d'un gris blanchâtre; les pennes intermédiaires sont d'un gris terreux; l'abdomen est blanc; les pieds sont rouges, et le bec noir. Nous n'avons vu de cette belle espèce de Colombe que le seul individu qui fait partie du Muséum de Paris.

C'est au zélé naturaliste Maugé que nous devons la connoissance de cette nouvelle et rare espèce; elle habite l'Inde, mais nous ignorons dans quelle île Maugé a trouvé lindividu qu'il a préparé. 


\title{
COLOMBE VINEUSE.
}

\author{
PL. XLI.
}

+ Columba Vinacea. Mihi

$I_{L}$ ne sera pas inutile de prévenir les naturalistes, et principalement les méthodistes, de ne pas confondre la Colombe Vineuse, dont nous faisons le sujet de cẹt article, avec le Pigeon que Gmelin, et, d'après lui, Latham, citent dans leurs méthodes et index ornithologiques. La Colomba Vinacea (1) de ces auteurs n'est pas une espèce distincte. Nous avons fait observer, à l'article de la Colombe Blonde, que le Pigeon que ces naturalistes avoient en vue étoit le véritable type de nos tourterelles à collier, et nous avons à cause de cela ajouté tonte la synonymie de la Colomba Vinacea de Latham à celle de la Colomba Risoria du même auteur.

La Colombe Vineuse de cet article est une de ces espèces qu'on peut appeler nouvelle, aucun auteur' n'en ayant fait mention. Nous ne connoissons aussi de cet oiseau que l'extérieur, dont la seule dépouille que nous ayons examinée fait partie du Muséum de Paris. Nous nous bornerons donc à décrire succinctement les couleurs du plumage de ce Pigeon.

La longueur totale de la Colombe Vineuse est de dix pouces; son bec a huit lignes; la quene est étagée comme celle de nos tourterelles vulgaires; mais ses ailes sont plus courtes en proportion de celles de nos tourterelles. La tête, le cou, ainsi que toutes les parties inférieures de l'oiseau sont d'une belle couleur lie-de-vin, ou pourpre foncé. Les ailes, le dos et la quene sont d'un brun-bistre uniforme; le bec est noir, les pieds sont d'un rougebrun, et les ongles bruns.

(1) Gmel. Sy.st. 1, pl. 782. - Lath. Ind. orn. v. 2, pl.61 r. - Le même que le Turtur 'Torquatus Senegalensis. Briss. orn. v. 1, pl. I24. - Enfin le Pigeon figuré par Buffon, $\%$. $16 \mathrm{r}$, sous la dínomination de Tourterell à collier du Sénégál. 
Cette Colombe est la moins bigarrée de toutes les espèces connues; sa livrée uniforme charme cependant par la nouveauté des teintes. Nous remarquons généralement que la couleur vineuse est répandue sur le plumage d'une grande quantité d'espèces de Pigeons; aucune cependant ne l'a si décidée, et d'une nuance absolument semblable au dépôt ou à la lie d'un vin fortement coloré.

Cette espèce habite la Guiane française. 


\title{
COLOMBE TOURTERELLE.
}

\author{
PL. XLII.
}

\author{
Columba Turtur. Latr. Ind. Orh. v. 2, p. 605, sp. 47. - Gret. Syst. x, p. 786.

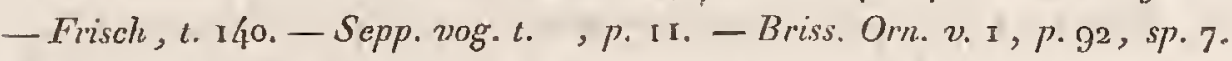 \\ Columba Orientalis. Latн. Ind. Orn. v. 2, p. 606, sp. 48. \\ Turtur Auritus. Ray, Syn.p. I84, sp. 26. - Sloan. Jam.p. 304 , t. 262. \\ La Tourterelle. Buff. (Ois. v. 2, p. 545, t. 25 . - Id. pl. enl. 394. \\ La Tourterelle grise de l'île de Luçon. Sonnerat, Voy. p. 52, t. 2.2. \\ La Tourterelle brune de la Chine. Somnerat, Voy. Ind. v. 2, p. 177. \\ Common Turtle. Alb. v. 2, Ł. 47.-Latir. Syn. v. 4, p. 64亿. \\ Luzonian Turtle. and Chinese Turle. LAтr. Syn. v. 4, p. 646 et 647 .
}

Tous les naturalistes ont séparé les Tourterelles des Pigeons proprement dits et des Ramiers. Ces trois divisions, dans le genre Pigeon, n'ont été jusqu'ici fondées sur aucune règle constante. On ne sauroit mème trouver les causes qui ont déterminé les naturalistes à cette méthode. La seule à présumer nous paroìt résider dans la différence de taille qu'ont entre elles ces prétendues familles, différence qui peut servir de base pour distinguer nos quatre espèces de Pigeons propres au climat de l'Europe, mais qui n'a pas de limites assez exactement déterminées pour servir à ranger dans ces mèmes sous-classes toutes les espèces de Pigeons exotiques que nous connoissons dans ce genre déjà très nombreux. Rien n'est plus difficile, en faisant usage de cette ancienne méthode, que de classer les Pigeons dans les divisions Ramier-Pigeon proprement dit et Tourterelle, et d'assigner à chaque espèce sa véritable place. Le défaut de cette division est prouvé par le peu d'accord qui règne à cet égard dans la plupart des ouvrages qui traitent de ces oiseaux. Tel auteur donne le nom de Ramier à un oiseau qu'un autre a rangé dans sa division des Pigeons proprement dits, et rien n'est plus incertain que la place que doivent occuper les Tourterelles. Si on s'en étoit toujours tenu à la règle, toute défectueuse qu'elle est, de n'appeler 
Tourterelle que tel Pigeon qui seroit plus petit ou de la même taille que la Tourterelle d'Europe, on auroit du moins eu une base fixe et la limite certaine des subdivisions; mais des naturalistes ont donné la dénomination de Tourterelle à des oiseaux de la taille de notre Biset, parcequills avoient la queue fortement ćtagée, ainsi qu'à d'autres dont la queue se trouvoit carrée, caractère cependant qui auroit dû les déterminer à ranger préférablement ces oiseaux dans leur division des Pigeons proprement dits, quoique ces premiers se trouvoient être en effet plus petits que la Tourte- . relle vulgaire qui servoit de type à ces auteurs.

Nous a vons déjà rendu compte aux naturalistes qui nous ont précédés, des raisons qui nous ont détermınés à ne pas adopter leur manière de voir sur ce point, et nous avons eru que la division des Pigeons en sous-classes se trouveroit mieux définic par la méthode que nous établissons pour cet ouvrage. Nous continuerons donc à placer tous ces oiseaux qui ont des rapports avec notre Tourterelle dans notre première famille. Celle-ci contiendra, comme nous avons dit ailleurs, tous les Ramiers, Pigcons proprement dits, ainsi que les Tourterelles dont les formes extérieures ont rapport à l'espèce qui habite notre climat. Nous établirons ensuite une seconde section dans la famille des Colombes, pour ceux de ces Pigeons qui ont la queue fortement étagée en forme de cône.

La Tourterelle, ou Colombe Tourterelle, est un oiseau de passage qui arrive dans les parties tempérées de l'Europe vers le commencement de mai, et dans les régions plus froides vers la moitié du même mois : elle nous quitte à la fin de l'été, à l'époque où les jeunes de l'année se trouvent en état de soutenir les fatigues dı voyage; c'est alor's qu'elles vont chercher des contrćes plus chaudes, afin d'y séjourner jusqu'au renouvellement de la belle saison dans nos climats.

La Tourterelle est non seulement répandue dans presque toute l'Europe, mais on la trouve aussi en Chine, ou elle porte le nom de Pancou. Celle dont Sonnerat (1) fait mention sous le nom de Tourterelle brune de la Ghine apparticnt indubitablement à notre espèce. Il en est de même de la Tourterelle grise de Luçon, décrite par le même

(I) Son eou, sa poitrine et son dos sont d'une teinte terreuse brunàtre, qui est plus elaire vers la gorge; de chaque eôté du cou il $y$ a quelques plumes noires, dont les extrémités sont d'un gris-cendré elair. Les petiles couvertures des ailes sont brunes, terninées par du jaune d'orpiment; quelques unes, sur les bords de l'aile, sont grises; le ventre et les euisses sont teints d'un gris vineux plus clair, et blanehâtre sur les couvertures inférienres de la queue; l'iris, le bec et les pieds sont rouges. 
auteur (1). Nous voyons dans le second voyage de Siam (2) que notre espèce se trouve aussi dans ce royaume : elle est encore répandue dans tout le vaste continent de l'Inde. Nous avons reçu une Tourterelle tuée au Bengale, absolument semblable à celles qui habitent en Europe. Ce fait, et le témoignage de quelques voyageurs qui ont vu notre Tourterelle dans les diverses parties de l'Inde et sur les côtes d'Afrique nous semblent des preuves assez convaincantes à opposer au sentiment de Buffon, qui présume que les climats de la zone torride opèrent, par la seule influence de leur température, plus exposée aux rayons ardents du soleil, des changements dans le plumage des oiseaux.

Si notre Tourterelle est effectivement le type d'un grand nombre de variétés, dont Buffon fait l'énumération, et qu'il attribue à l'influence du climat, comment se fait-il donc que l'espèce se retrouve en Chine, dans l'Inde et sur les côtes d'Afrique, revêtue de la même livrée que dans notre pays?

La Tourterelle recherche les lieux les plus retirés et les plus sauvages; elle aime la fraicheur en été, et son nid se trouve d'ordinaire près de quelque eau limpide. Ge nid est composé de menu bois, disposé à clairevoie, tellement qu'il est facile de découvrir à travers, et du pied de l'arbre, les deux oufs blancs que l'oiseau couve. La femelle partage alternativenent avec le mâle les soins de l'incubation.

Les Tourterelles sont très communes en Angleterre, particulièrement dans la province de Kent; leur migration dans cette contrée a lieu vers la fin d'août ou au commencement de septembre. A l'arrière-saison, elles se répandent dans les champs de blé et d'avoine nouvellement moissonnés; elles sont aussi très friandes de pois : on voit ces Pigeons se réunir par centaines dans les endroits où on a fait la récolte de ces semences.

La Tourterelle mesure en totalité onze pouces; ses ailes ont six pouces et demi de longueur; elles s'étendent jusqu'aux trois-quarts de la longueur de la quene. La partie supérieure de la tête et la partie postérieure du cou

(I) La poitrine et le ventre sont d'un gris-vinenx; la tête et le eou d'un gris-cendré; quelques plumes sur les eôtés du cou sont terminées par une bande noire; les rémiges sont noirầtres, les couvertures sont de cette eouleur, mais terminées par une teinte d'un jaune brunàtre; les plumes du dessus de la queue sont noires, celles du dessous sont blanches; le bec, l'iris et les pieds sont rouges.

(2) Nous vîmes dans le royaume de Siam deux sortes de Tourterelles; la première est semblable aux nôtres, et la chair en est bonne; la seconde a le plumage plus heau, mais la chair en est jaunátre el de mauvais goût. Les campagnes sont pleines de ees Tourterelles. (Second voyage de Siam, p. 248, et Geronier, Histoire naturelle et politique de Siam, $p .35$.) 
sont cendrées; le dos, le croupion et les couvertures du dessus de la queue sont bruns; les couvertures des ailes sont variées de brun et de roux. La première de ces couleurs occupe le centre des plumes, et la seconde les contours; le poignet de l'aile, ainsi que les convertures qui la bordent, sont grises; les rémiges sont d'un brun noirâtre, liserées de gris-blanc; le devant du cou et la poitrine sont d'une belle couleur vineuse; les flancs sont gris; le ventre, l'abdomen et les couvertures inférieures de la queue sont d'un blanc pur; les pennes caudales sont gris-brun en-dessus, et noirâtres en-dessous; toutes, excepté les deux du milieu, sont terminées de blanc; la plus extérieure de chaque côté a aussi ses barbes extérieures blanches. Sur les côtés du cou sont quelques plumes noires terminées de blanc, ce qui forme une espèce de tissu en mailles lâches; les yeux sont entourés d'un petit cercle rouge dénué de plumes; l'iris est d'un rouge tirant sur le jaune, le bec d'un brun bleuâtre; les pieds sont rouges et les ongles noirs.

Nous terminerons la description de cette espèce, en faisant observer que toutes les plumes de la Colombe Tourterelle, ainsi que celles des individus rapportés des climats chauds, sont arrondies et parfaitement intactes du bout, tandis que dans un grand nombre d'espèces très distinctes, mais que Buffon désigne comme autant de variétés qui doivent leur origine à notre espèce vulgaire, il s'en trouve plusieur's dont les plumes de certaines parties sont échancrées du bout, en forme d'angle ouvert. Une variété dans celte espèce de Pigeon a toute l'étendue des deux côtés du cou garnie de plumes noires, terminées par une tache blanche de forme arrondie; elle diffèrè en cela de la précédente, qui n’a qu'une tache peu considérable, composée seulement de dix-huit ou de vingt plumes noires à leur origine, et terminées par une bande blanche. Latham nous apprend que des individus ainsi variés ont été envoyés du Cap de Bonne-Espérance et de la Chine : ils se trouvent aussi dans nos climats. Un pareil individu tué en Angleterre est déposé dans le Leverian Muséum.

Une autre variété est figurée par Albin, v. 2, pl. 48, et décrite par Brisson, v. 1 , p. 99, en ces termes: Tout son corps, savoir la tète, la gorge, le cou, le dos, le croupion, la poitrine, le ventre, les côtés, les jambes et les couvertures du dessus et du dessous de la queue, sont d'un brun foncé; de chaque côté du cou sont quelques plumes uoires terminées de blanc. Les petites couvertures des ailes sont noires bordées de blanc; toutes les autres sont d'un brun foncé bordées de jaune; les rémiges sont noirâtres, et leur 
DES COLOMBES.

bord extérieur est blanchâtre : celles du milieu de la queue sont d'un cendré foncé, et terminées de blanc. Les latérales sont blanches à leur côté extérieur et à leur bout, et leur côté intérieur est d'un cendré foncé. L'iris est jaune, le bec noir, et les pieds rouges.

Il nous paroît probable que la variété dont nous venons de faire mention doit être considérée comme accidentelle. La couleur généralement rembrunie du plumage de cet individu semble être produite par le genre de nourriture. La graine de chanvre, donnée en trop grande quantité aux Pigeons, ainsi qu'à tous les autres oiseaux, opère une variété singulière dans leur plumage, qui se teint le plus souvent de couleurs sombres. Quelquefois aussi elle produit une bigarrure noirâtre. 


\title{
COLOMBE A NUQUE PERLÉE.
}

\author{
PL. XLIII.
}

Columba Tigrina. Miki.

Columba Suratensis. Laтr. Ind. orn. v. 2, p.609, sp. 55.

- Gmed. S st. $1, p .778$.

La Tourterelle grise de la Chinc. Son. voy. Ind. $2.3, p .176, t .102$.

- Sonnini, édit. de Buff. v. 7 , p. 277 , note.

La Tourtcrelle de Surate. Son. voy, Ind. v. 2, p. 179.-Sonnini, édit. de Buff. v. 7, p. 307 .

(où ce naturaliste réunit trois espèces très distinctes.)

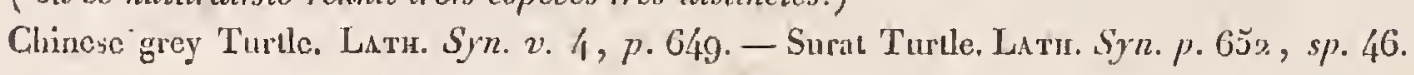

IL nous paroît que Sonnini a eu tort de réunir dans son- article de la Tourterelle de Surate trois espèces bien distinctes. Sonnerat, qui le premier a décrit ces Pigeons, en fait mention comme formant autant d'espèces; et rien n'est plus facile, en prenant la peine de confronter ces descriptions avec les espèces mentionnées par cet auteur, que de s'assurer de cette vérité. Il est hors de tout doute que Sonnerat a fait un double emploi du Pigeon que nous décrivons à cet article. Ce voyageur le décrit et en donne une figure assez exacte sous le nom de Tourterelle grise de la Chine, et plus loin il cite encore cet oiseau comme étant la Tourterelle de Surate. Au reste, cette erreur de Sonnerat est excusable, et il n'est pas difficile d'en sentir la cause.

Il n'a pas fait attention que l'espèce dont nous nous occupons se trouvoit également répandue dans tout le continent de l'Inde, ainsi qu'à la Chine. Il n'est donc pas étonnant qu'induit en erreur sur l'existence de ce Pigeon dans deux contrées très distantes l'une de l'autre, il les ait supposé former deux espèces, d'autant plus que les individus de cette Colombe qui se trouvent au Béngale ainsi que dans les îles du vaste Océan indien (où l’espèce est aussi répandue), diffèrent de ceux envoyés de la Chine, en ce que les premiers ont de chaque côté, sur les bords des plumes qui composent 
l'espèce de collier, une tache blanche carrée (1), tandis que les individus envoyés de la Chine ont sur les parties latérales de ces plumes une tache plus ou moins arrondie: du reste, ils se ressemblent parfaitement.

Il sera donc nécessaire d'ajouter doréna vant toute la synonynie du Columba. Suratensis de Gmelin et de Latham à celle de la Tourterelle grise de la Chine, indiquée par Sonnerat. Nous avons donné une nouvelle dénomination systématique à ce Pigeon; parceque l'espèce ne se trouve pas exclusivement confinée dans l'Inde, et que plusieurs naturalistes ont confondu cette Colombe avec leur Columba Risoria, qui est notre Colombe blonde : il suffira de jeter un coup-d'oil sur nos planches qui représentent cés Pigeons, pour se convaincre que ces oiseaux n'ont entre eux aucun rapport.

La Colombe à Nuque perlée est non seulement répandue daus le vaste empire de la Chine, mais on trouve encore l'espèce sur le continent de l'Inde et dans toutes les îles de l'Océan indien; elle est très commune à Java, où M. Laischeneau a vu l'espèce et en a rapporté un individu. Les voyageurs qui furent de l'expédition du capitaine Baudin ont rapporté un individu tué à Timor. Plusieurs m'ont été envoyés de la Chine, d'autres m’ont été adressés de Batavia. Nous avons déjà parlé de la légère différence qui se trouve dans les individus de ces contrées; variété qui peut-être ne doit être attribuée qu’à l'âge ou au sexe.

La Colombe à Nuque perlée mesure en totalité dix pouces et demi; ses ailes ployées ont cinq pouces deux lignes. Celles-ci atteignent environ à la moitié de la longueur des pennes caudales. Le haut de la tête et la nuque sont d'un gris-vineux; la gorge blanchâtre prend une teinte vincuse sur le devant du cou. La poitrine est colorée de vineux clair. Sur la nuque est un collier large d'un pouce; toutes les plumes qui le composent sont profondément échancrées en forme d'angle ouvert : elles sont noires dans toute leur longueur. Celles du haut du cou ont sur la partic latérale de chaque plume une tache quadrangulaire; celles du bas du cou ont une pareille tache, mais de couleur terreuse. Les plumes du haut du dos sont d'un gris brun, terminées par une bande d'un jaune terre d'ocre: les grandes, les moyennes

(1) Ces taches carrées ont été eonsidérées et indiquées par Sonncrat comme des bandes blanches et rousses qui terminent eharjue plume: on peut eependant s'assurer que ce ne sont pas effectivement des bandes qui termincnt les plumes de la collerette. Elles paroissent telles quand les plumes sont couchées les unes sur les autres; mais quand on les relève, on voit que la tache blanchc ne sc trouve gne snr les parties latérales des plumcs, le centre de celles-ci étant profondément échancré. 
couvertures, et quelques unes des petites les plus proches du corps sont gris-brun. Les petites couvertures du poignet de l'aile et le bord extérieur de celle-ci sont de couleur gris-cendré. Sur tontes les plumes de ces parties se dessine une bande longitudinale plus sombre, qui suit la direction de la baguette; cette bande s'élargit vers l'extrémité des plumes, qui ont encore une tache couleur d'ocre sur la partie latérale de chaque barbe. Les rémiges sont noiràtres, légèrement frangées de grisâtre; les pennes moyennes de l'aile, le croupion, les couvertures supérieures de la queue et les quatre pennes intermédiaires de celle-ci sont gris-brun, les autres sont grises à leur origine, ensuite elles ont une bande noirâtre qui les traverse vers leur centre, et les trois pennes latéraleśs de chaque côté sont terminées de blanc. En dessous toute la queue est noire depuis son origine jusqu’à la moitié de sa longueur: le reste est blanc. Le ventre, les cuisses, l'abdomen et les couvertures inférieures de la queue, sont blancs; les flancs ont des teintes de gris et de vineux : les petites plumes qui forment les paupières sont blanches; le bec est noir, les yeux sont ronges et les pieds jaunes.

M. Laischeneau a rapporté un individu qu'il a tué dans l'île de Java. Il a eu la bonté de me communiquer que les Javans désignent l'espèce par le nom de Frecoucou. Ce Pigeon est commun daus les forêts; il habite de préférence la lisière des bois. On l'apprivoise facilement.

Lindividu qui a servi de modèle au dessin de madame Knip est déposé dans le Muscum de Paris, ainsi que celui rapporté de Timor. La Colombe à nuque perlée que je possède m’a été envoyée de Batavia. 


\section{COLOMBE BLONDE.}

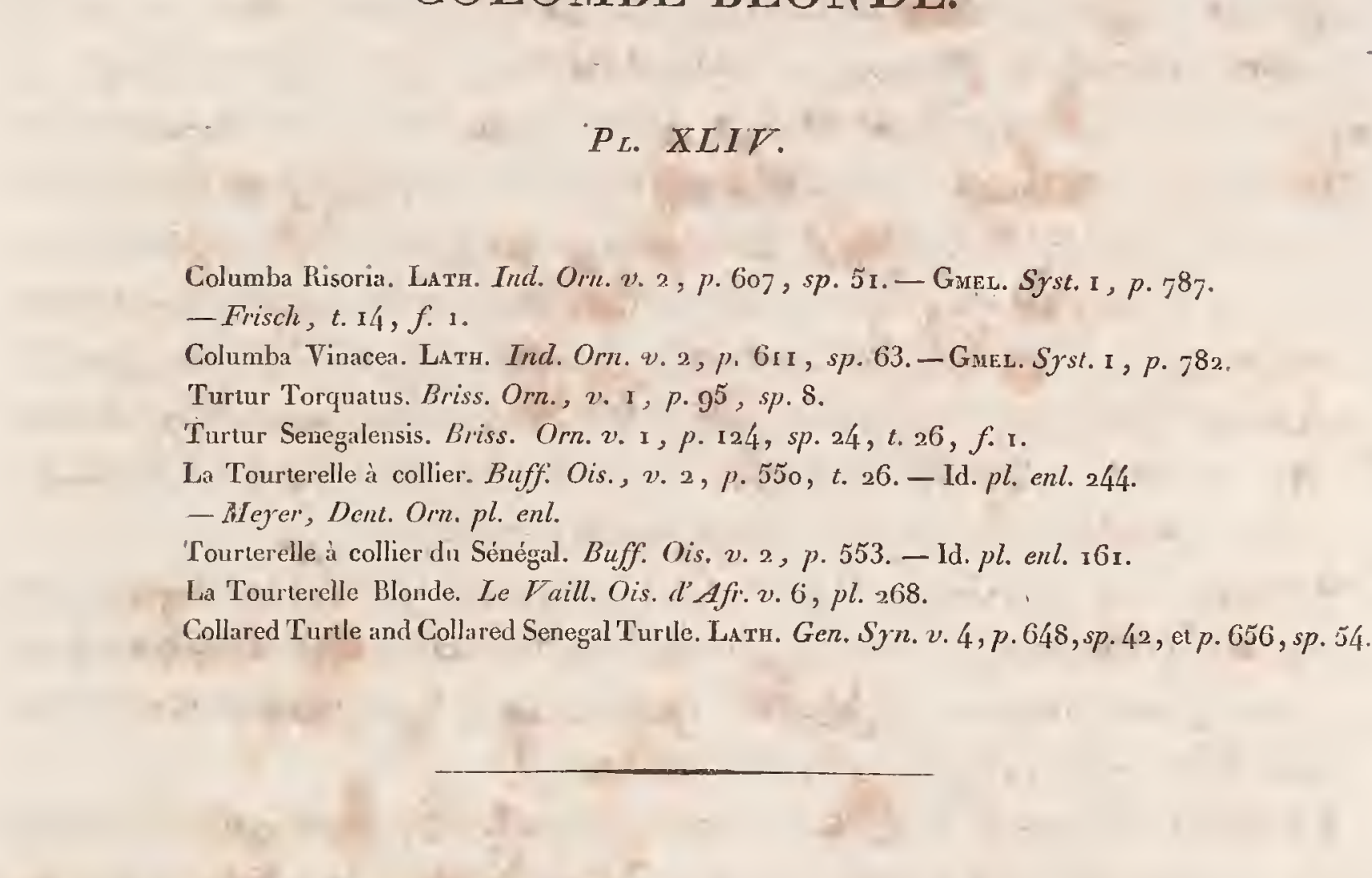

$\mathrm{O}_{\mathrm{N}}$ ne sauroit se faire une idée juste des raisons qui ont pu déterminer Buffon à considérer la Colombe à collier comme une seconde race ou variété constante dans l'espèce de notre Tourterelle Vulgaire, bien moins encore ce qui a pu porter ce célèbre naturaliste à avancer qu'elle se trouve dans nos climats. Quoi qu'il en soit, il est certain que ces Pigeons ne forment pas une race ou variété constante de notre Tourterelle commune, puisque c'est même avec quelque difficulté que nous réussissons à tirer des métis du mélange de ces espècẹs, métis qui ne doivent l'existence qu'aux soins industrieux de l'homme, et que la nature n'auroit jamais pu produire. Au reste, la Tourterelle vulgaire est propre à nos climats, et l'autre n'y est tenue qu'en cage, où elle produit par les soinś que nous avons coutume de lui prodiguer.

L'espèce qui fait le sujet de cet article a donc été transportée des pays chauds; ce que nous prouve son naturel sensible au froid, même encore après une domesticité qui paroît déjà fort ancienne. Nous reconnoissons cet oiseau, à ne pas s'y méprendre, dans la description que Brisson donne de la Tourterelle à collier du Sénégal, espèce que Buffon rapporte mal à propos à sa Tourterelle du Sénégal, pl. enlum. 160. Nous avons déjà parlé de cette erreur de Buffon à l'article de notre Colombe Emeraudine. Un naturaliste 
moderne, à qui nous sommes déjà redevables de plusieurs découvertes intéressantes pour l'ornithologie, a trouvé l'espèce qui nous occupe vivant dans une entière liberté, et pullulant dans l'état sauvage au milieu des antiques forêts de l'Afrique méridionale (1). Thunberg a trouvé dans toutes les contrées australes de l'Afrique cette Tourterelle à collier : elle se plait surtout dans les lieux garnis de buissons. Cet oiseau, dit-il, ne change jamais de place sans rire ensuite, d'où lui vient son nom spécifique de Risoria. Ses ris et ses hou-hou indiquent le lieu de sa retraite; sa chair rôtie est assez sèche. On peut présumer, en combinant ces découvertes avec l'état de domesticité où ce Pigeon se trouve réduit par-tout ailleurs, que l'espèce est originaire d'Afrique, et considérer l'oiseau décrit par Brisson, sous le nom de Tourterelle à collier du Sénégal, ainsi que celui décrit par Le Vaillant, pl. 268, comme le type de nos Tourterelles à collier.

Sonnini nous apprers qu'il a vu des Tourterelles à collier en Egypte, où les habitants les aiment beaucoup et en prennent un soin particulier. Nous ignorons si cet auteur a vu l'espèce en liberté, ou bien si elle s'y trouvoit, comme chez ṇous, réduite à la domesticité.

La dénomination de Colombe à collier pouvant être appliquée à plusicurs autres espèces qui portent-ussi de ces colliers sur la partie postérieure du cou, nous préférons de nous ranger de l'avis de Le Vaillant, et d'adopter la dénomination de Colombe Blonde, comme plus propre à distinguer cette espèce.

Le Vaillant n'a rencontré des Tourterelles Blondes que sur les confins du pays des Grands-Namaquois; elles sont plus petites de taille que celles que nous élevons en domesticité; mais leur roucoulement est absolument le même. Elles nichent sur les arbres, pratiquent un nid plat pareil à ceux que construisent nos Tourterelles, et pondent deux cufs tout blancs.

Cette espèce mesure en totalité dix pouces et demi; ses ailes, lorsqu'elles sont en l'état du repos, ont six pouces trois lignes. Tout son plumage est d'un joli gris de perle, nué d'une légère teinte purpurine, blanchissant sur le devant de la tête et sur les parties inférieures, et prenant un ton fauve isabelle sur le dos et les ailes. Les rémiges sont noirâtres, bordées de fauve. Les pennes de la queue sont cendrées en dessus, et toutes, excepté les deux du milieu, terminées de blanc. La plus extérieure de chaque côté a aussi ses barbes extérieures blanches: la partie supérieure du cou est entourée 
DES COLOMBES.

d'un collier noir d'environ deux lignes de largeur : le bec est noirâtre ; l'iris et les pieds sont rouges.

La femelle diffère peu du mâle, sinon que son collier est plus étroit que celui de ce dernier, et qu'elle a la poitrine d'une teinte plus claire.

Le mâle a beaucoup de tendresse pour sa femelle; il se tient volontiers auprès d'elle, sur-tout pendant la nuit, et cherche à lui témoigner son amour par des sons qui ressemblent assez à l'éclat de rire. Il fait encore entendre un son plaintif, mais qui n'a rien de désagréable, et qu'on peut rendre par les syllabes kukuruku.

La Colombe Blonde, ainsi que plusieurs autres oiseaux, est sujette à prendre une livrée entièrement blanche. Dans cet état, il seroit facile de confondre l'espèce avec la véritable Colombe Blanche, qui est toujours de cette couleur; mais il suffira de_dire ici que, sans prendre garde à la taille ni aux formes totales de ces oiseaux, qui diffèrent sensiblement entre eux, il est malgré cela facile de reconnoître la Colombe Blonde Blanche. Outre que tout le manteau et les couvertures des ailes conservent toujours dans celle-ci une légère teinte isabelle, et que l'origine des pennes caudales est d'un ton plus grisâtre, elle se distingue encore par les petites plumes qui forment le collier, et sont toujours nuancées, vers leur extrémité, d'une teinte moins blanche, qui forme le caractère distinctif de l'espèce. 


\title{
COLOMBE MAILLÉE.
}

\author{
PL. XLV.
}

Columba Cambayensis. Latr. Ind. Orn. v. 2s p. 6og, sp. 56. - Guel. Syst. 1, p. 779

Turtur gutture maculato Senegalensis. Briss. Orn. v. $1, p .125, s p .25, t .8, f .3$.

Columba Senegalensis. Lath. Ind. Orn. v. 2 , p. Gro, sp. 6r. - Gmer. Syst. I, p. 782.

Tourterelle à gorge tachetée du Sénégal. Buff. Ois. थ. 2, p. 552, à l'arlicle de la Tourlcrelle du Sénégal.

La Tourterelle grise de Surate. Sonnerat, Voy. Ind. 2'. 2, p. 180.

- Sonnini, édit. de Buff. v. 7, p. 307 .

La Tourterelle Maillée. Le Vaill. Ois. d'Afr. v. 6, pl. 270 .

Senegal Turtle. Lath. Gen. Syn. v. 4, p. 655, sp. 53.

Cambayan Turtle. Id. p. 652, sp. 47.

Nous avons dit, à l'article de la Colombe Émeraudine, espèce que nous avons fait connoître d'une manière à éviter dorénavant toute méprise, que Buffon avoit méconnu l'espèce que nous décrivons ici, en la confondant avec la Tourterelle du Sénégal, de même qu’avec celle qu'il nomme Tourterelle à collier du Sénégal, trois pigeons qui forment cependant autant d'espèces très distinctes.

Brisson parle de notre Colombe Maillée avec cette vérité que nous admirons toujours dans les descriptions de ce naturaliste. Le Vaillant, qui a étudié les mœurs de ces Pigeons dans les parties méridionales de l'Afrique, nous en donne aussi une description très exacte. Enfin Sonnerat l'a décrit, à ne pas le méconnoître, sous le nom de Tourterelle grise de Surate, espèce que cet auteur donne à juste titre comme différente de sa Tourterelle de la côte de Malabar, et encore différente de la Tourterelle de Surate, qui est notre Colombe à nuque perlée, $\mathrm{pl}$. 43. On ne sauroit dire pourquoi Sonnini réunit sous un même article ces trois Pigeons; certes ce n'est pas d'après un examen de leur extérieur, puisquili a méconnu deux de ces Pigeons qqui sont déposés dans les galeries du Muséum de Paris, où cet anteur auroiı pu s'assurer des différences qui caractérisent ces espèces.

La Colombe Maillée semble répandue sur une grande étendue de pays du continent d'Afrique; Le Vaillant a trouvé l'espèce dans la partie méridionale qu'il a parcourue. Brisson nous apprend qu'un individu fut envoyé 
du Sénégal par M. Adanson à M. de Réaumur. Le Vaillant en a vu plusieurs venant de cette partie de l'Afrique; et Sonnerat, au témoignage duquel nous devons ajouter foi, a rencontré l'espèce sur le continent de linde, aux environs de Surate.

La longueur de cet oiseau, prise du bout du bec à l'extrémité de la queue, est d'environ dix pouces; ses ailes pliées s'étendent jusque vers la moitié de la longueur de la queue; la tête et le haut du cou sont d'une belle couleur vineuse; toutes les plumes de la poitrine sont profondément échancrées; cette partie prend une teinte roussâtre variée agréablement de lignes noires, formant des espèces de mailles lâches; la partie supérieure du dos est d'un brun mêlé de roux, chaque plume étant brune et terminée de roussâtre clair' les couvertures les plus proches du corps sont colorées de même; les autres sont d'un gris-bleu; les moyennes pennes de l'aile sont cendrées; les rémiges sont noirâtres; le ventre a une légère teinte vineuse; cette couleur blanchit vers l'abdomen et les couvertures inférieures de la queue; celles-ci sont d'un blanc pur. Les pennes de la queue sont noires en dessous, depuis leur origine jusque vers la moitié de leur longueur, le reste est blanchâtre en dessus; les six pennes du milieu sont d'un brun-cendré, et les trois latérales de chaque côté sont plus foncées à leur origine, et le reste, vers le bout, est blanc. Le bec est d'un noirbrun jaunissant vers la pointe; les yeux sont orangés, et les pieds d'un rouge clair.

La femelle est un peu plus petite que le mâle, et ses couleurs sont moins vives.

" Le Vaillant nous apprend que cette Colombe habite la côte ouest au " sud de l'Afrique : on commence à la rencontrer vers les monts Camis, " et de là jusque chez les Grands-Namaquois. On la voit par-tout sur les " bords du Kausi, du Swart-Doorn; mais elle n'est nulle part aussi abon" dante que sur les bords de la Grande-Rivière, ou rivière d'Orange, et celle " des Lions. Ce Pigeon niche, comme nos Tourterelles, sur les arbres, " et roucoule à peu près comme elle. La femelle pond deux oufs blancs. » Nous avons vu plusieurs individus de cette espèce rapportés d'Afrique par Le Vaillant. Un de ceux-ci fait partie de mon cabinet. Nous en avons vu d'autres exactement semblables venant du Sénégal. Dans le Muséum de Paris se trouve un bel individu de ce joli Pigeon, qui a servi de modèle à Madame Knip. Nous ne saurions dire au juste de quelle partie du globe il a été rapporté. 


\section{COLOMBE BLANCHE.}

Columba Alba. Mihi

La Tourterelle Blanche. Sonnini, édit. de Buff. v. $7, p .6_{7}, f .2$.

Nous donnons à cette espèce, bien caractérisée, le nom de Colombe Blanche, parceque effectivement elle est toujours et totalement de cette couleur.

Il est étonnant qu'on ait constamment confondu cette petite Colombe avec la Colombe Blonde, planche 44, qui est sujette à prendre une livrée blanche. Nous avons déjả parlé de cette variété; mais il nous paroît nécessaire de réitérer à cet article notre observation, que les Colombes Blondes Blanches se distinguent du premier coup-d'œil, en ce que le manteau, les couvertures des ailes, le croupion et les deux pennes intermédiaires de la queue conservent toujours une légère teinte isabelle, et que la partie supérieure du dessous de la queue est d'un ton plus grisàtre; elles se distinguent encore par la couleur plus sombre des petites, plumes qui forment le collier. En ne prenant même aucuné notice de ces différences qui se trouvent seulement dans les teintes plus ou moins vives du plumage, et qui sont susceptibles à varier dans les divers individus, il sera encore facile de reconnoître l'espèce de cet article.

La Colombe Blanche est moins forte de taille que la Colombe Blonde; elle a un pouce de moins sur sa longueur totale, sa queue est plus courte; ses ailes, plus longues en proportion, atteignent aux trois quarts de la longueur des pennes caudales, tandis que les ailes de la Colombe Blonde aboutissent vers le milieu de la queue, qui, dans cette espèce, est allongée et plus étagée; enfin la Colombe. Blanche a tout le plumage d'un blanc de lait; ses pieds sont d'un rouge rosé; lïris est rouge, et le bec est d'un rouge noirâtre. 
Sonnini a représenté, dans sa planche 67 , fig. ${ }^{\mathrm{re}}$, notre Colombe Blonde, et sa fig. 2 représente la Colombe Blanche. Les caractères qui ont rapport aux formes, et qui servent à distinguer ces deux Pigeons, y sont parfaitement saisis. La Colombe Blanche paroît être originaire de la Chine; elle se trouve souvent représentée sur les papiers et tapisseries travaillés dans ce pays.

M. Dúfresne, du Muséum d'Histoire naturelle, nous a fait voir deux figures très exactes de cet oiseau dans deux collections différentes de dessins originaux peints sur les lieux par les Chinois. Dans nos climats, l'espèce est réduite à la domesticité; on ne voit ces oiseaux qu'en cage. Ils sont très sensibles au froid, qu'ils paroissent supporter moins facilement que les Colombes Blondes. 


\title{
COLOMBE A LARGE QUEUE.
}

\author{
PL. LXVII.
}

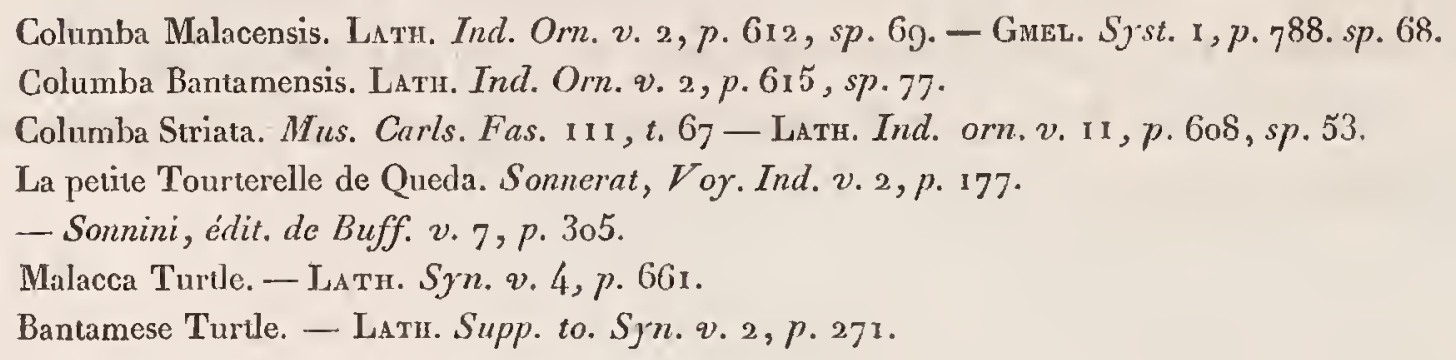

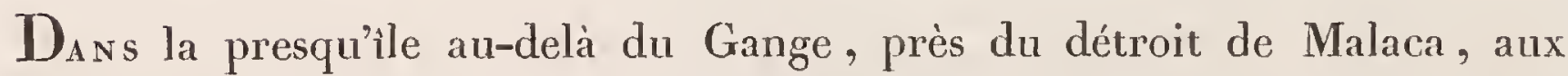
Moluques et dans les îles de la Sonde, habite une jolie petite espèce de Colombe dont le corps n'est guère plus gros qu'un moineau, mais qui est plus allongée: la queue est presque aussi longue que le corps et la tête prises ensemble; elle est composée de quatorze pennes, ce qui la rend très large, sur-tout quand l'oiseau l'étale, ce qu'il a l'habitude de faire souvent. Mon ami Laischenault, qui a vu ce petit Pigeon dans l'île de Java, dit qu'il fréquente les lisières des grands bois, où il construit son nid sur les arbres. Les Javans font grand cas de cet oiseau. Ces peuples superstitieux présument que, tenus en cage dans leurs habitations, ils les préservent de l'enchantement par les sons agréables de leur roucoulement; aussi est-il fréquent de voir payer les Javans vingt piastres pour une de ces Colombes, sur-tout si elles ont la voix belle et les signes extérieurs de bon augure; et, ce qui doit les rendre encore plus recherchées, c'est que leur chair offre un mets très délicat. Ils sont connus en langue javane par le nom de BouronPercoutoute. A la Chine on leur donne le nom de Forvat.

Ces jolis Pigeons ont été transportés à l'île de France, où ils ont pullulé : l'espèce s'y trouve maintenant en grande abondance; nous en avons reçu 
plusieurs de Batavia. On doit les mettre à l'abri du froid, sur-tout dans les premiers temps de leur séjour. Ces charmants oiseaux s'apprivoisent facilement; leur roucoulement est aussi harmonieux que touchant. Le mâle et la femelle se prodiguent mille caresses, et tous leurs mouvements sont gracieux : il n'est cependant point d'exemple qu'ils aient produit dans nos climats. Deux individus de cette espèce ont vécu long-temps dans la volière de mon père.

La longueur totale de la Colombe à large queue est de huit pouces; la queue seule a quatre pouces; les ailes, peu allongées, dépassent de fort peu l'origine des pennes caudales. Nous avons déjà fait remarquer que cette espèce a la queue large, composée de quatorze pennes; les dix qui occupent le centre sont d'égale longueur; mais les deux latérales de chaque côté sont beaucoup plus courtes. L'extérieure aboutit à la moitié de la longueur des pennes intermédiaires; ce qui fait que, vue en profil, la queue paroît fortement étagée. Nous terminons par cette espèce la première section dans la famille des Pigeons Colombes; elle se lie, par la forme de sa queue à pennes latérales, étagées, aux Colombes de la seconde section, qui ont toutes les pennes d’inégale longueur, et dont la queue présente la forme d'un fer de lance.

C'est pour n'avoir pas bien saisi cette conformité, que Latham décrit l'espèce sous le nom de Malacca Turtie et de Barred Turtle, et que, dans sa section des Pigeons à queue très étagée, il en fait encore un article séparé, sous la dénomination de Bantamese Turtle. Il nous paroît que ce naturaliste auroit dù s'apercevoir de cette méprise, ses différentes descriptions se rapportant évidemment à notre Colombe à large queue.

Cette espèce a le front et la gorge d'un gris bleuâtre clair ; l'occiput est brun; les plumes de la nuque des côtés du cou, des parties latérales de la poitrine et des flancs, sont rayées alternativement de blanchâtre et de brun noiràtre. Celles de la nuque ont une teinte plus roussâtre : tout le dos, les couvertures des ailes et le croupion sont d'un gris terreux; les plumes de ces parties sont terminées par une étroite bande noire; les grandes et les moyennes pennes des ailes sont d'un brun noirâtre en dessus. L'aile est roussâtre; le centre de la poitrine a une légère teinte vineuse. Cette couleur devient plus claire en approchant du ventre, qui, de mème que l'abdomen et les couvertures inférieures de la queue, est d'un blanc pur; les pennes de la queue sont d'un noir brun : les deux intermédiaires sont d'un brun terreux. Les trois latérales, noires depuis leur origine jusqu'aux trois quarts de leur longueur, sont blanches sur le reste. La quatrième penne de chaque 
côté a seulement sa pointe terminée de blanc. Le bec est noir, lavé de jaune à sa racine et à son extrémité ; l'iris et les pieds sont de couleur jaune d'orpiment.

La femelle diffère peu du mâle; elle a les teintes en général moins vives; le gris bleuâtre du front et de la gorge est plus terne, et les raies transversales du cou et des flancs sont moins prononcées dans celle-ci.

Nous avons reçu de Batavia plusieurs individus de cette belle espèce. Celui que M. Laischenault a rapporté fait partie du Muséum de Paris: M. Dufresne en possède un. Deux individus, dont l'un mâle et l'autre femelle, font partie de mon cabinet. Celui qui a servi de modèle à Madame Knip appartient à M. Le Vaillant. 


\section{LES COLOMBES.}

SECONDE SECTION.

Colombe à queue fortement étagée dans la forme d'un cône.

COLOMBE VOY A GE USE, Màle et Femelle.

$P_{L .} X L V I I I$ et $X L I X$.

MAs.

Columba Migratoria. Lath. Ind. Orn. v. 2, p. 612, sp. 70

- Gmer. Syst. I , p. 789 .

OEnas Americana. Briss. Or'n. v. 1, p. I00, sp. 12.-Frisch., t. 142

Pigeon de passage. Cat. Car. v. I, t. 23. - Sonnini, édit. de Buff. v. 7, p. 210

Passenger or Migratory Pigeon. LA Ti. Syn. v. $4, p .66 \mathrm{I}$

FEMINA.

Columba Canadensis. LAтr. Ind. Orn., v. 2, p.613, sp. 72.

- GuÉL. Syst. I , p. 785. - Briss. Orm. v. I p p I18, sp. 2 I.

Tourterelle de Canada. Buff.pl. enl. I 76 - Sonnini, v. $7, p .280, p l .68, f$. I

Canada Turtle. Lath. Syn. v. 4, p. 658.

$\mathrm{L}_{\mathrm{A}}$ belle espèce de Colombe qui fait le sujet de cet article doit avoir été mal connue des naturalistes, puisque aucun d'eux ne donne de l'extérieur de ce Pigeon une description vraie que l'on puisse présumer être le fruit de la connoissance parfaite de l'espèce. Tous font mention de la femelle Colombe Voyageuse dans un article différent de celui du mâle, et forment de celle-ci une espèce distincte. Nous réunissons done ici sous un même 
article ces deux indications (1), qui ont rapport au mâle et à la femelle de notre Colombe Voyageuse.

Buffon, v. 2, p. 527 , fait mention de cet oiseau, que nous supposons être le mâle, puisque l'auteur cite à cet endroit le Pigeon de passage de Frisch, et celui décrit par Catesby sous le même nom, qui en effet ont donné tous les deux une figure assez exacte du mâle de notre Colombe Voyageuse. Buffon dit, à l'endroit cité : “Que ce Pigeon ne diffère de nos "Pigeons fuyards et devenus sauvages que par les couleurs et par les plumes « de la queue qu'il a plus longues, ce qui semble le rapprocher de la Tour“ terelle; mais ces différences ne nous paroissent pas suffisantes pour en " faire une espèce distincte et séparée de celle de nos Pigeons. »

Un peu plus loin, à la page $55_{2}$ du même volume, Buffon fait mention et donne une figure, pl. 176 , de la femelle de notre Colombe Voyageuse, qu’il désigne comme une espèce différente, puisque ce naturaliste en parle sous le nom de Tourterelle du Canada; mais ce qui est encore plus inconcevable, c'est qu'à cet article Buffon compare la femelle de notre Colombe à l'espèce de la Tourterelle Vulgaire, tandis qu'il paroît considérer le mâle comme peu différent de nos Pigeons sauvages, ou Bizets. Voici, au reste, ce que l'auteur cité dit à l'article de sa Tourterelle du Canada : “ La Tourterelle, comme le “Pigeon et le Ramier, a subi des variétés dans les différents climats, et se " trouve de mème dans les deux continents. Celle qui a été indiquée par “M. Brisson sous le nom de Tourterelle du Canada, et que nous avons fait " représenter, est un peu plus grande, et a la queue plus longue que notre "Tourterelle d'Europe; mais ces différences ne sont pas assez considérables “ pour qu'on en doive faire une espèce distincte et séparée (2). Il ine paroît " qu'on peut y rapporter l'oiseau donné par Edwards sous le nom de Pigeon “ à longue queue, planche 15 , et que M. Brisson a appelé Tourterelle “ d'Amérique (3). Ces oiseaux se ressemblent beaucoup; et comme ils ne “ diffèrent de la Tourterelle que par leur longue queue, nous ne les regar" dons que comme des variétés produites par l’influence du climat. »

(I) Voyez l'Index Aves Columber qui termine ce volume.

(2) Pour réfuter Buffon à cet article, il suffira de renvoyer les naturalistes à la pllanche 42, qui représente notre 'Tourterelle vulgaire; en la comparant anx planches de cet article, il ne restera, je pense, aucun doute sur les différences hien caractérisécs qui se trouvent entre ces deux espèces de Pigeons.

(3) Buffon se trompe encore à cet endroit: Je Pigeon déorit par Edwards, et fignré par lui planche r5, est une espèce toute différente, que Buffon décrit très exactement dans un autre article, sous le nom de Tourte, sans qu'il paroisse se douter de ce donble emploi. (Voyez notre planche 5o.) 
Les Colombes habitent l'Amérique, entre le vingtième et le soixantième degré de latitude. Elles passent la saison chaude dans les contrées septentrionales, et, aux approches des frimas, elles émigrent et vont chercher un climat plus doux. Dans les pays situés à une latitude plus méridionale, on les appelle Pigeons des bois. Ces oiseaux construisent leur nid sur les arbres de haute futaie, et pondent deux oufs blancs : leur chair est un mets exquis.

On a peine à se faire une idée, dit Latham, de l'innombrable quantité de ces Pigeons voyageurs. A l'époque de leur migration, leur essaim nombreux, dont l'étendue occupe quelquefois deux lieues de terrain sur un quart de lieue de largeur, obscurcit l'air. A la chûte du jour, toute une troupe se perche en peloton serré sur les arbres, dont les branches plient sous le poids. Le peuple de Philadelphie a coutume de les abattre de dessus les toits des maisons. A la Nouvelle-Angleterre, on les abat durant leur halte de nuit; ce qui n'est pas difficile, vu que ces Colombes sont aisées à approcher, la fatigue les rendant peu farouches. A la Louisiane, on les surprend pendant la nuit. Quand les chasseurs se sont assurés qu'une troupe de ces Pigeons a pris possession d'un arbre pour s'y reposer, ils l'entourent d'herbes odoriférantes, et y mettent le feu. Les Colombes, suffoquées par la fumée, tombent de l'arbre, et devienuent pour eux une proie facile.

Latham s'est trompé en déçrivant la femelle Colombe voyageuse sous le nom de Cancida Turlle, et avançant, a cet article, dans le Synopsis of birds v. 4 , p. 658, que cet oiseau (qu’il décrit du reste fort exactement). a les plumes de la queue d'égale longueur. Ce naturaliste répare cette dernière erreur dans son index, où il en fait mention dans la division des Pigeons ă queue en forme de cône. Brisson décrit succinctement le mâle sous le nom de Pigeon sauvage d'Amérique. Le même auteur parle un peu plus loin de la femelle, sous la dénomination de Tourterelle du Canada. Nous reconnoissons parfaitement cette dernière dans la description de Brisson; mais il a eu tort de parler d'une femelle qu'il croit appartenir à l'espèce de sa Tourterelle du Canada. L'oiseau que ce naturaliste présume être de ce sexe n'est effectivement qu'une variété accidentelle dans l'espèce, variété qui cependant est assez rare, et que nous nous contenterons d'indiquer succinctement, après avoir décrit le mâle et la femelle, que nous avons figurés dans les planches qui accompagnent cet article.

Le mâle a seize pouces depuis la pointe du bec jusqu'à l'extrémité de la queue, qui seule en a huit. Les ailes, longues de huit pouces, aboutissent vers le milieu de la longueur de la queue : un gris-bleu cendré est la couleur 
dominante du haut de la tête, des jones, du derrière du cou, des moyennes couvertures des ailes et du croupion. Sur les côtés du cou sont quelques plumes violacées à reflets dorés; du gris-terreux est répandu sur le manteau et sur les grandes couvertures des ailes, qui ont toutes des taches noires disposées irrégulièrement sur les barbes extéricures. Les rémiges sont noirâtrés, bordées de blanc roussâtre; une teinte d'un roux nuancé de vineux est répandue sur les plumes du devant du cou, de la poitrine et du ventre. Elles prennent un ton plus clair sur cette dernière partie, et deviennent blanches vers l'abdomen. Les couvertures inférieures de la queue sont de cette dernière couleur; les deux pennes du milieu de la queue sont noirâtres : toutes. les autres sont d'un gris-blanchâtre. Celles-ci ont vers leur origine, sur leurs barbes intérieures, une grande tache rousse au-dessous de laquelle est une grande tache noirâtre. Les yeux sont placés dans un petit espace dénué de plumes, de couleur rouge : l'iris est d'un rouge orangé; le bec est noir et les pieds rouges.

La femelle, qui est d'un ponce moins grande dans toutes ses dimensious que le mîle, s’en distingue aussi par les couleurs du plumage. Chez celle-ci, le haut de la tête, le derrière du cou, le manteau et les grandes couvertures alaires sont d'un gris-brun; elle a, comme le mâle, des taches noires sur ces dernières. Les plumes des cộtés du cou, quoique nuancées de légères teintes violacées, n'ont cependant pas les reflets brillants et dorés. Le croupion est, comme chez le mâle, d'un gris-cendré ; mais les convertures du dessus de la queue, et les deux pennes intermédiaires de celle-ci sont d'un brunterreux; toutes les autres pennes sont gris-blanc: la partie intérieure des barbes a les mêmes grandes taches rousses et noires. Le devant du cou, la poitrine et le ventre ont diverses teintes de cendré-brun et de blancgrisâtre. Cette première nuance règne principalement sur la poitrine, tandis que la dernière est répandue sur le reste des parties inférieures de l'oiseau.

Une variété que Brisson donne à tor't comme la femelle de sa Tourterelle du Canada a toutes les plumes de la tête, du cou, de la poitrine et de la partie supérieure du dos, terminées par une bande d'un blanc-grisâtre.

Nous avons examiné plusieurs individus de cette espèce. Parmi ce nombre il s'en trouvoit qui u'avoient pas une taille aussi forte que celle des deux individus dont nous donnons ici la mesure. Un mâle de cette espèce est déposé au Muséum de Paris, et M. Dufresne possède celui qui a servi de modèle au dessin de madame Knip. Deux de ces Pigeons, mâle et femelle, font partie de mon cabinet; c'est cette dernière que représente la planche 49. 


\title{
COLOMBE TOURTE, Măle.
}

\author{
Pr. L. \\ + Columba Carolinensis. Latr. Ind. Orn. v. 2, p. 613, sp. 71. - Gmer. Syst, 1, p. 789 . \\ -Briss. Orn. v. I, p. I10. sp. I8, $1.8, f$. I. \\ Columba Marginata. Latr. Ind. Orn. w. 2, p. 614, sp. 73. - Guex. Syst. ז, p. 79 г. \\ Turtur Americanus. Briss. Orn., v. I, $p$. 1or, sp. 24. \\ La Tourte, ou Tourterelle de la Caroline. Buff. pl. enl. i 75 . Femelle. \\ La Tourterelle à longue queue. Ediv. t. 15. Le mále. \\ Tourterelle de Caroline. Seligm. Samm. selt. Vogel, v. I, pl. 48. Mâle. \\ Carolina Pigeon. Lath, Syn. v. 4 , p. 663. \\ Marginated Pigeon. $I d, v .4, p .66 \%$.
}

LA plupart des auteurs ont encore fait un double emploi de cette espèce; ils donnent la description du mâle dans un article, sous les noms de Tourterelle à longue queue, Tourterelle d'Amérique, et de Tourterelle de Caroline. Buffon en fait mention comme d'une variété dans l'espèce de sa Tourterelle du Canada (1). Il décrit la femelle de la Tourte sous cette dénomination; mais dans sa planche enluminée, l'oiseau y porte le nom de Tourterelle de la Caroline. Latham, en copiant Brisson, a commis la même erreur. Cet auteur décrit le mâle sous le nom de Marginated Pigeon; et, un peu avant, il fait un autre article de la ferrielle sous le nom de Carolina Pigeon. Nous pensons qu'il est nécessaire de relever ces erreurs, afin de procurer par la suite aux méthodistes et aux compilateurs la faculté de déterminer avec plus de précision leur synonymie, vu que ces derniers ne se soucient guère de vérifier leurs méthodes sur la nature: renfermés dans le centre de leur bibliothèque, ils assignent de là à chaque espèce la place qu'elle doit occuper.

La Tourte mesure en totalité onze pouces; la queue seule en a environ cinq. Les ailes, lorsqu'elles sont pliées, sétendent jusqu'au quart de la longueur de celle-ci. Le mâle, dans cette espèce, se distingue principalement par quelques plumes noires, lustrées de violet, placées immédiatement

(1) Cet oiseau, dont nons ıenous de parler dans l'article précédcut, est la femelle de la Colomive voyagense. 
au-dessous de l'orifice des oreilles. La partie antérieure de la tête et la gorge sont d'un brun roussâtre; l'occiput est d'un bleu-cendré; les parties supérieures de l'oiseau sont d'un gris-brun foncé; les scapulaires et les grandes couvertures des ailes les plus proches du corps sont marquées vers leur extrémité de taches noires ovales de différentes grandeurs. La partie inférieure du dos, le croupion et les convertures du dessus de la queue, sont d'une teinte cendrée. La partie inférieure du cou jette des reflets de violet et de vert-doré : la poitrine et le devant du cou sont d'un rouge vineux qui s'éclaircit par demi-teintes sur les flanes et sur le ventre, prenant un ton de brun-cendré. Depuis la base du bec jusqu'aux yeux s"étend, de chaque côté, une étroite ligne blanchc; les pennes de l'aile sont d'un brun foncé, et ont leur bord extéricur roussàtre; celles de la queue sont fortement étagées; les deux du milieu sont les plus longues; les autres vont en diminuant par degrés jusqu'à la plus extérieure, qui n'excède guère la moitié des pennes du centre. Ces dernières sont brun-cendré; les deux qui suivent de chaque côté sont cendrées à leur origine, marquées de noir dans le milieu, et cendré-clair vers le bout : les trois latérales sont cendrées depuis leur origine jusqu'au centre; ensuite elles sont noires, et toutes sont terminées de blanc. Le tour des yeux est nu, de couleur terne; liris est brun; le bec est couleur de corne, et les pieds sont rougeâtres.

La femelle est un peu moins grande que le mâle; elle n'a pas de tache violacée au-dessous de l'orifice des oreilles. Les plumes des cơtés du bas du cou n'ont point de reflets dorés, et le devant du cou, ainsi que la poitrine, est d'un cendré-brun : cette couleur règne en général sur toutes les parties inférieures de l'oiseau.

La Tourte se trouve à la Caroline, au Brésil, à Porto-Rico et à SaintDomingue. Latham nous dit que l'espèce habite à la Caroline durant toute l'année, et qu'elle y niche.

L'individu mâle qùi a servi de modèle appartient à M. Dufresne. Nous avons vu un mâle et une femelle dans le Leverian Muséum, à Londres, et un au Muséum de Paris. 


\section{COLOMBE A MOUSTACHE.}

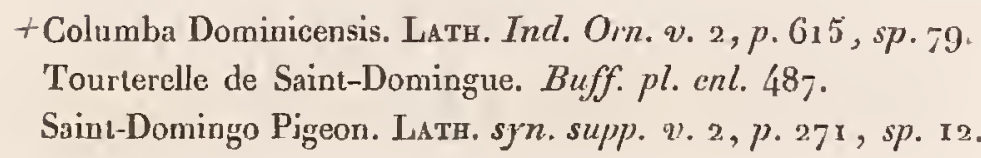

Ciet te jolie espèce, dont Buffon a donné le premier une figure très exacte, habite, avec l'espèce du précédent article, les contrées méridionales du nouveau continent. Nous ne connoissons de cette Colombe que l'extérieur, dont nous donnerons une description succincte. La longueur totale de la Colombe à Moustache est de onze pouces; la queue est moins longue que dans les espèces dont nous venons de parler; elle est cependant à pennes d'inégale longueur, et présente la forme d'un còne. Le front et la région des yeux sont blancs; la gorge l'est aussi. Cette couleur se dirige sur une partie des côtés du cou, et se joint sur la nuque. Sur le haut de la tête est une large bande transversale noire, qui semble la partager en deux parties. De la base du bec se dirige, en passant sous les yeux, une moustache noire qui s'élargit vers son extrémité, et dont les plumes recouvrent l'orifice des oreilles : un large collier noir entoure le cou vers le milieu de sa longueur. La poitrine est de couleur vineuse; mais vers les parties latérales il y a des plumes pourprées à reflets métalliques : toutes les parties supérieures sont d'un brun-terreux. Sur les plumes scapulaires et les grandes couvertures sont quelques taches noires. Les rémiges sont noirâtres, bordées extérieurement de gris-blanc. Le ventre est brun-cendré; les pennes de la queue sont grises; toutes, excepté les deux du milieu, ont leur extrémité blanche : le bec est noir, et les pieds sont rougeitres. 
On trouve l'espèce à Saint-Domingue, et probablement aussi dans les autres parties de l'Amérique méridionale situées sous le même degré. Nous présumons que l'individu figuré par nous à cet article est le mâle de l'espèce : nous ne saurions cependant l'affirmer. Le seul individu que nous ayons eu occasion de voir faisoit autrefois partie du Muséum Leverian, à Londres. 


\title{
COLOMBE MAUGÉ.
}

\author{
Pr. LII.
}

+Columba Maugeus. Mihi.

Nous dédions aux mânes d'un des naturalistes les plus zélés pour l'Histoire naturelle la nouvelle et rare espèce de Colombe qui fait le sujet de cet article. La découverte de ce Pigeon étant due aux recherches de l'infortuné Maugé, nous espérons que le foible tribut que nous nous empressons de consacrer à sa mémoire emportera l'approbation des amis qui lui furent attachés; et nous osons nous flatter que les naturalistes conserveront le nom donné à cette espèce, par égard au dévouement actif de celui qui s'exposa plusieurs fois dans des voyages périlleux afin d'enrichir les sciences du fruit de ses découvertes intéressantes.

Cette Colombe ressemble tellement, au premicr abord, à la Colombe à large queue, qu'on la croiroit être de la même espèce. Ces Pigeons diffẻrent cependant beaucoup, et forment deux espèces distinctes et séparées. Il ne sera donc pas inutile, en renvoyant nos lecteurs aux planches qui représentent ces oiseaux, d'indiquer encore les principaux caractères qui les distinguent.

La Colombe à large queue est moins grande que celle de cet article; elle n'a pas la taille aussi svelte; sa queue, composée de quatorze pennes, a les dix pennes du milieu d'égale longueur, et seulement les deux latérales de chaque côté plus courtes et étagées; ses pieds sont jaunes; enfin tout le devant de la poitrine, le milieu du ventre et l'abdomen, n'ont point de stries horizontales. En comparant cette courte indication à la description que nous allons donner de la Colombe Maugé, les naturalistes seront convaincus que ces deux espèces, quoique d'une grande ressemblance entre elles, à les voir superficiellement, n'ont effectivement aucune analogie. 
La Colombe Maugé mesure en totalité dix pouces; son corps n'est guère plus gros que celui de l'Étourneau; la queue est très longue, composéc de douze pennes fortement étagées; la penne latérale de chaque côté n'atteint pas à la moitié de la longueur des deux pennes du centre, qui sont les plus allongées; le front et la gorge sont d'un gris couleur de plomb; le devant du cou, la poitrine, les flancs et le ventre, sont rayés d'étroites bandes qui alternent régulièrement du blanc au noir; le dos est gris-terreux, avec des taches irrégulières plus foncées; les deux pennes intermédiaires sont gristerreux dans toute leur longueur; les latérales sont noires, et terminées de blanc; le bec et les pieds sont noirs.

La Colombe Maugé habite les îles de l'Australe-Asie. Le naturaliste à qui nous sommes redevable de la connoissance de cette belle espèce, n'ayant pas eu le bonheur de retourner dans sa patrie, nous ignorons jusqu'aux plus légers détails relatifs à sa manière de vivre.

Deux individus parfaitement conservés sont déposés dans les galeries du Muséum de Paris. M. Dufresne en possède aussi deux qui nous ont servi de modèle. 
COLOMBE TOURTELETTE, Mâle et Femelle.

\author{
P. LIII et LIV
}

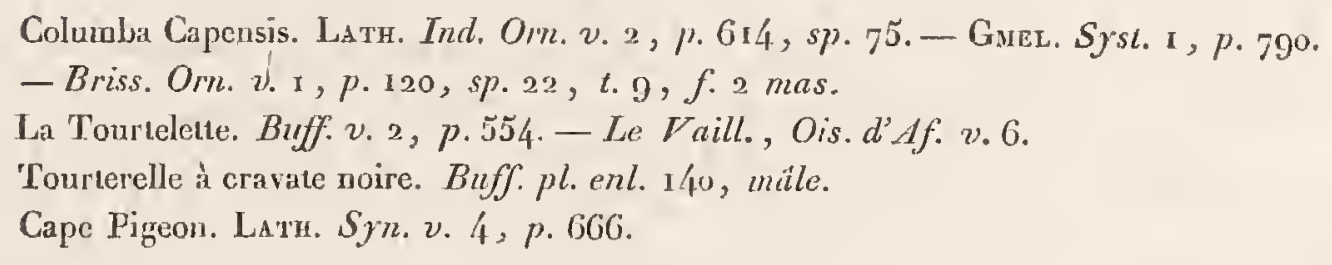

$\mathrm{L}_{\Lambda}$ Tourtelette est la plus petite espèce d'entre la famille des Colombes; son corps est de la grosseur d'un moineau vulgaire; mais sa queue, longue de cinq pouces un quart, le fait paroître d'un plus gros volume; la longueur totale de l'oiseau, mesurée depuis le bout du bec jusqu'à celui de la queue, est de neuf pouces six lignes; ses ailes, lorsqu'elles sont pliées, atteignent au tiers de la longueur de la queue, qui est très étagée; les six pennes intermédiaires sont de beaucoup plus longues que les trois latérales de chaque côté, et ces dernières ne sont que légèrement étagées entre elles. Le mâle de cette espèce a toute la face, de même que le devant du cou, d'un beau noir; cette couleur forme une large bande longitudinale le long du cou, et se termine sur la poitrine. L'occiput, le derrière du cou, le manteau, le dos et toutes les couvertures supérieures, tant des ailes que de la queue, sont d'un cendré-terreux; sur quelques unes des grandes couvertures alaires est une tache d'un noir violacé à reflets dorés; trois bandes noires très étroites traversent le croupion. Les rémiges sont rousses sur leurs barbes intérieures; en dehors et vers le bout elles sont noirâtres; les pennes de la queue sont d'un gris foncé à leur origine; les six intermédiaires sont terminées de noiràtre; les latérales ont une bande noire vers leur extrémité, et leur bout est gris; la plụs extérieure de chaque côté a sa barbe extérieure blanche; en 
dessous la quene est entièrement noire; le ventre et l'abdomen sont d'un blanc pur; le bec est jaunâtre, et les pieds sont rouges.

La femelle a toute la tête, le cou, la poitrine, les grandes couvertures des ailes, le dos, et l'origine des deux pennes du centre de la queue, d'un gristerreux; toutes les petites couvertures des ailes, et quelques unes des moyennes couvertures, sont d'un gris-cendré ; elle a, comme le mâle, trois petites bandes transversales sur le croupion: lé ventre et l'abdomen sont blancs. On trouve l'espèce répandue dans toute la partie méridionale de l'Afrique. Elle habite aussi au Sénégal, et pent-être mème sur toute la côte d'Afrique.

Le mâle et la femelle de cette espèce font partie du cabinet de M. Raye de Breukelerwaert, a Amsterdam. Deux individus semblables sont déposés dans mon cabinet. Un mâle fait partie de la collection du Muséum de Paris. M. Dufresne possède les deux oiseaux qui nous ont servi de modèle.

Quoique nous ayons visité la plupart des cabinets marquants, il est cependant quelques espèces de Pigeons indiquées par les nomenclatures que nous n'avons pas eu occasion d'examiner en nature; nous les décrirons succinctement à la suite de chaque famille, en nous bornant à donner à ces. Pigeons des dénominations françaises, qui peuvent servir à les distinguer, et en renvoyant les naturalistes, pour la synonymie de ces espèces, à l’index qui termine ce volume.

\section{GOLOMBE GOAD-GANG.}

Cette Colombe, dont Latham fait mention, mesure en totalité treize ponces et demi. La face, jusque vers les yeux, est blanche; entre l'oil et le bec est un espace triangulaire noir, et derrière l'œil une tache rouge; le haut de la tête et l'occiput sont d'un gris-clair; le con d'un gris-brun; les parties supéricures de l'oiseau d'un brun-verdâtre; la poitrine, le ventre el l'abdomen, blancs; les plumes placées ver's l'insertion du poignet de l'aile sont de la même couleur que le manteau; on remarque enfin sur les flancs des taches noires irrégulièrement semées : les pieds et le bec sont rouges.

Cette espèce, qui habite la Nouvelle-Hollande, a des rapports avec notre Colombe-Grivelée; mais nous ne pouvons garantir leur identité spécifique. 


\section{COLOMBE MORDOREE.}

Elle est à peu près de la taille du Ramier d'Europe : la tète est grise; le devant du cou, le ventre et l'abdomen sont d'un gris-vineux clair; la partie postérieure du cou et le dos sont d'un violet-pourpré foncé; les plunies qui couvrent les côtés du cou sont profondément échancrées dans leur centre; elles sont noires, terminées par une bande d'un gris-vineux; les petites plumes qui forment les épaulettes sont d'un mordoré foncé; les couver'tures sont d'un brun-terreux; le croupion est d'un gris-lilas; les premières plumes de la queue sont d'un noir-terreux; les latérales sont d'un gris-noir jusque vers la moitié de leur longueur, et blanches sur le reste. Les recouvrements du dessous de la queue sont blancs; le bec est jaunatre, l'iris rouge, et les pieds sont bruns. Gette espèce habite la Chine.

\section{COLOMBE EGYPTIENNE.}

Taille non déterminée. La tète est d'un violet couleur de chair. Les plumes du devant du cou sont allongées et profondément échancrées dans la forme d'un còne; elles sont noires à leur origine, et les parties latérales des barbes, qui sont prolongées, sont couleur de rouille; le dos est gris, la poitrine a des teintes de violet; le ventre et l'abdomen sont blanchâtres. Les ailes sont, en grande partie, brunes : les deux plumes latérales de chaque côté de là queue sont d'un gris-brun à leur origine, noires sur leur centre, et terminées de blanc: les deux qui suivent de chaque côté sont gris-brun à la base, noires au milieu, et leur pointe seulement est blanche; la cinquième, de chaque côté, est brune, et leur milieu est noirâtre; enfin les deux pennes du centre sont entièrement brunes. Les pieds sont de couleur de chair; le bec est noir, et l'espace qui entoure les yeux est dénué de plumes, et bleuâtre. Cette espèce habite en Égypte; elle n'est pas farouche. On la trouve habituellement à l'entour des demeures. 


\section{COLOMBE HAGARRERO.}

Cette espèce est de la plus forte taille; elle mesure en totalité dix-sept pouces deux lignes. Le bec a environ un pouce; il est rouge, ainsi que les orbites, les yeux et les pieds. Les parties supérieures de l'oiseau sont d'un ronge brun : cette couleur se change sur le devant du cou en teintes vertes. Les pennes des ailes sont noirâtres; le croupion est bleu, la queue noire, et les parties inférieures, depuis la poitrine jusques à l'abdomen, sont blanches: les couvertures inférieures de la queue prennent un ton bleuâtre.

Cette espèce habite la baie de Dusky, dans la Nouvelle-Zélande, où les sauvages la désignent par le non de Hagarrero.

\section{COLOMBE A COLLIER POURPRE.}

La longueur totale de cette colombe est à per près de quatorze ponces. Le sommet de la tête et la nuque sont bruns; le front, la gorge et le devant du cou sont d'un roux pâle, ou couleur lie de vin : les côtés du cou sont d'un rouge-brun. Cette couleur se change successivement par nuances en un beau pourpre; elle forme sur la poitrine une espèce de ceinturon, accompagné d'une bande blanche. Les couvertures des ailes sont du même pourpre que le collier ; les rémiges sont noirâtres ; le ventre est d'un grisnoiràtre; les pieds sont rouges, et le bec noir.

Cette espèce habite l'ile d'Eimeo, dans la mer du Sud.

\section{COLOMBE A VENTRE ROUGE.}

La longueur totale de cette jolie espèce est de dix ponces et demi. Le sommet de la tête est d'un gris-cendré; les joues et les cơtés du cou sonı jaunes. Toutes les plumes de cette dernière partie sont terminées de rouge. L'occiput, la partie postérieure du cou, le dos, le croupion et les couvertures supérieures de la queue sont bruns, transversalement rayés de 
bandes noires; la poitrine, le ventre et l'abdomen sont d'un rouge-rosé; les petites couvertures des ailes sont brunes, marquées de raies transversales blanches et noires; les autres couvertures des ailes sont noires, avec les extrémités blanches; les rémiges sont noires, bordées de blanc; la queue est d'un brun pâle; les pieds sont rouges, et le bec est d'un bleu couleur de corne.

Ce Pigeon habite le vaste empire de la Chine.

\section{COLOMBE A GORGE POURPRE, Sp: 38.}

Cette Colombe a environ huit pouces; le front et la gorge son gris-cendré; l'occiput, la partie postérieure du cou, le dos, les ailes, le croupion, les couvertures supérieures de la queue, la poitrine, le ventre et l'abdomen sont d'un beau vert foncé ; le devant du cou est teint d'une brillante couleur de violet-pourpré; les rémiges sont noires; la queue est d'un bleu-verdâtre, bordée de vert, et terminée d'un gris-brun; les deux pennes du milieu sont entièrement vertes; le dessous de la queue est noir, et les pennes sont terminées de blanchìtre: les tarses sont à moitié emplumés, la partie nue est rouge. Le bec est rougeâtre.

Cette Colombe habite les Moluques.

\section{COLOMBE BR UVER'T.}

Latham nous donne très succinctement la description de cette espèce en ces termes : "Son bec et ses pieds sont d'un rouge couleur de sang; le haut de la tête, la partie postérieure du cou, le dos et les couvertures des ailes sont d'un rouge-brun; le devant du cou, la poitrine et le croupion sont d'un beau vert. » Elle habite la Nouvelle-Zélande.

\section{COLOMBE FERMIN.}

Sa longueur totale est de dix pouces; le bec est menu et très long, d'un bleu foncé en dehors, et rougeâtre en dedans; la tête et le dos sont cendrés; 
le cou est varié de vert et de noir; les rémiges sont brunes, mais les pennes secondaires sont de couleur cendrée; la poitrine et le ventre sont blanchâtres; les pieds sont rouges.

Fermin dit que cette espèce est très commune à Surinam; elle y pond deux fois par an, et pratique son nid sur les plus hauts arbres des forêts les plus retirées; il observe que sa chair est un mets exquis.

\section{COLOMBE BRAME.}

Elle est de la taille de notre Colombe Blonde; la tête, le manteau, le dos et les ailes sont d'un gris-brun clair; la poitrine et le devant d'un grisvineux; les moyennes' couvertures alaires ont des taches ovales d'un blanc pur; les deux pennes du milieu de la queue sont grises; les autres sont noires depuis leur origine jusqu'aux deux ticrs de leur longueur, et blanches sur le reste; le ventre est blanc; le bec, les pieds et l'iris des yeux sont rouges.

Cette espèce habite l'Inde. 


\title{
COLOMBE ERYTHROPTÈRE.
}

\author{
PL. LV.
}

Columba Erythroptera. Latr. Ind. Oın. v. 2, p. 597

Pigeon à ailes rouges de la mer du Sud. Sonnsns, édit. de Buff. v. $7, p .223$.

Garnetwinged Pigeon. Latr. Syn.v.4, p.6a4.

$\mathrm{L}_{\mathrm{A}}$ livrée de cette belle espèce lui vaut une place distinguée dans les oiseaux marquants qui composent le genre du Pigeon. Le blanc pur de la poitrine, de la gorge et du front contraste à merveille avec le noir pourpré qui colore le reste du plumage, tandis qu'une teinte vive d'un rouge couleur de grenat brille sur les convertures supérieures des ailes.

La longueur de la Colombe Erythroptère est de neuf pouces et demi; le front est blanc : cette couleur forme sur I'œil une large bande ou sourcil; elle se trouve aussi répandue sur la gorge, le devant du cou et la poitrine. L'occiput, la partie postérieure du cou, le dos et les couvertures des ailes sont d'un violet pourpré. Le ventre est noir, à reflets pourprés; les grandes couvertures des ailes, les rémiges sont noires; la queue, dont toutes les plumes sont d'égale longueur, est d'un gris foncé à son origine, et est terminée par une bande noire; les pieds sont orangés et le bec est noir.

J'ai vu des individus (ceux-ci paroissent des variétés de l'espèce) qui n'avoient point de blanc sur la gorge ni sur la poitrine; d'autres, dont Latham fait mention, diffèrent de notre individu par de très légères nuances dans le plumage, qu'on ne peut attribuer qu'au sexe ou bien à l'âge.

Cette espèce a été rapportée des îles d'Éimeo, d'Otahiti et de Tanna, toutes situées dans le vaste Archipel de l'australe Asie; ce qui fait présumer que l'espèce se trouve dans la plus grande étendue de ces mers.

Nous avons vu plusieurs de ces oiseaux dans les cabinets de Londres. M. Gevers, à Rotterdam, possède l'individu qui nous a servi de modèle. 


\section{COLOMBE A MOUSTACHES BLANCHES.}

+ Columba mystacea. Mihi

Conme nous ne connoissons aucun des caractères habituels de cet oiseau, nous sommes restreint aux seuls détails qui ont rapport à son extérieur. Sa longueur totale est de onze pouces et demi; la queue, qui mesure quatre pouces, est carrée; les ailes aboutissent à la moitié de sa longueur.

La Colombe à moustaches blanches se distingue en effet par une large bande de cette couleur qui, partant de chaque côté de l'angle où commence l'ouverture du bec, se dirige au-dessous des yeux vers la nuque; le haut de la tête, les petites et les grandes couvertures des ailes, le dos, le croupion et les deux pennes intermédiaires de la queue sont d'un brun foncé, changeant, suivant les incidens de la lumière, en couleurs métalliques; les còtes du cou, le laut du dos et la poitrine brillent d'un vert doré qui se fond par nuances imperceptibles en un violet pourpré très éclatant; elle prend une teinte vineuse sur la poitrine, où les reflets sont moins vifs. Le ventre est d'un vineux terne, et cette couleur se fond graduellement en blanc-roussâtre sur les plumes de l'abdomen et les couvertures inférieures de la queue. Les rémiges, les pennes secondaires, le fouet de l'aile et toutes les pennes latérales de la queue sont d'un roux très vif; la peau nue qui entoure les yeux, ainsi que le bec et les pieds, sont d'un beau rouge; la pointe du bec est jaunâtre.

Cette espèce habite l'Amérique; mais nous ignorons dans quelle partie de ce vaste continent elle est le plus répandue.

Le seul individu que j’ai vu fait partie de mon cabinet. 
COLOMBE GEOFFROY.

PL. LVIT.

+ Colomba Godefrida

Novs avons donné le nom de M. Geoffroy, professeur de zoologie au Muséum de Paris, à l'une des nombreuses espèces d'oiseaux que ce savant a le premier fait connoître en France, lorsqu'à son retour de Portugal il déposa dans les galeries du Muséum d'Histoire Naturelle les nouvelles acquisitions provenantes en grande partie des provinces de l'Amérique appartenantes à ce royaume.

Nous désirons que M. Geoffroy accueille favorablement cet hommage, et l'expression de notre reconnoissance, pour les facilités et les moyens de recherche et d'étude qu'il nous procura dans les galeries du Muséum.

La longueur totale de la Colombe Geoffroy est d’à peu près huit pouces; la queue est courle et les pennes sont également étagées entre elles, ce qui la fait parôttre arrondie.

Une teinte d'un gris-blanc couvre le dessus de la tête, le devant du cou, et devient d'un gris de perle mat sur le reste du corps; la queue est d'un blanc-bleuâtre plus clair que le dessus de la tête; sur le laaut des épaules on voit cinq ou six taches d'un noir-violet changeant au moindre mouvement en bleu ou en vert; plus bas, sur les grandes couvertures des ailes, sont sept ou huit autres taches plus grandes que les premières, dont trois sont de la même couleur que celles du haut de l'aile, et cinq d'un roux couleur de tabac d'Espagne; chaque tache rousse est bordée d'une ligne transversale noire; les rémiges sont noires ainsi que le bec; les pieds sont rouges.

Cette espèce habite au Brésil. L’individu qui a servi de modèle à madame Knip appartient au Muséum de Paris. 


\section{COLOMBE SOURIS.}

$p_{L .} \quad L V I I I$

+ Columba cinerea. Mihi

$\mathrm{L}_{\mathrm{A}}$ nouvelle espèce de Pigeon de cet article paroit avoir, au premier coup d'œil, quelque analogie avec celle que nous venons de décrire. Cette ressemblance ne porte cependant que sur la conformité des coulenrs du plunage de ces espèces que nous considérons comme différentes.

La Colombe Souris est moins grande que la précédente, ne mesurant, en totalité, que sept pouces; sa queue est plus longue, en proportion de ses ailes, que dans la Colombe Geoffroy. Chez celle-ci les plumes caudales sont étagées entre elles, tandis que celles de la Colombe Souris sont d'égale longueur.

Le front, la gorge et toutes les parties inférieures de cet oiseau sont d'un blanc légèrement teint de gris-bleu; la tête, les côtés du cou et le haut du dos sont d'un gris-bleu plus foncé; le manteau, les couvertures des ailes, le croupion, les deux plumes du milieu de la queue, et l'origine seulement des pennes latérales de celle-ci, sont d'un gris de souris; les rémiges sont d'un gris-brun, et les trois quarts de la longueur des pennes latérales, de même que la partie intérieure de la queue, sont noires; le bec est jaune, et les pieds sont rouges.

Cette espèce habite au Brésil. L'individu qui a servi de modèle fait partie de mon cabinet. 


\title{
COLOMBE ÉCAILLÉE.
}

\author{
P.. CIX.
}

+ Columba squamosa. Miki.

Vorci encore une des espèces dont le Muséum de Paris doit la possession au voyage de M. Geoffroy à Lisbonne. C'est d'après l'individu déposé dans les galeries de cet établissement que nous avons représenté ce joli Pigeon.

Depuis peu ma collection a aussi été augmentée par un individu de l'espèce que nous décrivons. Il me fut envoyé par $M$. le comte de Hoffansegg, de Berlin, savant amateur, dont le nom sera à jamais célèbre dans les annáles de l'Histoire Naturelle.

La Colombe Écaillée mesure un peu plus de huit ponces; sa queue seule en a trois, et les ailes ne dépassent pas de beaucoup son origine. Cette queue, composée de quatorze pennes, en a dix d'égale longueur, tandis que les deux latérales, de chaque côté, sont fortement étagées. Tout le plumage de l'oiseau est couvert d'écailles noires, chaque plume étant terminée par une bande plus ou moins large de cette couleur. Les nuances sont pour le reste d'un gris-vineux sur la tête et le derrière du cou; d'un vineux très clair sur le devant du cou et sur la poitrine, où cette teinte prend successivement un ton blanchâtre en gagnant les autres parties inféricures. La couleur des pennes du dos du croupion, des pennes du milien de la queue et des grandes couvertures des ailes, est d'un gris-brun terreux; quelques unes des petites et toutes les moyennes couvertures des ailes ont leurs barbes extérieures blanches; les rémiges sont noires, ainsi que l'origine des pennes latérales de la queue, dont les quatre extérieures de chaque côté sont terminées d'un grand espace blanc; le bec est noir, et les pieds sont rouges. 
Cette espèce habite dans le territoirc de Bahin au Bresil. Lindividu qui fait partie de mon cabinet est un mâle; il ressemble en tout a celui du Muséum de Paris. 




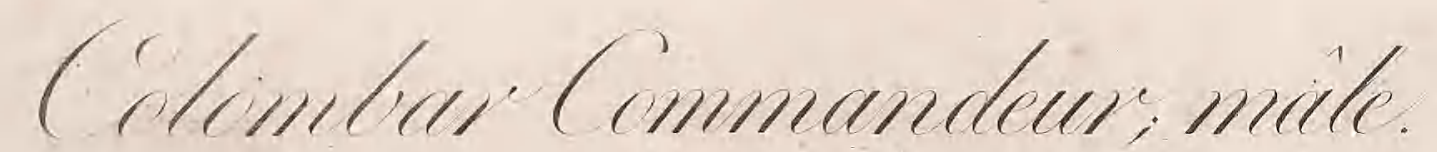

COLUMBAA MILITARIS. Nihi. 



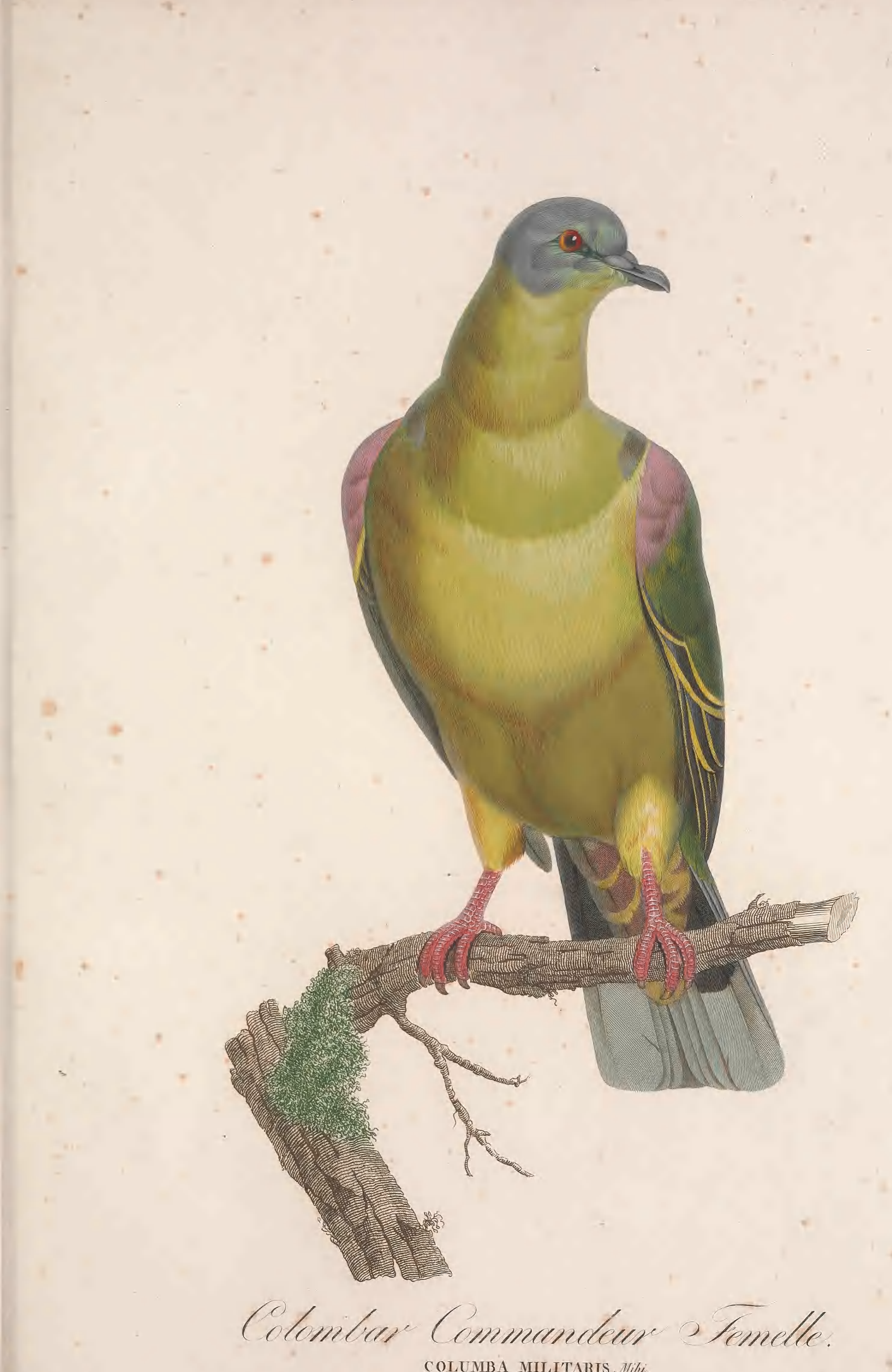





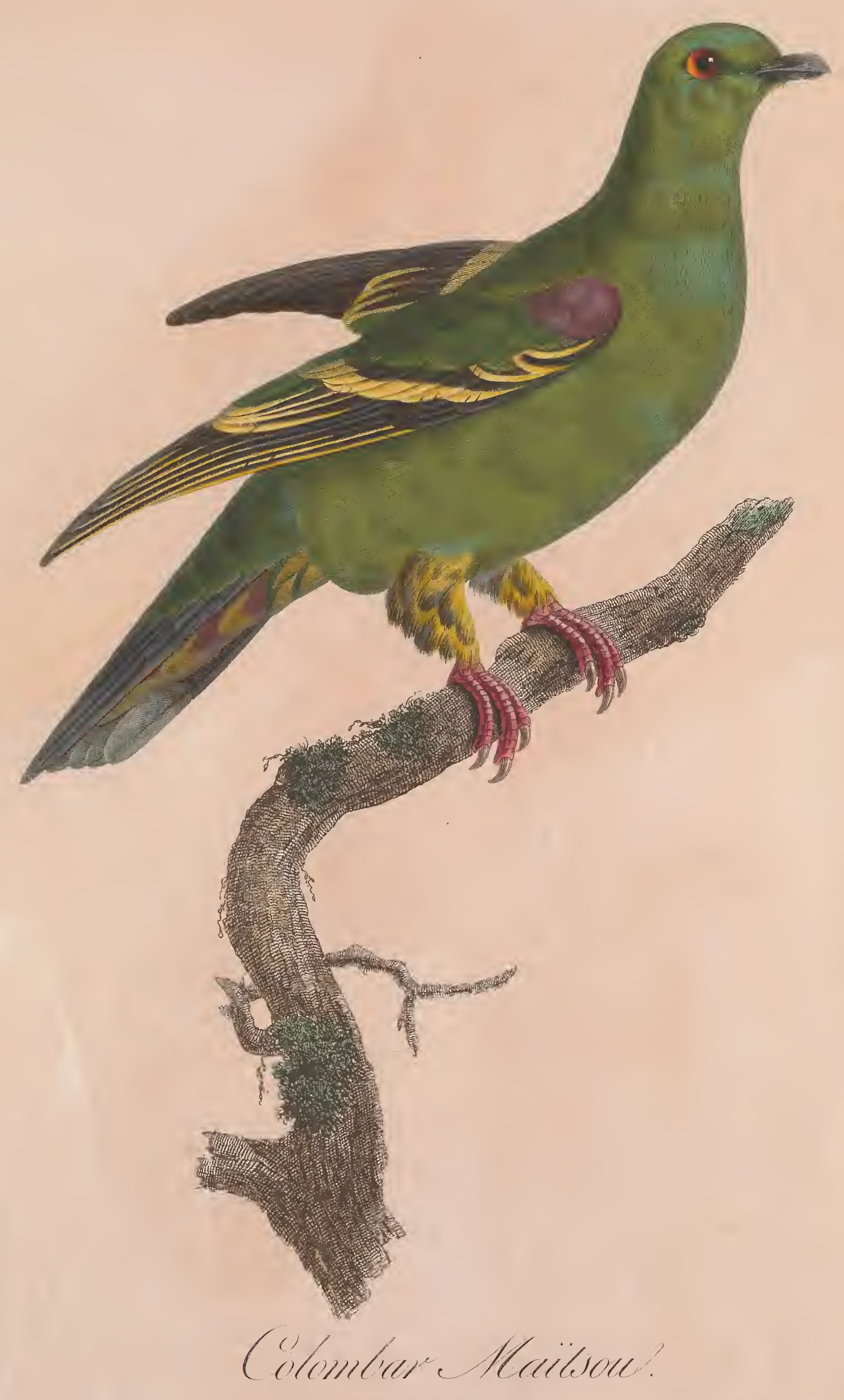

COLUMBA AUSTRALIS. Lath.

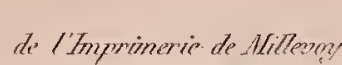







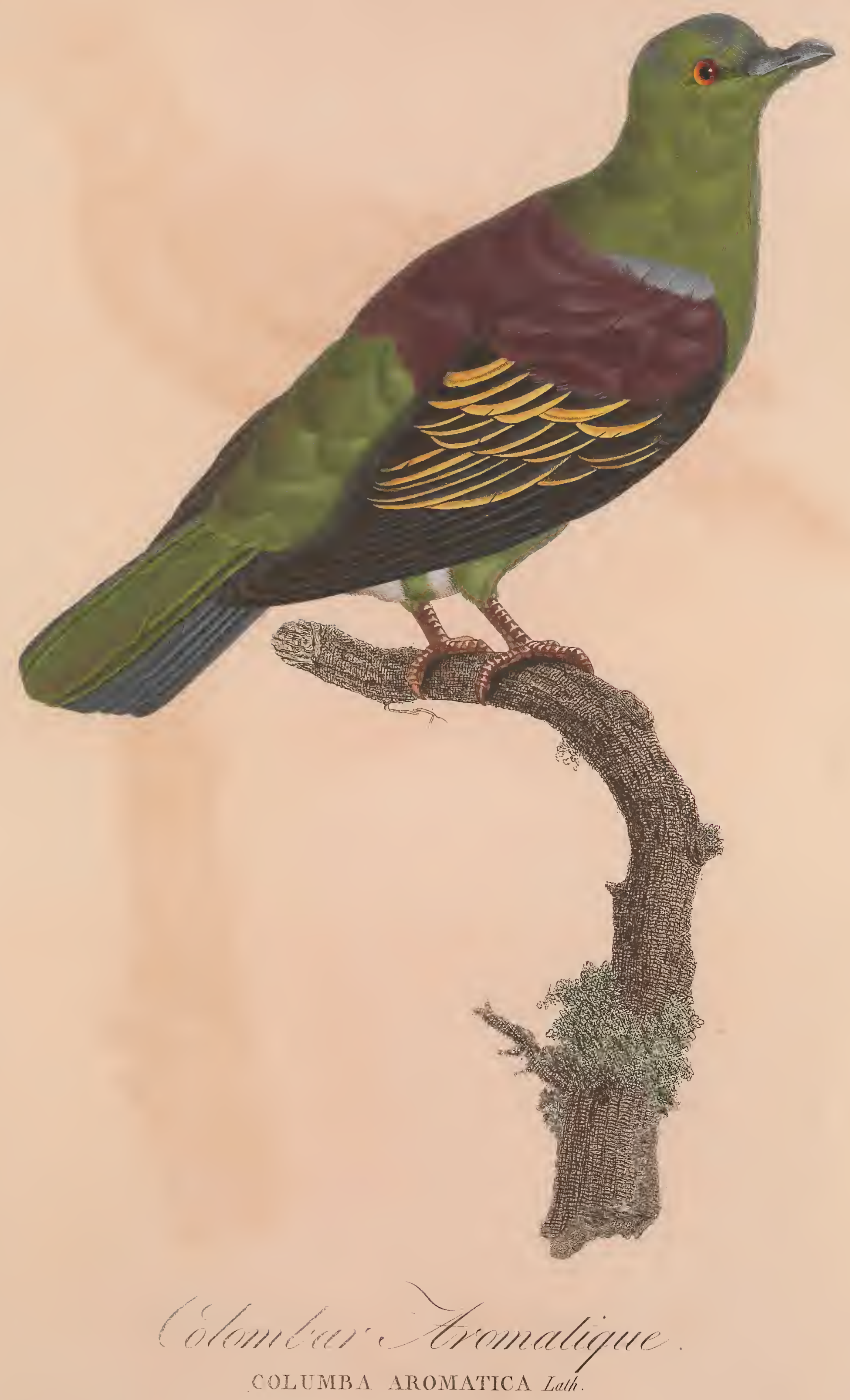







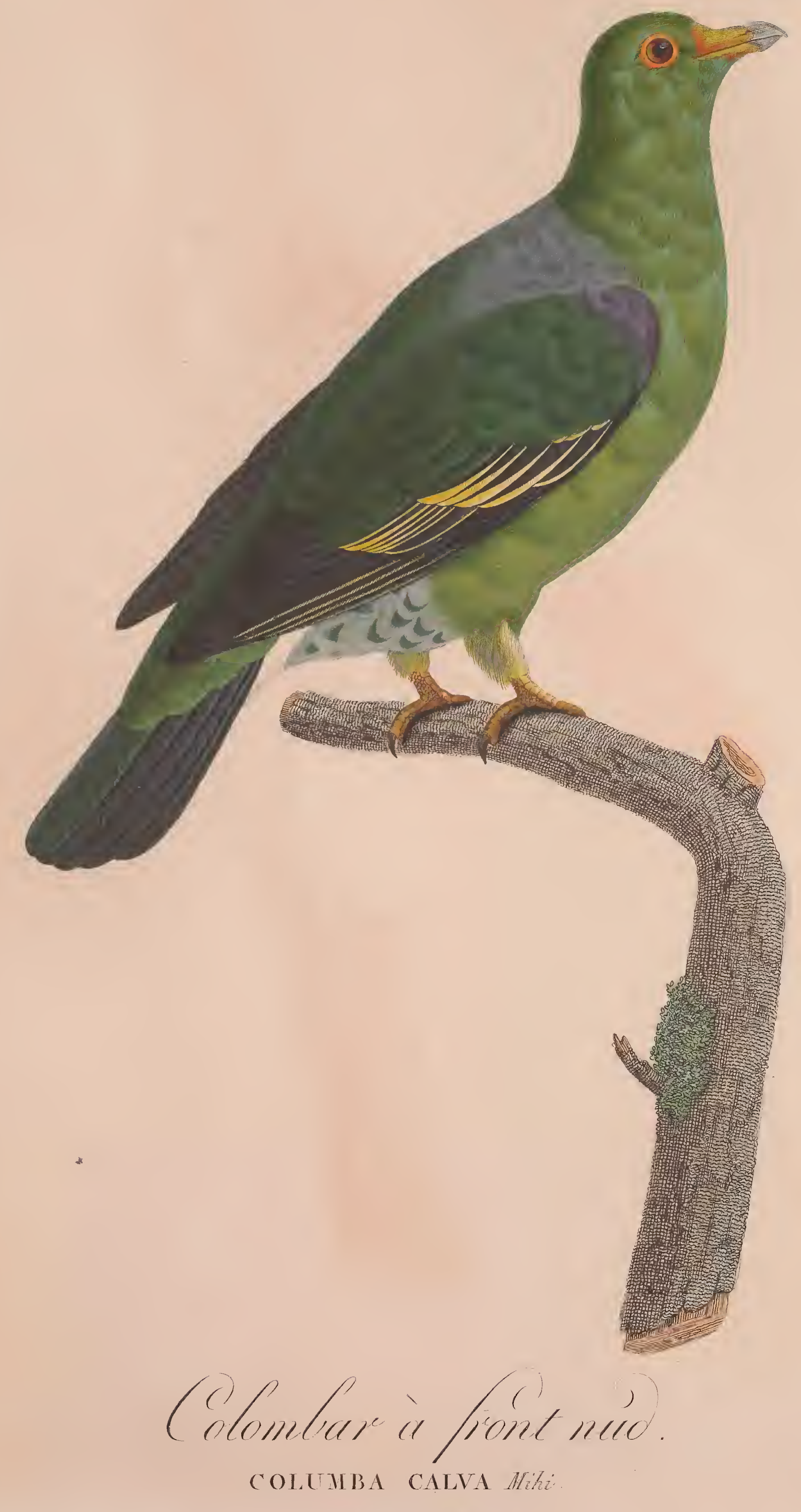

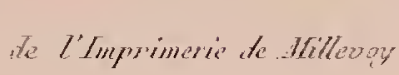




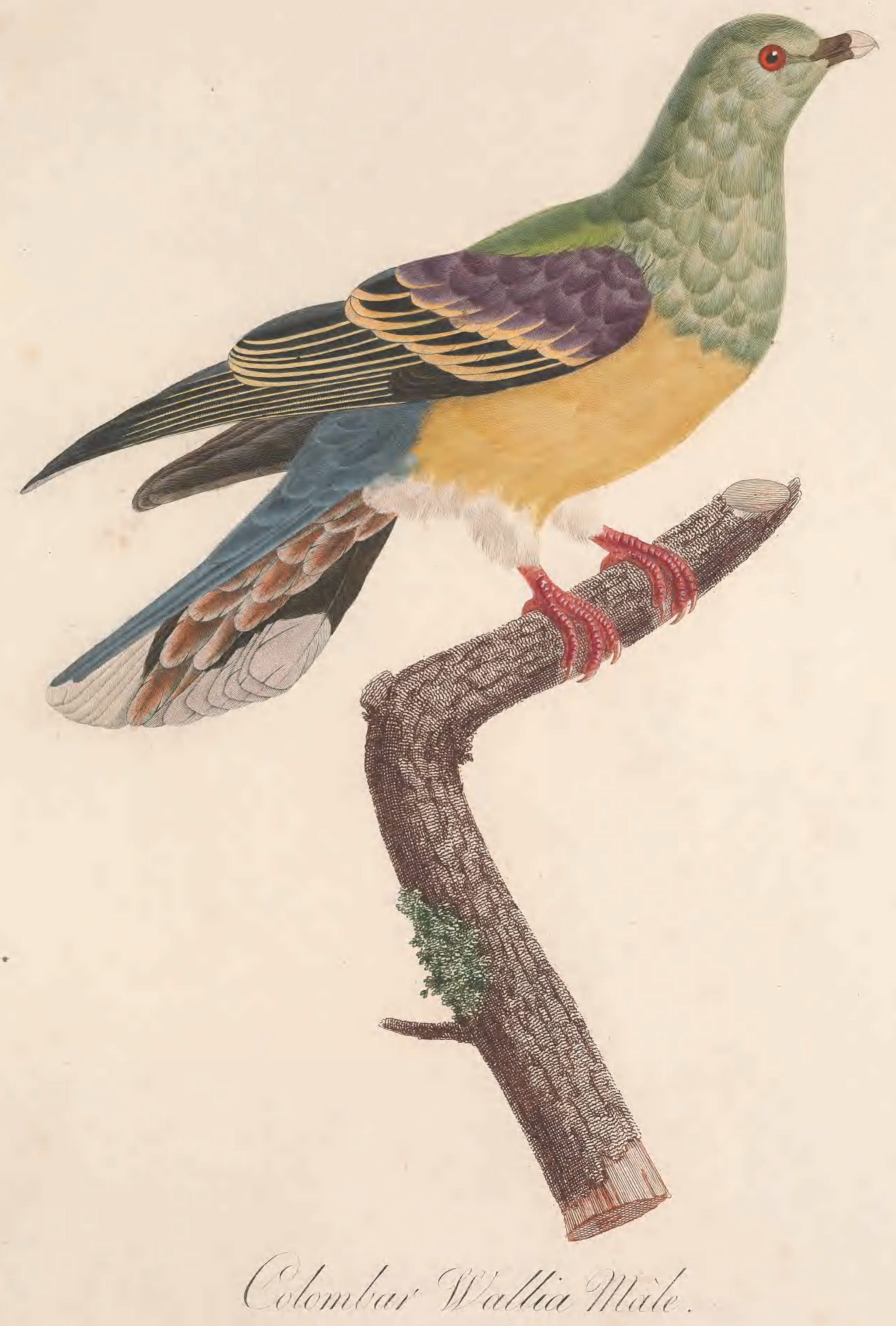

COLUMBA ABŸSSINICA MAS Lath. 



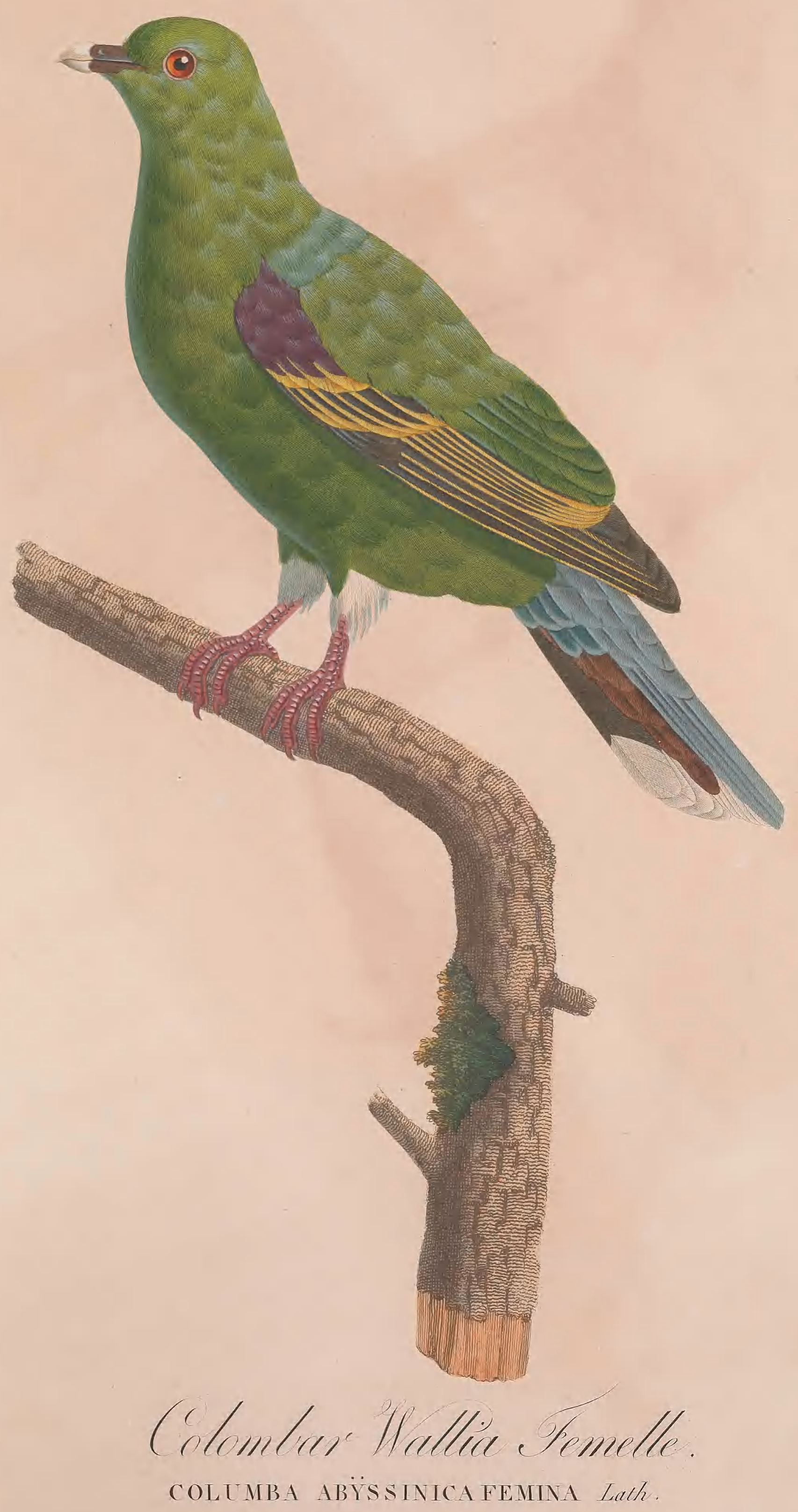





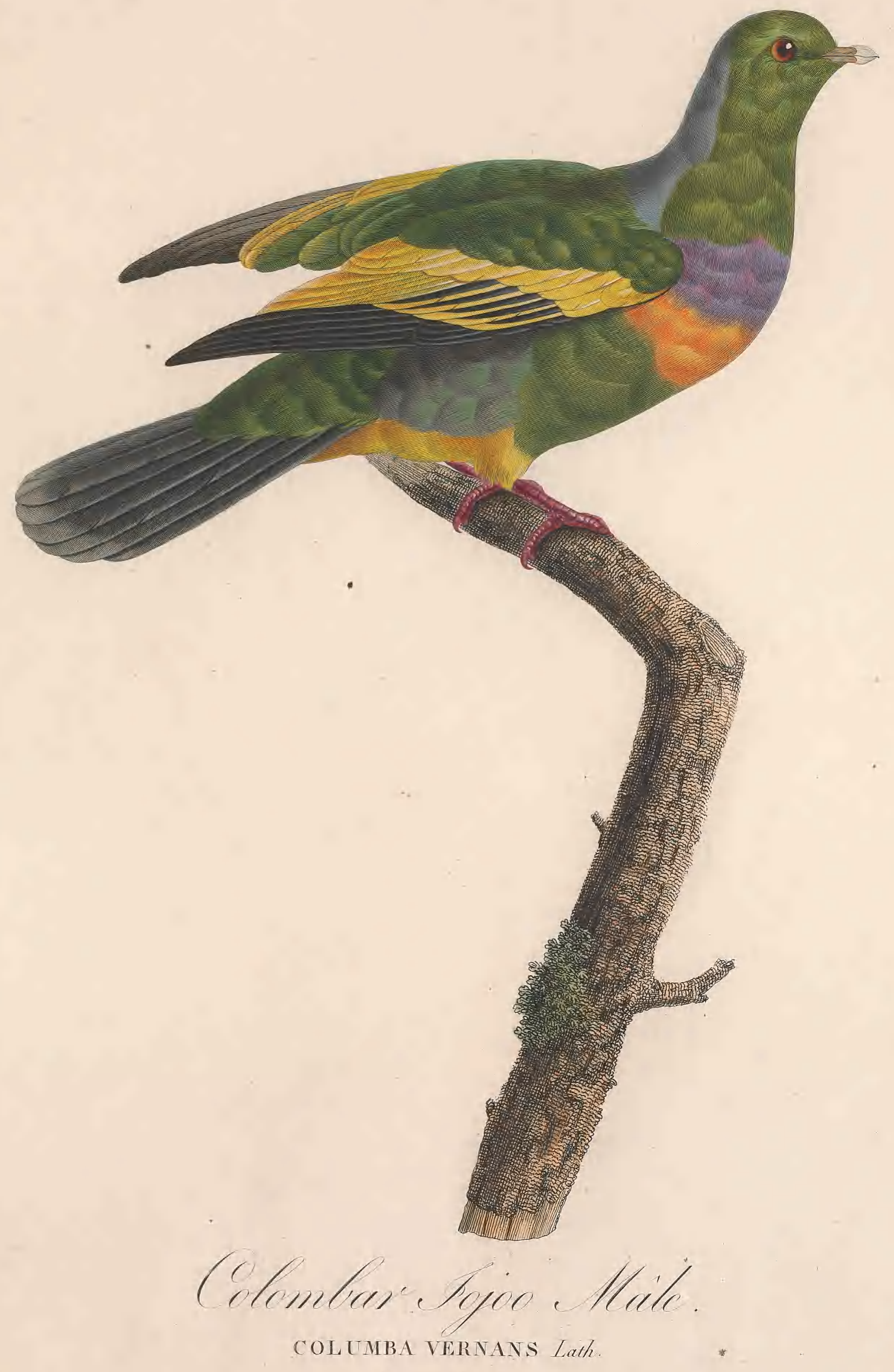

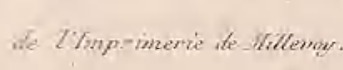





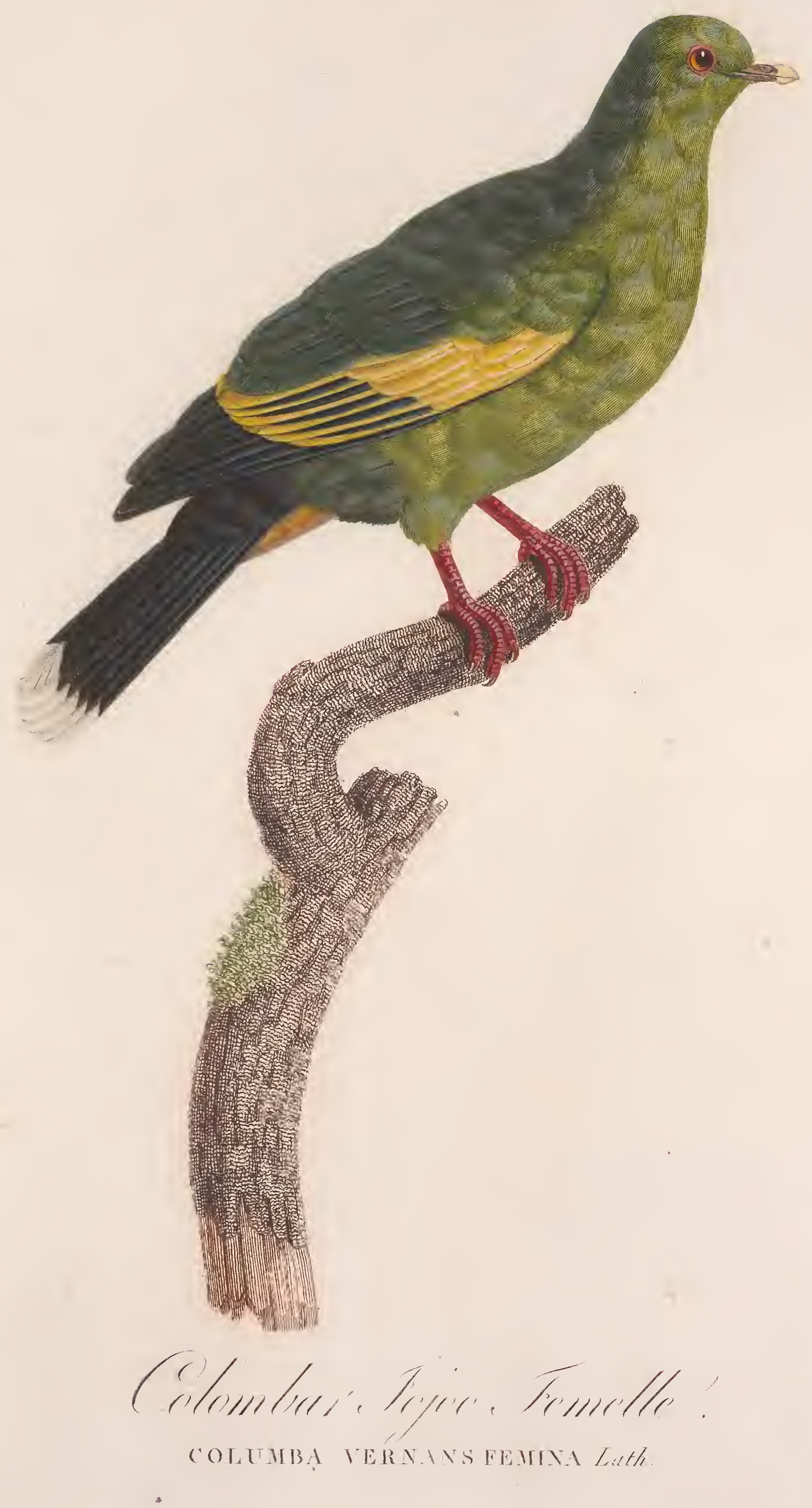




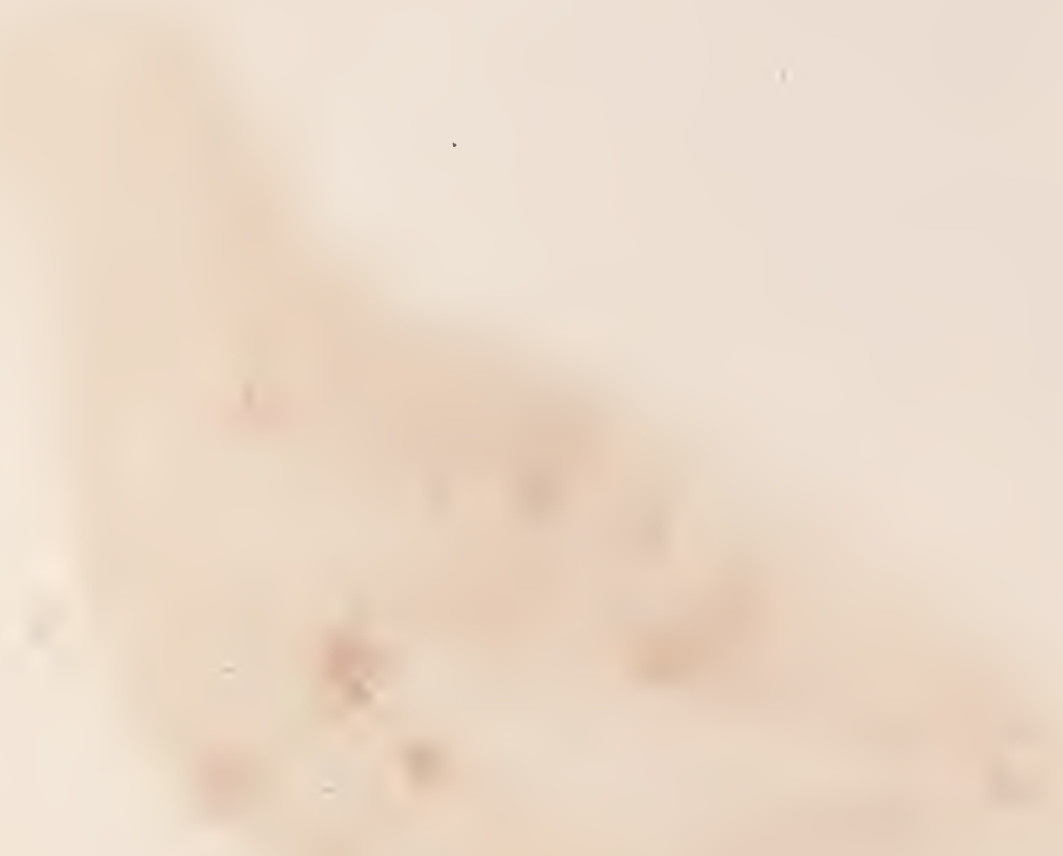




$$
3
$$




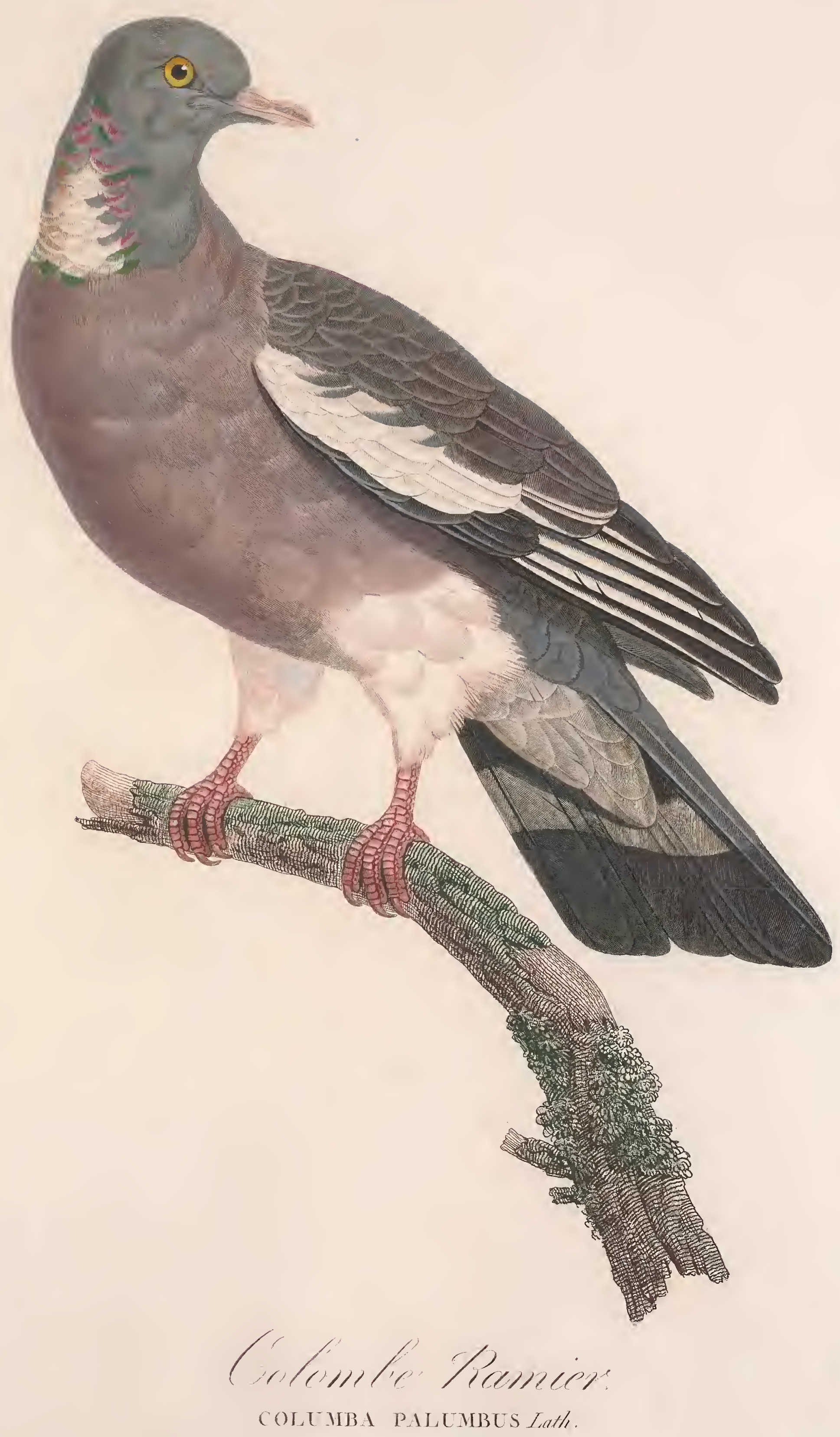





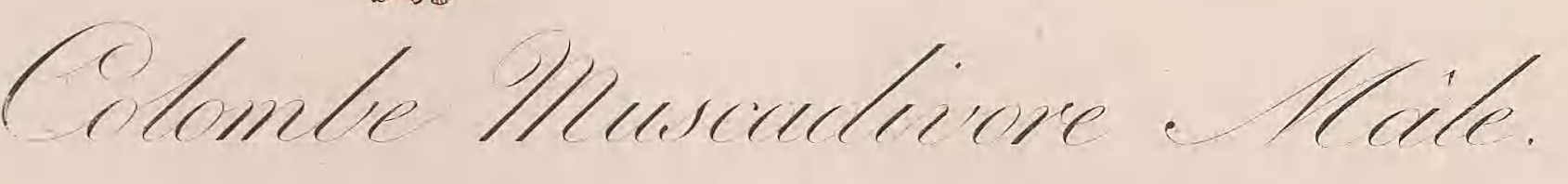

COLUMBA GNEA Lath. 



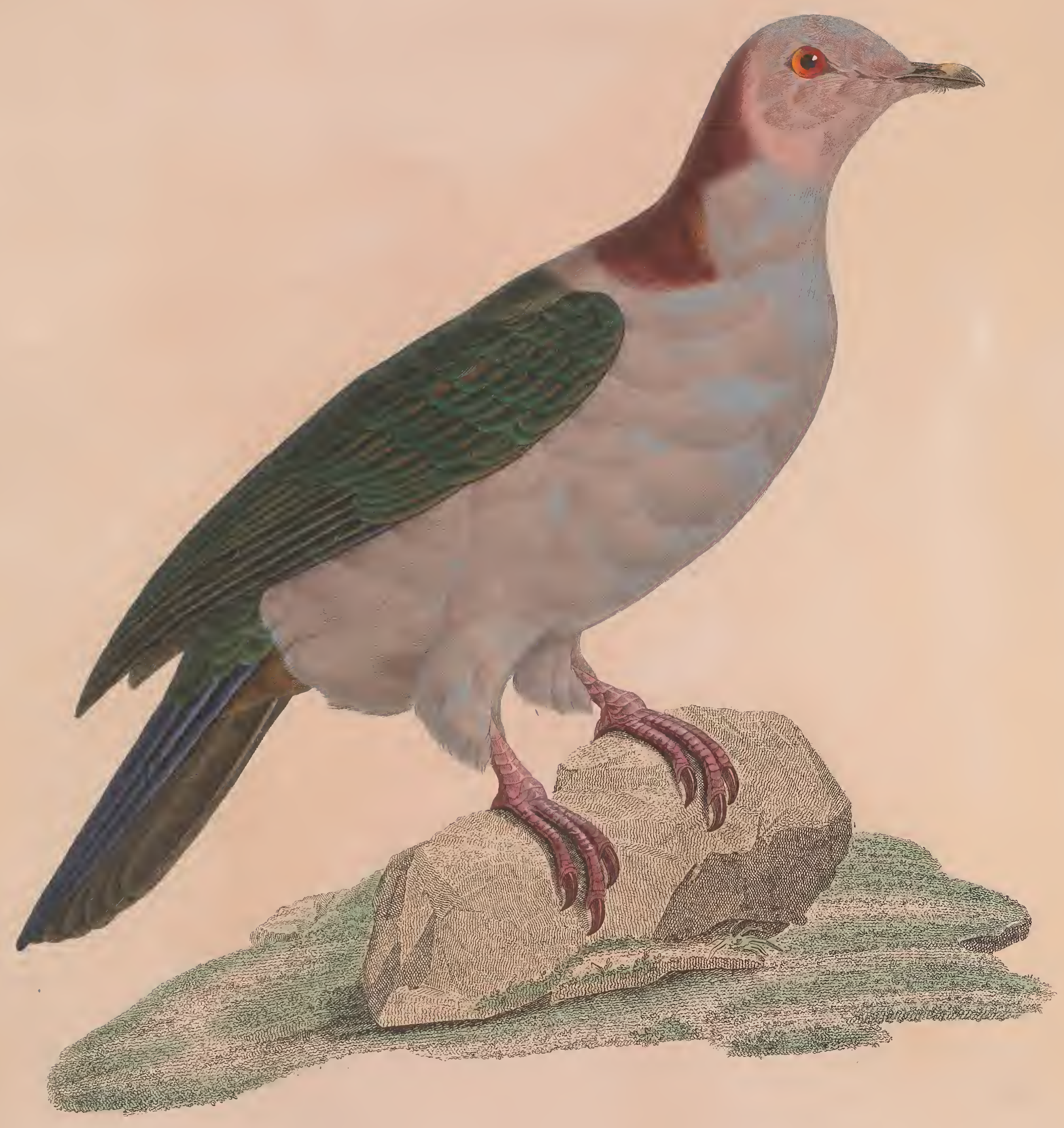

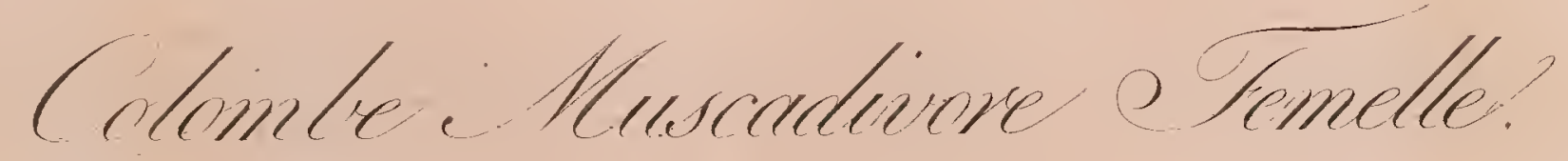

COLUMBA AENEA FEMINA. Tath. 




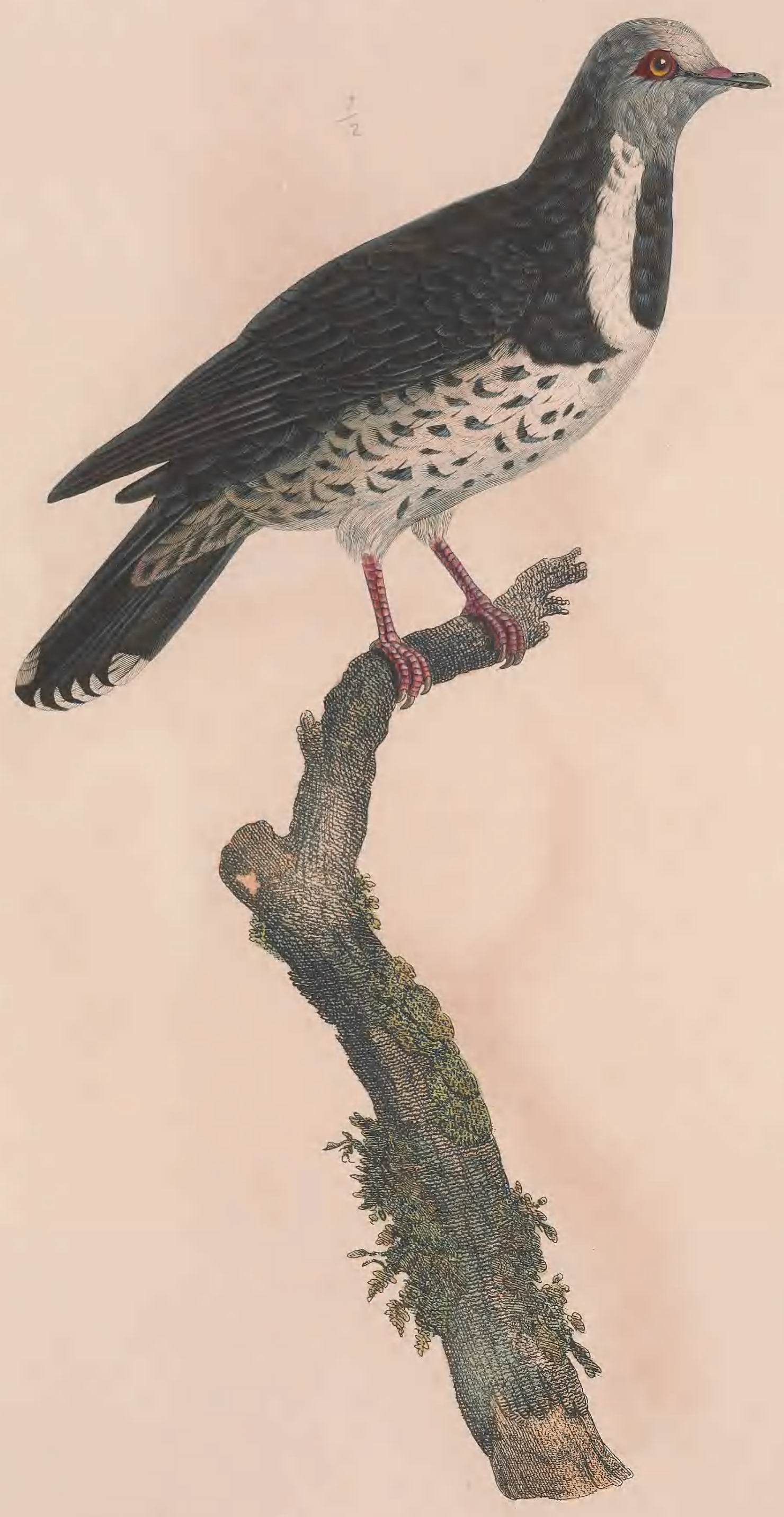

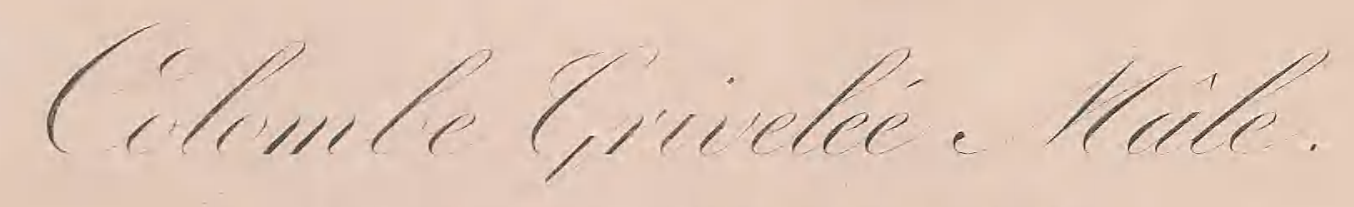

COL.UMBA ARMULI. ARIS Mili. 



$$
\text { of }
$$




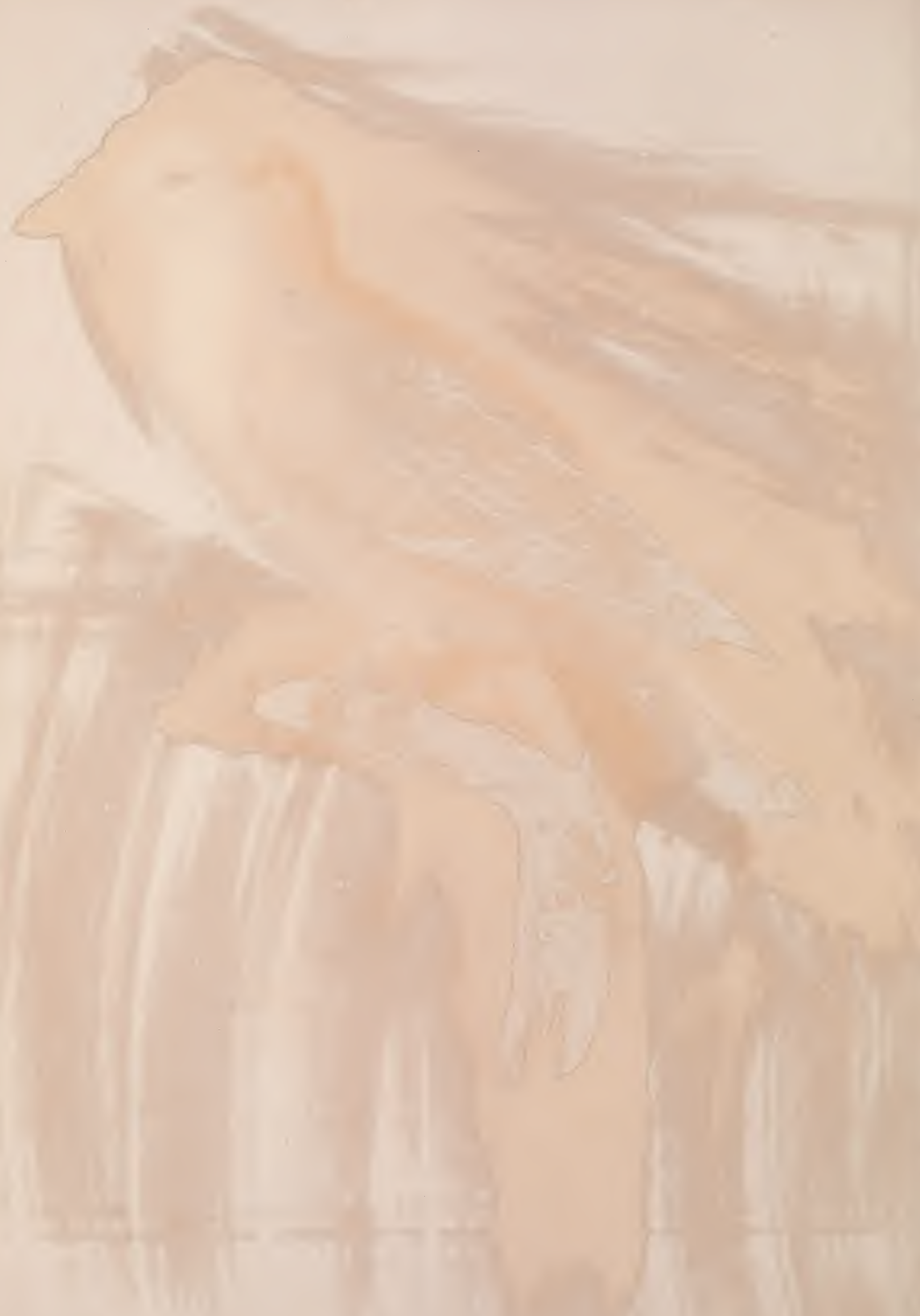




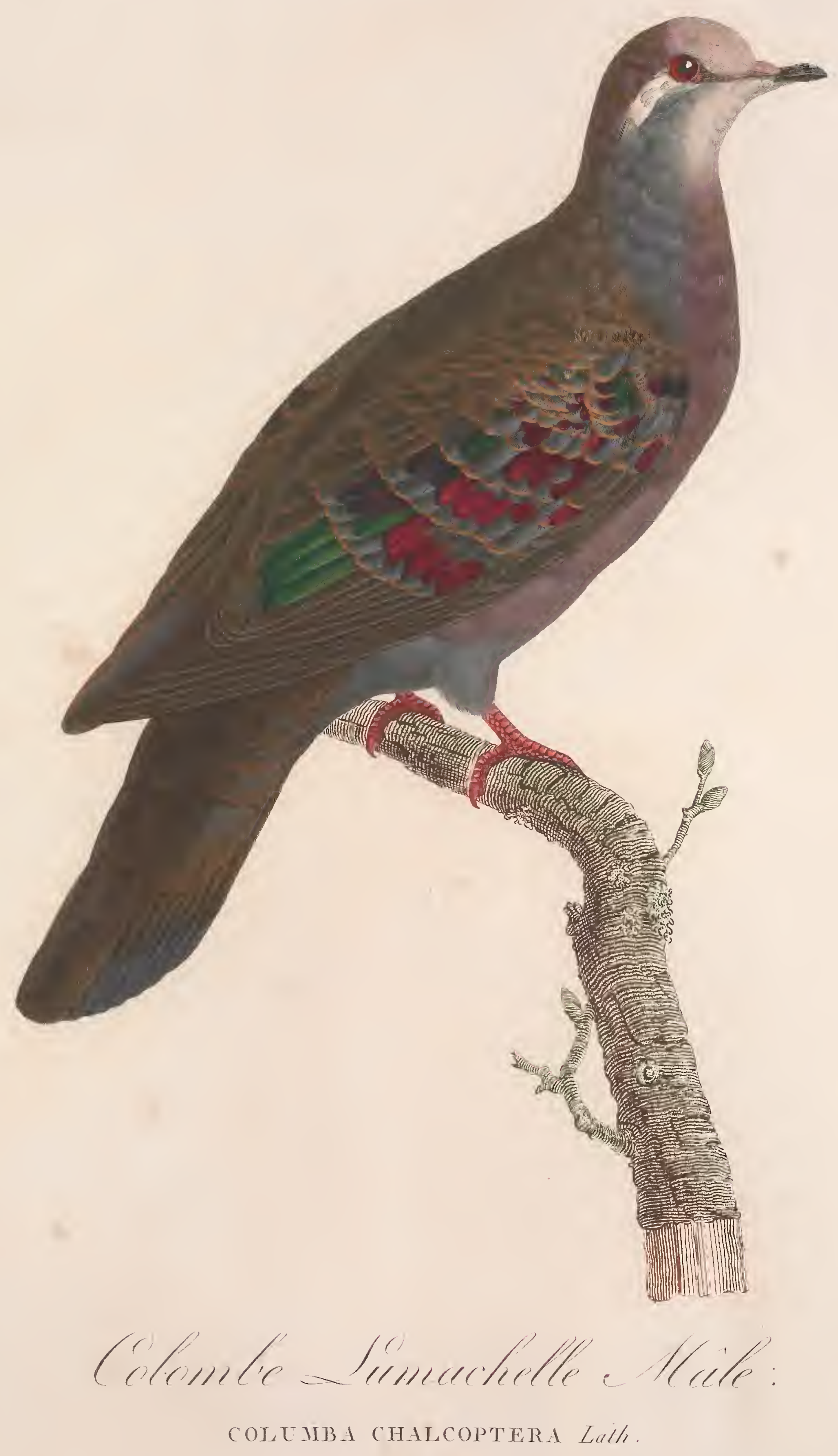





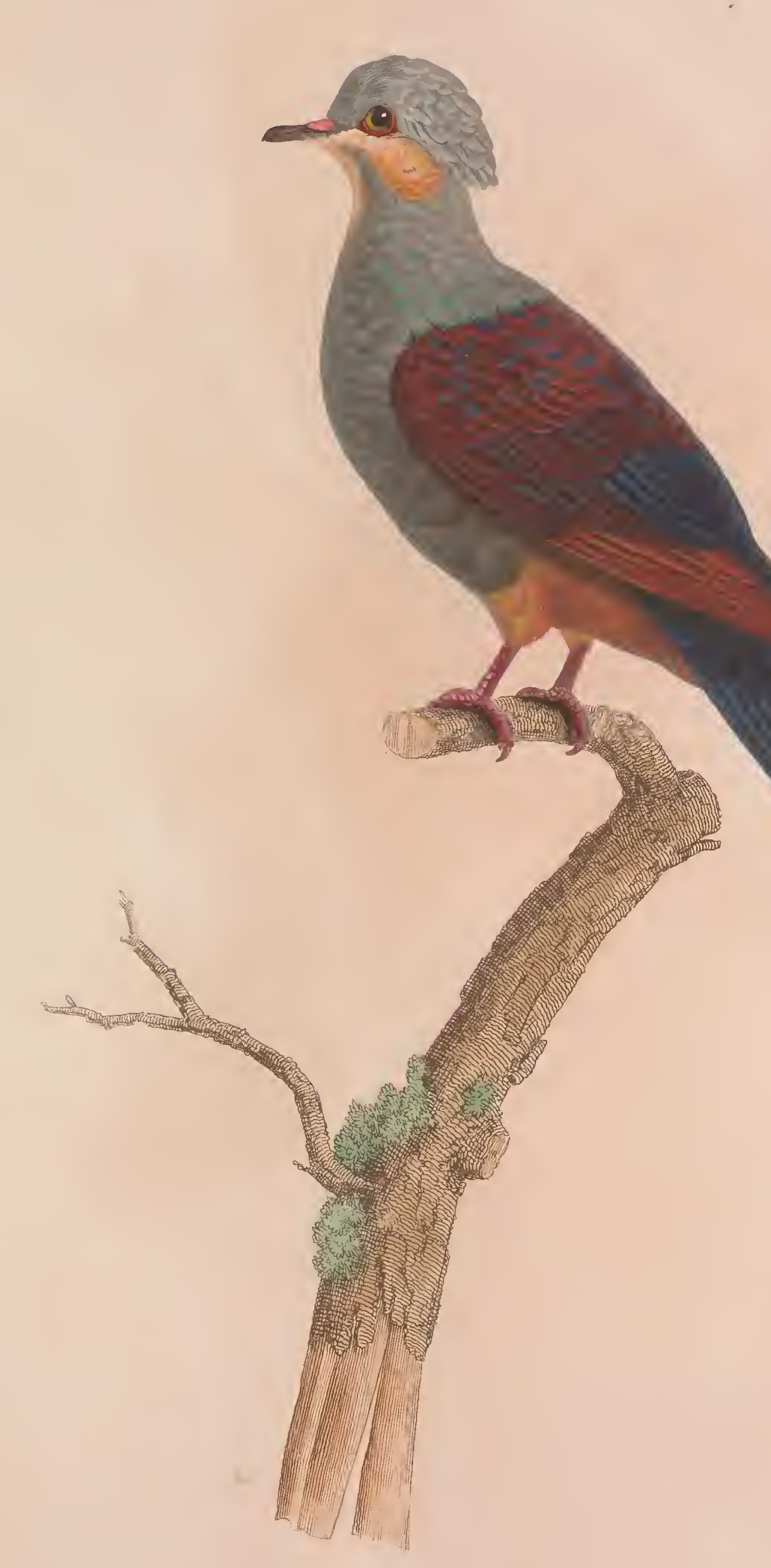

Golombe Saryurpe. 



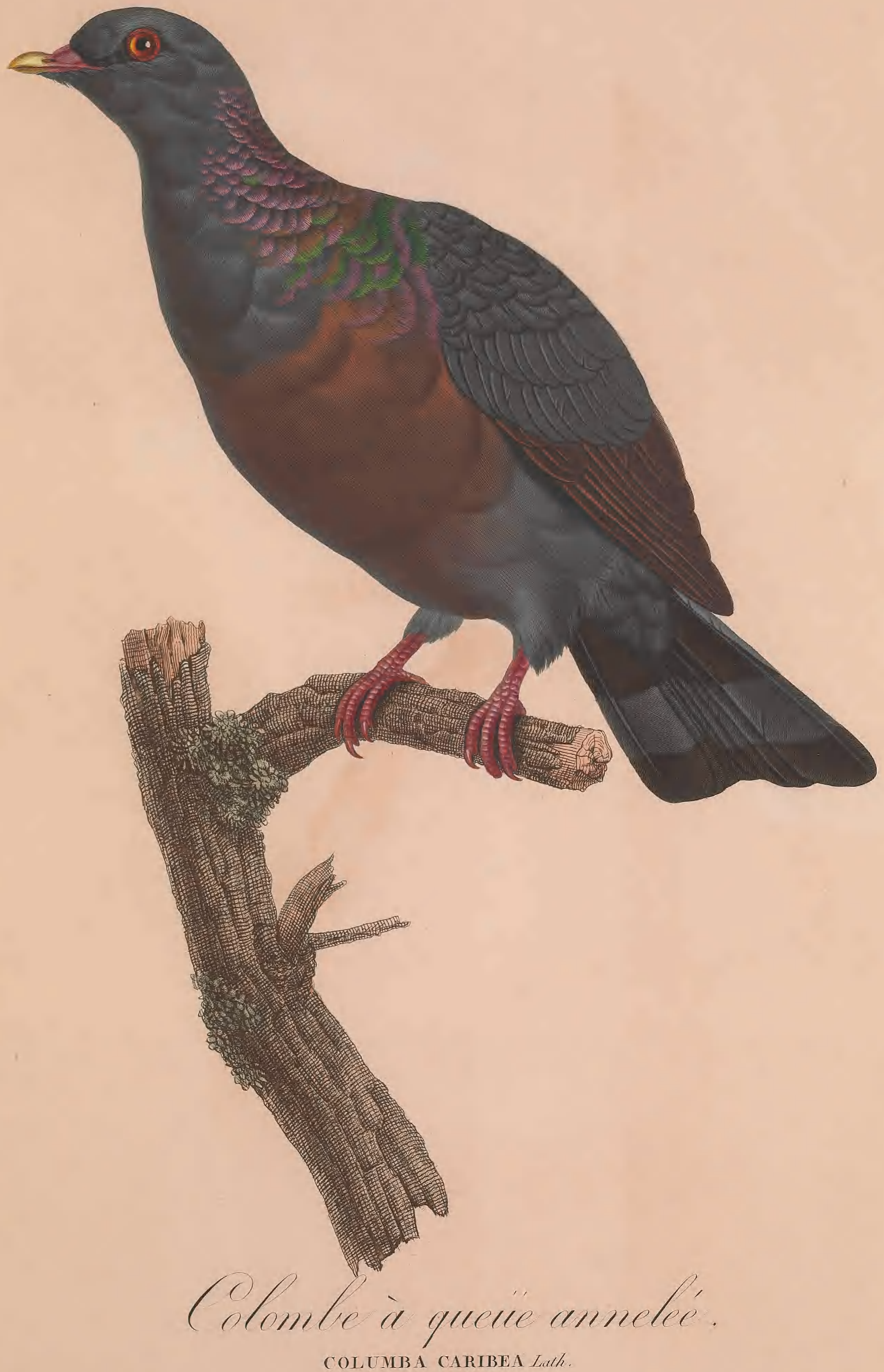





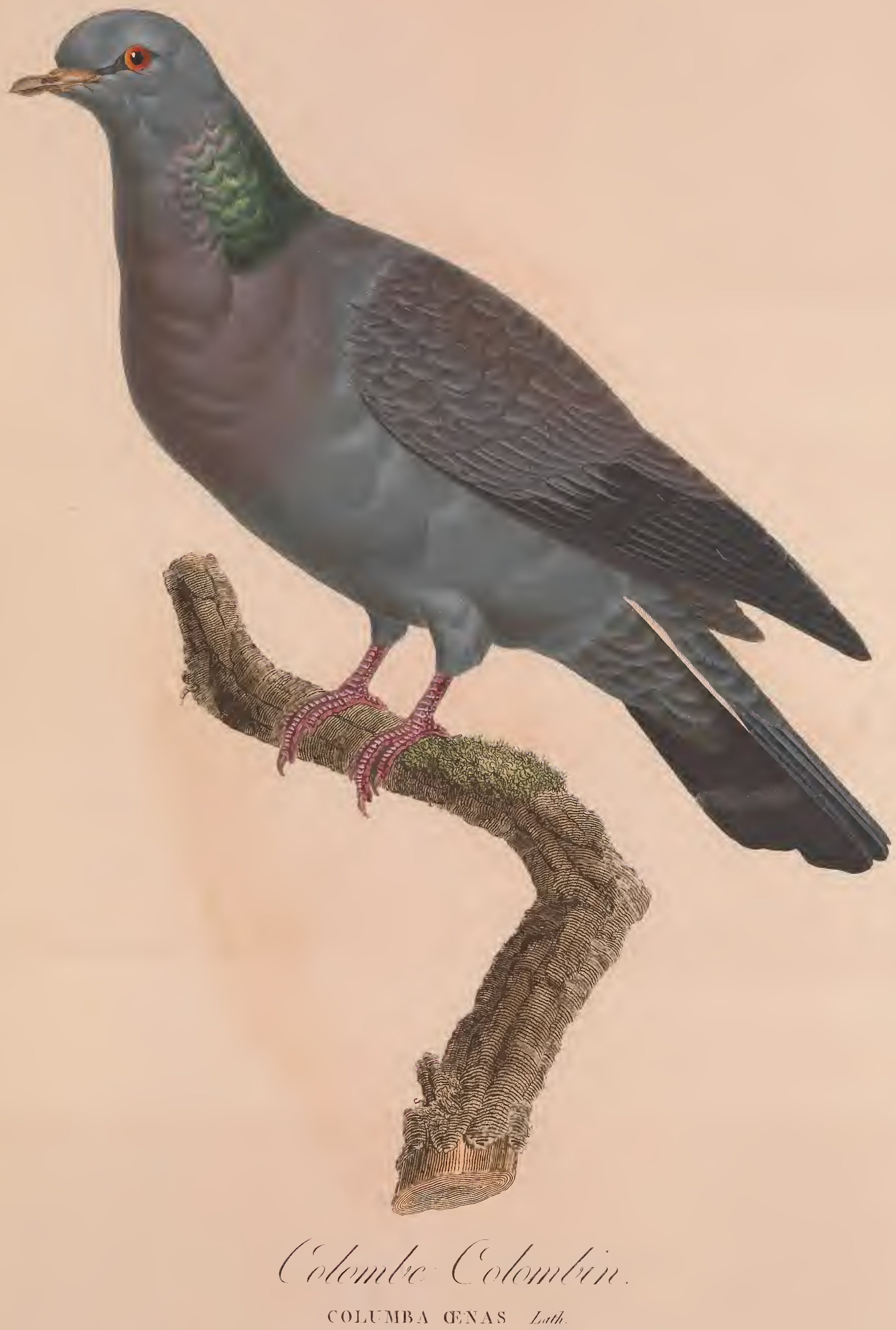




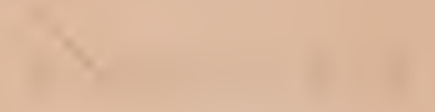




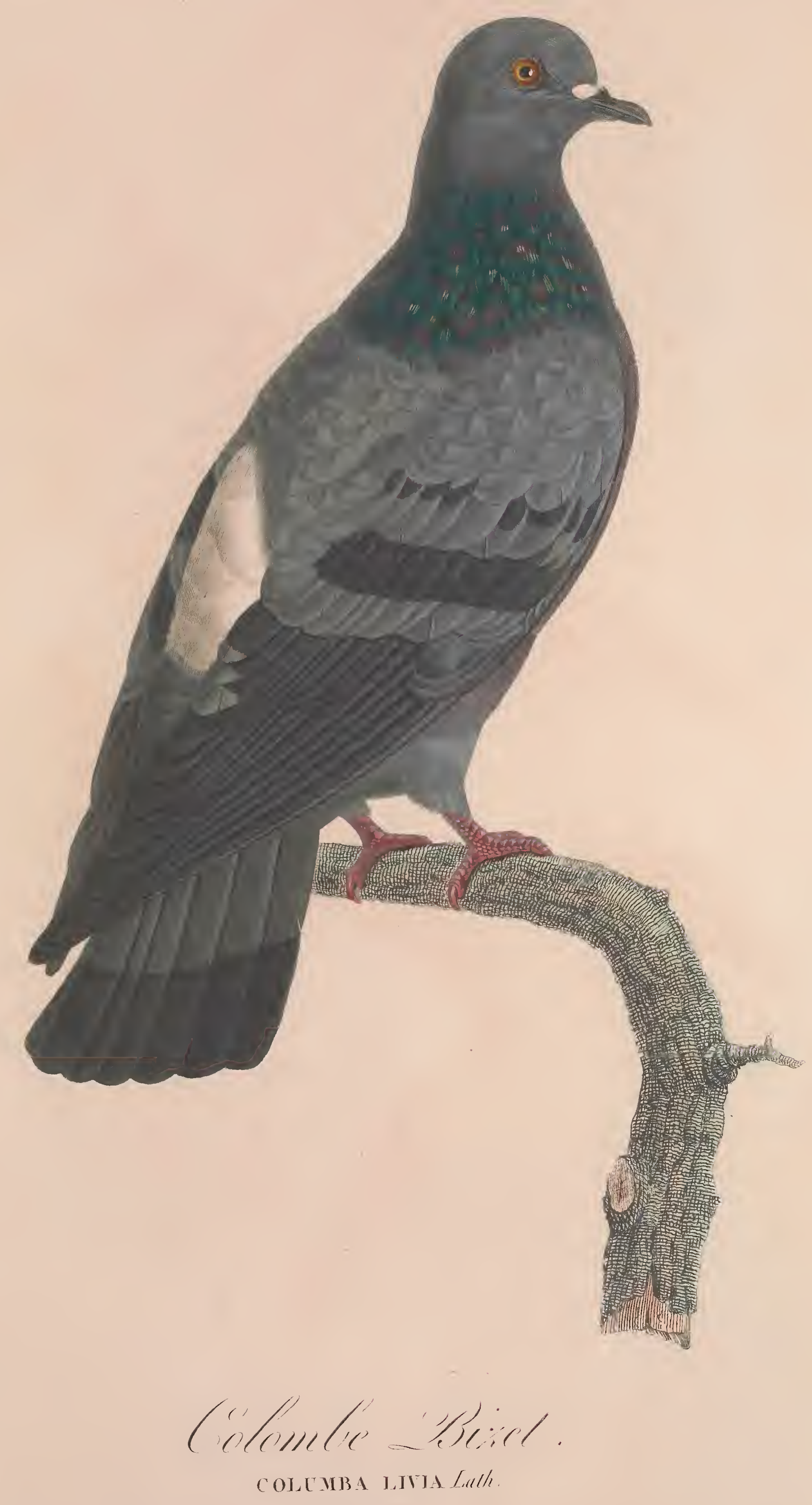




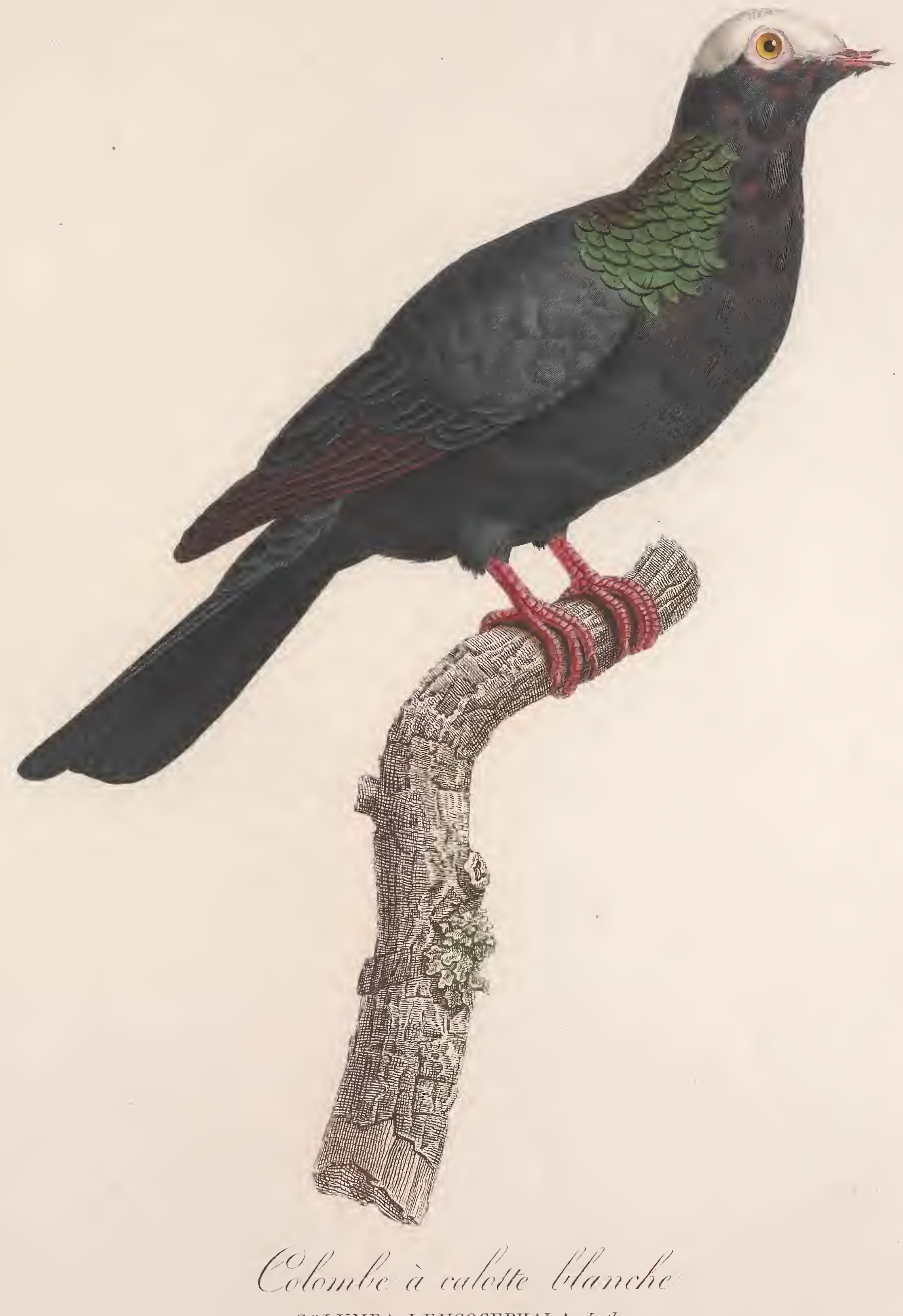

COLTMBA IEUCOCEPHALA Lath. 



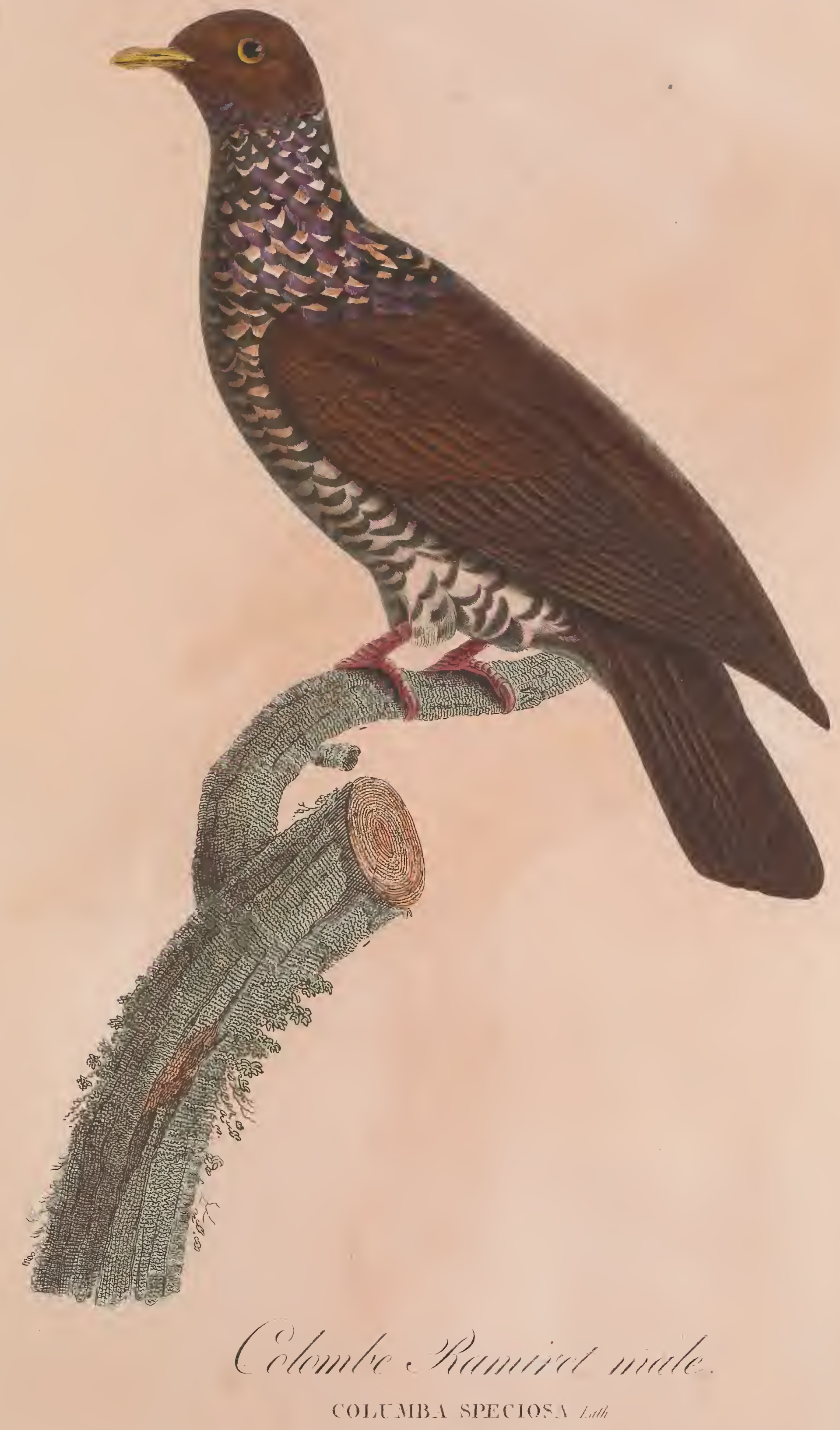





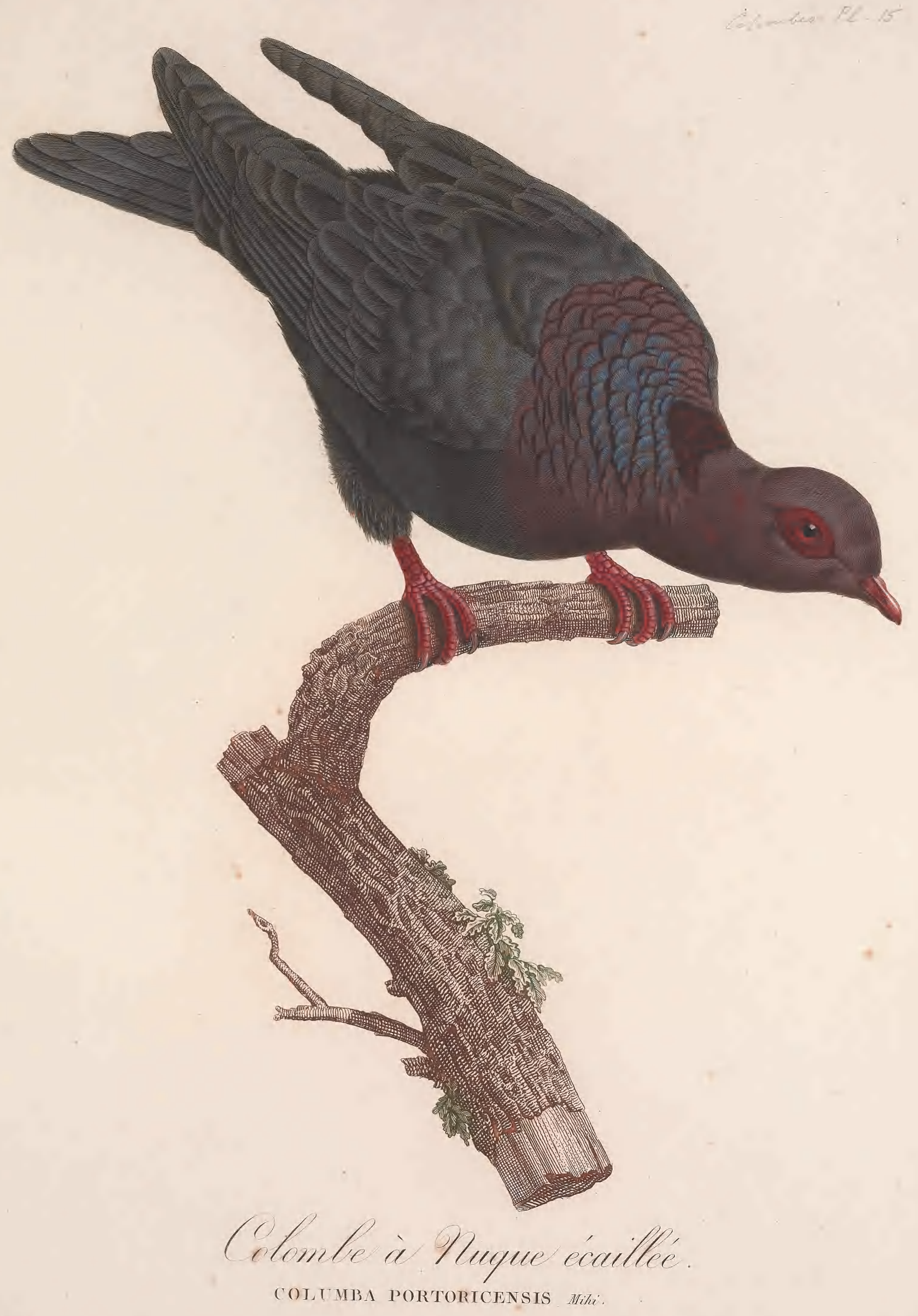




$$
8
$$




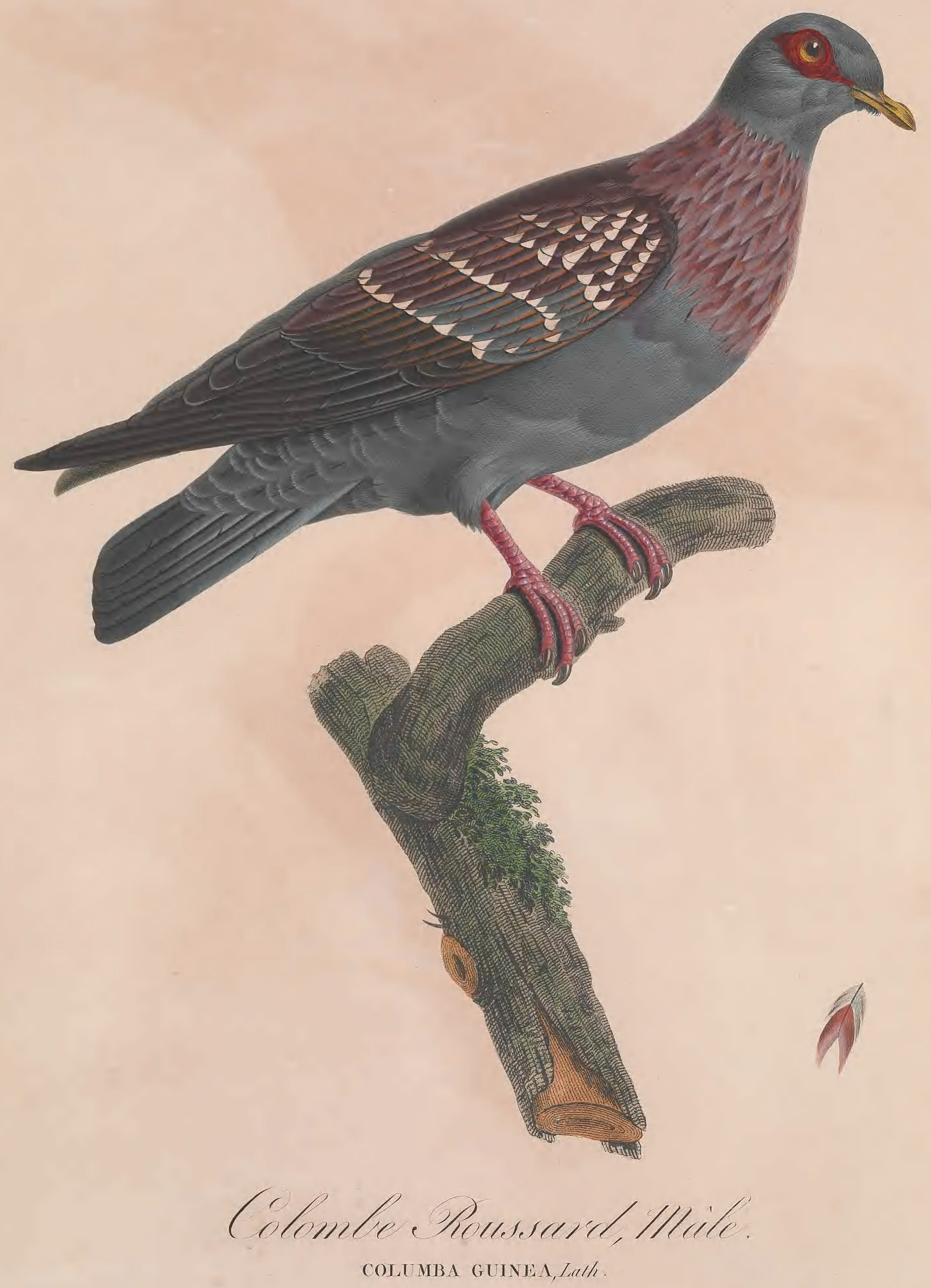


$x$ 


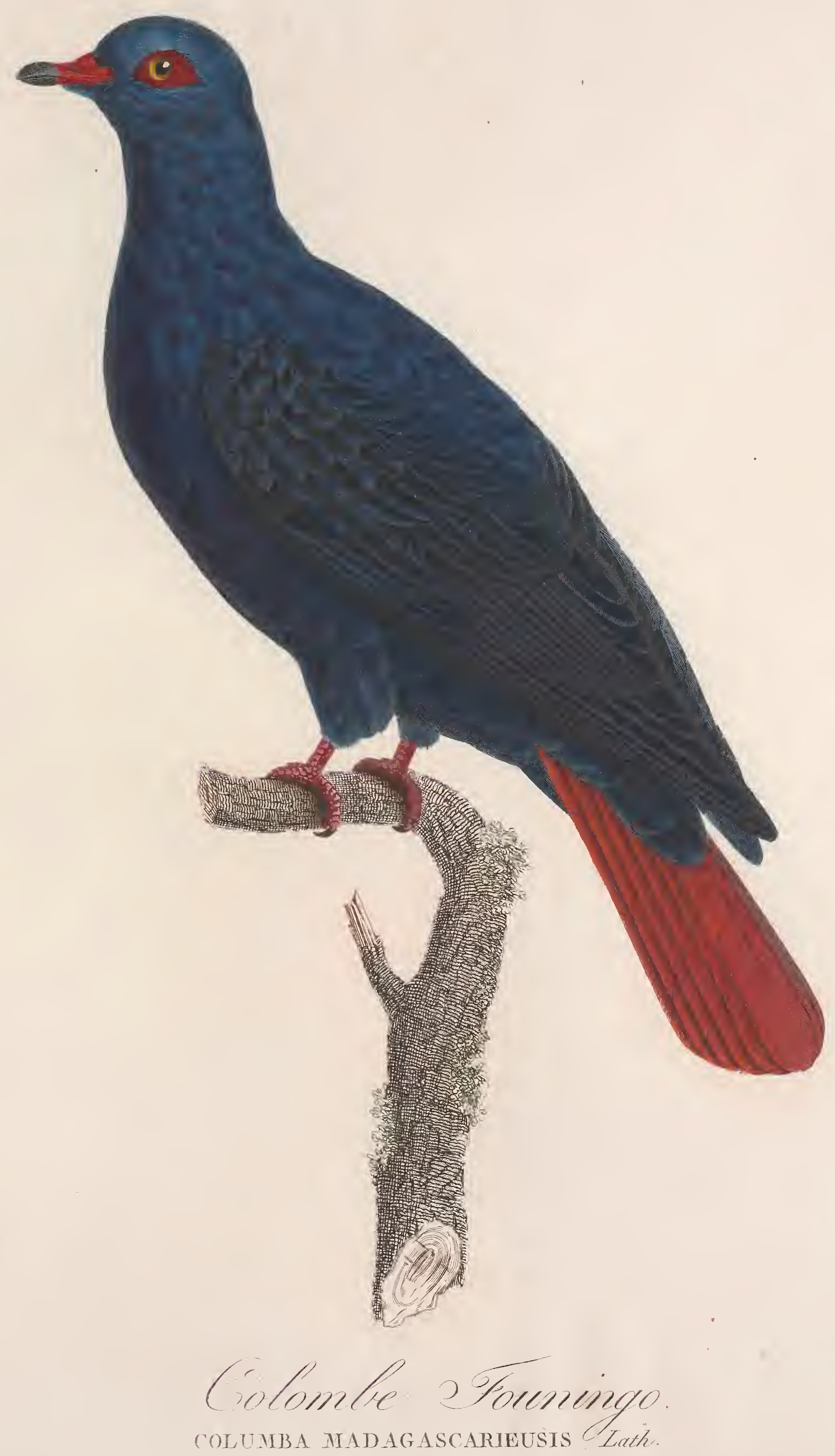




$$
5
$$





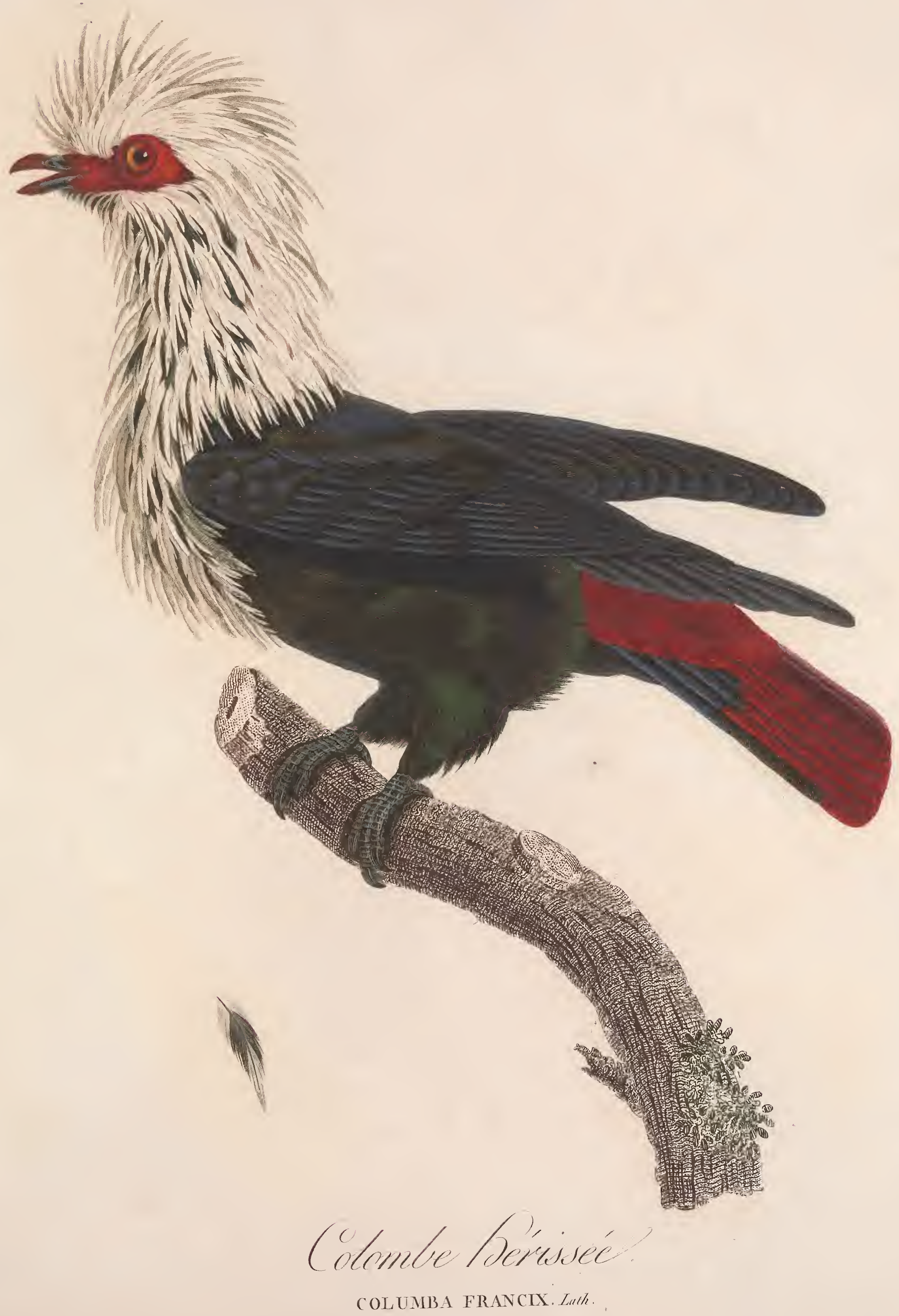







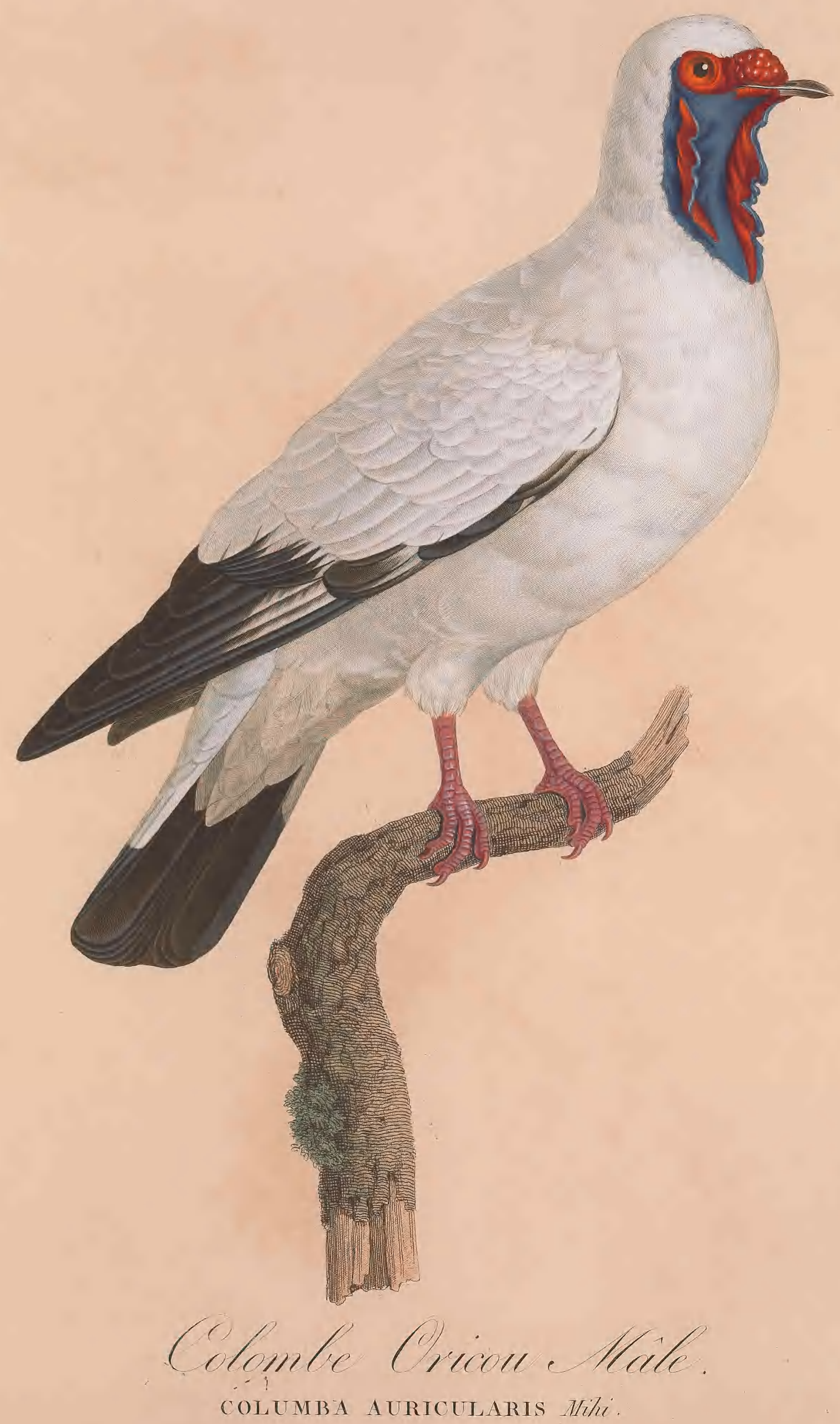






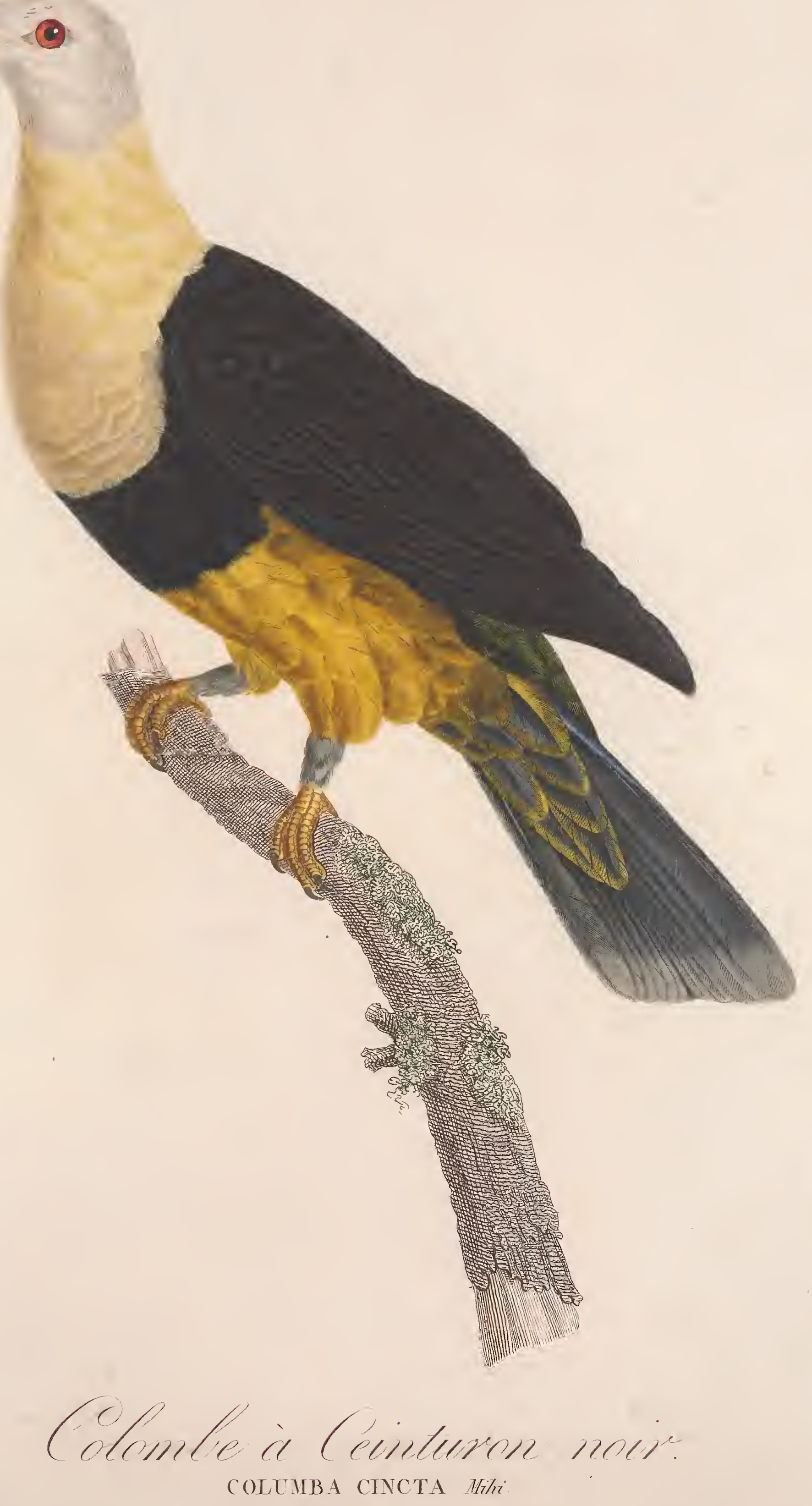







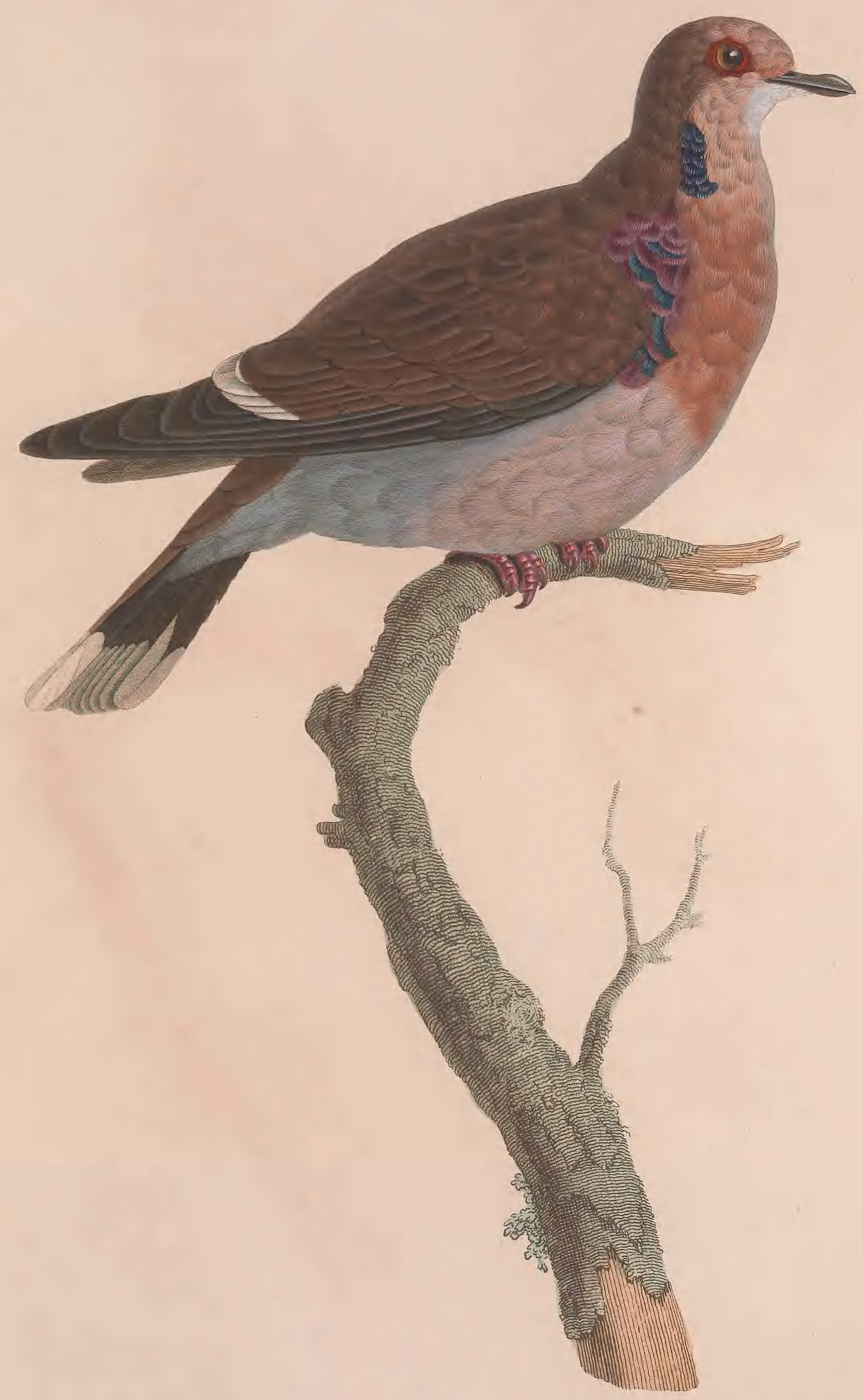

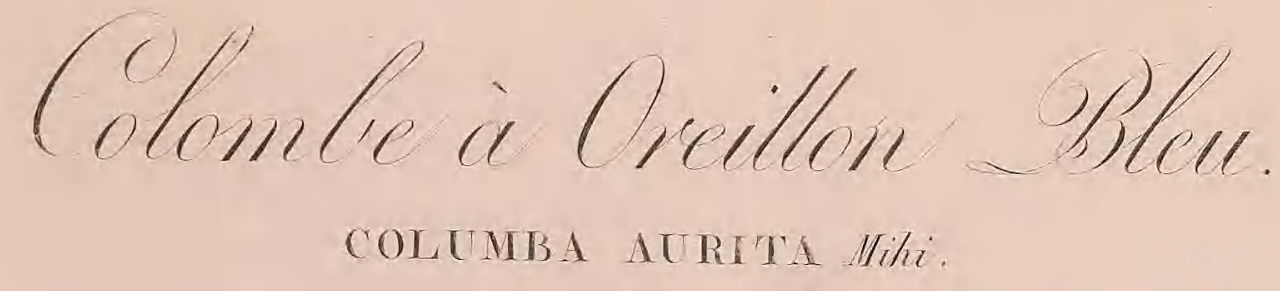




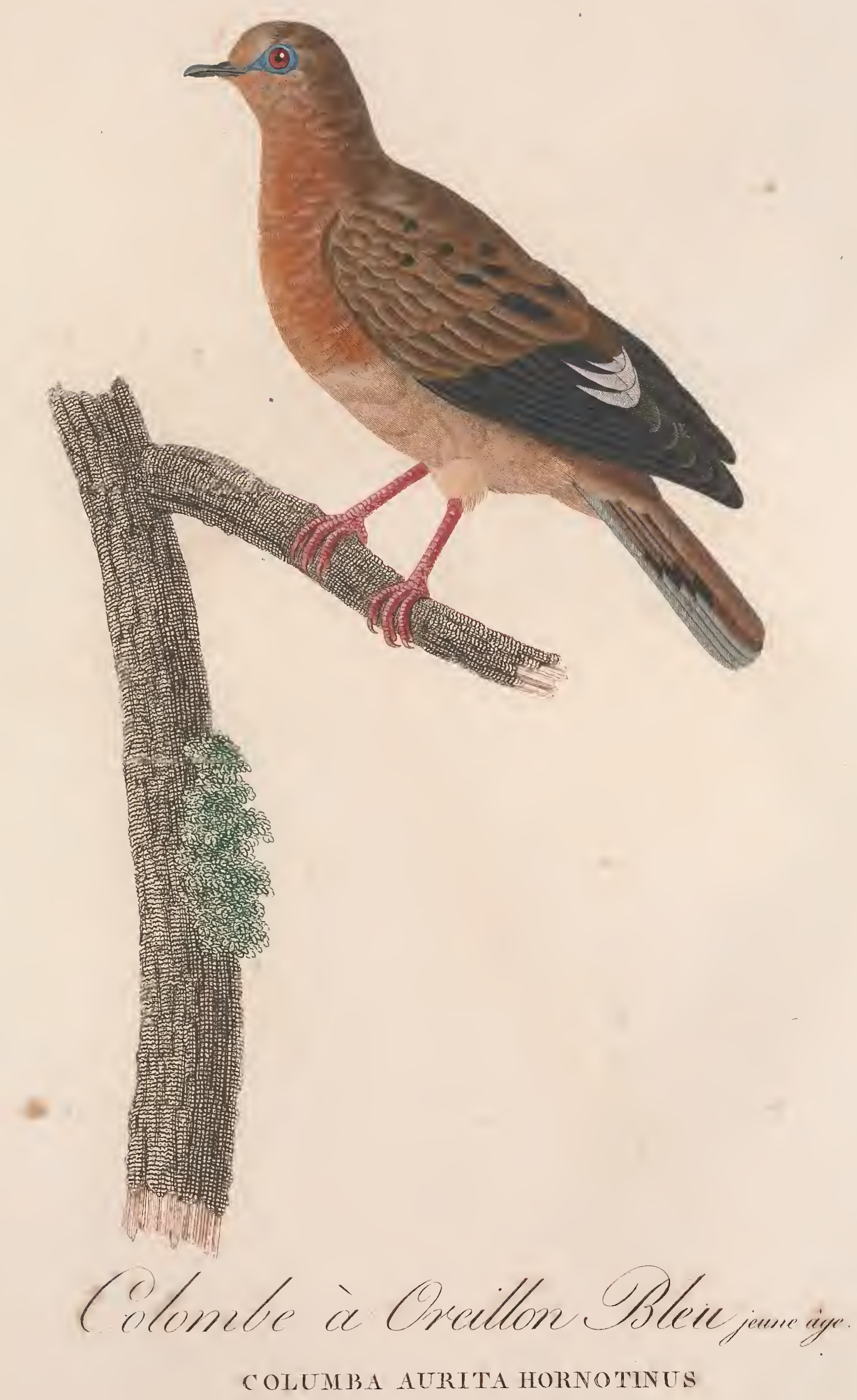



.

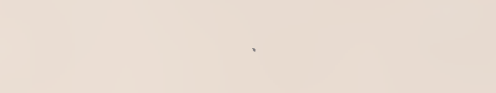




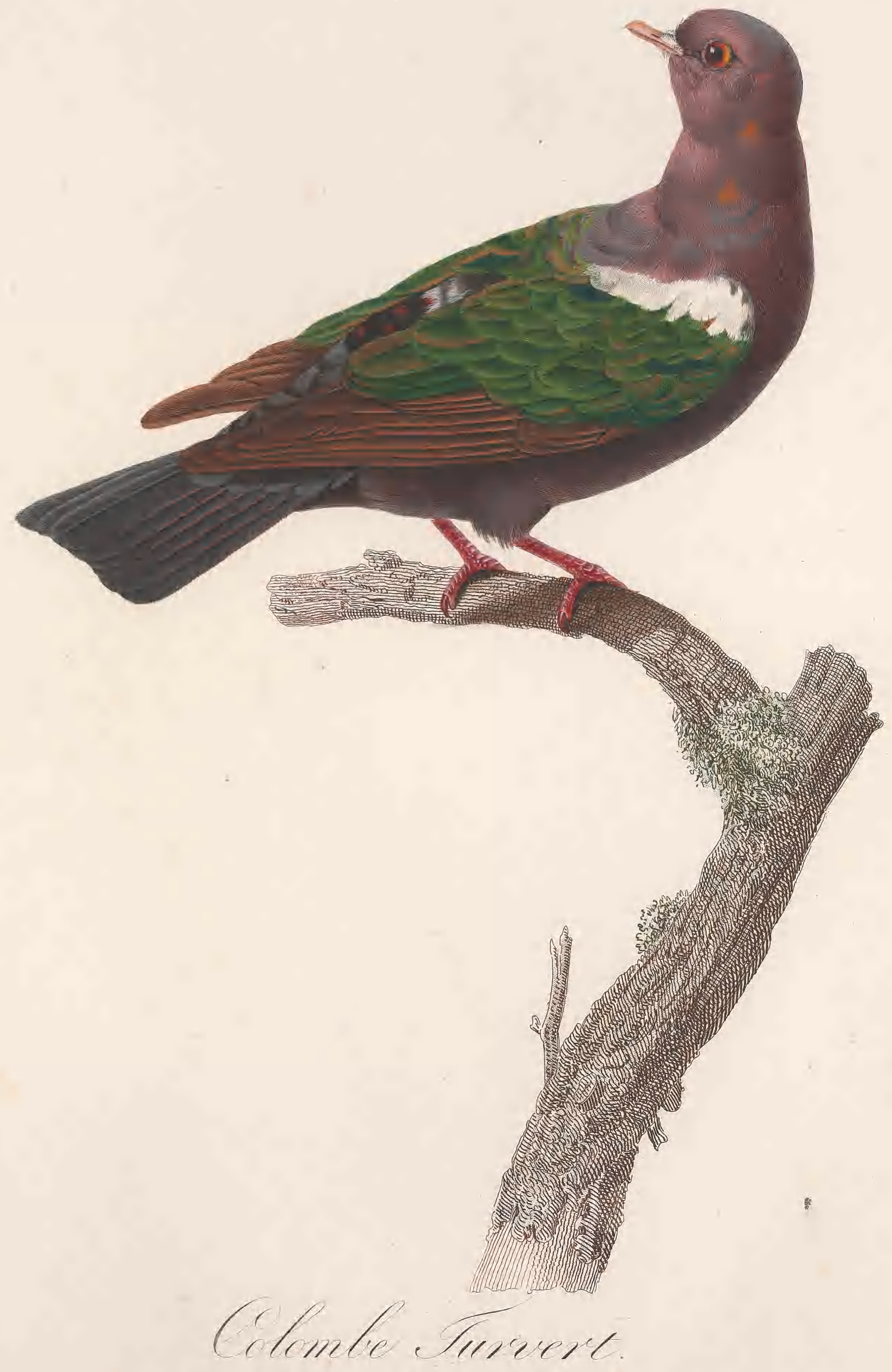

COLUMBA JARANICA Lath. 



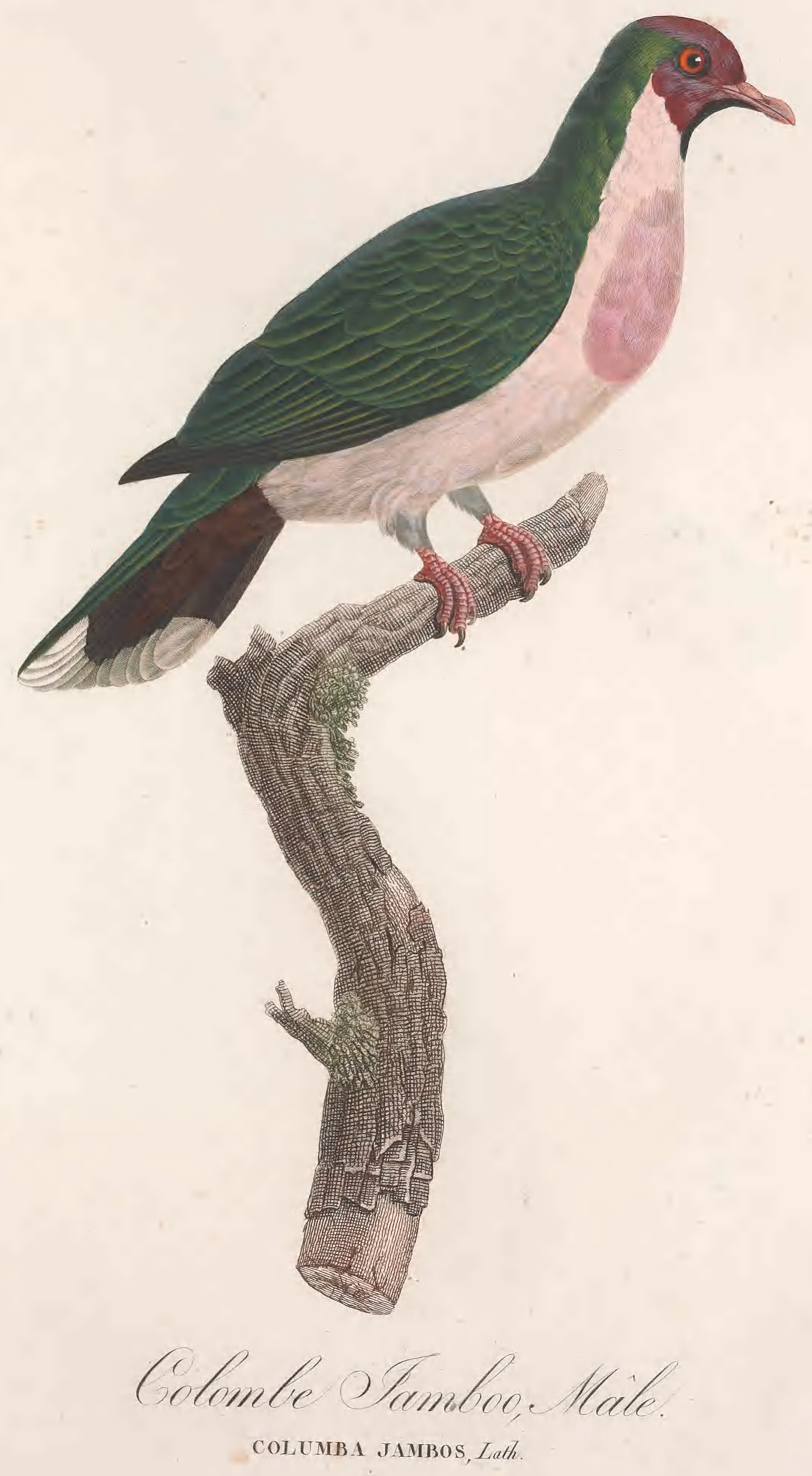





$$
\lambda
$$





$$
1
$$




$$
3
$$




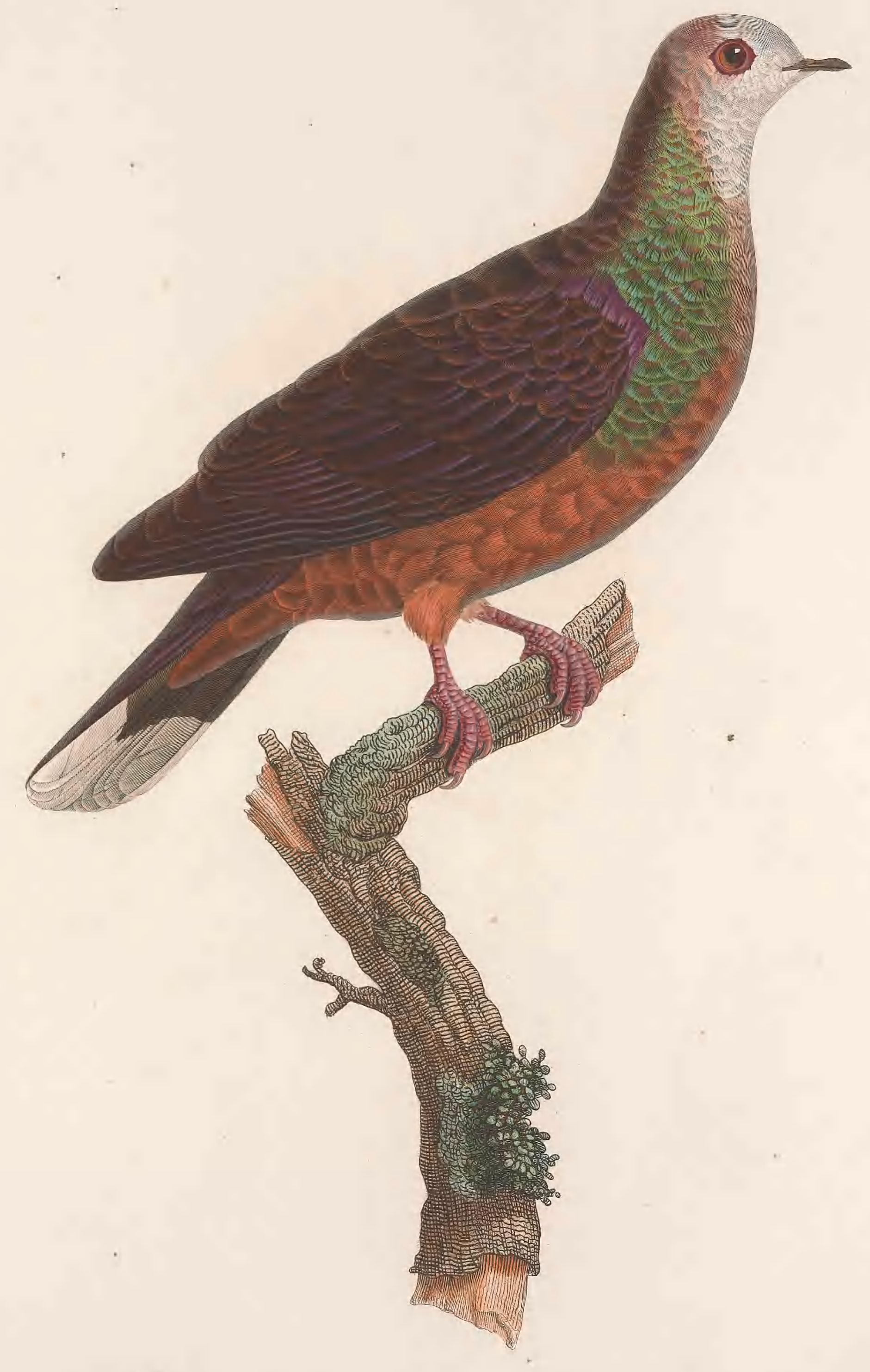

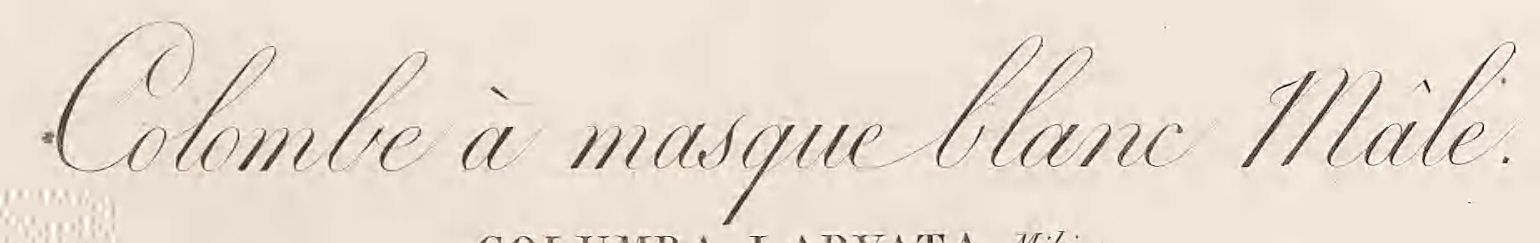

COLUMBA LARVATA Wiki. 



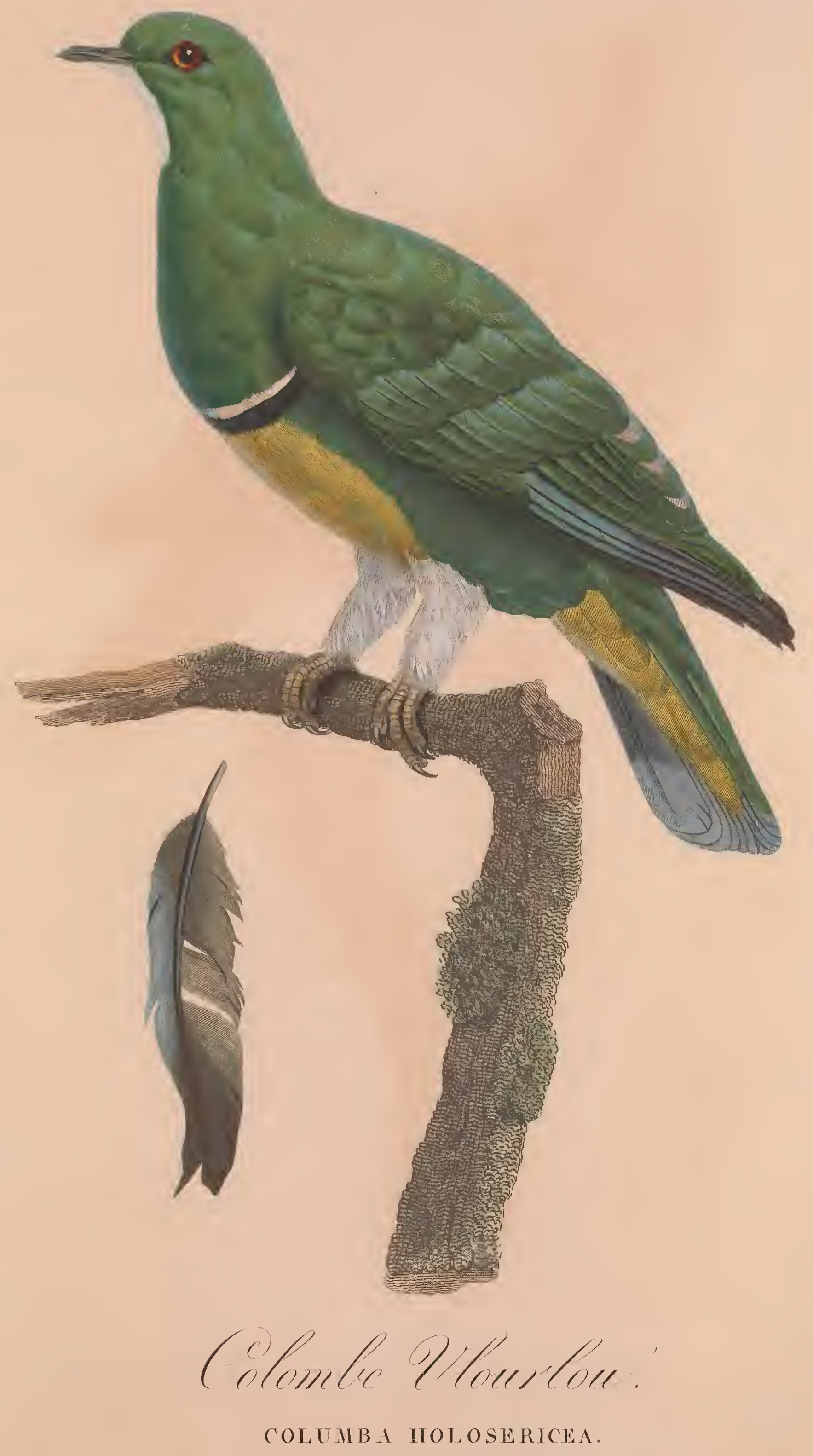




$$
\xi
$$




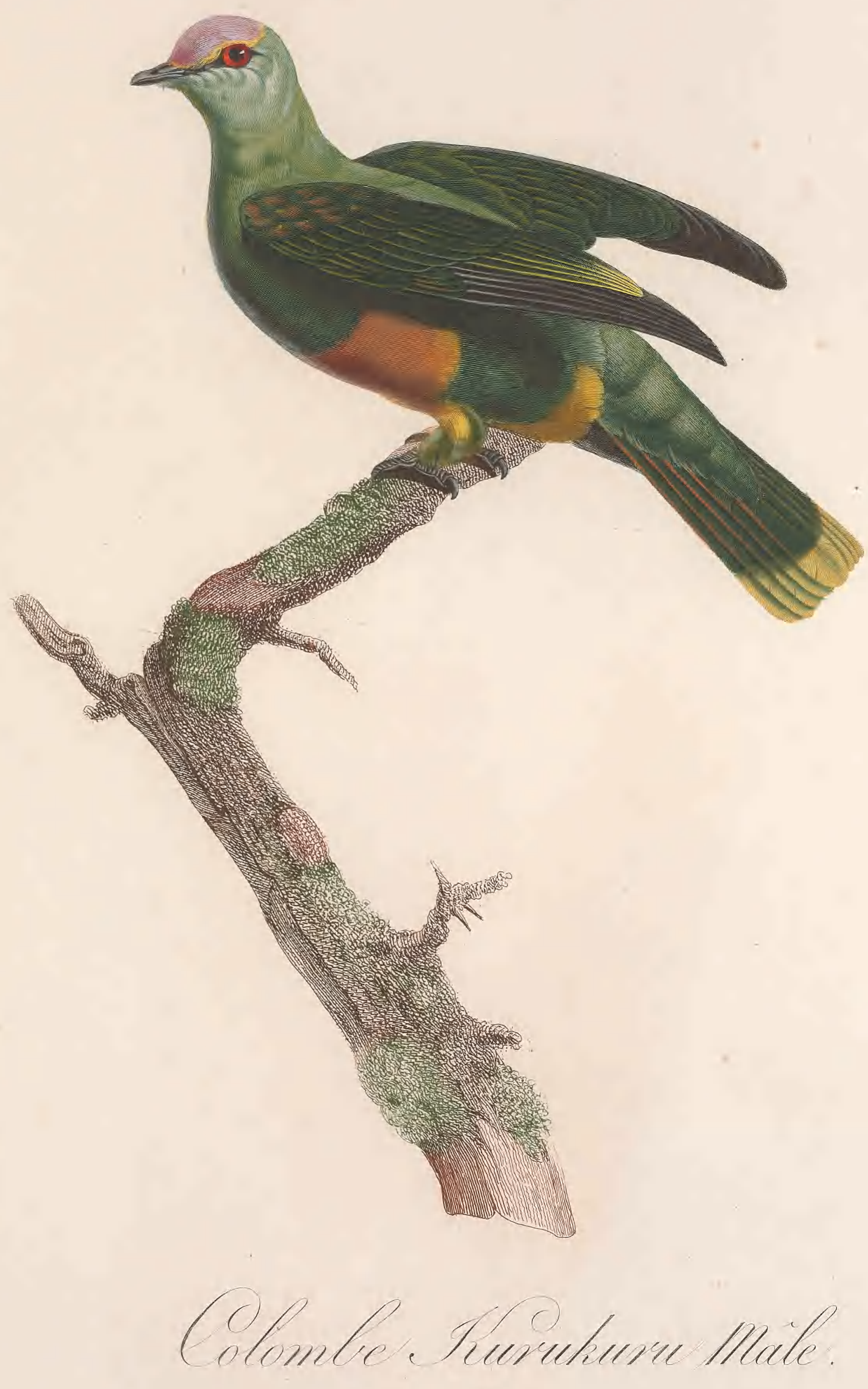

COLUMBA PURPURATA Lath. 



$$
3
$$






$$
\$
$$







$$
\text { f }
$$





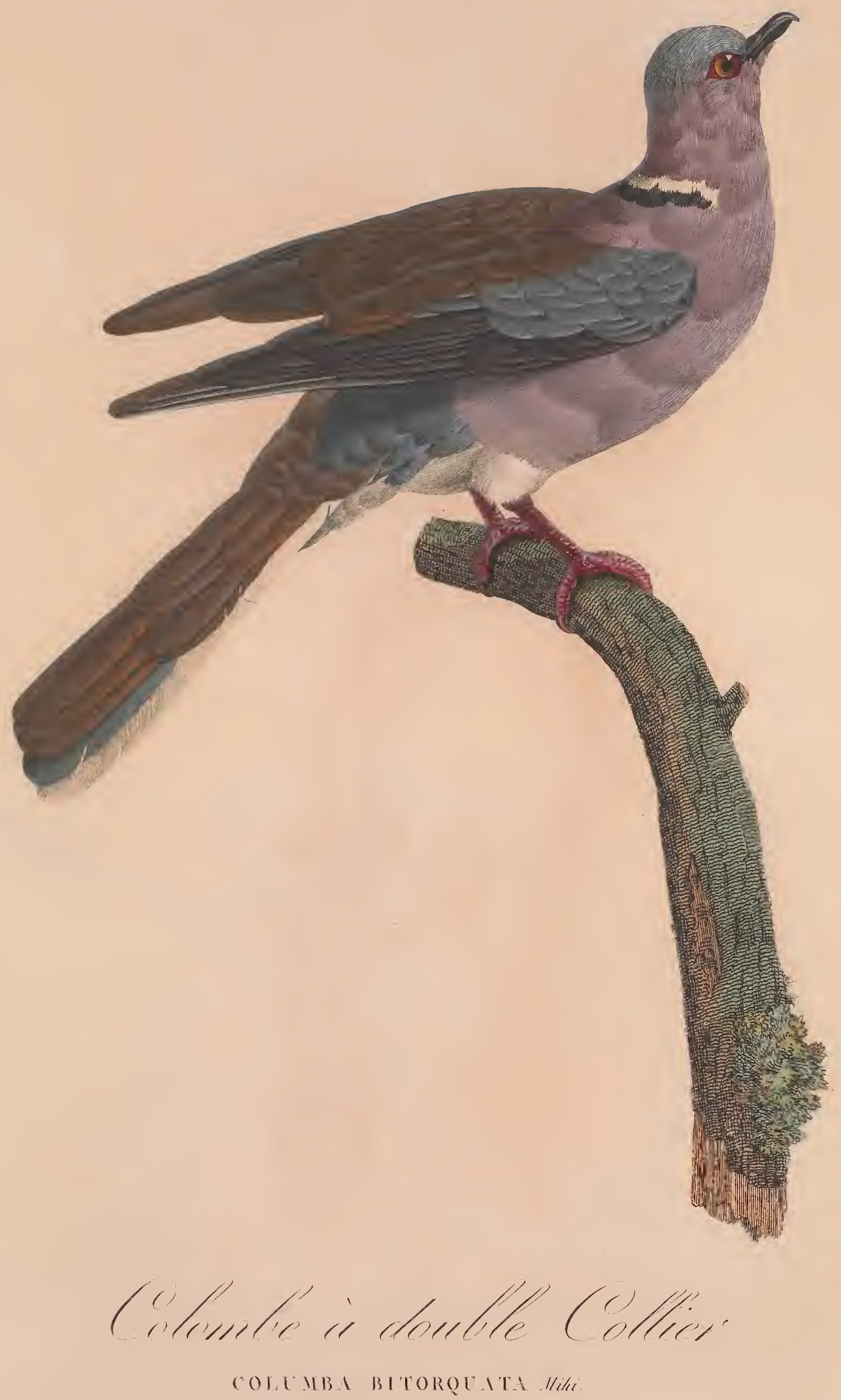







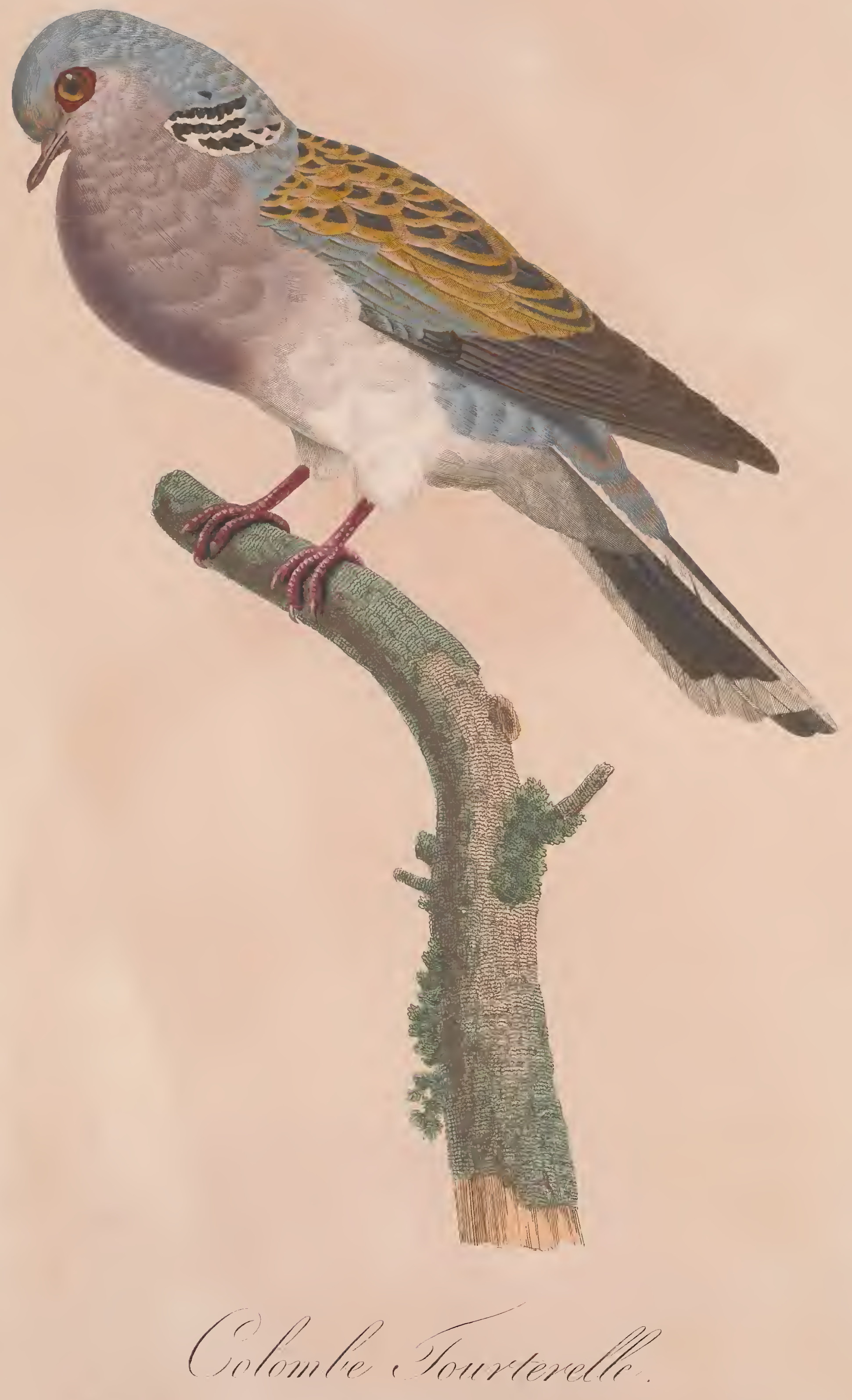

COISAMA TIRTER Lath. 




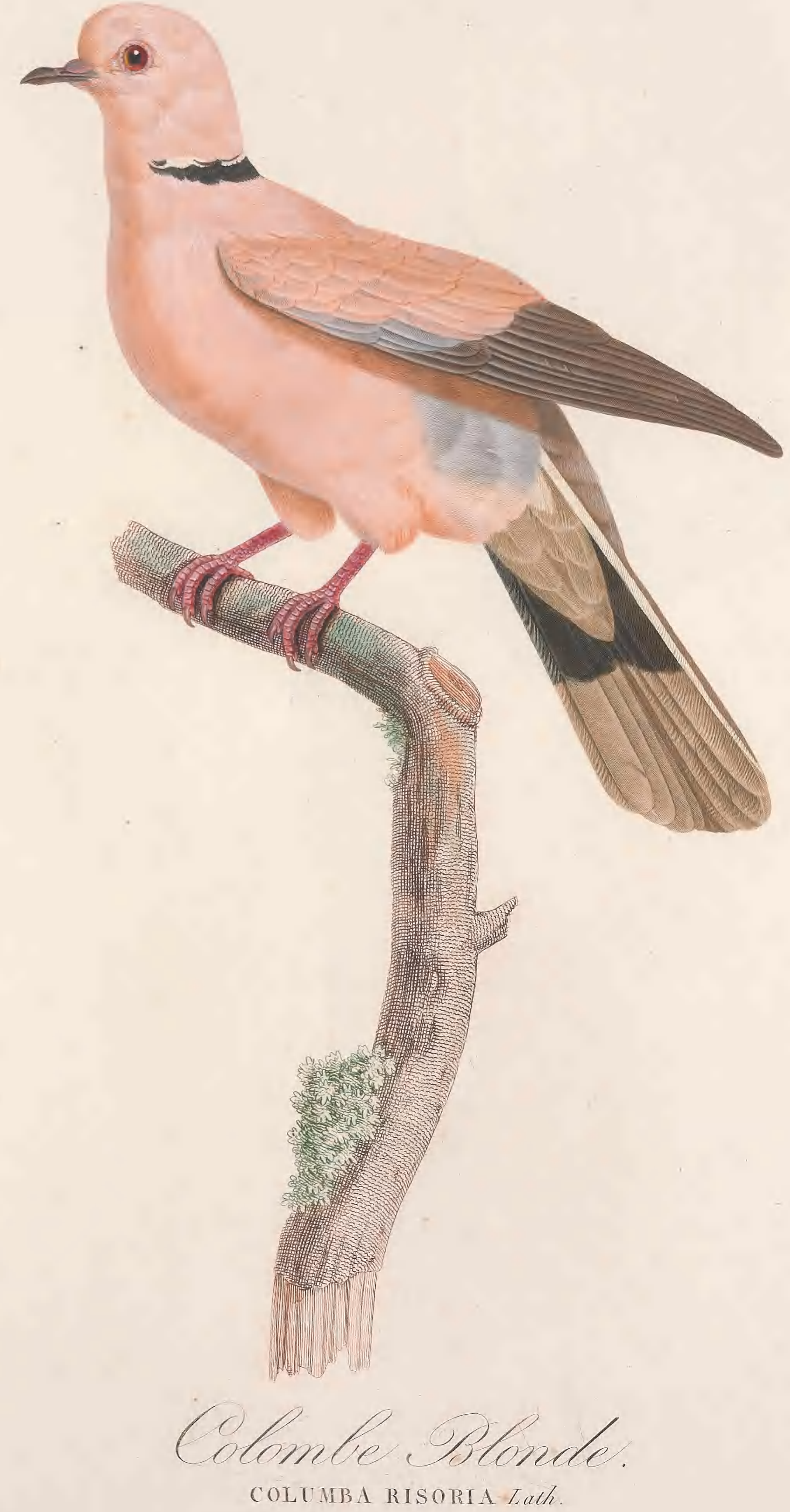







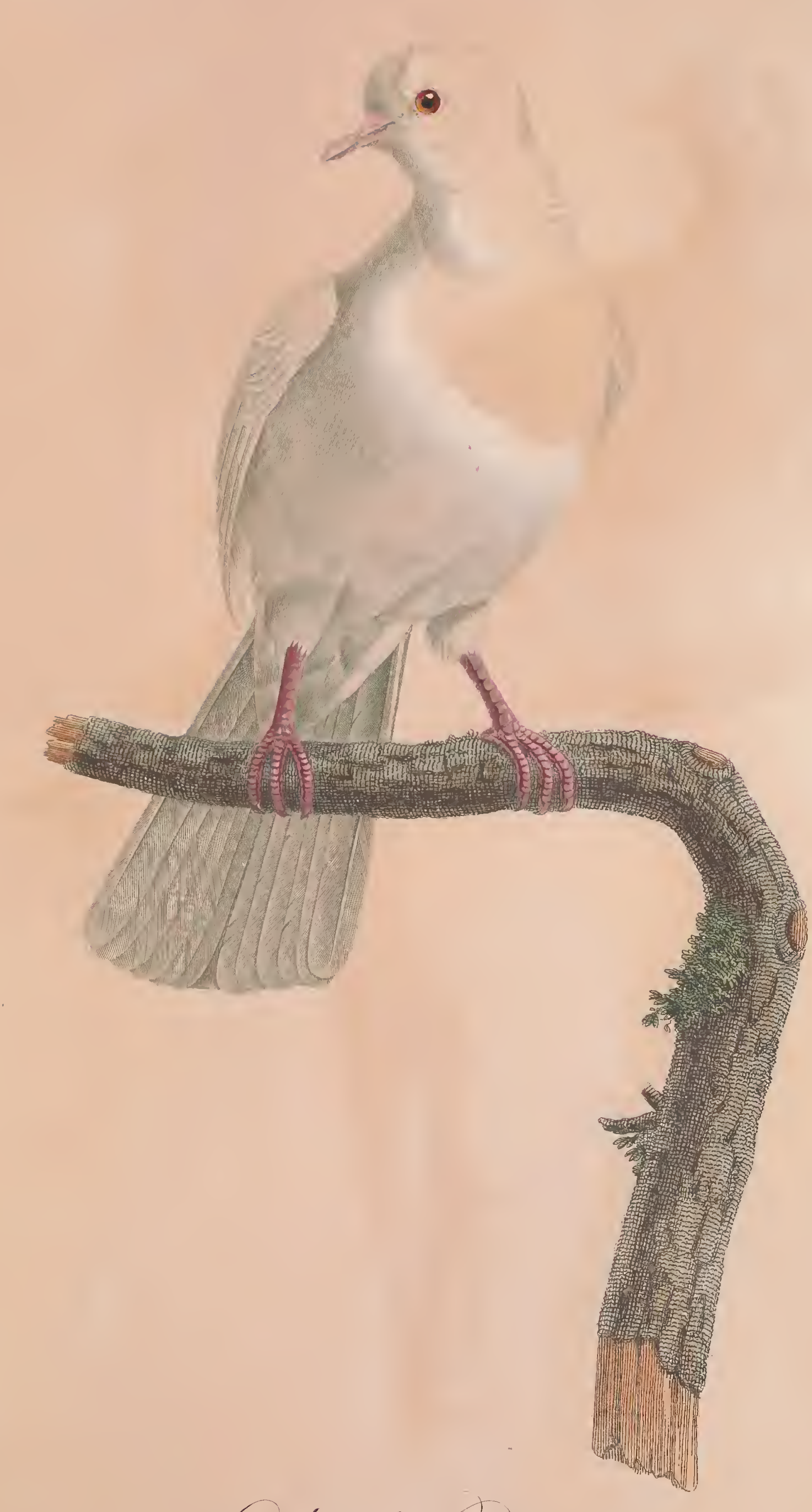

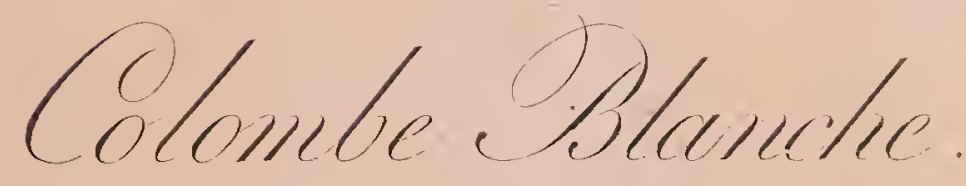
COLUMBA ALBA Mike 



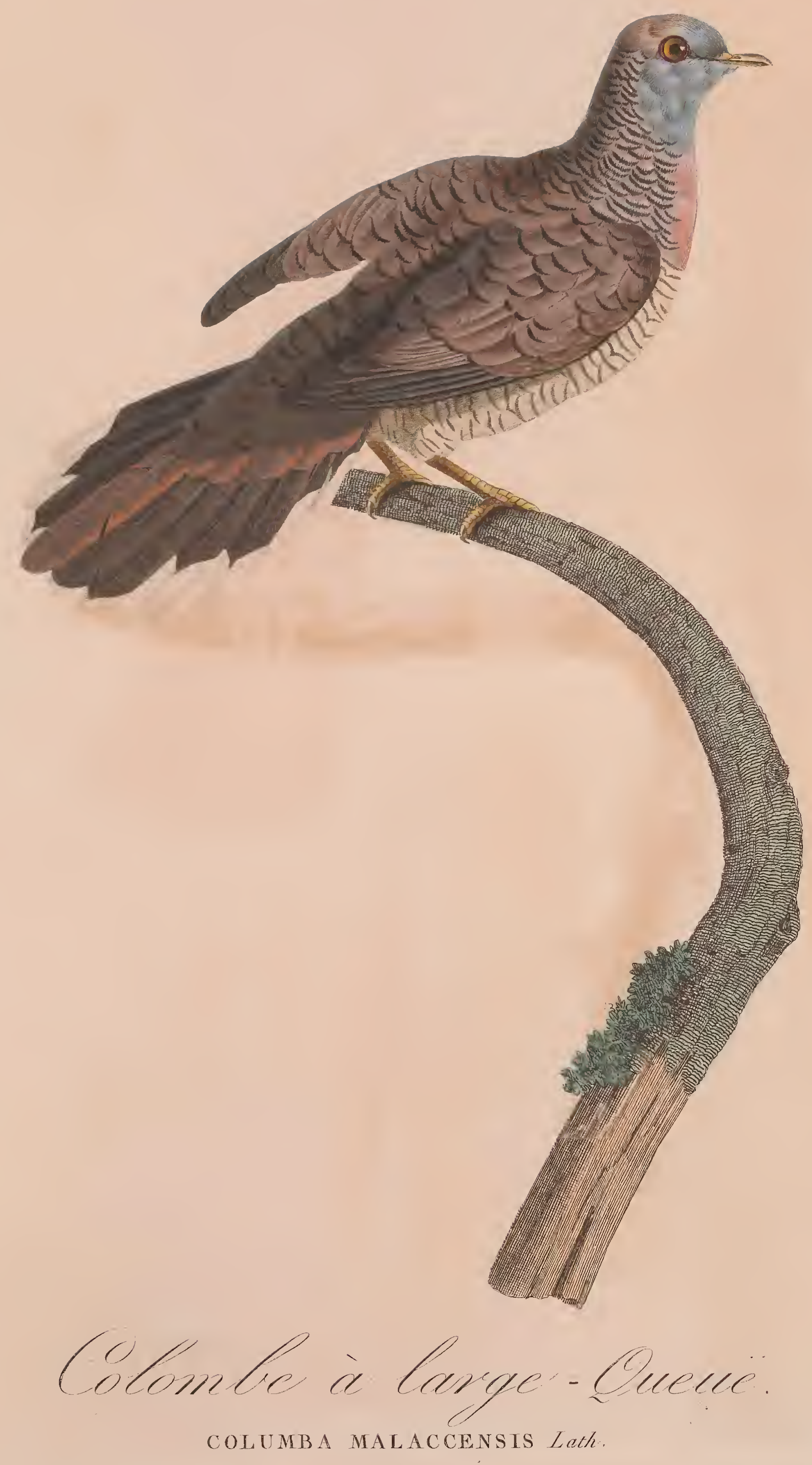





$$
\text { R }
$$





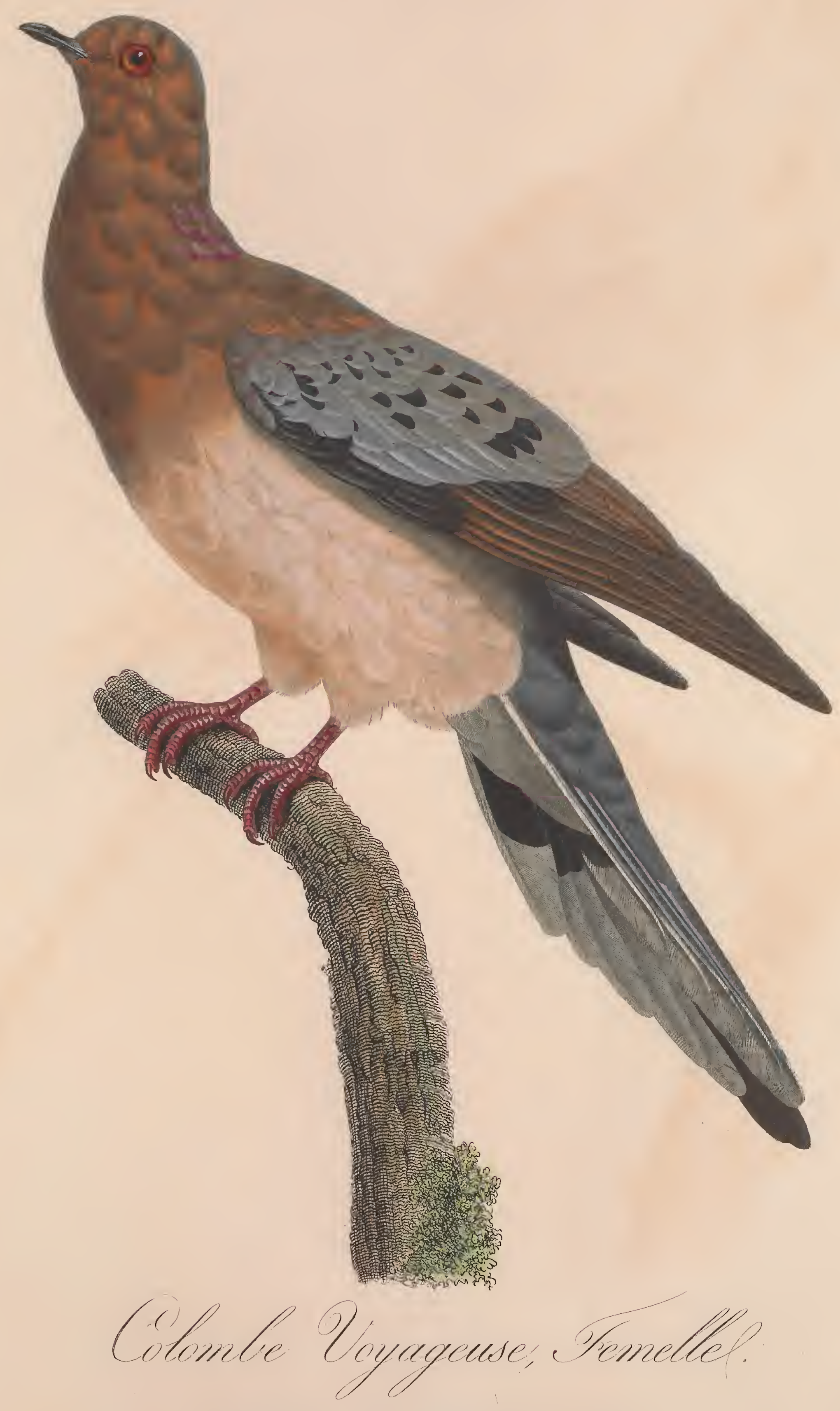

COLUmba migratoria Femina Miki,

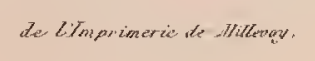





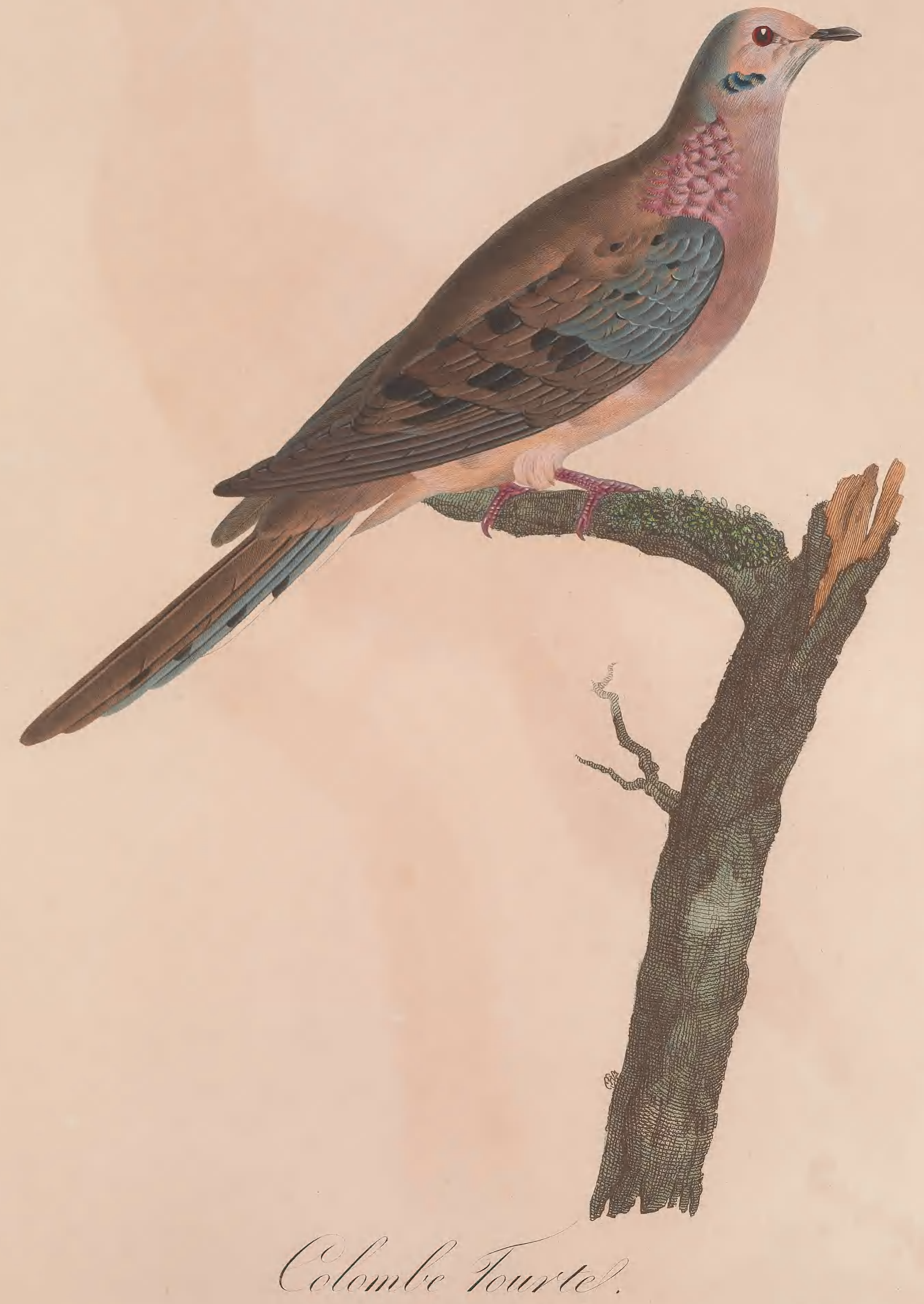

COLUMBA CAROLINENSIS Tath 



$$
1
$$





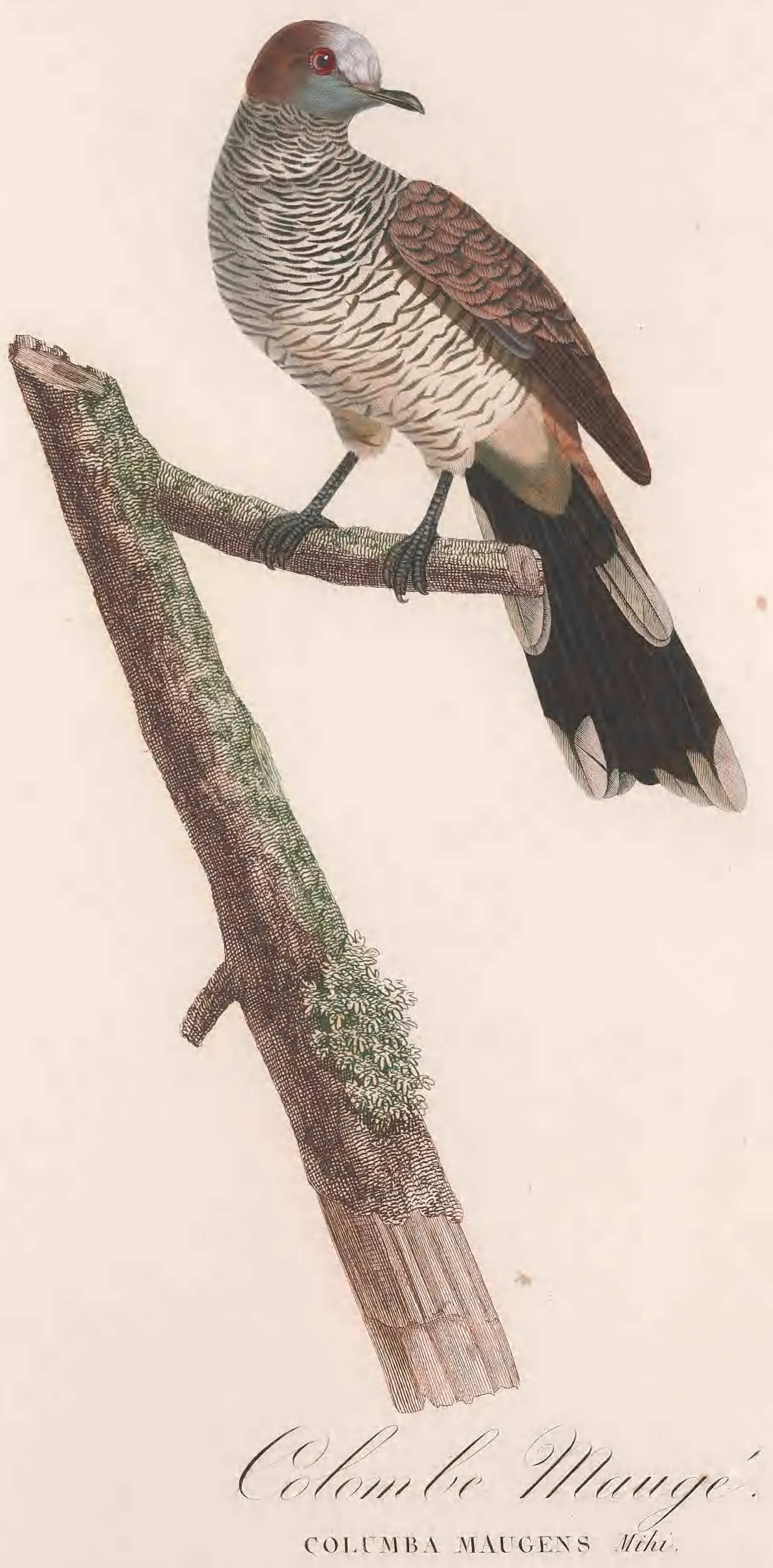


, 1 


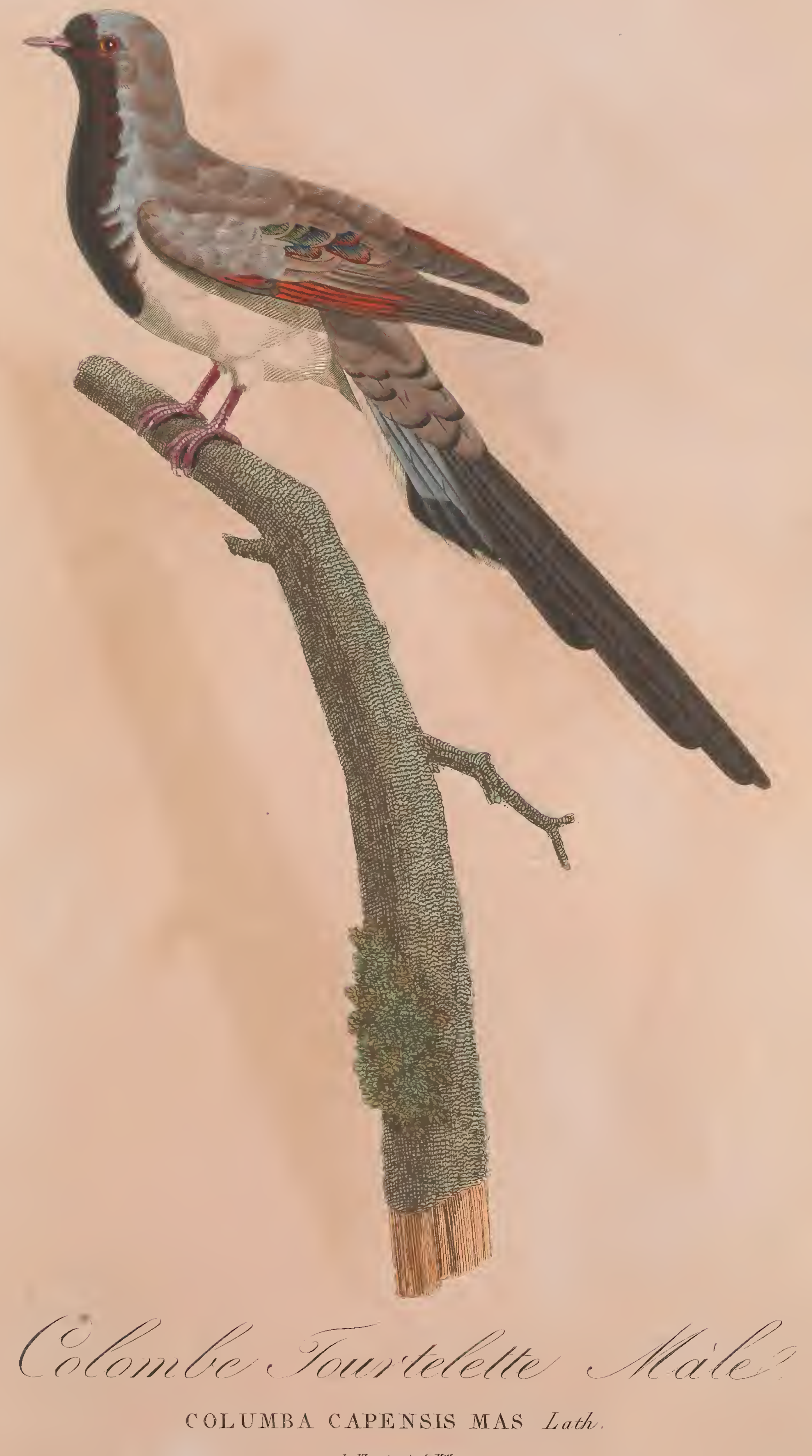




$$
\text { 存 }
$$





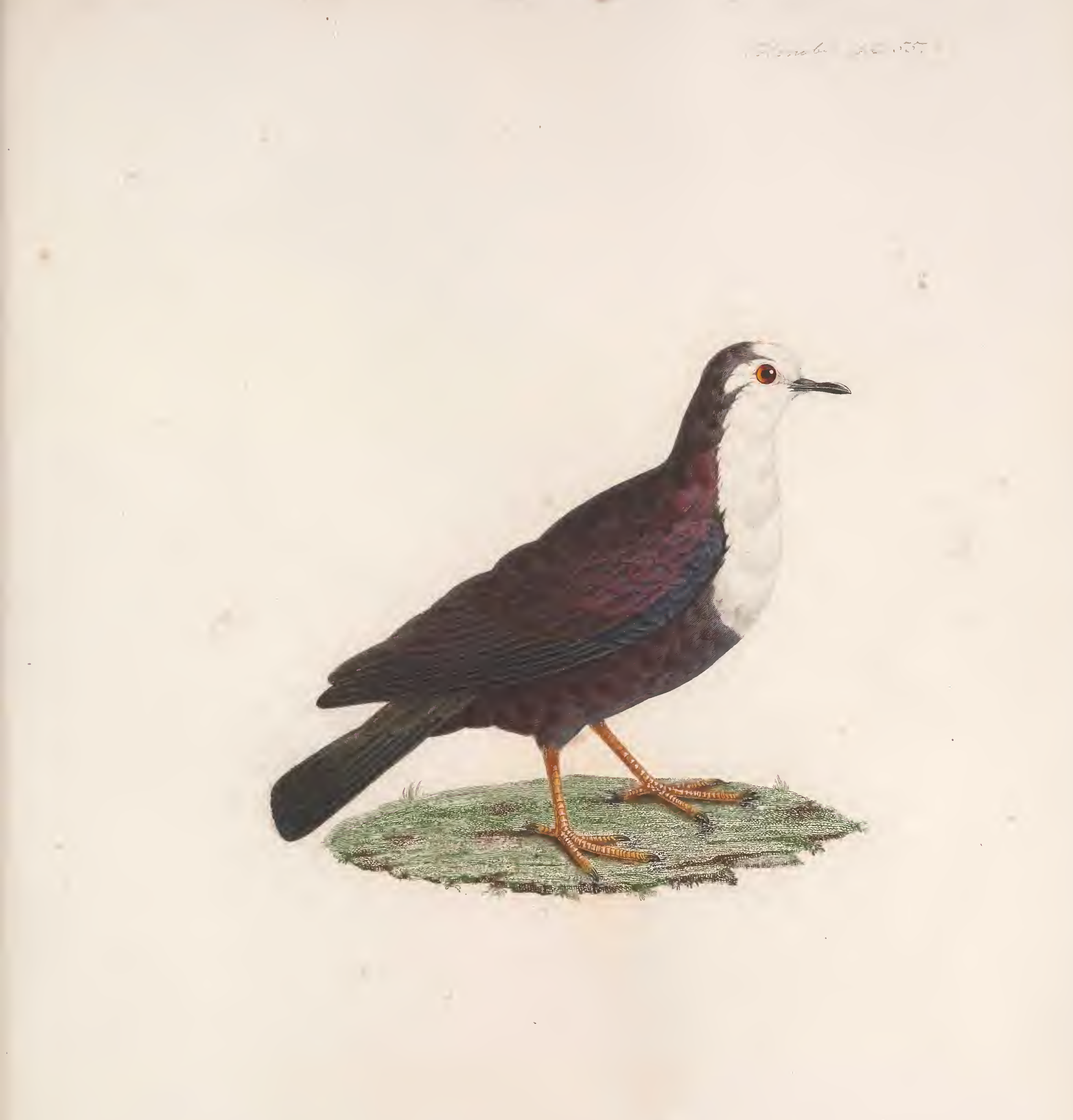




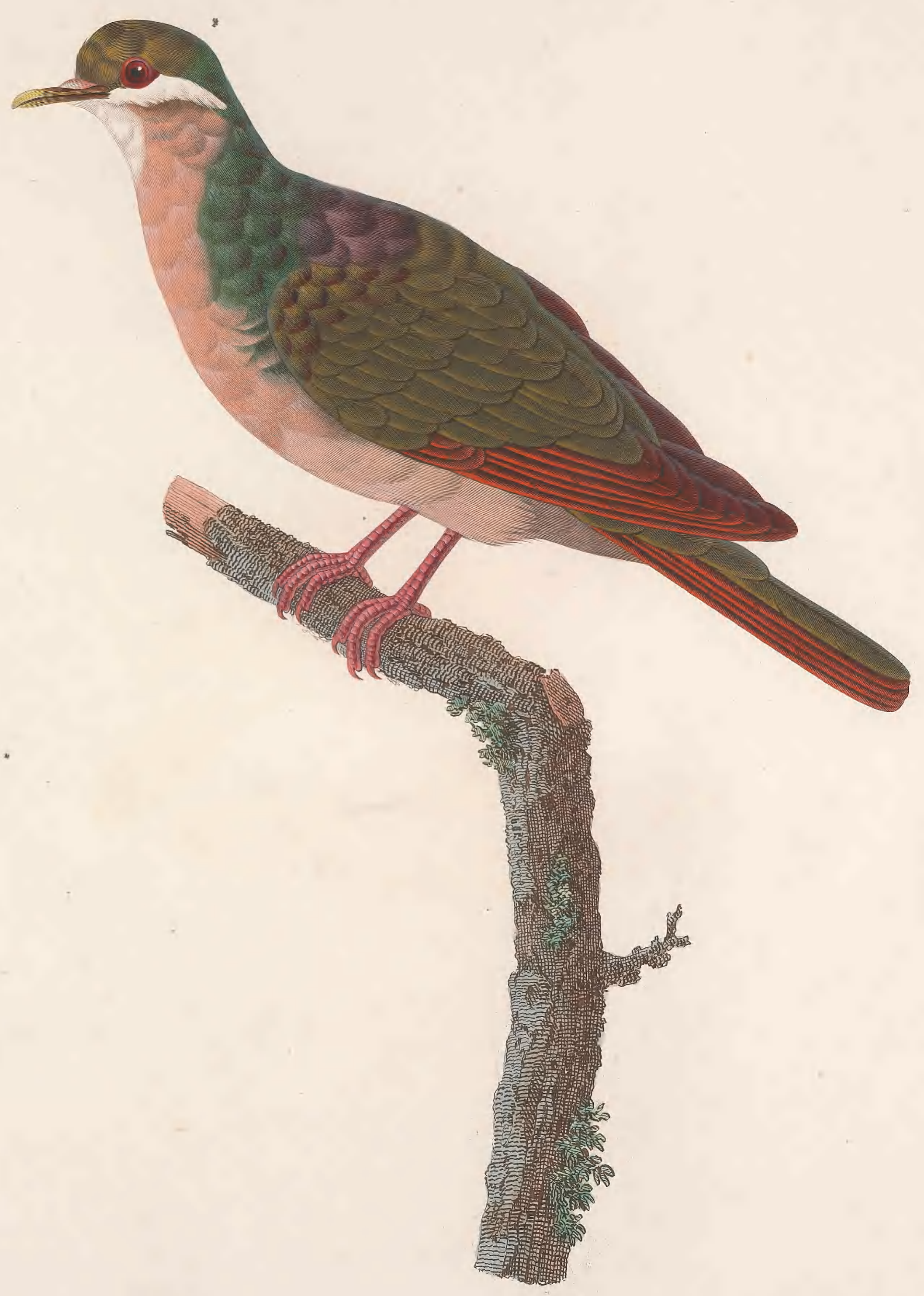

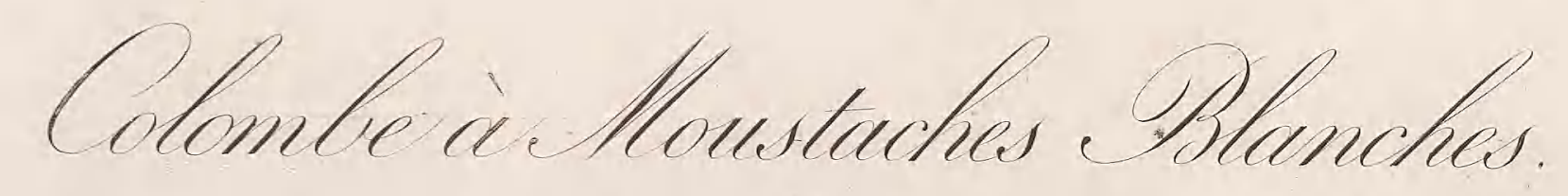
COLUMBA MYSTACEA Mihi: 



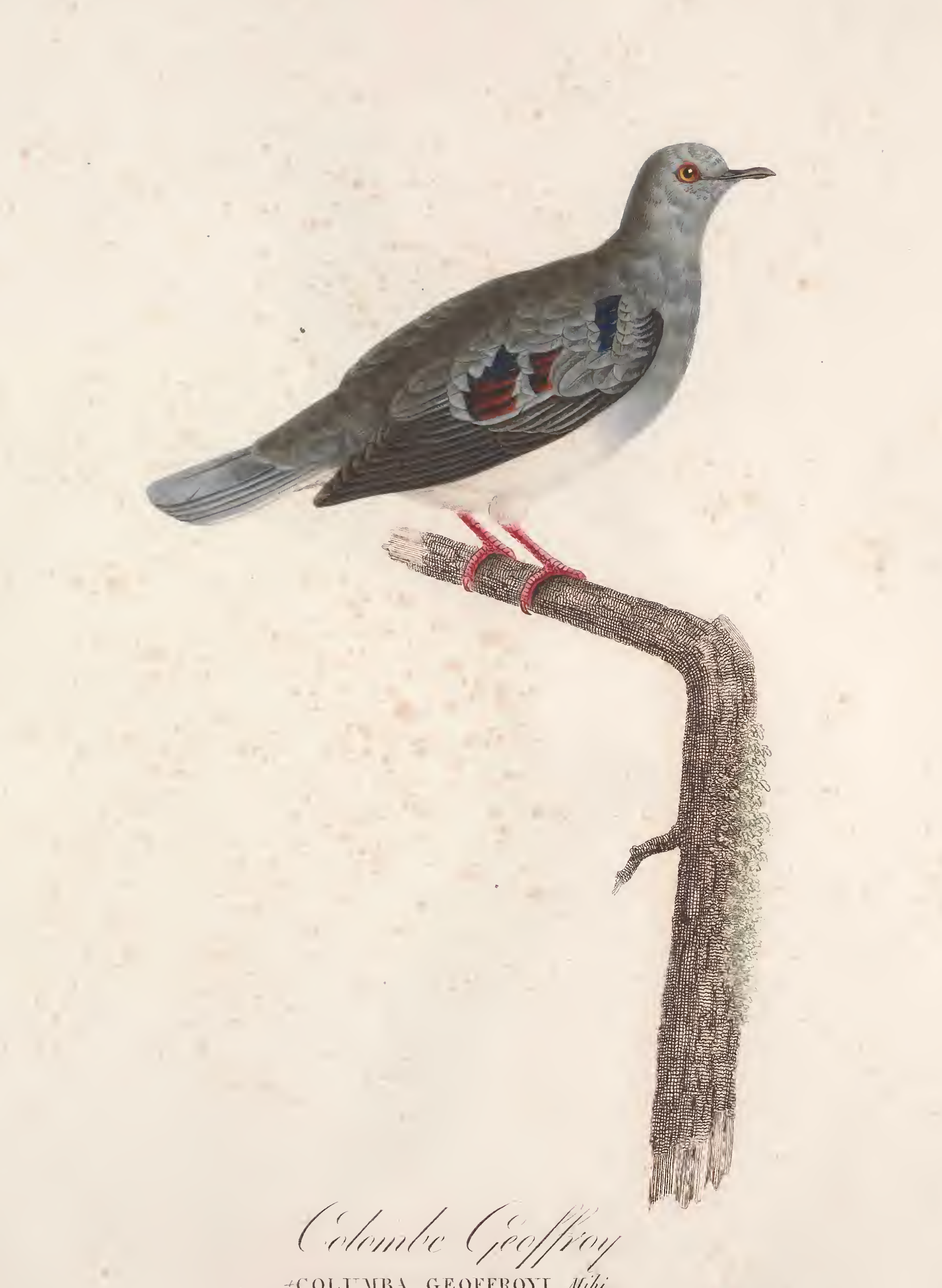







$$
\uparrow
$$





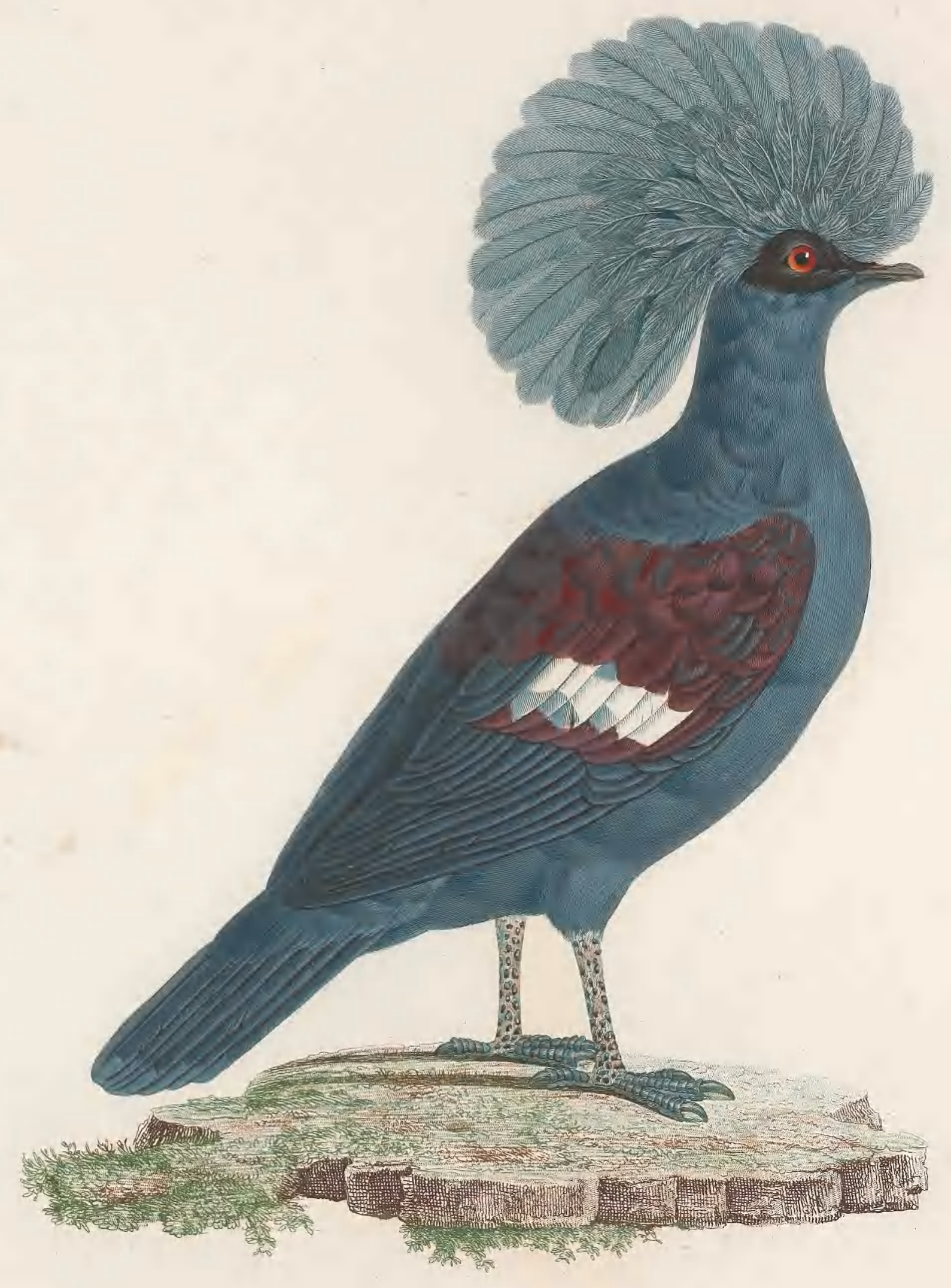

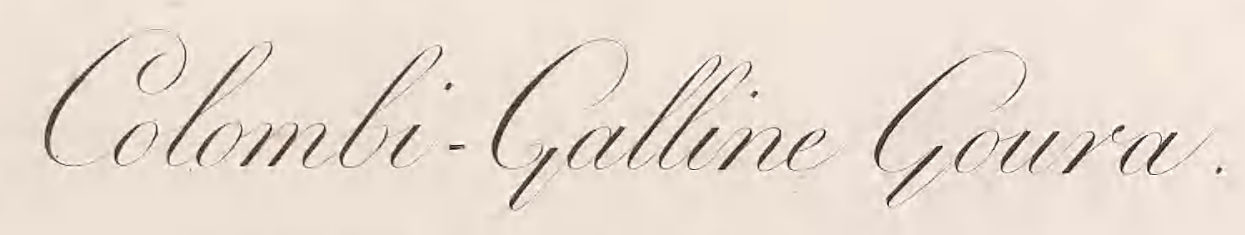

COLUMBA CORONATA Lalh. 



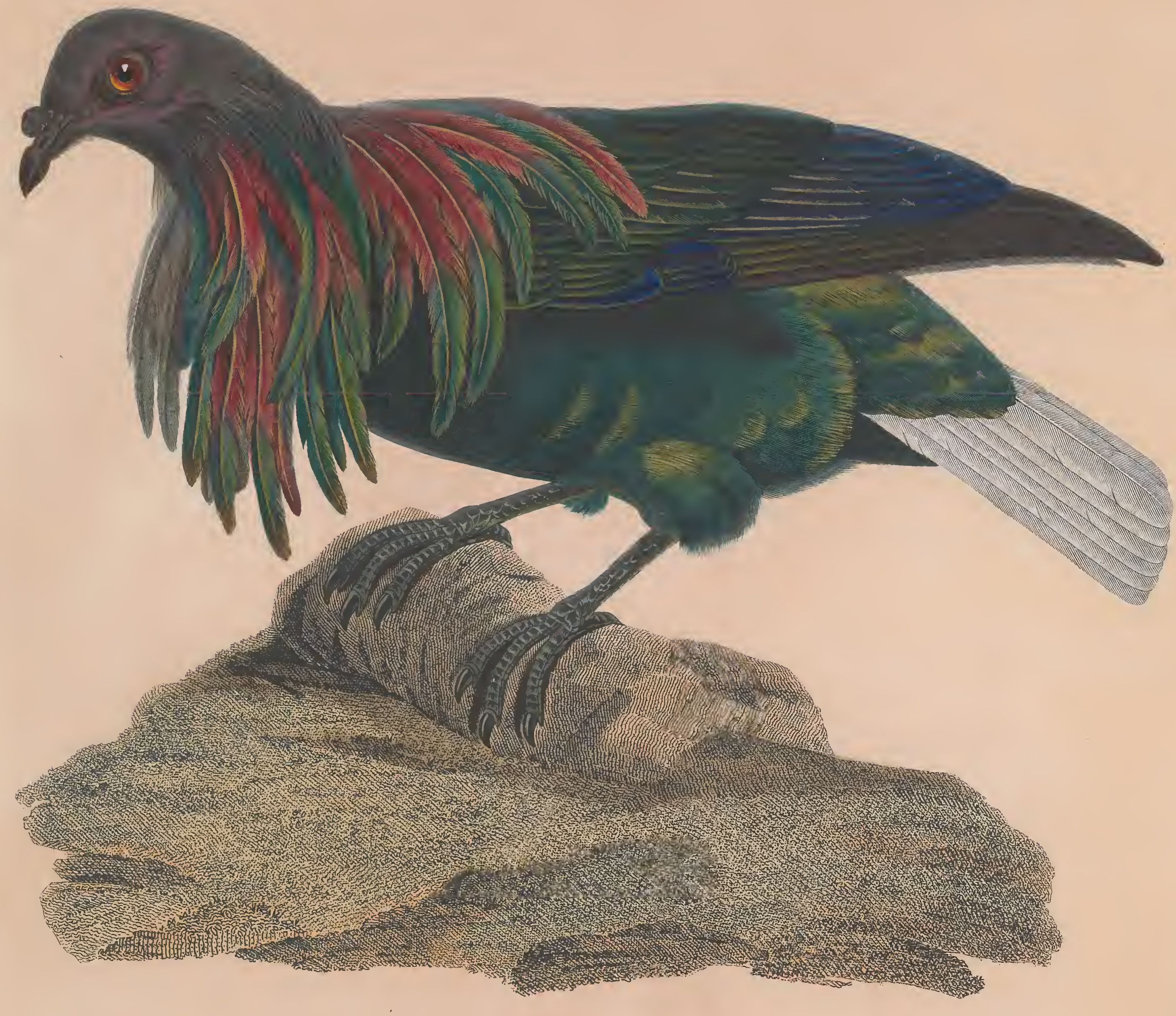

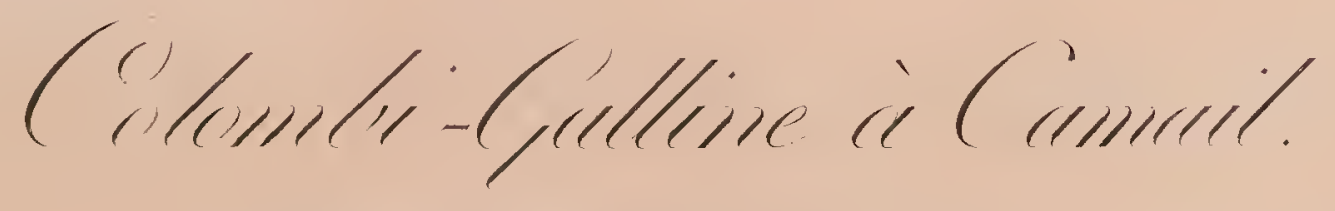

COJ C MIBA NICOBARICA. Lalh. 



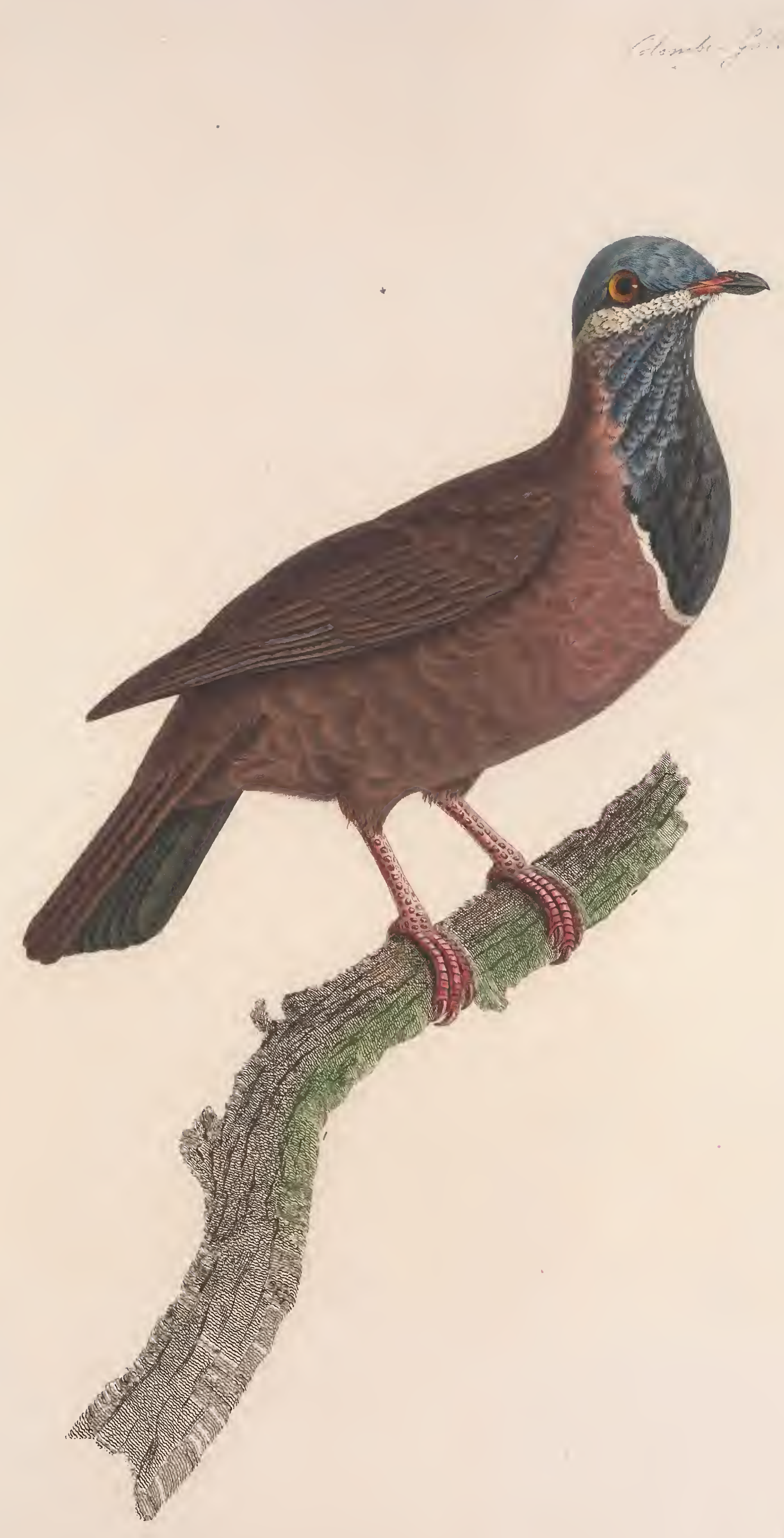

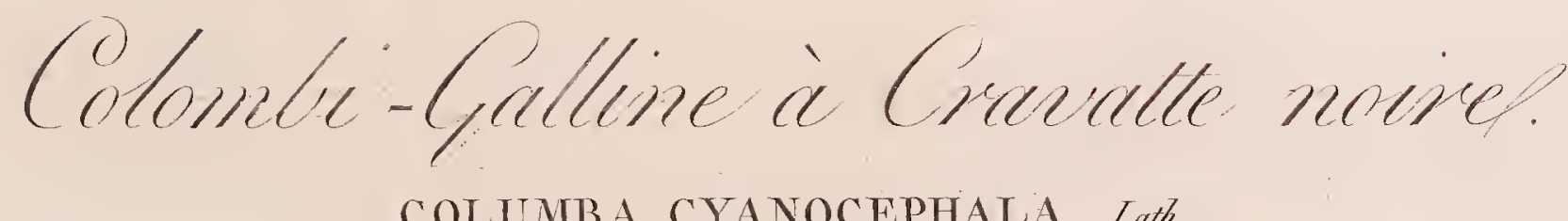





$$
1
$$





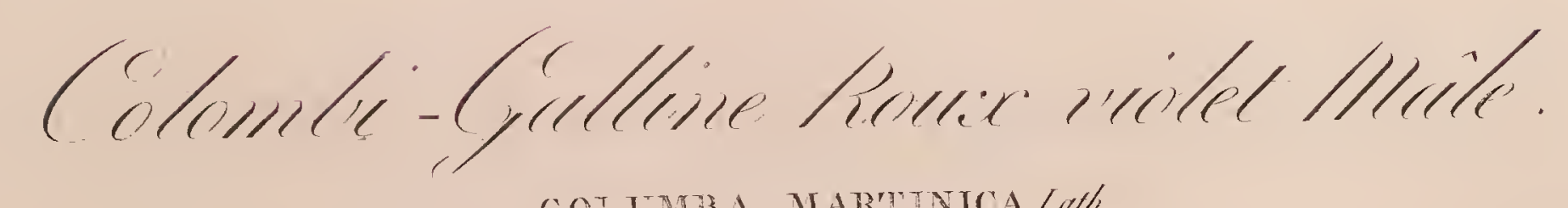
COLCMB3A MARTINICA Lath. 



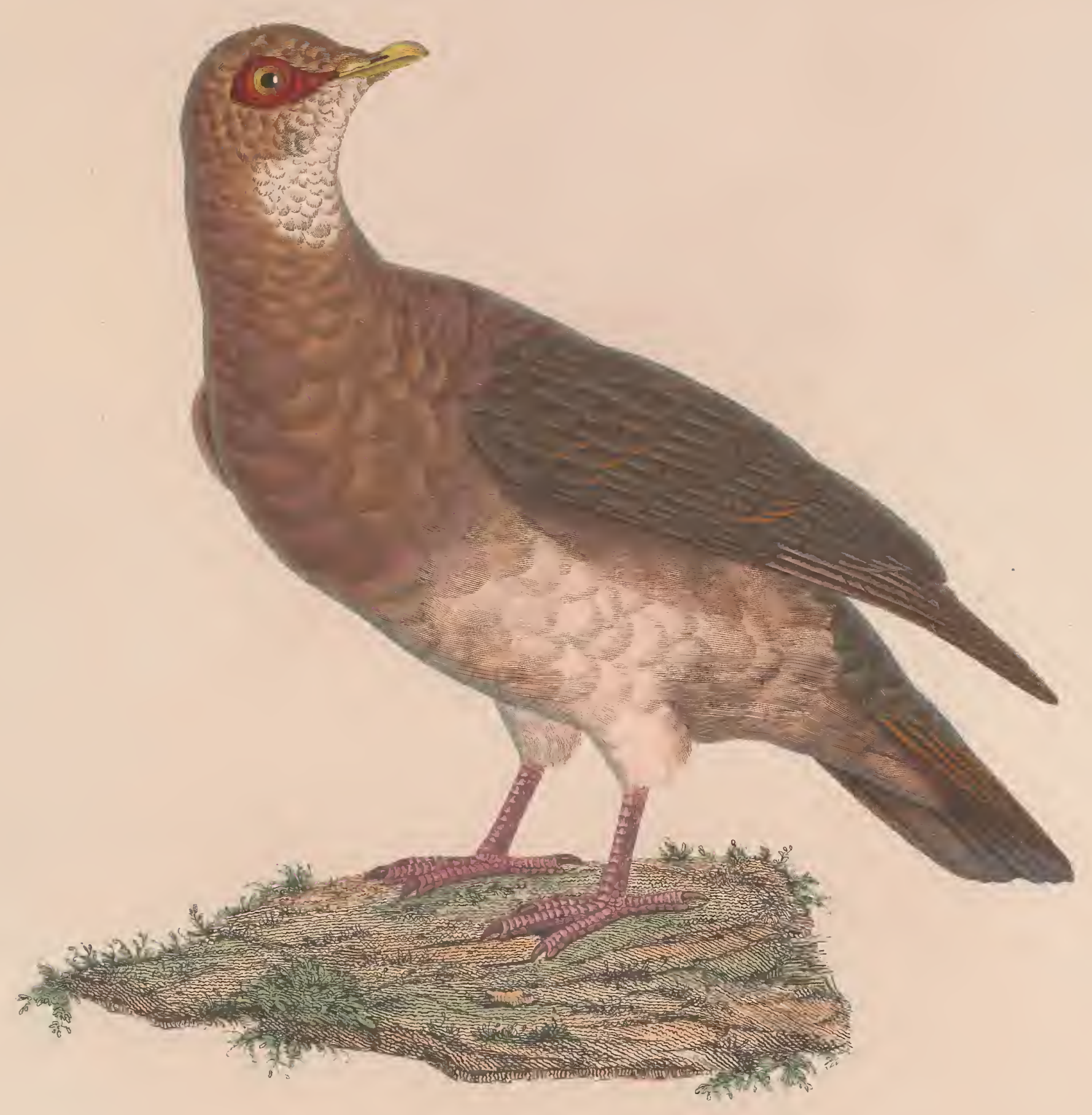

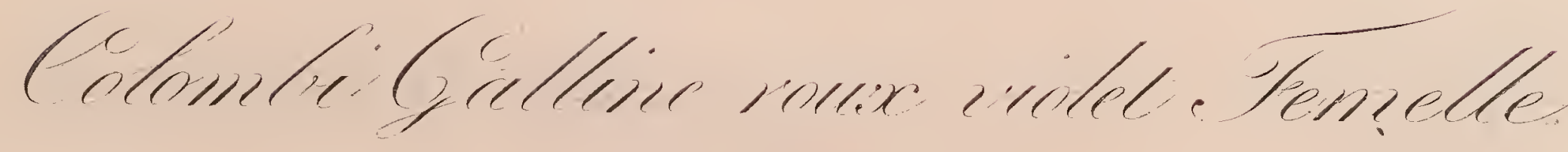

COLEAIBA MARTINICA. 



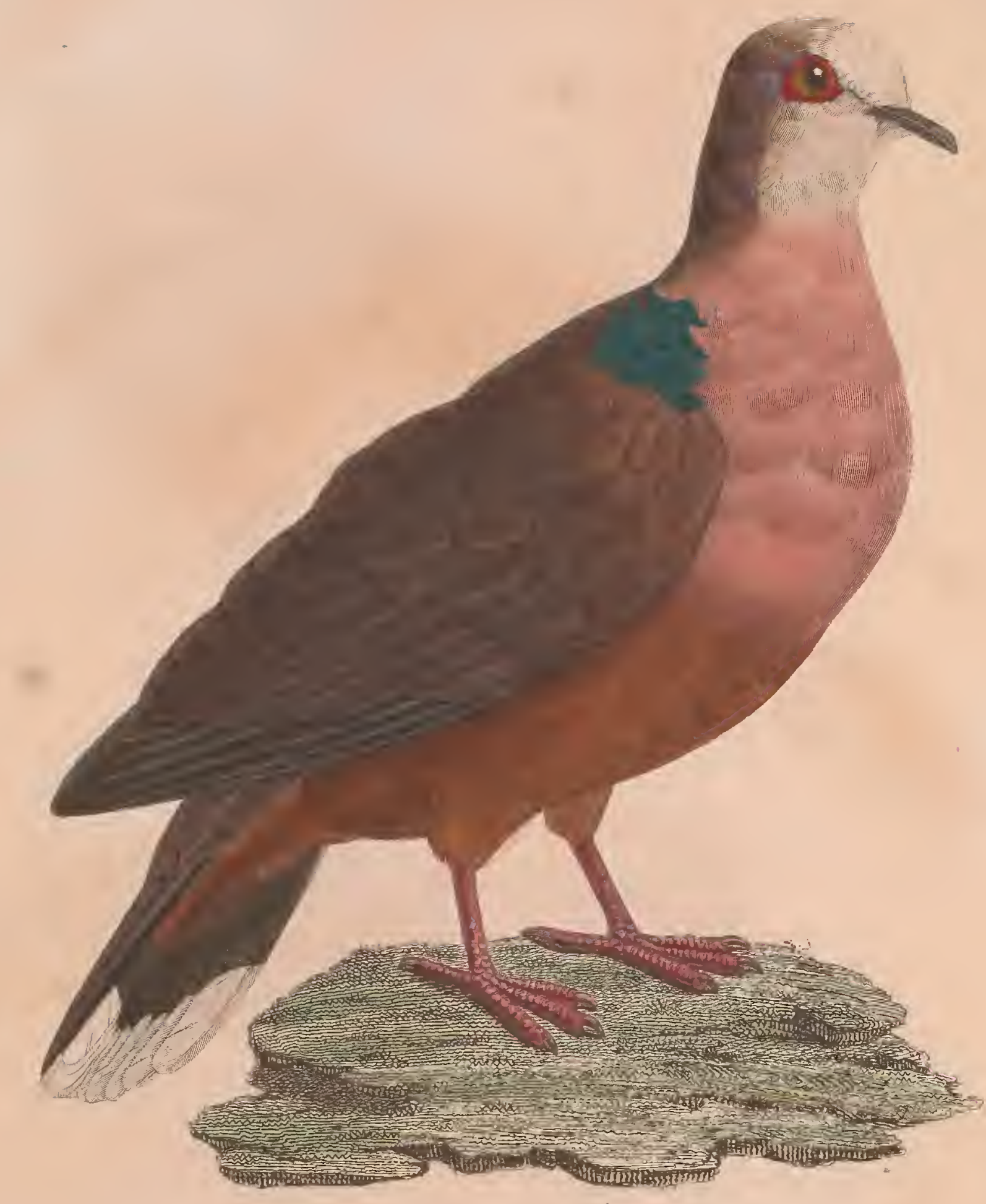

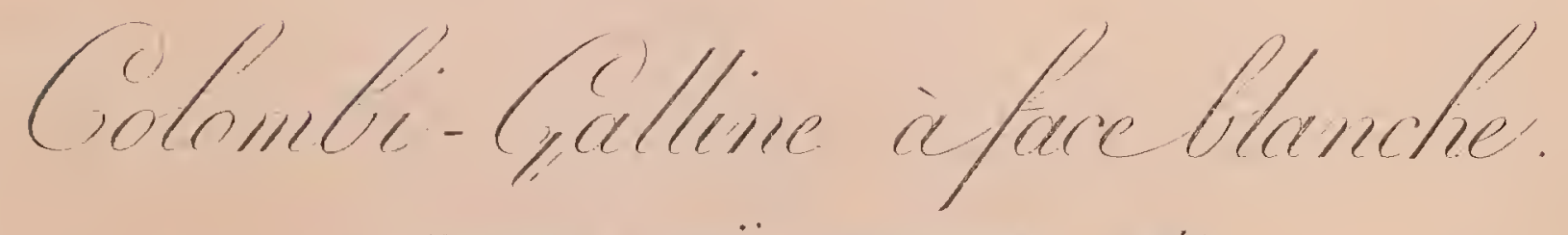

COLUMBA ER ŸTHROTORAX Mihi. 



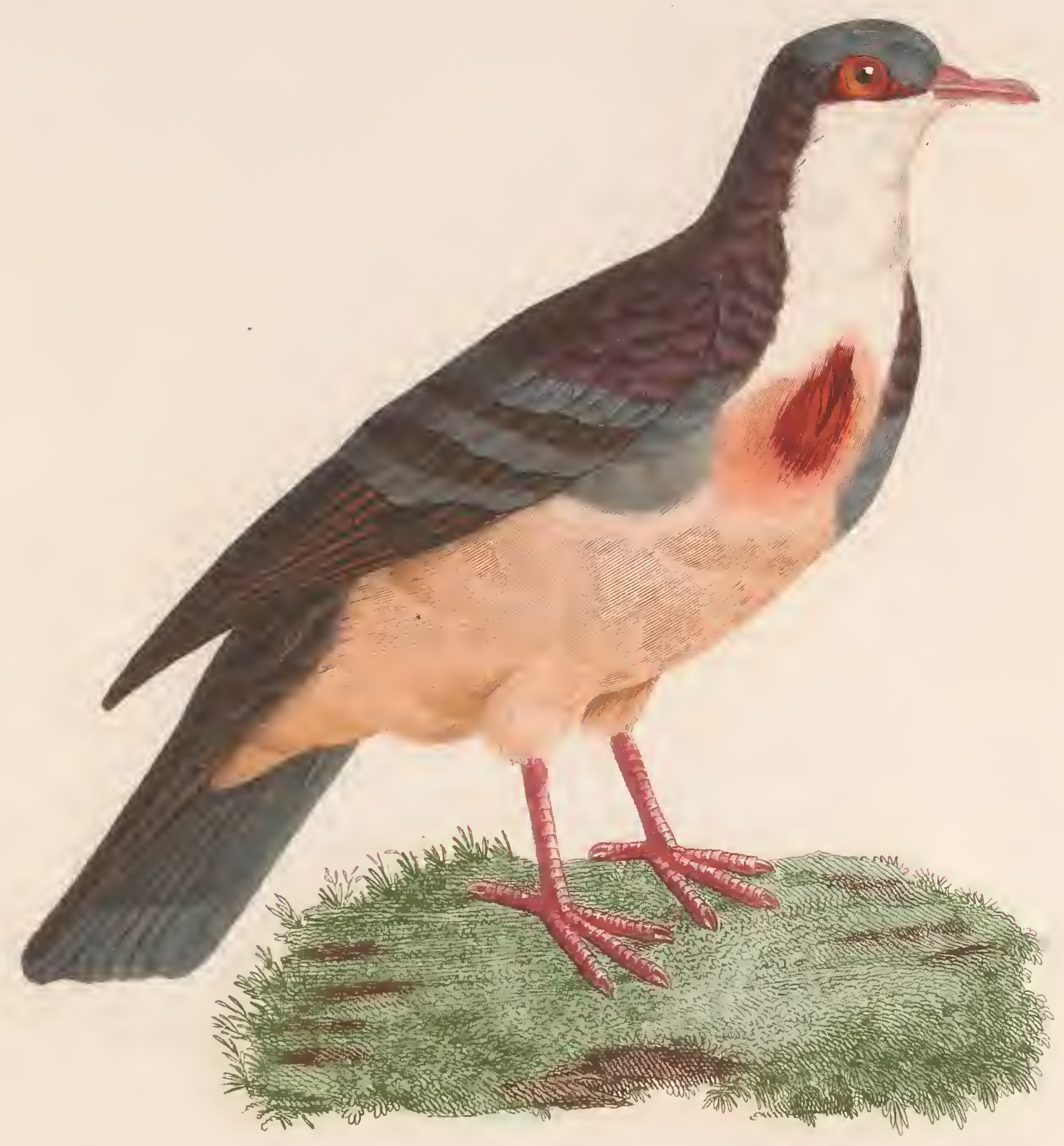

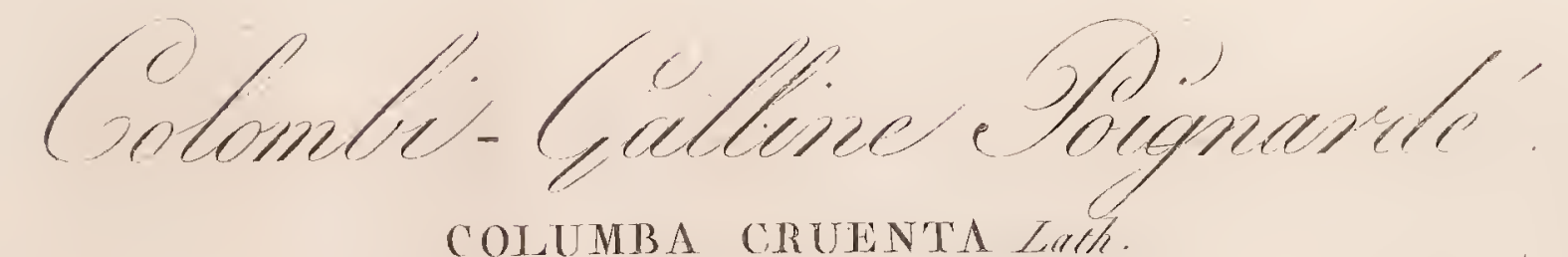





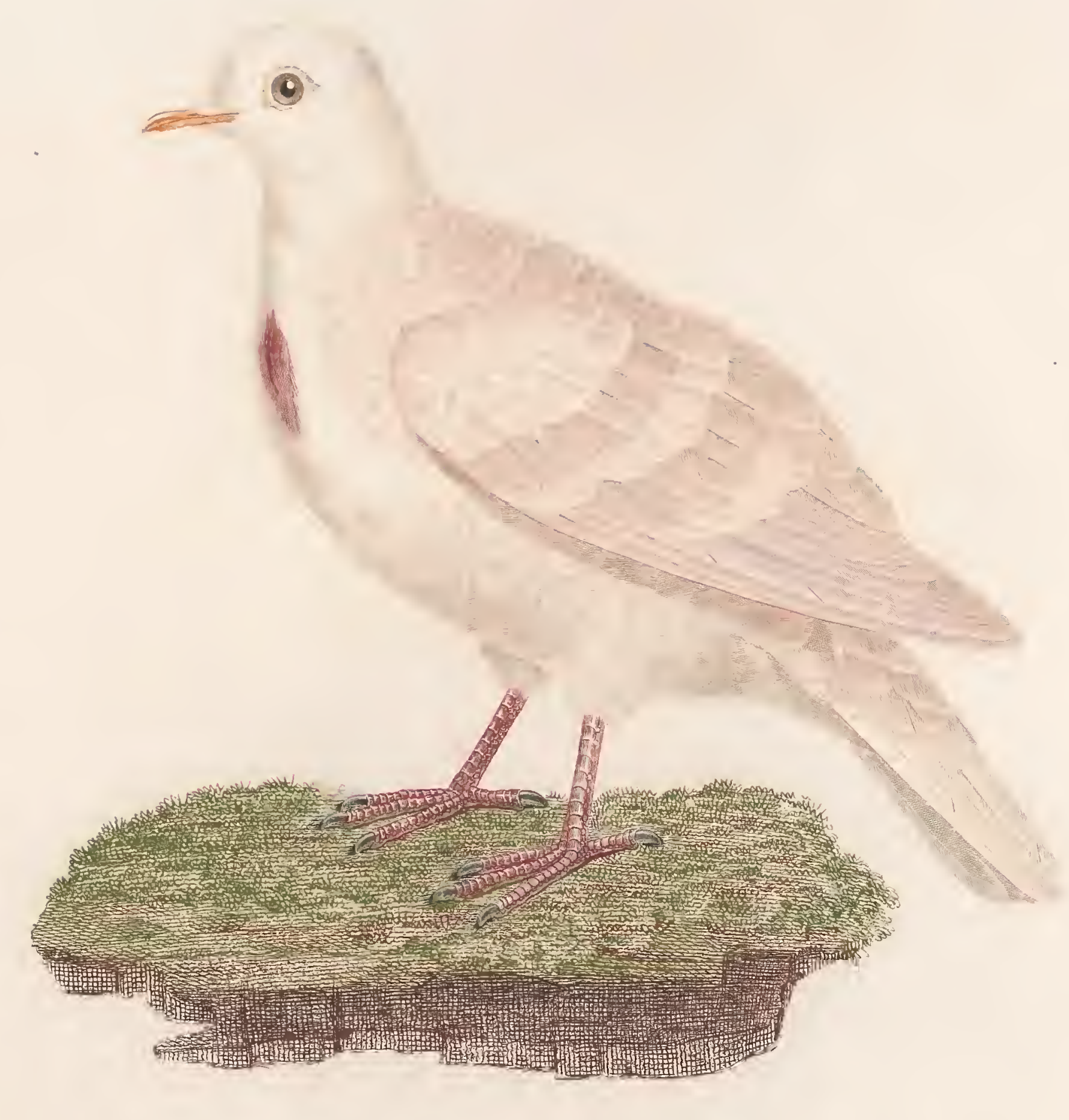

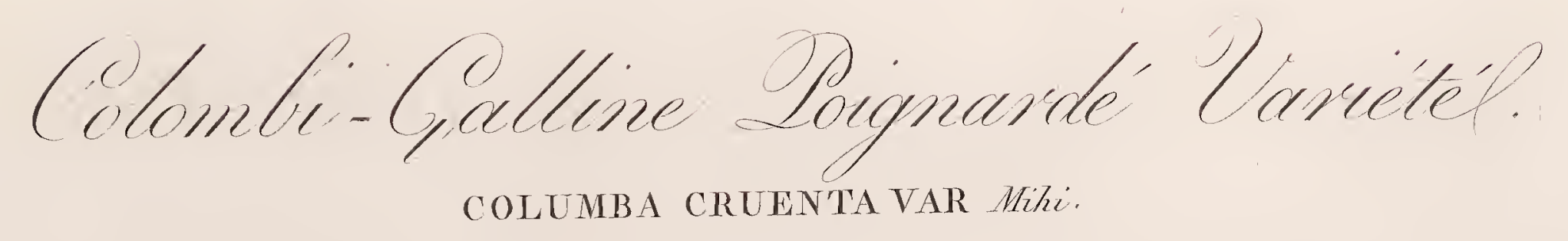





$$
\uparrow
$$





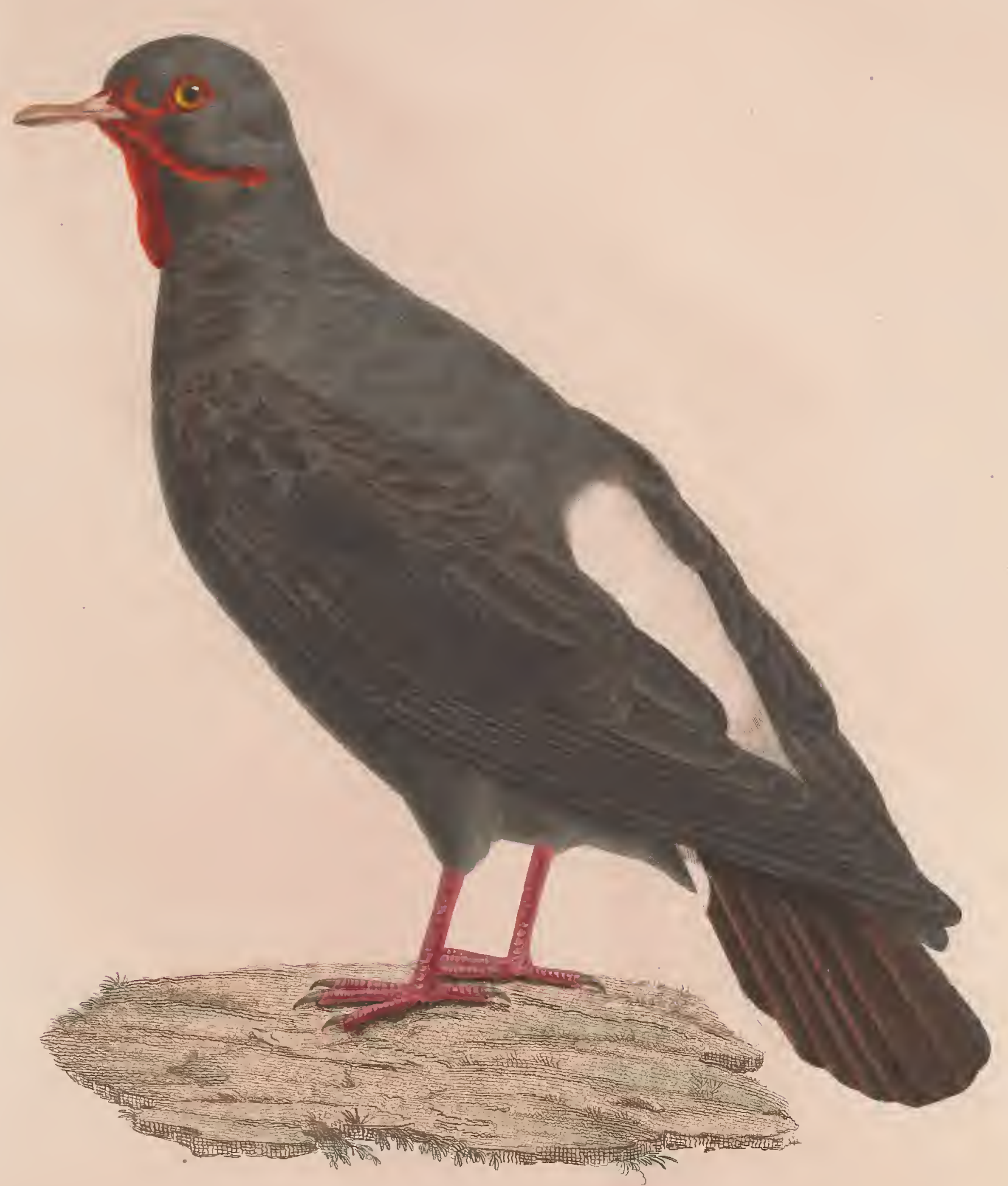

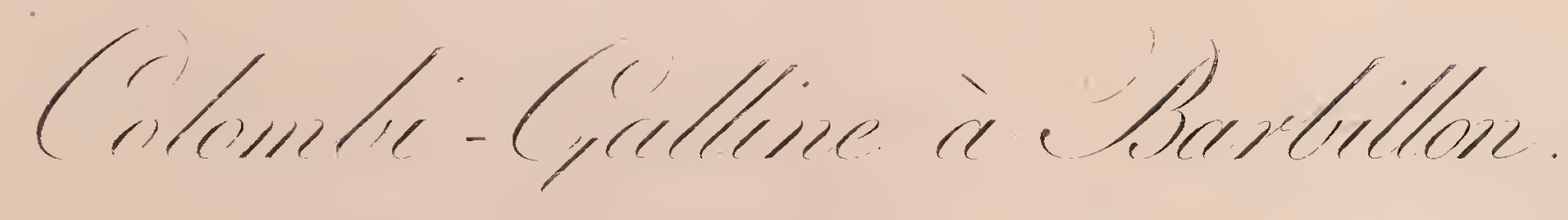

COLUMBA CARGNGUATA Milhi 



\section{Sormoli gathenes plit}

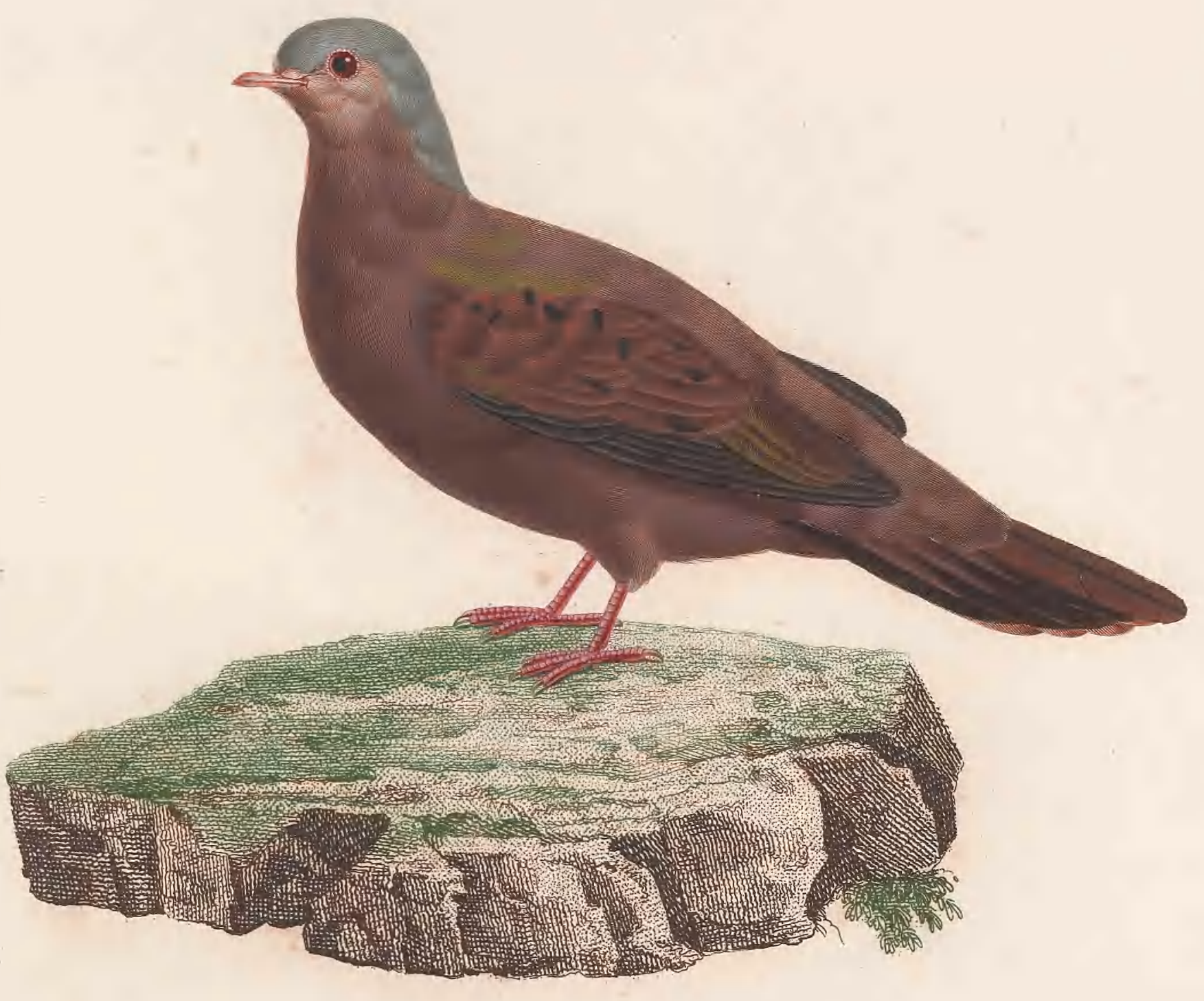

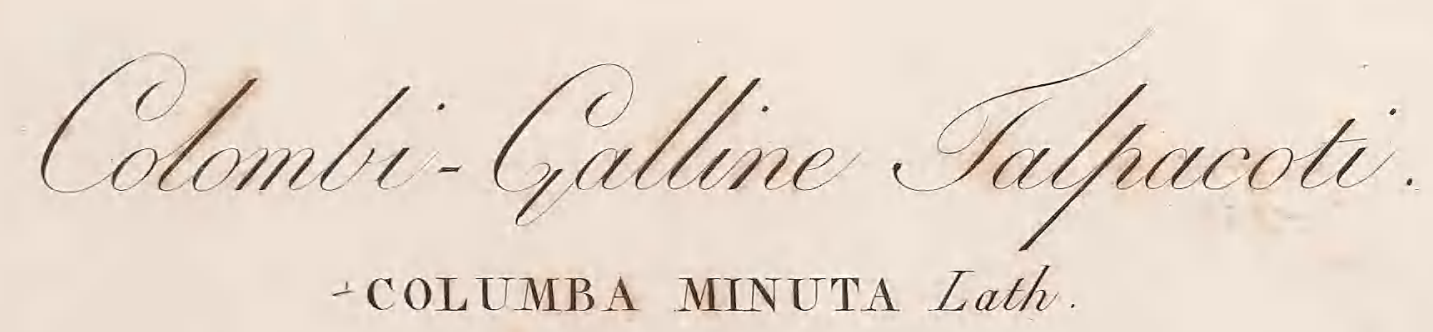





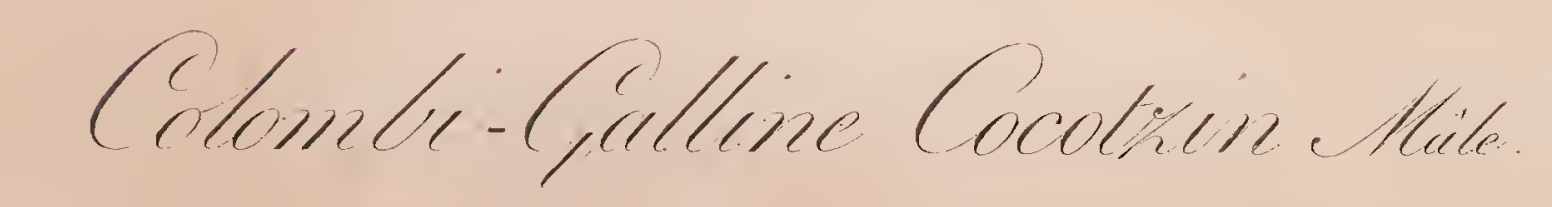
COLUMBA PESSERINA MAS Lath.

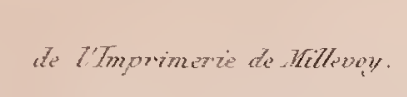



Colonti-Gialline Gocotion Tromste COLUMBA PESSERINA, FEMINA Lath 



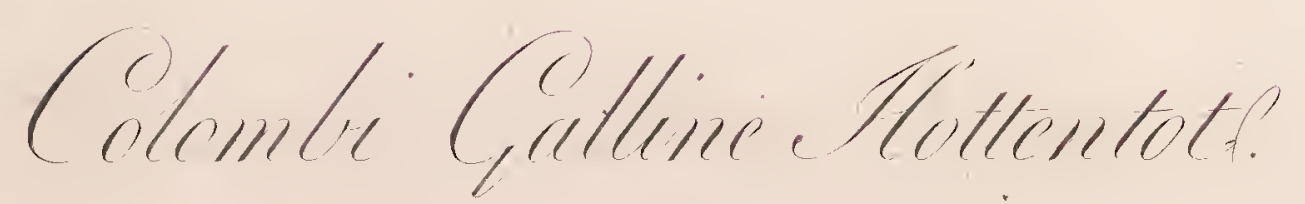
COLUMBA HOTTENTOTTA Mihi 



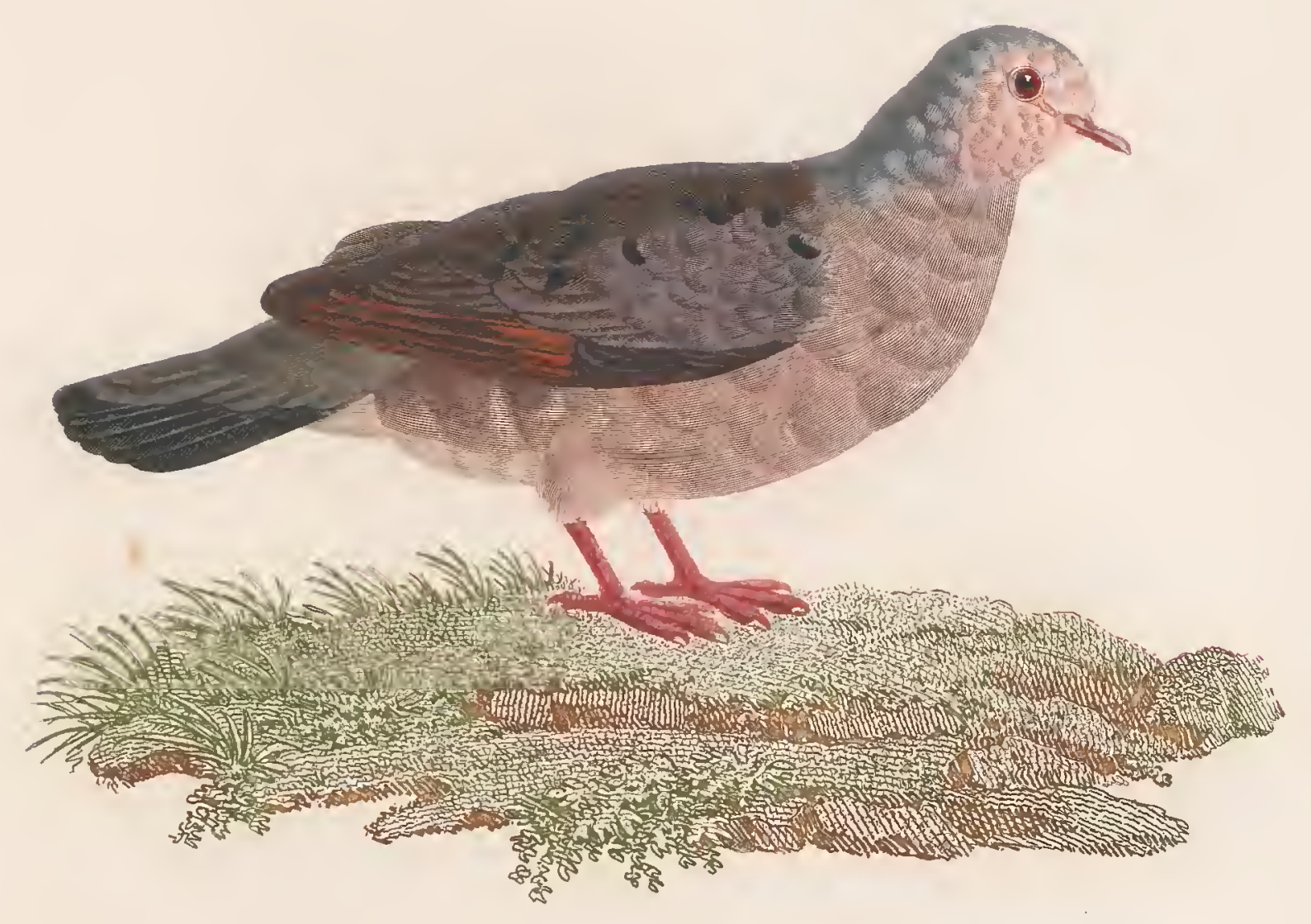

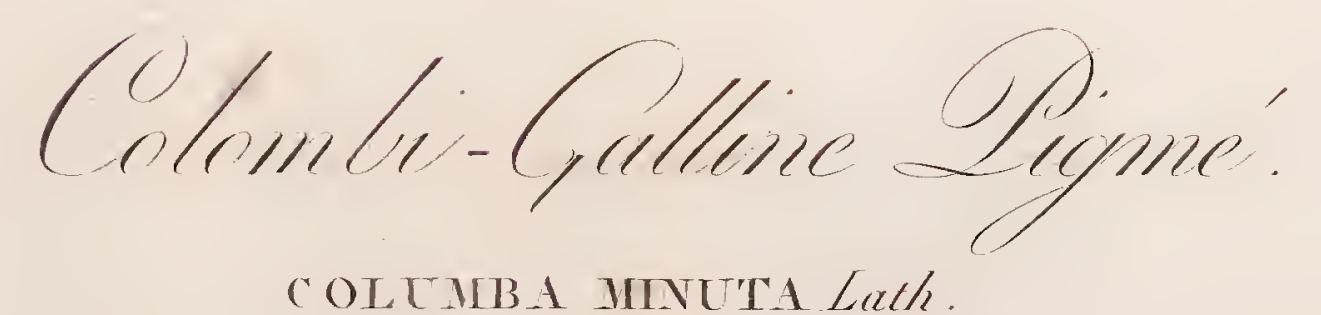








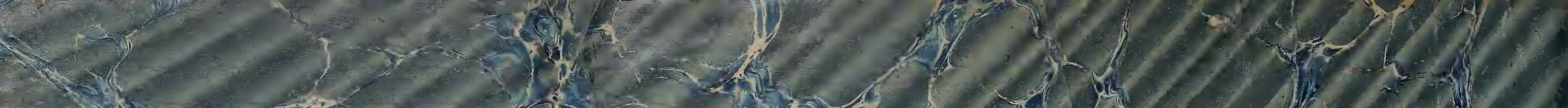

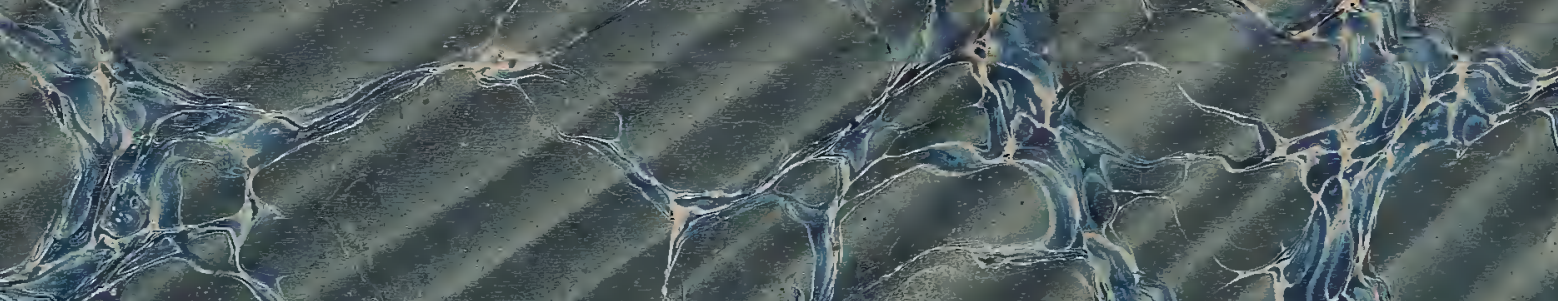

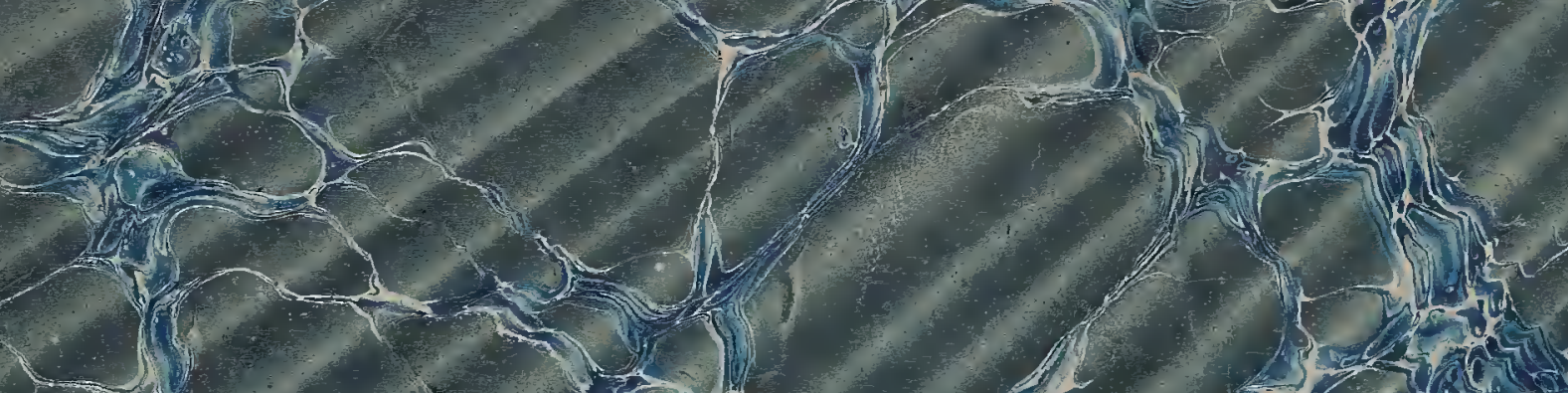
2.

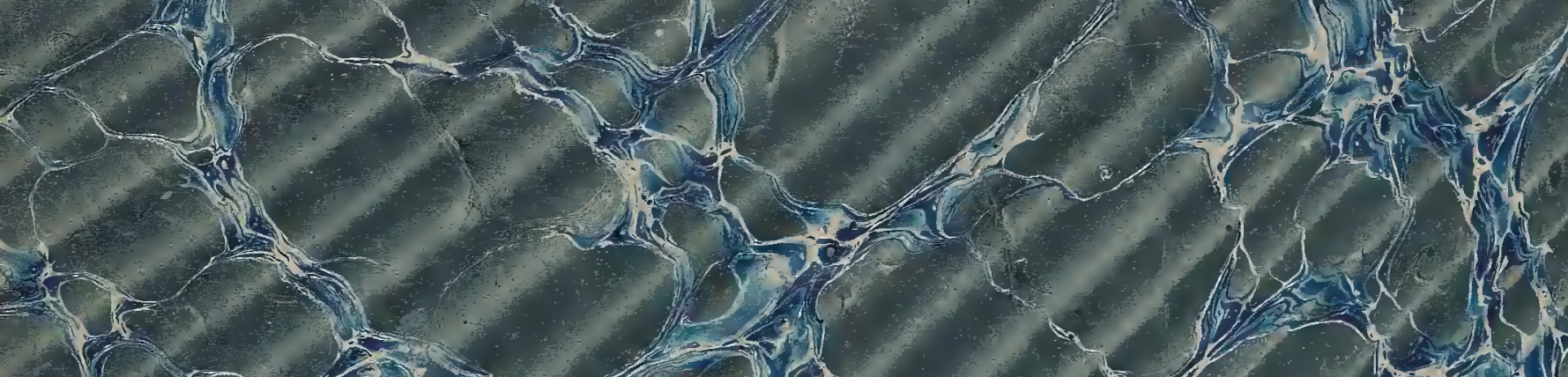

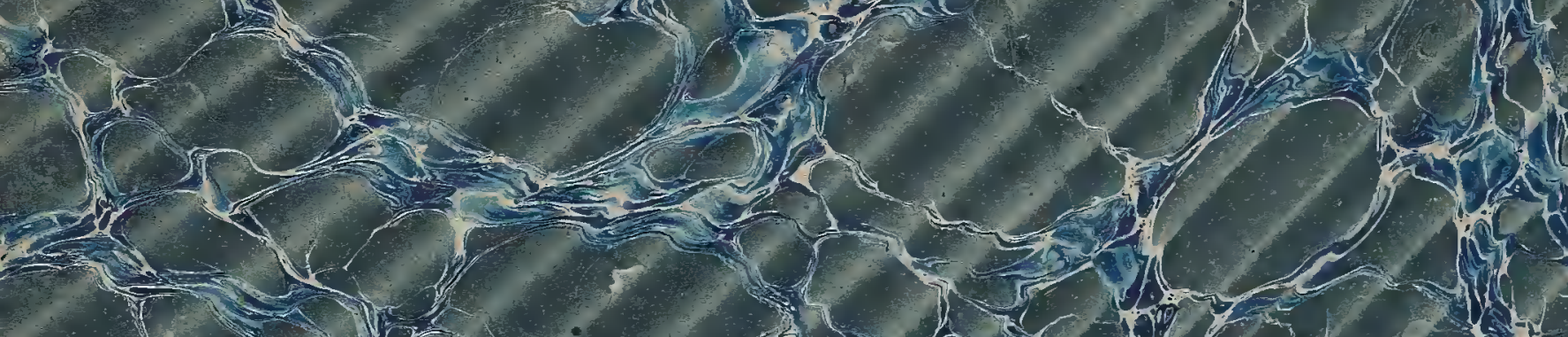

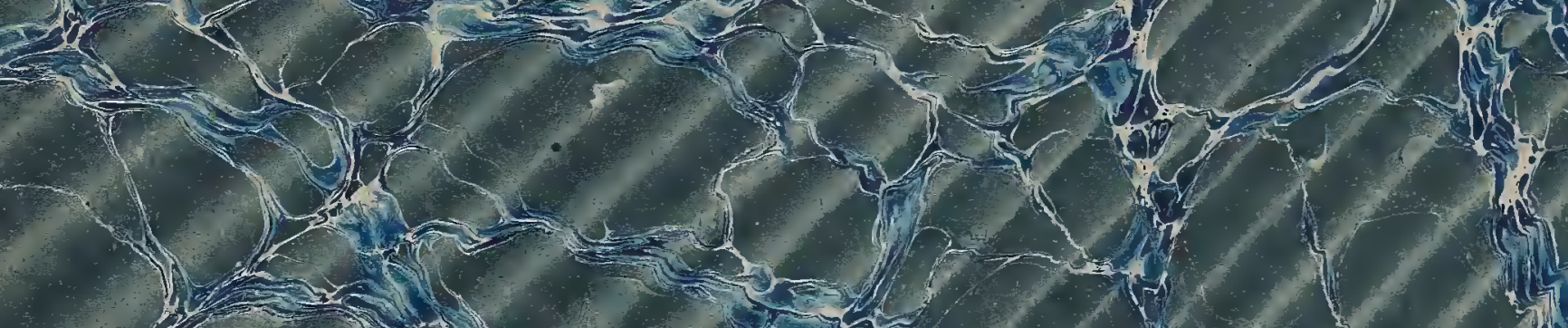
the wa

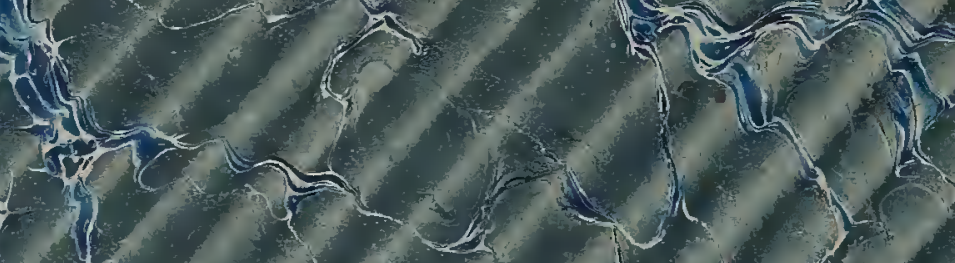

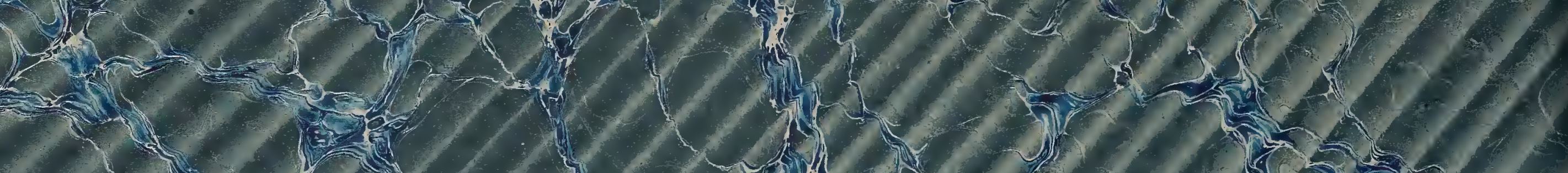

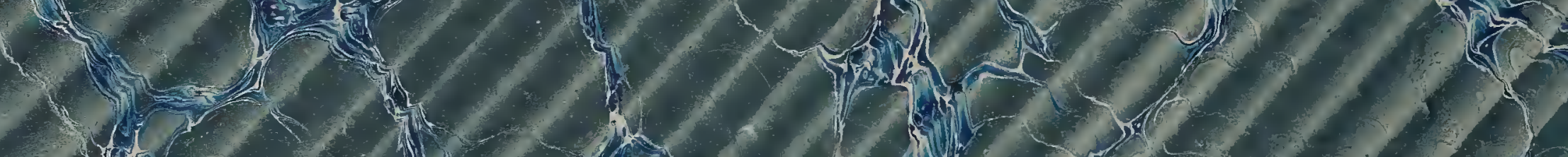

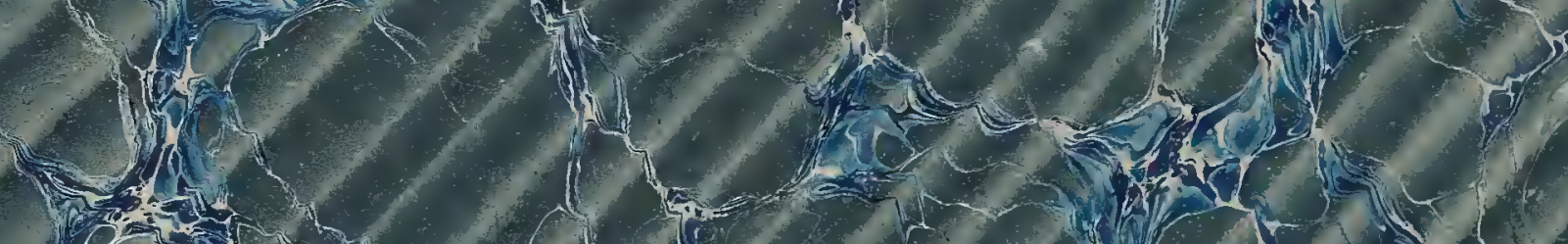
- $\left.x^{2}-2 x+2\right)$

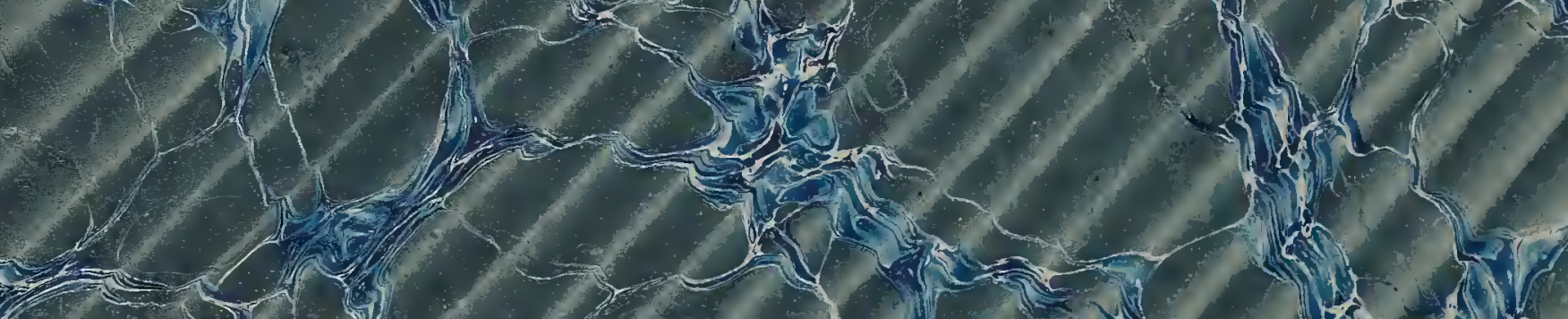

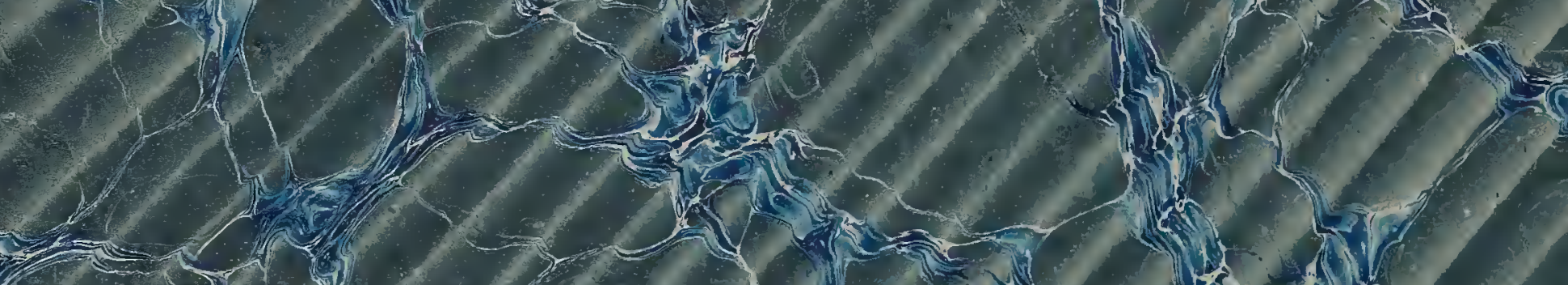

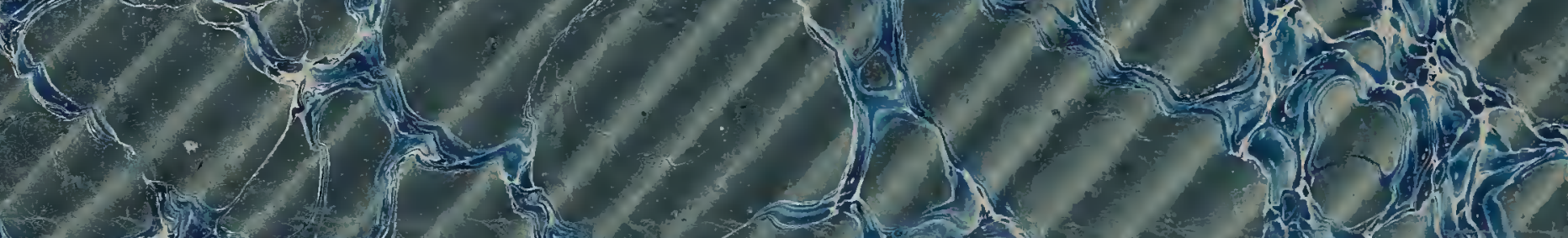

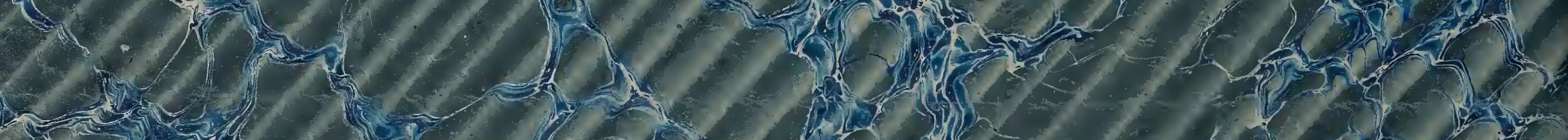

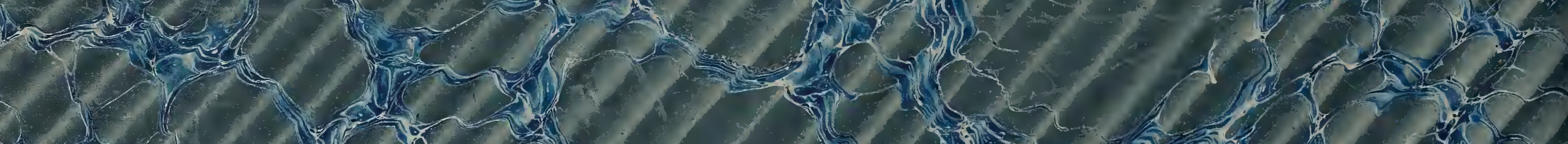

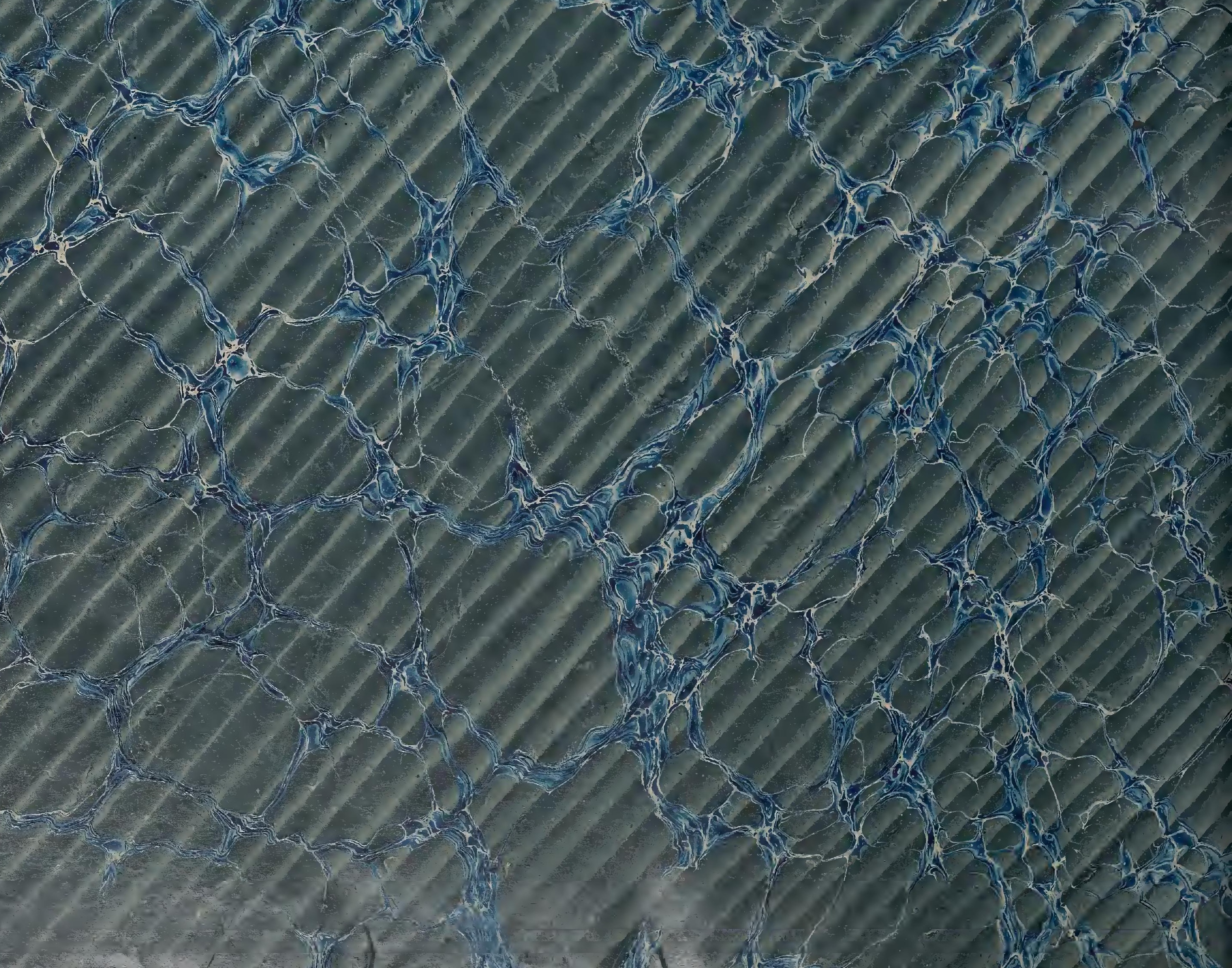




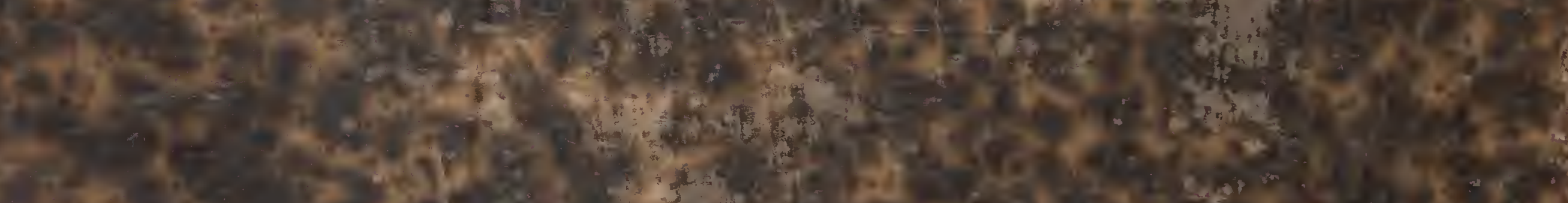

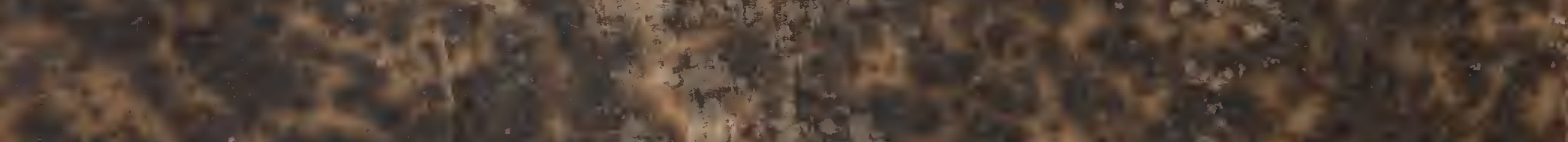

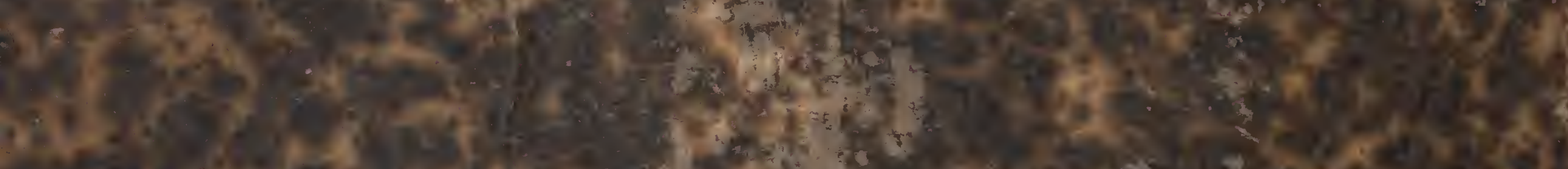

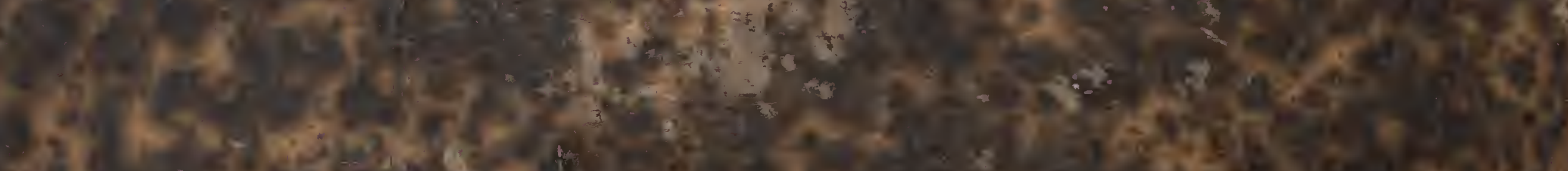

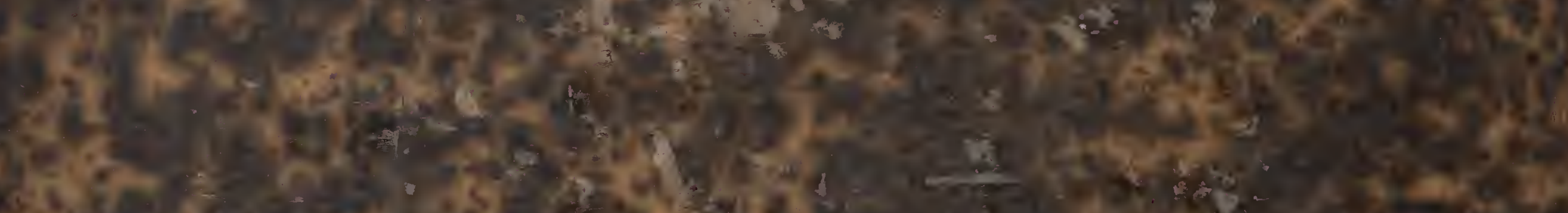

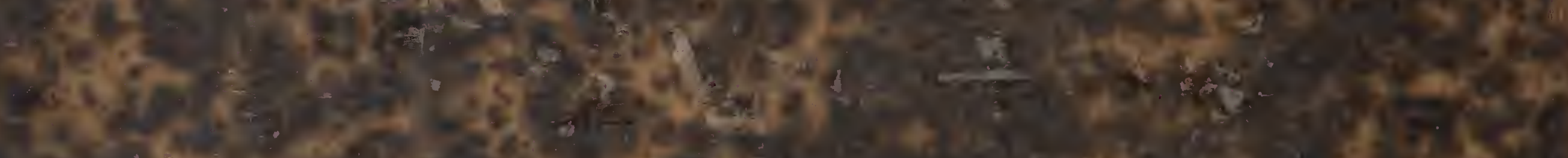

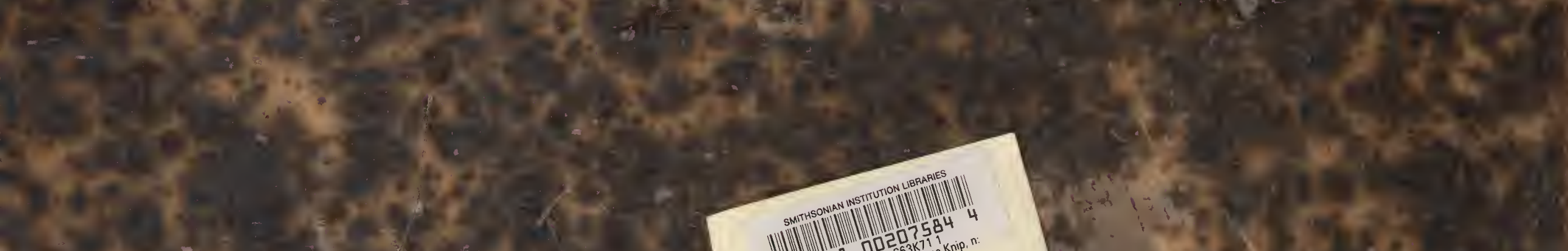

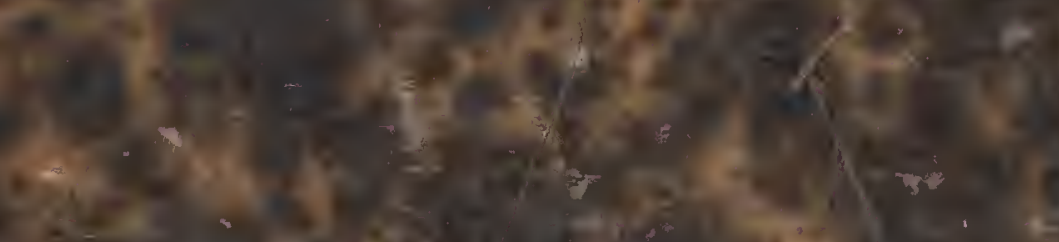
.

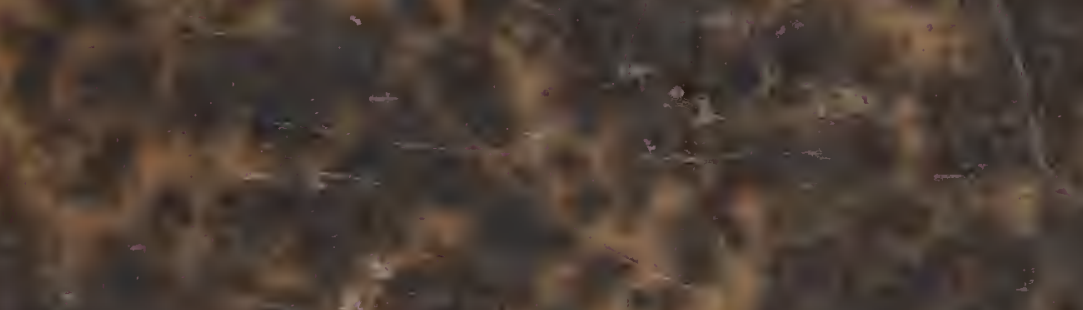

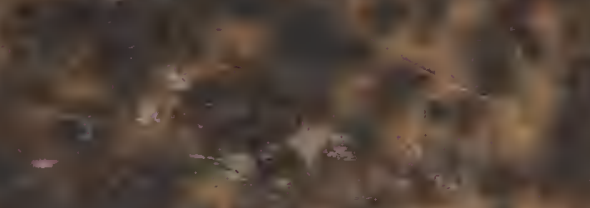
as?

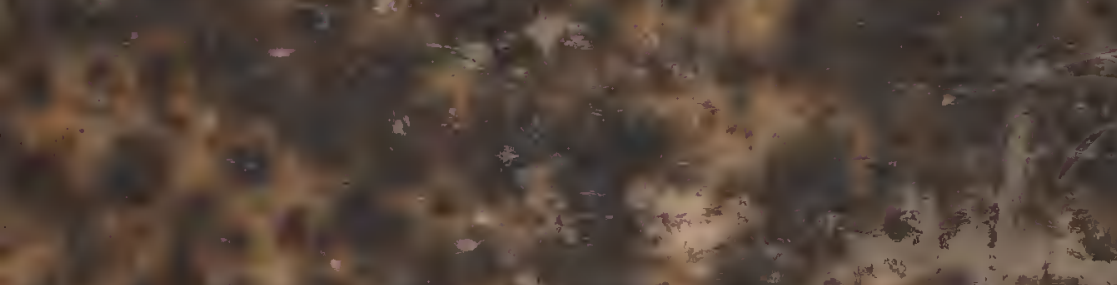

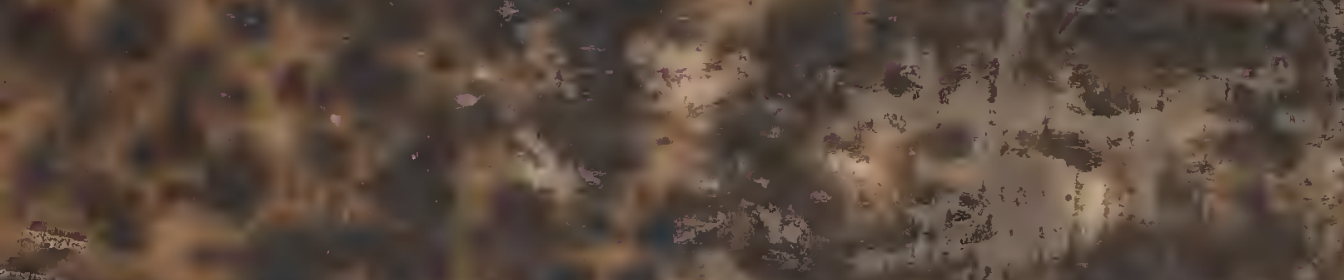
한

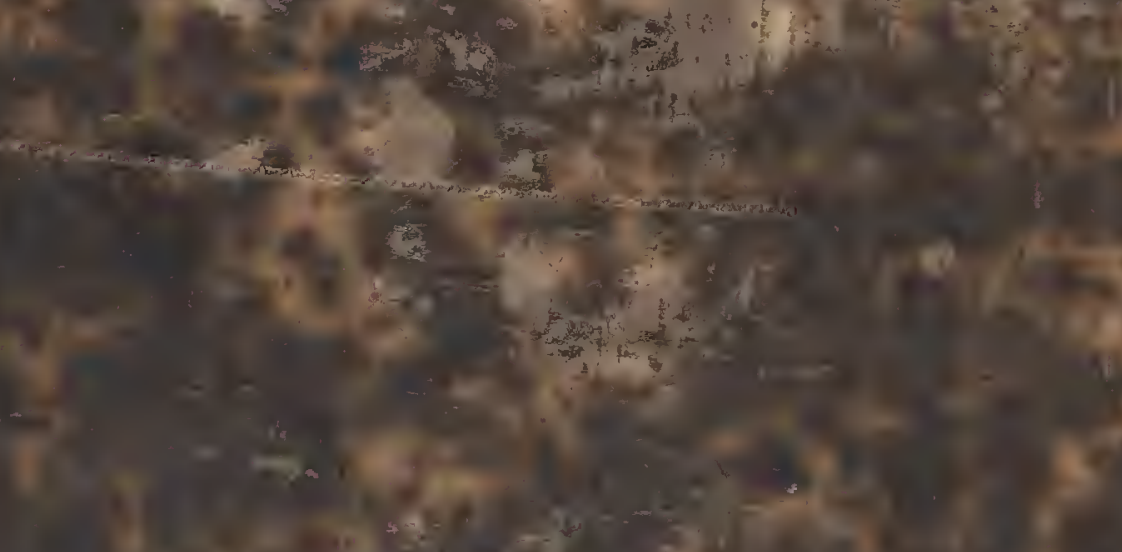

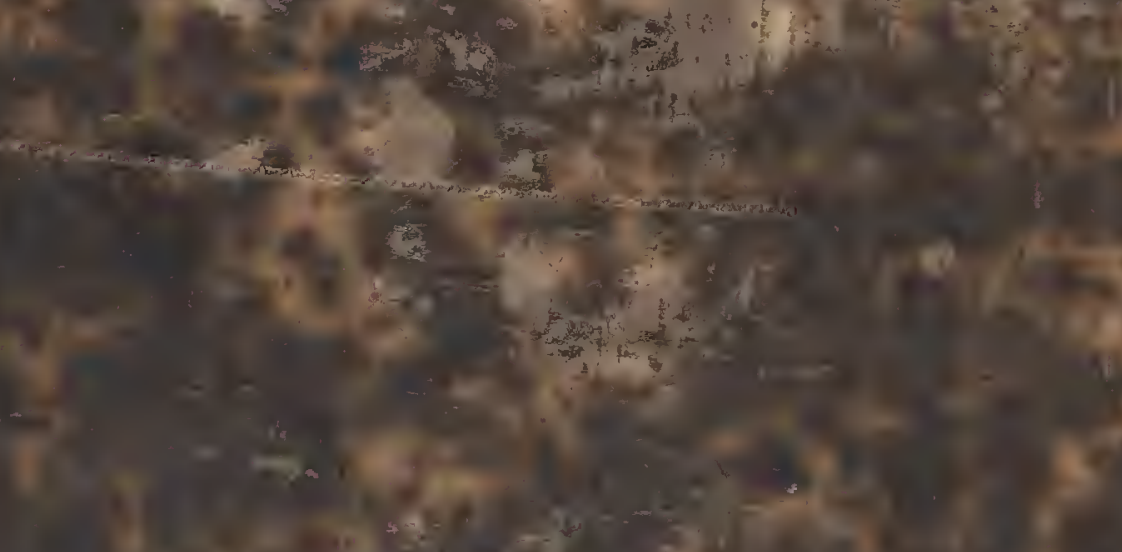

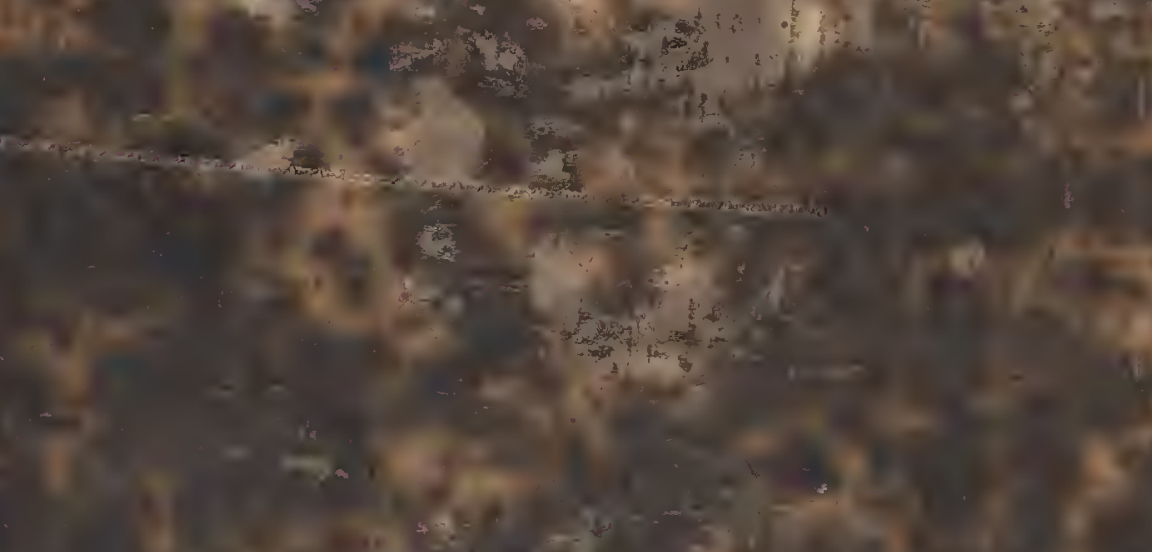
Withen

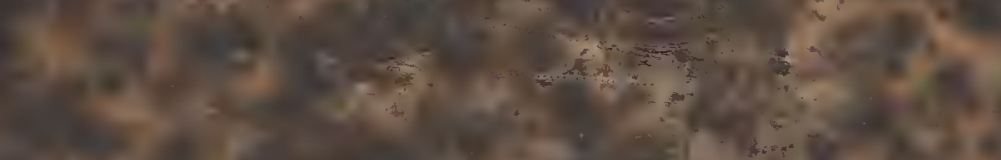
cotse -5 सos: .

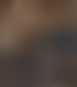<smiles>[12BH]</smiles>
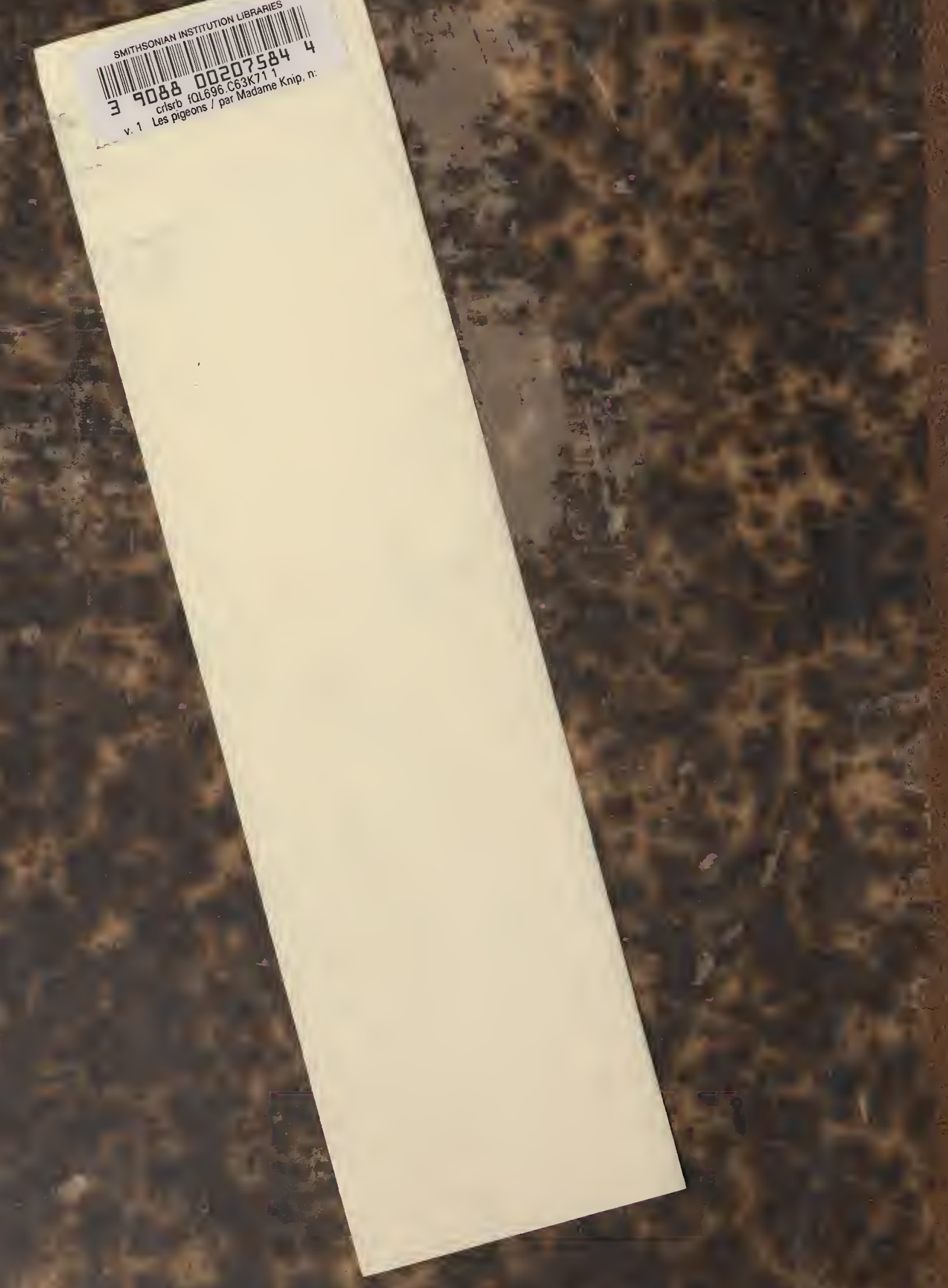